\title{
Gwendolin Engels
}

\section{Gattungsdiskurs und Subjekt}

bei Michel Foucault 
Gwendolin Engels

Gattungsdiskurs und Subjekt bei Michel Foucault 
ROMBACH WISSENSGHAFTEN - REIHE LITTERAE

herausgegeben von Gerhard Neumann, Günter Schnitzler und Maximilian Bergengruen

Band 193 
Gwendolin Engels

\section{Gattungsdiskurs und Subjekt bei Michel Foucault}

N"'/ rombach verlag 


\section{Bibliografische Information der Deutschen Nationalbibliothek}

Die Deutsche Nationalbibliothek verzeichnet diese Publikation in der Deutschen Nationalbibliografie; detaillierte bibliografische Daten sind im Internet über < http:/dnb.d-nb.de $>$ abrufbar.

(C) 2013. Rombach Verlag KG, Freiburg i.Br./Berlin/Wien

Zugelassen als Dissertation an den Universitäten Bonn und Gent im Jahr 2011 1. Auflage. Alle Rechte vorbehalten

Lektorat: Dr. Friederike Wursthorn

Umschlag: typo|grafik|design, Herbolzheim i.Br.

Satz: Rombach Druck- und Verlagshaus GmbH \& Co. KG,

Freiburg im Breisgau

Herstellung: Rombach Druck- und Verlagshaus GmbH \& Co. KG,

Freiburg im Breisgau

Printed in Germany

ISBN 978-3-7930-9723-5 


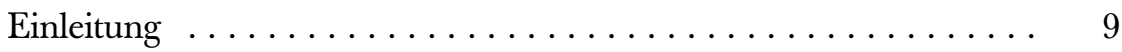

Erster Teil: Subjekt und Tragödie

I. Subjekt und Tragödie . . . . . . . . . . . . . . 21

Tragische Subjektkonstitution in Hegels Phänomenologie des Geistes 22

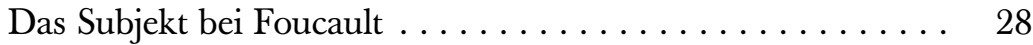

Subjekt und Tragödie bei Foucault $\ldots \ldots \ldots \ldots \ldots \ldots . \ldots 42$

II. Die Tragik der Individuierung $\ldots \ldots \ldots \ldots \ldots \ldots \ldots . \ldots 4$

Der tragische Ausschluß des Wahnsinns (Foucault und

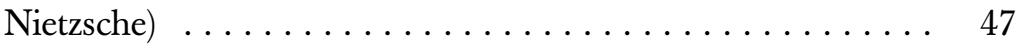

Tragik der Individuierung $\ldots \ldots \ldots \ldots \ldots \ldots \ldots \ldots$

III. Die Tragödie der Subjektivierung im Rechtsdiskurs und ihr Ende ......................... 57

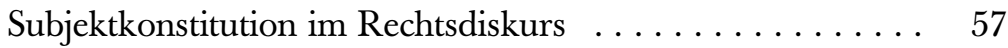

Die Wahrheit und die juristischen Formen . . . . . . . . . 58

Überwachen und Strafen: Die Geschichte des Strafdiskurses als

Tragödie ........................ 60

Die Guillotine (I): Zwischen Mythos und Logos . . . . . . 63

Tragische Individuierung der Gefangenen . . . . . . . . . . 64

Die Seele des Verbrechers: Der Delinquent . . . . . . . . . 64

Tragödie der Selbsterkenntnis: Verinnerlichung der

Machtstrukturen im Panopticon . . . . . . . ....... 66

Ende der Tragödie ................. 68

Zweiter Teil: Subjekt und Gattung

Tragödie, Komödie, Roman

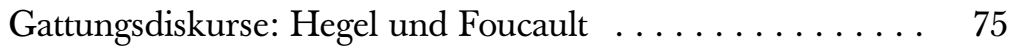

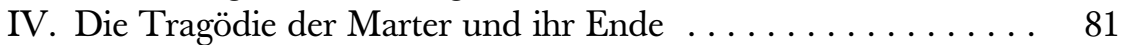

Tragödie der Marter: Körper, Blut, Ähnlichkeit . . . . . . 81

Das Ende der Tragödie: Körper und Blut verlassen die

Bühne - die Seele tritt auf . . . . . . . . . . . . . . 84 
Die Trennung der tragischen Einheit von Täter und Tat der Verlust der Einheit des tragischen Charakters .... . . 85

V. Die Komödie der reformierten Strafen und das Ende des

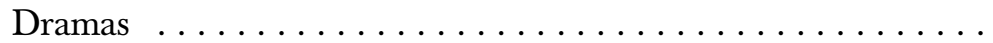

Die Komödie in den Dramentheorien und die Bestrafung in den Straftheorien der Aufklärung . . . . . . . . . . . . . . 89

Die Lektion der reformierten Strafen . . . . . . . . . . . . . 92

Die Komödie der Repräsentation . . . . . . . . . . . . . . 97

Der Schauspieler als Zeichen statt als Körper . . . . . . . . 99

Die komische Maske (I): Als Zeichen der Zeichenhaftigkeit . 100

Schauspieler und Maske in Hegels Phänomenologie des Geistes . . 101

Die komische Maske (II): Als Rechtsperson . . . . . . . . . 106

Zwischenbilanz: Komödie und Bestrafung . . . . . . . . . 111

Die neuen Figuren auf der Bühne der Justiz: Die »kleine

Delinquenz" . . . . . . . . . . . . . . . . . . . . . 113

Die komische Maske (III): Kodifizierung und Typisierung,

Individualisierung und Psychologisierung . . . . . . . . . . 120

Komische Schatten und Gespenster . . . . . . . . . . . . 124

Höhepunkt und Ende der Komödie: Sokrates . . . . . . . . 127

Innerlichkeit, Fleischlosigkeit, Ironie und Positivität . . . . . 128

Der Zuschauer betritt die Bühne: Die Komödie der

Hoffräulein und das Ende des Dramas .............. 131

Napoleon und die Guillotine (II): Grenze des Schauspiels . . . 136

Das Ende des Dramas im Ende des Rechts . . . . . . . . . 139

Unvereinbarkeit von Recht und Psychologisierung . . . . . . 140

VI. Die Prosa der Disziplin und das Ende der Literatur . . . . . . . . 143

Recht und Norm, Tragödie und Roman ... . . . . . . . 143

Unvereinbarkeit von Disziplin und Handlung . . . . . . . . . . 144

Auflösung der dramatischen Einheit der Handlung, der

Zeit und des Ortes . . . . . . . . . . . . . . . . . . 145

Variante: Übergang vom Epos zum Roman . . . . . . . . . . 148

Der humanwissenschaftliche Panoptismus der

Erzähltechniken . . . . . . . . . . . . . . . . 150

Dichtung und Geschichtsschreibung, Kriminologie und

Literatur . . . . . . . . . . . . . . . . . . . . . . . . . . . 154

Das Ende des Romans in der Wissenschaftsprosa . . . . . . 156

Schafott-Diskurse, Vermischte Meldungen, Kriminalroman . 159

Variante: Epos - Tragödie - ১lettres de cachet . . . . . . . 160 
Dritter Teil: Gattung, Geschichte und Subjekt

VII. Archäologie, Genealogie, Gattungstheorie . . . . . . . . . . 165

Gegen die Gattung: Die Ordnung der Dinge und die Archäologie des Wissens . . . . . . . . . . . . . . . . 165

Gattung und Archäologie - Gattungstheorie und

Diskursanalyse ...................... 172

Gattung und Genealogie - Gattungstheorie und

Machtanalytik ...................... 180

VIII. Gattungsdiskurs, Geschichtsphilosophie, Subjektphilosophie 187

Funktionen des Gattungsdiskurses . . . . . . . . . . . 194

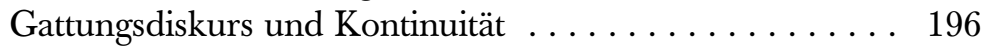

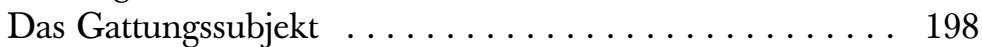

Gattungsdiskurs und Kausalität . . . . . . . . . . . 207

Das Gespenst der Gattung . . . . . . . . . . . . . 213

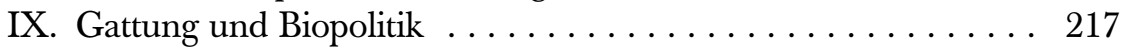

Genealogie und Evolutionstheorie . . . . . . . . . . . 217

Gattungstheorie und Biopolitik - Gattungspolitik . . . . . . 222

Der Staat als Subjekt . . . . . . . . . . . . . . . . 229

Ausblick ............................... 233

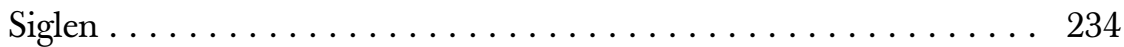

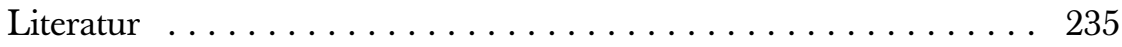




\section{Einleitung}

In der Literaturwissenschaft ist jüngst ein erstarkendes Interesse an gattungstheoretischen Fragestellungen zu beobachten. ${ }^{1}$ Daneben steht das gegenwärtige literatur- und kulturwissenschaftliche Interesse an biologischen und biologiehistorischen Fragestellungen, an Darwin, Evolutionstheorien und Genetik, ${ }^{2}$ verbunden mit der Wiederaufnahme lebensphilosophischer und morphologischer Denkmodelle. Es darf als eine Reaktion auf die heutigen Biowissenschaften und die in ihnen implizierte Biopolitik verstanden werden, als der Versuch, den `biopolitischen Paradigmen` der Gegenwart etwas entgegenzusetzen. Der literarische Gattungsdiskurs könnte gerade in der »anhebenden Debatte « ${ }^{3}$ um die Lebenswissenschaften eine Schlüsselposition einnehmen, denn es ist der Gattungsbegriff, in dem sich geisteswissenschaftlicher und biopolitischer Diskurs kreuzen. Daß es mit Michel Foucault ausgerechnet der Theoretiker des postmodernen Endes des Subjekts sein soll, der eine so entschieden geisteswissenschaftliche Position ermöglicht, klingt überraschend - doch zeigt die vorliegende Arbeit über Gattungsdiskurs und Subjekt bei Michel Foucault genau das. Sie nimmt dazu zwei der prominentesten literatur- und geisteswissenschaftlichen Diskurse der vergangenen Jahrzehnte in den Blick: zum einen den literarischen Gattungsdiskurs seit Beginn des 19. Jahrhunderts und das sogenannte Ende der Tragödie, zum anderen den besagten Diskurs vom sogenannten Ende des Subjekts.

1 Vgl. Thomas Borgstedt: Gattungstheorie im 21. Jahrhundert, in: Rüdiger Zymner (Hg.): Handbuch Gattungstheorie, Stuttgart/Weimar 2010, S. 217-219, hier S. 217: "Im ersten Jahrzehnt des 20. Jh.s ist ein deutlich ansteigendes Interesse an gattungstheoretischen Fragestellungen zu verzeichnen."

2 Vgl. das aktuelle Stichwort der sogenannten Lebenswissenschaften; dazu beispielsweise Ottmar Ette (Hg.): Literaturwissenschaft als Lebenswissenschaft, Tübingen 2010. Anders das ebenfalls relativ neue Forschungsfeld der Biopoetik, das auf tendenziell positivistisch-reduktionistische Weise biologische, anthropologische oder entwicklungspsychologische Erklärungsansätze auf die Literatur überträgt; vgl. etwa Karl Eibl/Katja Mellmann/Rüdiger Zymner (Hg.): Im Rücken der Kulturen, Paderborn 2007.

3 Ottmar Ette (Hg.): Literaturwissenschaft als Lebenswissenschaft, S. 137ff. Vgl. auch Hans-Walter Schmuhl: "Die Bewegung zur Schaffung eines Neuen Menschen [...] wird aufgrund des biotechnologischen Fortschritts auf der politischen Agenda des 21. Jahrhunderts ganz weit nach oben rücken." Hans-Walter Schmuhl: Sozialdarwinismus, Rassismus, Eugenik/Rassenhygiene, in: Philipp Sarasin/Marianne Sommer (Hg.): Evolution. Ein interdisziplinäres Handbuch, Stuttgart/Weimar 2010, S. 366-375, hier S. 373. 
Eine starke und spezifische These der Verbindung von Subjektgenese und Tragödie stellt Hegel in der Phänomenologie des Geistes (1807) auf. Im die theoretische Tradition dieser Verbindung gründenden Sittlichkeitskapitel ${ }^{4}$ beschreibt er den Übergang von der Sittlichkeit zum Rechtszustand und den Übergang vom bloßen Bewußtsein zum Selbstbewußtsein anhand seiner berühmten Antigonelektüre. Die sich in Sophokles' Antigone stufenweise vollziehende Entwicklung des Selbstbewußtseins erweist sich damit als eine tragische Entwicklung, und andererseits bedeutet erst das Ende der Tragödie den eigentlichen Beginn des modernen Selbstbewußtseins. In der Tragödie konstituiert sich demnach erstmals das autonome und frei handelnde Subjekt, und mit seiner Konstitution geht die Tragödie zu Ende. Bei Hegel stehen folglich Subjektgenese und Tragödie in einem Bedingungsverhältnis, und Subjektkonstitution, Tragödie und Ende der Tragödie sind substantiell miteinander verknüpft. ${ }^{5}$ Vielleicht noch prominenter als das 'Ende der Tragödier (und in jüngerer Zeit: ihre Gegenwart ${ }^{6}$ ) ist das 'Ende des Subjekts``

4 G.W.F. Hegel: Phänomenologie des Geistes (= Werke, hg. von Eva Moldenhauer und Karl Markus Michel, Bd. 3), Frankfurt a.M. 82003, Kap. VI. A: »Der wahre Geist. Die Sittlichkeit«, S. 327-359 (im folgenden per Sigle PG im laufenden Text zitiert).

5 Vgl. Menke, der Hegel (zusammen mit Schlegel, Schelling und Nietzsche) dem "romantische[n] Paradigma" vom Ende der Tragödie in der Moderne zuordnet, das die Moderne als Zeit nach der Tragödie faßt und das in zwei "Grundformen" auftritt: »Diese beiden Grundformen sind die Theorie des Subjekts und die des Spiels. In seiner subjekttheoretischen Version sieht das romantische Paradigma die Moderne als die Zeit eines autonom gewordenen Subjekts [...].« Christoph Menke: Ethischer Konflikt und ästhetisches Spiel. Zum geschichtsphilosophischen Ort der Tragödie bei Hegel und Nietzsche, in: Andreas Arndt/Karol Bal, Henning Ottmann $(\mathrm{Hg}$.): Hegels Ästhetik. Die Kunst der Politik - die Politik der Kunst, Berlin 2000, S. 16-28, hier S. 16 f.

6 Vgl. ders.: Die Gegenwart der Tragödie. Eine ästhetische Aufklärung, in: Neue Rundschau, 111.1 (2000), S. 85-95; ders.: Die Gegenwart der Tragödie. Versuch über Urteil und Spiel, Frankfurt a.M. 2005.

7 Vgl. Wolfgang Hübener: Der dreifache Tod des modernen Subjekts, in: Manfred Frank/Gérard Raulet/Willem van Reijen (Hg.): Die Frage nach dem Subjekt, Frankfurt a.M. 1988, S. 101-127; Michael Gans: Das Subjekt der Geschichte. Studien zu Vico, Hegel und Foucault, Hildesheim 1993, Kap. C.I: »Der Tod des Menschen oder der Untergang des Subjekts in Michel Foucaults Diskurstheorie«, S. 229-260; Hans Michael Baumgartner: Welches Subjekt ist verschwunden? Einige Distinktionen zum Begriff der Subjektivität, in: Hermann Schrödter (Hg.): Das Verschwinden des Subjekts, Würzburg 1994, S. 19-28; Hélène Védrine: Le sujet éclaté, Paris 2000 (hier auch der häufig verwendete Ausdruck einer "Krise des Subjekts«, S. 109f.); Jerrold Seigel: La mort du sujet: Origines d'un thème, in: Le Débat 58.1 (1990), S. 160-170; H.D. Mutschler: Verschwinden des Subjekts, in: Hermann Schrödter (Hg.): Das Verschwinden des Subjekts, S. 191-208. 
(und in jüngerer Zeit: seine Wiederkehr ${ }^{8}$ ). Das Schlagwort vom Ende der Tragödie kommt erstmals in bezug auf Hegel auf und wird in der Folge in den verschiedensten Varianten wiederholt. Das Schlagwort vom Ende des Subjekts wird vor allem mit Foucault in Verbindung gebracht und markiert die radikale Abkehr von der neuzeitlichen Konzeption des Subjekts als vorgängigem und von der modernen Konzeption des Subjekts als freiem und selbstbestimmtem.

Beide Theoriekomplexe sind, jeder für sich, ausgiebig erforscht, wurden bisher aber noch nie zueinander in Beziehung gesetzt. Der Grund dafür liegt auf der Hand: Das Ende der Tragödie liegt ja gerade darin begründet, daß das freie und selbstbewußte Subjekt auftritt. Hat dieses Subjekt einmal den Status autonomen Selbstbewußtseins erlangt, unterliegt es nicht mehr den mythischen Notwendigkeiten der Tragödie. Die Rede vom Ende der Tragödie stützt sich also auf den Glauben an das Subjekt und seine Freiheit. Dagegen behauptet die Rede vom Ende des Subjekts, daß es jenes freie Subjekt, das das Ende der Tragödie einleitet, gar nicht gibt. Moderner Tragödiendiskurs und postmoderner Subjektdiskurs sind daher fundamental inkompatibel, oder, stärker formuliert: Sie haben schlechterdings nichts miteinander zu tun. So scheint es.

In seiner entschiedenen Absage an die neuzeitliche Subjektkonzeption stellt Foucault dem Ende der Tragödie, das an das Auftreten des modernen Subjekts gebunden ist, das Ende des Subjekts entgegen. Dieses Ende des Subjekts müßte nun, wie gesagt, zugleich auch ein Ende der Verknüpfung von Subjektkonstitution und Tragödie und, in der Folge, ein Ende der Rede vom Ende der Tragödie in Hegels Sinn bedeuten. Mit dem selbstbewußten und autonomen Subjekt fällt auch das Konzept seiner notwendig tragischen

8 Vgl. Matthias Rüb: Suche nach den Wurzeln des Subjekts. Der erstaunliche Wandel im Spätwerk des Michel Foucault, in: Spuren in Kunst und Gesellschaft 18 (1987), S. 49-52; ders.: Foucaults 'Kehrer. Neuere Literatur zum Werk Michel Foucaults, in: Philosophischer Literaturanzeiger 41 (1988), S. 198-207; Peter Dews: The Return of the Subject in Late Foucault, in: Radical Philosophy 51 (1994), S. 37-41; David Stern: The return of the subject? Power, reflexivity and agency, in: Philosophy \& Social Criticism 26.5 (2000), S. 109-122; Manfred Frank: Das Subjekt kommt zurück, in: Die Zeit, 08.07.2004 (Rezension zu Michel Foucaults Hermeneutik des Subjekts. Vorlesung am Collège de France 1981/82, Frankfurt a.M. 2004), http://www.zeit.de/ 2004/29/ST-Foucault [letzter Zugriff: 24.04.2012]; Elías Palti: The >Return of the Subject< as a Historico-Intellectual Problem, in: History and Theory 43.1 (2004), S. 57-82; Denise Jodelet: Le mouvement de retour vers le sujet et l'approche des représentations sociales, in: Connexions 89 (2008), S. 25-46. 
Konstituierung; die Idee einer tragischen Subjektkonstitution dürfte es bei Foucault eigentlich nicht geben. Nun stößt man in seinen frühen Texten aber durchaus auf ein Tragikkonzept, am deutlichsten im Vorwort zu Wahnsinn und Gesellschaft (1961). ${ }^{9}$ Er geht hier allerdings nicht auf Hegel, sondern auf Nietzsche und insbesondere dessen Geburt der Tragödie (1871) zurück ${ }^{10}$ worin dieser bekanntlich ebenfalls einen "Tod der Tragödie« verkündet. Diese frühe, nietzscheanische Konzeption einer ursprünglichen tragischen Trennung, die durch die ihr inhärente Notwendigkeit dem Konzept archäologischer wie genealogischer Diskontinuität widerspricht, verabschiedet Foucault in seinen mittleren Schriften; dementsprechend streicht er in der Neuausgabe von Wahnsinn und Gesellschaft (1972) das Vorwort und ersetzt es durch ein neues, in dem die Wörter >Tragik und >Tragödie nicht mehr fallen.

In Die Wahrheit und die juristischen Formen (1973) und in Überwachen und Strafen (1975) nimmt Foucault dann aber einen neuen Tragikdiskurs auf; genauer: einen Tragödiendiskurs. ${ }^{11}$ Das ist um so erstaunlicher, als er sich in diesen machtanalytischen Schriften zugleich der Frage der Subjektkonstitution zuwendet. Plötzlich tritt hier also die Untersuchung der Subjektwerdung zusammen mit der Verwendung einer tragödientheoretischen Begrifflichkeit und konkreten Bezugnahmen auf literarische Tragödien auf. Zwar handelt es sich hier um ein ganz anderes Subjekt, nämlich um ein dem Machtdiskurs und den Machttechniken unterworfenes, und um eine ganz andere Subjektkonstitution, nämlich um eine subjektivierende Unterwerfung (assujettissement). Dennoch perpetuiert Foucault damit, wiewohl unter umgekehrten

9 Vgl. Michel Foucault: "Einführung« zu Ludwig Binswangers Traum und Existenz [1954], in: ders.: Schriften in vier Bänden. Dits et écrits, hg. von Daniel Defert und François Ewald, Frankfurt a.M. 2001-2005, Bd. 1, S. 107-174 (Texte dieser Ausgabe im folgenden per Sigle $S$ und Angabe der Bandnummer und Seitenzahl im laufenden Text zitiert); ders.: Psychologie und Geisteskrankheit, Frankfurt a.M. ${ }^{12} 2002$ [Paris 1954/1962]; ders.: Wahnsinn und Gesellschaft. Eine Geschichte des Wahns im Zeitalter der Vernunft, Frankfurt a.M. ${ }^{16} 2005$ [Paris 1961] (im folgenden per Sigle WG im laufenden Text zitiert).

10 Friedrich Nietzsche: Die Geburt der Tragödie. Oder: Griechenthum und Pessimismus (= Werke. Kritische Studienausgabe, hg. von Giorgio Colli und Mazzino Montinari, Bd. 1), München/Berlin 1980 (im folgenden per Sigle GT im laufenden Text zitiert).

11 Michel Foucault: Die Wahrheit und die juristischen Formen, Frankfurt a.M. 2003 [1973] (frz. La vérité et les formes juridiques, Paris 1994) (im folgenden per Sigle WjF im laufenden Text zitiert); ders.: Überwachen und Strafen. Die Geburt des Gefängnisses, Frankfurt a.M. ${ }^{15} 2004$ (im folgenden per Sigle ÜS im laufenden Text zitiert). 
Vorzeichen, die seit Hegel übliche Figur der Korrelation von Subjektkonstitution und Tragödie, und zwar im spezifischen Sinne der Tragödie als literarischer Gattung und nicht nur im Sinne einer allgemeinen Tragödie der Kultur.

Foucault geht aber noch weiter. Er beschränkt sich nämlich nicht auf Ausführungen zur Tragödie - was man ihm noch als Relikte seines frühen Tragikbegriffs hätte durchgehen lassen können -, sondern deutet auf ein Ende der Tragödie und ruft darüber hinaus noch die Komödie und den Roman auf. So eröffnet er in Überwachen und Strafen, und das ist die zentrale These der vorliegenden Arbeit, einen regelrechten Gattungsdiskurs - der noch viel entschiedener mit der teleologischen Geschichtsphilosophie des deutschen Idealismus verbunden und überdies auch von dessen subjektphilosophischen Voraussetzungen kaum zu trennen ist. Denn auch dieser Diskurs findet sich einschlägig bei Hegel. In der Phänomenologie unterscheidet Hegel im Unterkapitel zur Kunstreligion die Abfolge Epos, Tragödie und Komödie sowie, für den vorliegenden Zusammenhang von besonderem Interesse, episches, tragisches und komisches Bewußtsein. ${ }^{12}$ Ausgehend vom Epos geht das Hegelsche Selbstbewußtsein über die Tragödie weiter zur Komödie und schließlich bis zum Ende der Kunst. Deutlicher als die Vorlesungen über die Ästhetik zeigt das Kunstreligionskapitel, wie sich in den Kunstformen und den literarischen Gattungen jeweils Stufen der Subjektivität manifestieren und verwirklichen. Hegels idealistisches System zeigt sich hier in seiner ganzen Geschlossenheit; es handelt sich um eine systematische Verknüpfung von Gattungstheorie, Subjekttheorie und Geschichtsphilosophie. Und auch Foucaults Gattungsdiskurs stiftet eine geradezu systematische Geschlossenheit. Er verbindet die drei historischen Straftechniken Marter, reformierte Strafen und Gefängnis mit den drei literarischen Gattungen Tragödie, Komödie und Roman. Darüber hinaus beschränkt sich dieses triadische Gattungsschema nicht auf Überwachen und Strafen und den Strafdiskurs, sondern es lassen sich strukturelle Querverbindungen zu Die Ordnung der Dinge und den dortigen historischen Epistemen herstellen. Struktur und Funktionsweise der Straftechniken ebenso wie der Epistemen lassen sich erstaunlich detailliert auf gattungstheoretische Überlegungen zurückführen und erlauben umgekehrt, diese auf die gesamte Untersuchung zu übertragen. Foucault zeichnet auf diese Weise, von der Forschung gänzlich unbemerkt, die Zusammenhänge Ähnlichkeit - Marter

12 PG, Kap. VII. B: "Die Kunstreligion«, S. 512-544. 
- Tragödie, Repräsentation - reformierte Strafen - Komödie, Humanwissenschaften - Gefängnis - Roman und reproduziert damit nicht nur das Narrativ von der historischen Abfolge literarischer Gattungen, sondern aktualisiert ein quasiidealistisches Zusammenspiel historischer, epistemischer, subjektphilosophischer und gattungstheoretischer Phänomene. $\mathrm{Zu}$ Foucaults früher Tragikkonzeption gibt es einige Untersuchungen, die sich größtenteils auf die Bezüge zwischen Nietzsche und Foucault konzentrieren. ${ }^{13}$ Foucaults Auseinandersetzung mit der Tragödie als Gattung hat die Forschung bisher relativ wenig Aufmerksamkeit entgegengebracht, und Untersuchungen zu oder auch nur Hinweise auf eine Gattungsdiskussion bei Foucault fehlen gänzlich - wohl deshalb, weil ein Anknüpfen an den klassischen Gattungsdiskurs Foucaults 'postmoderner theoretischer Position so offensichtlich widerspricht.

Man muß sich daher fragen, warum Foucault das Risiko eingeht, sich mit den Gattungsbezügen auch die entsprechenden geschichts- und subjektphi-

13 Deborah Cook: Nietzsche, Foucault, Tragedy, in: dies.: The subject finds a voice. Foucault's turn towards subjectivity, New York u.a. 1993, S. 37-50; Achim Geisenhanslüke: Foucault und die Literatur. Eine diskurskritische Untersuchung, Opladen 1997, Kap. III.5.2: »Tragödie und Dialektik bei Nietzsche und Foucault«, S. 195-212; ders.: Tragödie und Infamie. Literatur und Recht bei Michel Foucault, in: KlausMichael Bogdal/Achim Geisenhanslüke (Hg.): Die Abwesenheit des Werkes. Nach Foucault, Heidelberg 2006, S. 91-109 (teilweise identisch mit der vorgenannten Monographie); ders.: Gegendiskurse. Literatur und Diskursanalyse bei Michel Foucault, Heidelberg 2008, Kap. 1: "Archäologie und Tragödie« und Kap. 5: »Tragödie und Infamie«, S. 19-37, 87-115 (geringfügige Erweiterung des vorgenannten Aufsatzes); Stefan Wunderlich: Foucault und die Frage der Literatur: Beitrag zu einer Archäologie des poststrukturalistischen Denkens, [Norderstedt] 2000, S. 46-53; Andrew Cutrofello: Foucault on tragedy, in: Philosophy \& Social Criticism 31.5/6 (2005), S. 573-584; Gerhard Unterthurner: Foucaults Archäologie als Kritik der Erfahrung. Wahnsinn - Literatur - Phänomenologie, Wien 2007, Kap. 3.6.1: »Tragik und Dialektik «, S. 141-153. Unterthurner betont weniger die Bezüge zu Nietzsche als die Nähe zu Heidegger. Erwähnung finden Foucaults Tragikbezüge bei Dominick LaCapra: Foucault, history and madness, in: Arthur Still/Irving Velody (Hg.): Rewriting the history of madness. Studies in Foucault's "Histoire de la folie«, London/New York 1992, S. 78-85, der auch auf politisch problematische Implikationen des Foucaultschen Tragikbegriffs hinweist (ebd., S. 84); Christoph Menke: Tragödie im Sittlichen. Gerechtigkeit und Freiheit nach Hegel, Frankfurt a.M. 1996, S. 19; ders.: Ethischer Konflikt und ästhetisches Spiel, S. 16; Martin Stingelin: Foucault-Lektüren. Die Literatur im Denkraum der drei Dimensionen Wissen, Macht und Selbstverhältnis, in: Michel Foucault: Schriften zur Literatur, Frankfurt a.M. 2003, S. 371-400, hier S. 393; und Angelika Pillen: Referenzautoren - G.W.F. Hegel und Karl Marx, in: Clemens Kammler/Rolf Parr/Ulrich Johannes Schneider (Hg.): Foucault-Handbuch. Leben - Werk - Wirkung, Stuttgart/Weimar 2008, S. 169-172, hier S. 171. 
losophischen Prämissen und Notwendigkeiten einzuhandeln, die mit seiner archäologischen und seiner genealogischen Methode so gänzlich unvereinbar sind. Dieser Frage geht die vorliegende Arbeit nach. Es geht im Folgenden also nicht um Foucaults Rezeption konkreter literarischer Texte oder um die Rolle der Literatur oder einzelner Literaturgattungen in Foucaults Werk; ${ }^{14}$ es handelt sich auch nicht um literaturwissenschaftliche Textinterpretation mit inhaltlichen Bezügen zu Untersuchungen Foucaults; ${ }^{15}$ es geht nicht um eine "Anwendung" oder um die "Frage der Anwendbarkeit" von Foucaults Theorie und der 'Diskursanalyse auf Literatur $;{ }^{16}$ und schließlich handelt es sich auch nicht um literatur- oder gattungssoziologische Untersuchungen, die literarische und literaturhistorische Erscheinungen mit Foucaults historischen Forschungen verknüpften - wiewohl es dazu durchaus Ansätze bei Foucault selbst gibt. Kurz: Es geht nicht um Literatur und literarische Gattungen, sondern um Status und Funktion des Gattungsdiskurses bei Foucault.

Allein der Befund eines Gattungsdiskurses bei Foucault ist bemerkenswert. Er ist zum einen in gattungstheoretischer Hinsicht interessant, weil die vermeintlich längst verabschiedete gattungspoetologische Diskussion hier

14 Wie etwa bei Achim Geisenhanslüke: Foucault und die Literatur; ders.: Tragödie und Infamie; ders.: Gegendiskurse; Clemens Pornschlegel: Die Literatur von der Literatur befreien. Notizen zu Foucaults "Das Leben der infamen Menschen«, in: Die Nummer. Kunst - Literatur - Theorie, 3.4/5 (1996), S. 92-100; Stefan Wunderlich: Foucault und die Frage der Literatur; Arne Klawitter: Die »fiebernde Bibliothek«. Foucaults Sprachontologie und seine diskursanalytische Konzeption moderner Literatur, Heidelberg 2003; Martin Stingelin: Foucault-Lektüren.

15 Vgl. Leo Bersani: The Subject of Power, in: Diacritics 7.3 (1977), S. 2-21; Mark Seltzer: The Princess Casamassima: Realism and the Fantasy of Surveillance, in: Nineteenth-Century Fiction 35.4 (1981), S. 506-534; Robert S. Leventhal (Hg.): Reading after Foucault: Institutions, Disciplines, and Technologies of the Self in Germany, 1750-1830, Detroit 1994; Brigitte Kaute: Die Ordnung der Fiktion. Eine Diskursanalytik der Literatur und exemplarische Studien, Wiesbaden 2006; Friedrich Balke: »Phädra« oder die Moralphysiologie des königlichen Fleisches, in: Bettine Menke/Christoph Menke (Hg.): Tragödie - Trauerspiel - Spektakel, Berlin 2007, S. $128-146$.

16 Vgl. Friedrich Kittler/Horst Turk (Hg.): Urszenen: Literaturwissenschaft als Diskursanalyse und Diskurskritik, Frankfurt a.M. 1977; Jürgen Fohrmann/Harro Müller (Hg.): Diskurstheorien und Literaturwissenschaft, Frankfurt a.M. 1988; Arne Klawitter: Michel Foucault als Ausgangspunkt einer Ontologie der Literatur, in: Zeitschrift für Semiotik 27 (2005), S. 115-136; Clemens Kammler: Die Abwesenheit der Theorie. Zur Frage der Anwendbarkeit des Foucaultschen Diskursbegriffs auf die Literatur, in: Klaus-Michael Bogdal/Achim Geisenhanslüke (Hg.): Die Abwesenheit des Werkes, S. 231-241; Brigitte Kaute: Die Ordnung der Fiktion. 
offenbar noch fortlebt; zum anderen ist er für die theoretische Situierung von Foucaults Werk oder, weiter gefaßt, für den Status des postmodernen Theoriediskurses überhaupt von Bedeutung - man denke nur an Lyotards Bestimmung der Postmoderne als die Zeit nach dem »Ende der großen Erzählungen ${ }^{17}$

Die These lautet, daß Foucaults eigenem Diskurs ein Gattungsdiskurs zugrunde liegt, der jenen strukturiert und beinahe unbemerkt mit den philosophischen Grundlagen ausstattet, die Foucault in großer Geste und scheinbar so eindeutig zurückweist. Eine zentrale dieser Grundlagen betrifft das verabschiedete Subjekt, das, wie gezeigt werden wird, durch ein 'Gattungssubjekt cersetzt wird. Auf diese Weise fungiert der Gattungsdiskurs als Garant einer letztlich doch notwendigen Kontinuität und Kausalität inmitten der von Foucault so nachdrücklich akzentuierten Diskontinuität und steht das Gattungssubjekt für die Idee einer Menschheit im emphatischen Sinne von Menschlichkeit oder Humanität ein.

Der erste Teil der Arbeit untersucht nach einer kurzen Einleitung zum Zusammenhang von Subjekt und Tragödie in Hegels Phänomenologie des Geistes und zu Foucault Subjektbegriff (I.) zunächst Foucaults frühe Konzeption von Tragik und Tragödie in Wahnsinn und Gesellschaft sowie ihren direkten Rückgriff auf Nietzsches Geburt der Tragödie. Dann wird die tragische Subjektkonstitution zunächst - wiederum - in Wahnsinn und Gesellschaft (II.) und dann in Die Wahrheit und die juristischen Formen und Überwachen und Strafen (III.) betrachtet. Der zweite Teil nimmt einen neuen Argumentationsfaden auf. Hier werden die Zusammenhänge zwischen der Tragödie, der Straftechnik der Marter und der Episteme der Ähnlichkeit herausgearbeitet und ein Ende der Tragödie bei Foucault skizziert (IV.). Es folgt die Untersuchung ihrer Ablösung durch die Komödie, die reformierten Strafen und die Episteme der Repräsentation (V.). Daraufhin wird der Übergang zum Roman, zum Gefängnis und zu den Humanwissenschaften beschrieben, der schließlich in ein Ende der Literatur mündet (VI.). Textgrundlage sind hier neben Die Ordnung der Dinge, Die Wahrheit und die juristischen Formen und Überwachen und Strafen die Vorlesung In Verteidigung der Gesellschaft sowie Der Wille zum Wissen und einige kürzere Aufsätze. Der dritte Teil betrachtet Archäologie (Archäologie des Wissens) und Genealogie unter gattungstheoretischen Gesichtspunkten, stellt unter Rückbezug u.a. auf Hegel, Marx und

17 Jean-François Lyotard: Das postmoderne Wissen. Ein Bericht, 6., überarb. Aufl., Wien 2009 [Paris 1979], S. 23f., S. 54. 
Nietzsche die Frage nach dem Status des Gattungsdiskurses bei Foucault und seinen in geschichtsphilosophischer (VII.) und subjektphilosophischer Hinsicht (VIII.) problematischen Konsequenzen und erarbeitet die These von Gattungsdiskurs und Gattungssubjekt als kausalitäts- und kontinuitätsstiftenden Elementen. Zuletzt eröffnet sich ein Ausblick auf die Abkehr von der Gattung in den Vorlesungen über die Geschichte der Gouvernementalität und späteren Texten (IX.). Hier erst vollzieht Foucault eine Trennung von Subjektdiskurs und Gattungsdiskurs. 
Erster Teil: Subjekt und Tragödie 


\section{Subjekt und Tragödie}

Subjekt und Tragödie werden in Theorie und Forschung immer wieder miteinander in Verbindung gebracht, und zwar dergestalt, daß man die Entstehung des Subjekts oder - je nach Begrifflichkeit - des Individuums in der griechischen Tragödie verortet. In der Regel ist damit die Idee eines erstmals von den Göttern und dem Schicksal unabhängigen, autonomen und also freien Handelns gemeint; in der Tragödie gründet also so etwas wie Selbstbewußtsein, Selbstbestimmung, Autonomie, Freiheit. Ganz allgemein und in erster Annäherung läßt sich die Subjektwerdung in der Tragödie konkreter als ein Übergang von der wörtlichen Ordnung des Mythos zu einer symbolischen Ordnung des Logos fassen. Dieser Übergang findet seine nähere Bestimmung z.B. darin, daß in der griechischen Tragödie der Übergang von einem vorrechtlichen Status in ein Rechtssystem bzw. von einem mythischen zu einem menschlichen Recht vollzogen wird. Das geschieht auf verschiedenerlei Weise, etwa durch den Urteilsspruch des Areopags in Aischylos' Orestie oder durch den Rechtskonflikt der sophokleischen Antigone, in dem (Hegels einflußreicher Interpretation zufolge) das von ihr vertretene göttliche Recht der Familie dem menschlichen Recht des Staates unterworfen bzw. darin aufgehoben wird. In der Tragödie tritt der Mensch also in eine Rechtsordnung ein; man könnte sagen, er wird zum Rechtssubjekt. Eine andere Bestimmung der Subjektwerdung in der Tragödie als dem Übergang vom Mythos zum Logos bezieht sich darauf, daß in der Tragödie eine Selbsterkenntnis erfolgt, wie überhaupt die ganze Tragödie etwa des Ödipus als der Weg einer Selbsterkenntnis gelesen werden kann, auf dem Ödipus nach und nach aufdeckt, wer er ist. Subjektkonstitution also als tragische Gründung des Rechtssubjekts und Subjektkonstitution als tragische Selbsterkenntnis. ${ }^{1}$

1 Hegel unterscheidet zwei tragische "Hauptgegensätze«: den zwischen Staat und Familie, wofür er Sieben gegen Theben und Antigone als Beispiele nennt, und den zwischen dem "Recht des wachen Bewußtseins, um die Berechtigung dessen, was der Mensch mit selbstbewußtem Wollen vollbringt, dem gegenüber, was er unbewußt und willenlos nach der Bestimmung der Götter wirklich getan hat«, wofür er Ödipus als Beispiel anführt. G.W.F. Hegel: Vorlesungen über die Ästhetik III (=Werke, Bd. 15), Frankfurt a.M. ${ }^{4} 1996$, S. 544f. (im folgenden per Sigle Ä III im laufenden Text zitiert). 
In der Phänomenologie des Geistes entwickelt Hegel, wie der Titel bereits angibt, ein System der Erscheinungsformen des Geistes. Diese sind Bewußtsein, Selbstbewußtsein und Vernunft (die er später in der Enzyklopädie der philosophischen Wissenschaften unter dem Begriff des subjektiven Geistes zusammenfaßt), Geist (der »objektive Geist" der Enzyklopädie) sowie Religion und absolutes Wissen (später der "absolute Geist«). ${ }^{2}$

Das Subjekt verstanden als Selbstbewußtsein behandelt strenggenommen nur der zweite Teil der Phänomenologie, 3 und zwar in der Form des je einzelnen oder individuellen Selbstbewußtseins. Seine Entstehung erklärt Hegel anhand der bekannten Herr-Knecht-Dialektik, in der zwei Bewußtseinsformen, die des Herrn und die des Knechts, einander im Kampf dialektisch bedingen und hervorbringen. Die wesentlichen Momente dieses Hegelschen Subjektivitätskonzepts sind Streit, Anerkennung, Vermittlung und Untergang, wobei der Untergang zugleich stets die Aufhebung auf einer höheren Stufe bedeutet. Die Phänomenologie kann aber auch im ganzen als eine Beschreibung der Genese des Subjekts als der "Bewegung des Sichselbstsetzens, oder [der] Vermittlung des Sichanderswerdens mit sich selbst « (PG 23) gelesen werden, weil sich die Bewegung der Selbsterkenntnis oder Selbstbehauptung, der Entäußerung, Aufhebung und Rückkehr in sich in jedem Kapitel, auf jeder Entwicklungsstufe des Geistes aufs neue vollzieht. Die "Erscheinungsformen" des Geistes sind damit seine Entwicklungsstufen, und zwar jeweils des allgemeinen wie des einzelnen Geistes. Es geht also auf keiner der Bewußtseinsstufen entweder nur um die historische Entwicklung der Menschheit, und d.h. die Weltgeschichte, oder nur um die je einzelne Entwicklung des einzelnen Menschen zum Subjekt, sondern immer um beide gleichzeitig:4 Die Phänomenologie ist zugleich eine Menschheitsgeschichte des Geistes als Weltgeschichte und eine beschreibende Entwicklungspsychologie (man könnte auch sagen: ist zugleich Phylogenese und

2 Vgl. ders.: Enzyklopädie der philosophischen Wissenschaften III (=Werke, Bd. 10), Frankfurt a.M. ${ }^{4} 1999$, S. 32.

3 PG, Teil B.: »Selbstbewußtsein«, S. 137-177.

4 Eine zweifache Methodik der Phänomenologie stellt auch Changyang Fan fest in: Sittlichkeit und Tragik. Zu Hegels Antigone-Deutung, Bonn 1998, S. 82-90. 
Ontogenese), weswegen die Entwicklungsstufen stets ebensosehr welt- und menschheitshistorische wie individuell-psychische sind. ${ }^{5}$

Das zentrale Moment jeder dieser Entwicklungsstufen ist das Selbstbewußtsein; daher macht Ernst Bloch zufolge »bereits der einzige Satz: Erkenne dich selbst, ein wichtiges Stück Hegel kenntlich« ${ }^{6}$ daher auch »das gleiche Erkenne dich selbst in den immer höheren Stufen oder Spiralen in der Phänomenologie des Geistes «. ${ }^{7}$ Hegel schreibt in der Vorrede zur Phänomenologie, die Wissenschaft habe "das Selbstbewußtsein als eins mit sich zu setzen" (PG 31) $;{ }^{8}$ Wissen ist demnach immer auch das Wissen von sich selbst. Indem die Phänomenologie nun also das "werdende Wissen« behandelt, behandelt sie das werdende Selbstbewußtsein - das werdende Subjekt.

Die lebendige Substanz ist ferner das Sein, welches in Wahrheit Subjekt, oder, was dasselbe heißt, welches in Wahrheit wirklich ist, nur insofern sie die Bewegung des Sich-selbst-setzens, oder die Vermittlung des Sich-anders-werdens mit sich selbst ist. (PG 23)

Das Bewußtsein kommt zu seiner Wirklichkeit als "selbständiges Selbstbewußtsein« (PG 149) oder Subjekt erst durch Vermittlung mit dem Anderen und Rückkehr zu sich selbst. Das Subjekt ist demnach die vermittelte Einheit von Allgemeinem und Besonderem. Vermittelt zu sein, bedeutet, sich durch Handeln nach außen gesetzt und so zugleich das Außen in sich aufgenommen zu haben, sich dem Kampf gestellt und aus ihm - sei es als Sieger oder als Verlierer, als Herr oder als Knecht - hervorgegangen zu sein. Das Subjekt ist nicht nur bloß an sich, sondern hat sich nach außen gesetzt (Fürsich/Individuum) und ist wieder in sich zurückgekehrt (vermitteltes Fürsich/Anundfürsich). Die Tat nun entspringt der »Einseitigkeit des Für-

5 Vgl. zu diesem Nebeneinander und der Gleichzeitigkeit der Formen des Geistes PG 32f.: "Der Einzelne muß auch dem Inhalte nach die Bildungsstufen des allgemeinen Geistes durchlaufen, aber als vom Geiste schon abgelegte Gestalten, als Stufen eines Wegs, der ausgearbeitet und geebnet ist; so sehen wir in Ansehung der Kenntnisse das, was in früheren Zeitaltern den reifen Geist der Männer beschäftigte, zu Kenntnissen, Übungen und selbst Spielen des Knabenalters herabgesunken und werden in dem pädagogischen Fortschreiten die wie im Schattenrisse nachgezeichnete Geschichte der Bildung der Welt erkennen."

6 Ernst Bloch: Subjekt - Objekt. Erläuterungen zu Hegel, erw. Ausgabe, Frankfurt a.M. 1972, S. 32; vgl. auch G.W.F. Hegel: Enzyklopädie der philosophischen Wissenschaften III, $\$ 377$.

7 Ebd., S. 37.

8 Vgl. auch PG 441. 
sichseins«. (PG 344) Subjektsetzung ist „Entäußerung`: Man gibt etwas auf (`ent-`), indem man sich nach außen setzt (>-äußert`), und zwar die eigene Ununterschiedenheit; indem man sich räußert , unterscheidet man sich, und nur durch diese Unterscheidung kann man dann auch für sich sein. Subjektwerdung ist Unterscheidung oder Trennung von sich selbst und dadurch Erlangung seiner selbst, ist Aufhebung der Ununterschiedenheit zugunsten einer Unterschiedenheit (Individuation), die die Rückkehr ins Selbst ermöglicht, das nun aber eine unterschiedene, vermittelte Einheit ist. Sie ist der Weg von ununterschiedener Einheit über Entzweiung und Vermittlung zur unterschiedenen Einheit; Subjektivität ist damit in einem gewissen Sinne auch das Aufgeben von Individualität; die Individualität als bloße Einzelnheit wird dem Allgemeinen unterworfen, mit ihm vermittelt und so zum Subjekt. ${ }^{9}$ Das Individuum ist also eine Zwischenstufe zwischen Ansich (Bewußtsein) und Anundfürsich (Subjekt/Selbstbewußtsein), es ist das Setzen des Fürsich, das sich damit zugleich auch für andere setzt. Denn: Individualität ist nur durch »ihren Gegensatz des Andern« für sich. Zwar hebt sie ihre Einfachheit auf, indem sie "das Andre in sich setzt", und "entzweit» sie, aber »dies Entzweien [...] ist eben das Setzen der Individualität«. (PG 142) Individuierung bedeutet die Entzweiung mit der Welt, Subjektwerdung die darauffolgende Einheit. Das Subjekt ist demnach die vermittelte Einheit von Allgemeinem und Besonderem, also wesentlich dialektisch. Das Dialektische umfaßt den Widerstreit, und so tritt dieser nicht nur in seiner Grundfigur als »Kampf auf Leben und Tod» (PG 149) im Herr-Knecht-Kapitel auf, sondern findet, wie gesagt, in jedem Kapitel des

9 Diese Verwendungsweise des Begriffs der Individualität bei Hegel muß allerdings von einer anderen unterschieden werden. Die hier beschriebene Individualität ist das bloß Partikuläre und Einzelne, das noch unvermittelte Fürsich, das sich auf jeder dialektischen Stufe des Hegelschen Systems wiederfindet. Demgegenüber steht ein anderes, emphatisches Verständnis von Individualität als der ausgebildeten Individualität des Christentums. Nur für dieses gilt, was Menke ein »Mehr der Individualität gegenüber der Subjektivität« nennt. (Christoph Menke: Tragödie im Sittlichen, S. 194) Manfred Frank schreibt - grundsätzlich und für den deutschen Idealismus, ausdrücklich auch für Hegel geltend: "'Subjekt‘ (und rich`) meinen ein Allgemeines, >Person ‘in Besonderes, 'Individuum ein Einzelnes«. (Manfred Frank: Die Unhintergehbarkeit von Individualität, Frankfurt a.M. 1986, S. 25) Das wiederum trifft Hegels Terminologie insofern nicht ganz exakt, als ein Allgemeines bei Hegel immer defizitär ist; es ist das abstrakte, noch unentwickelte und unvermittelte Ansich. Dagegen ist das Hegelsche Subjekt ein wesentlich vermitteltes, eines, das sich durch die Vermittlung erst bildet, weswegen ihm nicht der Status eines bloß Allgemeinen zuzuordnen ist. 
Textes, auf jeder Stufe des "werdenden Wissens« aufs neue statt - so auch in der Sittlichkeit.

Im ersten Teil des Geistkapitels wird mit der »Sittlichkeit« nicht allein eine Stufe des Bewußtseins eines Volkes ${ }^{10}$ oder eine historische Gesellschaftsstufe behandelt, sondern zugleich auch das einzelne Selbstbewußtsein. Die Sittlichkeit kann daher einerseits historisch am Übergang von der nachmythischen frühen griechischen Antike zur Polis verortet ${ }^{11}$ und andererseits entwicklungspsychologisch als eine höher entwickelte Stufe des je einzelnen Selbstbewußtseins verstanden werden. Es ist die Entwicklung dieses sittlichen Subjekts, die Hegel an der Tragödie, namentlich an Sophokles' Antigone exemplifiziert - wiewohl ohne diese Bezüge im einzelnen auszubuchstabieren. Aus dem Ineinander von Geschichte und Subjekt folgt auch, daß mindestens die historische und psychische Bewußtseinsstufe der Sittlichkeit erreicht sein muß, bevor die Tragödie als literarische Form überhaupt hervorgebracht werden kann. ${ }^{12}$ Der Schwerpunkt von Hegels Antigoneinterpretation liegt damit nicht auf tragödientheoretischen oder ästhetischen Aspekten, sondern es handelt sich um die Exemplifizierung und Verwirklichung einer Stufe der Selbstbewußtseinswerdung an und in der Tragödie. $^{13}$

Auf der Stufe der Sittlichkeit tritt der Widerstreit zwischen "menschlichem" und "göttlichem Gesetz «"4 oder "sittlichem Selbstbewußtsein« und »Wesen" hervor. (PG 344) Zunächst aber ist jenes vorrechtliche "sittliche Reich" »eine unbefleckte durch keinen Zwiespalt verunreinigte Welt«. (PG 341) In ihr stehen sich die "allgemeinen sittlichen Wesen" des menschlichen und des göttlichen Rechts, das allgemeine und das einzelne Bewußtsein, das Volk und die Familie, zwar gegenüber, sind aber zugleich durch die Verbindung von Mann und Frau vermittelt. In diesem noch allgemeinen Stadium tritt der Gegensatz der beiden Sphären also noch nicht zutage, er besteht nur an sich, äußert sich nicht und ist noch keine Wirklichkeit geworden. So steht

10 Vgl. PG 329.

11 Diese historische Einordnung deckt sich auch mit derjenigen Nietzsches, wonach mit Sokrates und seiner Dialektik die Trennung und mit Euripides der Untergang der Tragödie beginnt.

12 Vgl. Ä III, 476.

13 „Die klassische Tragödie [...] exemplifiziert die Konstitution einer modernen Subjektivität und Freiheit." Christoph Menke: Tragödie im Sittlichen, S. 73.

$14 \mathrm{Zu}$ menschlichem und göttlichem Gesetz siehe genauer das Kap. "Die sittliche Welt, das menschliche und das göttliche Recht, der Mann und das Weib«, PG 328-342. 
auch das Selbstbewußtsein in dieser Allgemeinheit zunächst als ein nicht näher bestimmtes bloßes Bewußtsein, das sich von der äußeren Welt nicht unterscheidet: Es ist ununterschieden und noch nicht »einzelne Individualität«; es ist nur erst der »unwirkliche Schatten« des Gegensatzes von »allgemeinem Willen" und "Blut der Familie«. (PG 342) Der Zwiespalt zwischen Allgemeinheit und Besonderheit bricht in ihm noch nicht hervor.

Es liegt nun aber in der Struktur oder, hegelisch ausgedrückt, im Begriff des sittlichen Bewußtseins begründet, sich als Individualität zu setzen. Das einzelne sittliche Bewußtsein gehört entweder dem göttlichen oder dem menschlichen Gesetz an ${ }^{15}$ und ist »für eins derselben entschieden«. (PG 343) (Übertragen auf Antigone bedeutet das: Antigone gehört dem göttlichen Recht der Familie an, Kreon dem menschlichen Recht des Staates.) Diese Entschiedenheit für eine Seite manifestiert sich in der Tat, in der sich das Bewußtsein gegen die jeweils andere Seite und gegen das andere Recht setzt. (Antigone begräbt Polyneikes, dem göttlichen Recht in Form des Begräbnisgebots folgend und gegen das menschliche Recht in Form von Kreons Verbot verstoßend.) Das sittliche Bewußtsein kann eine Seite so entschieden vertreten, weil es nicht um das Recht der anderen Seite weiß. Indem das handelnde Bewußtsein nun eine Seite wählt und aktiv vertritt, werden in dieser seiner Tat die beiden Bereiche des menschlichen und des göttlichen Rechts einander entgegengesetzt, und zugleich setzt sich das Bewußtsein selbst als Individuum. Zuvor war »noch keine Tat begangen; die Tat aber ist das wirkliche Selbst«. (PG 342) In der Tat des Individuums tritt der zuvor verborgene Widerstreit der beiden Rechte zutage. Nachdem es die Tat vollbracht hat, erkennt es aber, daß die zwei Rechte, die durch seine Tat in Widerstreit geraten sind, gleichberechtigte Ansprüche haben, daß es die Ansprüche der Gegenseite verletzt hat und an ihr schuldig geworden ist. Durch diese Einsicht des Individuums in das gleiche Recht beider Sphären und in seine Schuld geht es selbst von der Stufe des Individuums als Bewußtsein für sich ins wirkliche Selbstbewußtsein als Bewußtsein an und für sich über (Antigone: "weil wir leiden, anerkennen wir, daß wir gefehlt« [PG 348]16). Das sittliche Bewußtsein ist nicht Bewußtsein an sich geblieben,

15 Vgl. PG 343.

16 Entgegen Hegels Interpretation findet diese Einsicht in Sophokles' Antigone eigentlich nicht statt. Antigone fragt: "Welch göttliches Gesetz hab ich verletzt? / Was soll ich Arme zu den Göttern noch / Aufschauen? Welchen Helfer ruf ich an? / Heiß ich doch, weil ich fromm war, Frevlerin! / Ja, wenn es den Göttern wohlgefällt, / Dann seh ich 
sondern hat sich in der Tat als Individuum gegen das andere, ihm äußere Recht gesetzt und ist mit der Einsicht in das Recht und die Berechtigung auch des Äußeren, Anderen, in sich als vermitteltes Subjekt zurückgekehrt. "In der Tat aber ist die sittliche Substanz durch diese Bewegung zum wirklichen Selbstbewußtsein geworden, oder dieses Selbst zum Anundfürsichseienden«. (PG 328) Wenn Hegel schreibt, in der Tragödie sei das Selbstbewußtsein vorgestellt, ${ }^{17}$ präsentiert er die griechische Tragödie als Paradigma der dialektischen Entwicklung des Selbstbewußtseins und liest Sophokles' Antigone als den Gründungstext moderner Subjektivität. ${ }^{18}$

ein: ich leide, weil ich fehlte. / Doch fehlten diese, treffe sie nichts Ärgres, / Als was sie wider Recht an mir getan!« (Sophokles: Antigone, übers. von Wilhelm Kuchenmüller, durchges. Ausgabe, Stuttgart 2000, V. 921-928) Sie zieht offenbar gar nicht in Betracht, daß die andere Seite auch ein Recht haben könnte. In der Frage »Welch göttliches Gesetz hab ich verletzt?« impliziert sie zudem, daß sie eben kein göttliches Gesetz verletzt hat, sondern nur dasjenige, was Hegel das menschliche nennt, also 'nur das Gesetz des Staates. Einen möglichen Fehler möchte sie nur dann einräumen, "wenn es [so] den Göttern wohlgefällt". Nicht ein anderes Recht, sondern allein die Launen der Götter könnten ihre Tat als Fehler ausweisen. Antigone begeht zwar wissentlich, wie Hegel sagt, das Verbrechen, aber nur wissend, daß es als Verbrechen angesehen werden wird, nicht um das tatsächliche Recht der anderen Seite wissend. Man kann also sagen, Antigone stirbt, ohne vor der Tat um das Recht der anderen Seite zu wissen und ohne nach der Tat die Einsicht in das Recht der anderen Seite zu erlangen. Hegel hingegen zitiert Antigone in nur einem Vers und unterschlägt auf diese Weise den konditionalen Zusammenhang: weil wir leiden, anerkennen wir, da/s wir gefehlt (PG 348), was einem "ich seh ein: ich leide, weil ich fehlte« in Kuchenmüllers Ubersetzung entspräche. An dieses Zitat schließt er dann den Satz an: "Dies Anerkennen drückt den aufgehobnen Zwiespalt des sittlichen Zweckes und der Wirklichkeit [...] aus." Ganz sauber ist dieser Schluß nicht.

17 Vgl. PG 540.

18 Hierin erweist sich übrigens Judith Butlers Vorschlag, statt der Figur des Ödipus die der Antigone als Modell für den zentralen psychischen Grundkonflikt des Menschen zu betrachten, als bei Hegel bereits verwirklicht (vgl. Judith Butler: Antigones Verlangen. Verwandtschaft zwischen Leben und Tod, Frankfurt a.M. 2001, S. 93-95. Vgl. auch George Steiner: Die Antigonen, München 1990, S. 32f.). Diese These von der Tragödie als Entstehungsort des modernen Subjekts bei Hegel vertritt auch Menke sehr entschieden - allerdings spricht er von Individualität (vgl. Christoph Menke: Tragödie im Sittlichen, insbes. S. 165-201). Hiergegen ist einzuwenden, daß Hegel im Religionskapitel auch Epos und Komödie als Formen des Bewußtseins betrachtet (vgl. hierzu die Einleitung zum zweiten Teil der Arbeit). 
Als Auflösungstext moderner Subjektivität dagegen gilt Foucaults Die Ordnung der Dinge (1966). Eines der bekanntesten Foucaultzitate überhaupt dürfte der Schlußsatz sein, demzufolge der Mensch svielleicht bald « "verschwindet wie am Meeresufer ein Gesicht im Sand «. ${ }^{19}$ Das "Verschwinden" und der "Tod[ ] des Menschen" (OD 412) wurden, zusammengefaßt als 'Ende des Subjekts,${ }^{20} \mathrm{zu}$ Schlagwörtern für Foucaults Werk und die Postmodernediskussion überhaupt, wobei in den Debatten von Anfang an nicht immer ganz klar gewesen zu sein scheint, wovon bei einem solchen 'Ende des Subjekts eigentlich die Rede ist und ob alle über dasselbe sprechen. Hans Michael Baumgartners differenzierte Antwort auf die Frage, welches Subjekt im philosophischen Diskurs der Moderne - also nicht speziell bei Foucault - "verschwunden" sei, lautet: das Subjekt des deutschen Idealismus, das als »Einheit von Substanz und Subjekt im Begriff des Selbstbewußtseins" konzipiert ist - und nur dieses. Am »Subjekt als verantwortliche Person in rechtlicher und moralischer Hinsicht" hingegen hält er explizit fest. ${ }^{21}$ Das Ende des Subjekts spezifisch bei Foucault wird wahlweise als das Ende des cartesischen oder des kantischen Erkenntnissubjekts, das Ende des freien und autonomen Subjekts der Moderne oder das Ende des idealistischen Subjekts begriffen, oder als eine nicht näher bestimmte Mischung oder Kombination aus all diesen - was zum einen an Uneindeutigkeiten in Foucaults eigenen Konzeptionen liegt, die auch, aber nicht nur auf den prozessualen Charakter seiner Arbeit zurückzuführen sind, die er immer wieder Modifikationen unterzogen hat, zum anderen aber darauf, daß häufig fälschlicherweise von `dem`Subjekt gesprochen und nicht berücksichtigt wird, daß es sich dabei um verschiedene Subjektbegriffe handelt.

19 Michel Foucault: Die Ordnung der Dinge. Eine Archäologie der Humanwissenschaften, Frankfurt a.M. ${ }^{18} 2003$ [Paris 1966], S. 462 (im folgenden per Sigle OD im laufenden Text zitiert).

20 Vgl. hierzu oben, Einleitung, Anm. 7.

21 Hans Michael Baumgartner: Welches Subjekt ist verschwunden?, S. 24. Und er macht deutlich: "Hingegen ist nicht verschwunden, weil dies noch die Bedingung jeder sinnvollen Rede, auch eines möglichen Verschwindens, ist: 1) Die Selbstreferenz des Ich, 2) das Subjekt als individuelles erkennendes Bewußtsein, 3) das Subjekt als verantwortliche Person in rechtlicher und moralischer Hinsicht und 4) das kommunikative Ich als Bezugspunkt jeder gemeinsamen Rede über die Welt und das Leben in ihr [...].« (Ebd., S. 27) 
Natürlich ist der Forschung nicht entgangen, daß sSubjekt bei Foucault Unterschiedliches bezeichnet, und es fehlt nicht an Differenzierungsversuchen. ${ }^{22}$ Foucault selbst unterscheidet Anfang der achtziger Jahre rückblikkend drei Untersuchungsgegenstände, nämlich das "menschliche Sein als Erkenntnissubjekt", das "menschliche Sein als gesellschaftliches und rechtliches Subjekt« und das "menschliche Sein als ethisches Subjekt«. ${ }^{23}$ Diese drei Bereiche werden häufig drei Werkphasen Foucaults zugeordnet: Das "Erkenntnissubjekt" als Gegenstand von der Ordnung der Dinge, das "gesellschaftliche und rechtliche Subjekt« als Gegenstand von Überwachen und Strafen und dem Willen zum Wissen und das ethische Subjekt als Gegenstand der späten Schriften seit den achtziger Jahren. Philipp Sarasin kritisiert diese Zuordnung, "weil Foucault schon von Anfang an die sAchsen< von Wissen und Macht in ihren Verbindungen und Überkreuzungen analysierte und weil er von Anfang an vom Problem umgetrieben wurde, was ein Individuum bzw. ein Subjekt sei«. ${ }^{24}$ Das ist richtig, zumal sich insbesondere die ersten beiden der drei Gebiete in Foucaults Werk nicht sauber trennen lassen, wie gleich kurz gezeigt werden wird. Andererseits legt Sarasin, ebenso wie Foucault in seiner eigenen rückblickenden Unterscheidung in das "menschliche Sein als Erkenntnissubjekt", das "menschliche Sein als gesellschaftliches und rechtliches Subjekt" und das "menschliche Sein als ethisches Subjekt«, nahe, daß es sich hier nur um verschiedene Gegenstandsbereiche ein und derselben Subjektkonzeption handele, was nicht richtig ist. Denn das, wonach Foucault unter dem Begriff des Subjekts jeweils fragt, sowie die Arten und Weisen, wie er danach fragt, sind so unterschiedlich, daß seine eigene vielzitierte Aussage, es sei ihm immer schon um »das Subjekt « gegangen, ${ }^{25}$ kaum bestätigt werden kann. ${ }^{26}$

22 Vgl. Robert M. Strozier: Foucault, Subjectivity and Identity. Historical Constructions of the Subject and Self, Detroit 2002; Martin Saar/Axel Honneth (Hg.): Michel Foucault. Zwischenbilanz einer Rezeption, Frankfurt a.M. 2003; Carsten Wolfers: Die Foucaultschen Subjekte, Wien u.a. 2009.

23 Michel Foucault: Vorwort zu "Sexualität und Wahrheit«, erste Fassung, in: S IV, S. 707-715, hier S. 709; vgl. auch Wolfgang Detel: Foucault und die klassische Antike. Macht, Moral, Wissen. Mit einem neuen Vorwort, Frankfurt a.M. 2006, S. 17, der diese drei als "Subjekte des Wissens, der Einwirkung auf andere und der moralischen Haltung« bezeichnet.

24 Philipp Sarasin: Michel Foucault zur Einführung, Hamburg 2005, S. 12.

25 Vgl. Michel Foucault: Subjekt und Macht (1982), in: S IV, S. 269-294, hier S. $269 f$.

26 Andererseits sind die unterschiedlichen Subjektbegriffe zumindest werkgenetisch ineinander überführbar, so daß die Behauptung einer durchgängigen Beschäftigung mit dem Subjekt haltbar bleibt - nur eben so, daß sich dabei der Subjektbegriff und 
An dieser Stelle kann keine umfassende Einleitung in und kein Überblick über die Diskussion um das Subjekt bei Foucault gegeben werden, um so weniger, als eine solche die schier unüberblickbare Begriffs- und Forschungsgeschichte des Subjektbegriffs miteinschließt. Die Weite dieses Gebiets ist, neben Uneindeutigkeiten in Foucaults Texten und Äußerungen selbst, auch der Grund dafür, daß Klärungsversuche, was mit dem Menschen oder dem Subjekt (bei Foucault) eigentlich verschwindet oder stirbt, unterschiedlich und häufig begrifflich unscharf ausfallen. Als Einstieg in die Schwierigkeiten, denen sich die Forschung in der Frage des Subjekts bei Foucault gegenübersieht, soll hier beispielhaft nur eine der vielen Darstellungen des Subjektbegriffs bei Foucault auszugsweise wiedergegeben und daraus einzelne fragliche Punkte herausgegriffen und kurz diskutiert werden. Hannelore Bublitz schreibt in ihrem Artikel Subjekt im Foucault-Handbuch:

Gegenüber der Auffassung, Foucault habe das Subjekt eliminiert (vgl. Honneth 1985, 136) und sei der Bewegung der radikalen Auslöschung des Subjekts gefolgt (vgl. Habermas 1983, 324), kann man geradezu behaupten, das Subjekt sei das Thema von Foucaults machthistorischen Analysen gewesen. Geleugnet wird nicht die Existenz des Subjekts, sondern seine im autonomen Willen und Bewusstsein begründete Stifterfunktion.

Foucault kann zweifellos in einer theoretischen Strömung verortet werden, die sich mit der "Infragestellung der Theorie des Subjekts« (S IV, 66) von dem cartesianischen Grundpostulat eines souveränen Schöpfersubjekts befreit. Mit diesem Angriff auf die fundierende Rolle des Subjekts, das in ständiger Selbstreflexion seine Identität sucht, ist eine Dezentrierung des Subjekts verbunden, das nun als Epiphänomen des Willens zur Macht erscheint. Der Auffassung, das Subjekt sei der Drehund Angelpunkt der Welt, wird eine Subjektkonzeption entgegengesetzt, die das Subjekt als unterworfenes entwirft. Als solches bildet es eine zwar aktive Schaltstelle gesellschaftlicher Machtkämpfe, keineswegs aber einen souveränen Protagonisten in diesem Geschehen. ${ }^{27}$

sein jeweiliger Inhalt vollkommen wandeln. Maria Muhle versucht, einen Zwischenweg zu nehmen, indem sie einerseits die Figur der »Wende zum Subjekt" aufnimmt und andererseits eine "Kontinuität zwischen den machttheoretischen und den subjekttheoretischen Schriften auf konzeptueller Ebene« beschreibt (vgl. Maria Muhle: Eine Genealogie der Biopolitik. Zum Begriff des Lebens bei Foucault und Canguilhem, Bielefeld 2008, S. 276f.). Diese Differenzierung ist zu begrüßen, entgeht aber nicht der grundsätzlichen Problematik jeder Rede von >dem« Subjekt bei Foucault.

27 Hannelore Bublitz: Subjekt, in: Clemens Kammler/Rolf Parr/Ulrich Johannes Schneider (Hg.): Foucault-Handbuch, S. 293-296, hier S. $293 f$. 
Zunächst einmal stellt die Behauptung, »das Subjekt sei das Thema von Foucaults machthistorischen Analysen gewesen", anders als Bublitz impliziert, schon deshalb keinen Gegensatz zu Honneths und Habermas' Auffassungen einer 'Eliminierung` oder "Auslöschung« des Subjekts dar, weil das Subjekt auch als Gegenstand der Beschreibung einer 'Eliminierung، oder "Auslöschung « "Thema" von Foucaults Untersuchungen bliebe (wiewohl negatives Thema). Auf vergleichbare Weise geht Paul Veynes Feststellung, das Subjekt sei aus Foucaults Forschungen "niemals verschwunden gewesen ${ }^{28}$ am Inhalt der Rede vom Ende des Subjekts vorbei. Es ist offenbar nicht überflüssig, darauf hinzuweisen, daß die These eines Endes des Subjekts erstens die Beschäftigung mit dem Subjekt nicht ausschließt und zweitens nicht ausschließt, weiterhin oder aufs neue mit (anderen) Subjektbegriffen zu operieren.

Damit ist man auch schon bei der Frage angelangt, was Foucault mit dem Begriff des Subjekts »eliminiert« oder rauslöscht‘. Bublitz' erste Bestimmung lautet: "Geleugnet wird nicht die Existenz des Subjekts, sondern seine im autonomen Willen und Bewusstsein begründete Stifterfunktion.» Dieser Satz ist unklar, denn gerade jener autonome Wille und das Bewußtsein als Bewußtsein von sich ist dasjenige, was mit dem Begriff des Subjekts seit Kant üblicherweise bezeichnet wird. Was Bublitz hier mit dem "Subjekt", dessen Existenz (bei Foucault) nicht "geleugnet" werde, meint, ist wohl eher so etwas wie das "menschliche[ ] Individu[um] «29 überhaupt, oder, um den ebenfalls schwierigen Begriff des Individuums zu vermeiden, die »human material entity (including mind) $« .{ }^{30}$ Deren Existenz bei Foucault hatten aber auch Honneth und Habermas nicht geleugnet. Bublitz schreibt weiter, Foucault »befrei[e] « sich »von dem cartesianischen Grundpostulat eines souveränen Schöpfersubjekts«. ${ }^{31}$ Abgesehen davon, daß das cartesische Cogito kein "Schöpfersubjekt« ist, kann man festhalten, daß Foucaults machthistorische Analysen Bublitz zufolge Descartes' und Kants Erkenntnissubjekt verabschieden. Gleich darauf spricht sie vom Fehlen eines »souveränen

28 Paul Veyne: Michel Foucaults Denken, in: Martin Saar/Axel Honneth (Hg.): Michel Foucault, S. 27-51, hier S. 41.

29 Wolfgang Detel: Foucault und die klassische Antike, S. 17.

30 Robert M. Strozier: Foucault, Subjectivity and Identity, S. 9.

31 »Schöpfersubjekt« ist eine Bezeichnung, die im Zusammenhang mit Foucault eher an den Tod des Autors (der freilich letztlich auch wieder mit der Ablehnung des Erkenntnissubjekts und des autonomen Subjekts zusammenhängt) denken läßt, der eher in der Archäologie des Wissens eine Rolle spielt. 
Protagonisten« in Foucaults Machtanalysen. Damit sind jedoch zwei völlig unterschiedliche Subjektkonzeptionen umschrieben; die Abwesenheit eines "Souveränen Protagonisten" ist die Abwesenheit des selbstbestimmten und frei handelnden modernen Subjekts und bedeutet nicht dasselbe wie die Nichtexistenz des Erkenntnissubjekts (wiewohl bei Kant in der Tat die Konzeption eines transzendentalen Subjekts Voraussetzung für die Idee menschlicher Autonomie ist).

Paul Geyer beantwortet die Frage, welches Subjekt bei Foucault sverschwindet oder sendet<, mit dem "modernen, autonomen menschlichen Subjekt« der »Human- und Geisteswissenschaften seit Hegek bzw. dem »autonomen Subjekt[] der Moderne«.32 Auch diese Bestimmung führt allerdings zu einer gewissen Unklarheit, indem Geyer in der Wendung "Human- und Geisteswissenschaften" einen bei Foucault distinkten Begriff ('Humanwissenschaften $\varsigma$, dazu gleich) mit einem bei Foucault nichtdistinkten Begriff (`Geisteswissenschaften $<$ ) mischt und darüber hinaus das "moderne[ ], autonome[ ] menschliche[ ] Subjekt« nicht auf, z.B., Kant, sondern auf die Zeit »seit Hegel« datiert, womit dann eher das idealistische Subjekt angesprochen ist. Ute Frietsch dagegen betont: "Foucaults These des Passagencharakters der Episteme 'Mensch zielt nicht auf den Humanismus und auch nicht auf die Aufklärung«, sondern auf die "Anthropologie«. 33

Tatsächlich spricht Foucault selbst in der Ordnung der Dinge nicht vom Ende des Subjekts, sondern vom Ende des Menschen, womit im dortigen Untersuchungszusammenhang zunächst einmal >lediglich eine bestimmte Wissenskonfiguration oder Episteme, ein bestimmtes "historisches Apriori« gemeint ist, nämlich der »Mensch" als Erkenntnissubjekt und -objekt der Humanwissenschaften. ${ }^{34}$ Diesen »Menschen« bestimmt er als »erkenntnis-

32 Paul Geyer: Foucaults »Les mots et les choses«: Ende oder Anfang einer modernen Subjekttheorie?, in: Literaturwissenschaftliches Jahrbuch 38 (1997), S. 245-260, hier S. 246, 257.

33 Ute Frietsch: Die Ordnung der Dinge, in: Clemens Kammler/Rolf Parr/Ulrich Johannes Schneider (Hg.): Foucault-Handbuch, S. 38-50, hier S. 48.

34 Das bestätigt Foucault drei Jahre später, nach Veröffentlichung der Archäologie des Wissens, in einem Interview: Der »Tod des Menschen" ist "nur ein Sonderfall oder, wenn Sie so wollen, eine der sichtbaren Formen eines weitaus allgemeineren Sterbens. Damit meine ich nicht den Tod Gottes, sondern den Tod des Subjekts, des Subjekts als Ursprung und Grundlage des Wissens, der Freiheit, der Sprache und der Geschichte." (S I, 1002) Hier wird deutlich, daß der "Tod des Menschen" in der Ordnung der Dinge tatsächlich, zumindest zunächst, snur der Tod jenes sehr spezifischen Subjekts und Objekts der Humanwissenschaften ist - der aber, wie schnell 
theoretisches Bewußtsein des Menschen als solchen«. (OD 373) Das klingt zunächst nach dem üblichen reflexionstheoretischen Bewußtseinsmodell, doch meint Foucault damit gerade nicht das Erkenntnissubjekt Descartes', denn das Cogito gehört eindeutig der Episteme der Repräsentation an, wie er sogleich betont (vgl. OD 376f.), und er meint auch nicht Kants transzendentales Subjekt: »Aber das moderne Cogito ist ebenso von dem Descartes' unterschieden wie unsere transzendentale Reflexion von der kantischen Analyse entfernt ist."(OD 390) Es handelt sich Foucaults Anspruch nach durchaus um eine "transzendentale Reflexion", wie auch die Formulierung vom "anthropologischen Schlummer« (OD 410) ${ }^{35}$ an Kants Erkenntniskritik anknüpft - nur eben in bezug auf ein anderes Erkenntnismodell (nämlich die Episteme der Humanwissenschaften) und auf ein anderes, ein neu historisch definiertes Erkenntnissubjekt, nämlich den »Menschen«.

"Der Mensch ist in der Analytik der Endlichkeit eine seltsame, empirischtranszendentale Dublette, weil er ein solches Wesen ist, in dem man Kenntnis von dem nimmt, was jede Erkenntnis möglich macht«. (OD 384) Der Unterschied zu Kants erkenntnistheoretischer Position ist hier auf den ersten Blick nicht deutlich, zeichnet diese sich doch gerade durch die Zweiheit (oder eben Dopplung) aus Subjekt der Welt der Erscheinungen und Subjekt der Welt an sich, aus empirischem und transzendentalem Subjekt, aus. ${ }^{36}$ Sarasin schreibt, laut Foucault tauchte

(auch in der Kritik an der These) deutlich wurde und Foucault hier dann auch sagt, dem viel umfassenderen "Tod des Subjekts" angehört.

Andererseits verweist Foucault in der Ordnung der Dinge auch im Zusammenhang der "empirisch-transzendentalen Dublette" auf Nietzsche, der "ankündigte, daß der Mensch bald nicht mehr existieren werde«, was bedeutete, "daß der Mensch bereits seit langem verschwunden war und immer weiter verschwand, und daß unser modernes Denken vom Menschen, seine Sorge um ihn, unser Humanismus heiter auf seiner grollenden Nichtexistenz schliefen.«(OD 389) Foucault spielt also auch in seiner erkenntnistheoretischen Argumentation vom Ende des Menschen immer mit rantihumanistischen Anklängen; vgl. hierunter.

35 »Schlummer«, nicht »Schlaf«, wie Köppen übersetzt; analog zu Kants »dogmatischem Schlummer", aus dem ihn laut den Prolegomena Hume erlöste.

36 Foucaults Ausdruck »Dublette« (doublure) oder Dopplung ist deshalb mißverständlich, weil man auch Kants Unterscheidung in empirisches und transzendentales Subjekt als `Dopplung` oder `Dublette bezeichnen könnte, Foucault damit aber eine gegenteilige Position bezeichnet; vgl. die folgenden Ausführungen. 
der Mensch als Objekt und zugleich fundierendes Subjekt jeder Erkenntnis auf. Er tauchte auf $[\ldots]$ als »empirisch-transzendentale Doublette«: als empirisches Objekt vieler neuer Wissenschaften [...] und als transzendentales Subjekt der Wahrheit jeder Erkenntnis überhaupt. ${ }^{37}$

Damit sind jedoch der "empirisch-transzendentale" Charakter des "Menschen" der Humanwissenschaften und also auch der Dopplungscharakter der "Dublette" nicht korrekt erklärt, obwohl Sarasin gleich darauf den entscheidenden Unterschied zur kantischen Position nennt: daß nämlich »das Transzendentale in der Moderne nicht länger allein in der Figur einer sreinen Vernunft، gesehen wird, sondern in den 'Quasi-Transzendentalien Arbeit, Leben und Sprache «, ${ }^{38}$ die Bedingung und Gegenstand der seit 1800 sich ausbildenden neuen "Humanwissenschaften« Biologie, Ökonomie und Philologie sind. Foucault schreibt über diese "Quasi-Transzendentalien" (OD 307):

Die Arbeit, das Leben und die Sprache erscheinen jeweils als »Transzendentalien«, die die objektive Erfahrung der Lebewesen, der Produktionsgesetze und der Formen der Sprache ermöglichen. In ihrem Sein sind sie außererkenntnismäßig (hors connaissance), aber dadurch selbst sind sie Bedingungen der Erkenntnisse. Sie entsprechen der Entdeckung eines transzendentalen Feldes durch Kant, und dennoch unterscheiden sie sich davon in zwei wesentlichen Punkten. (OD 301)

Diese "zwei wesentlichen Punkte[ ] sind »die Tatsache, daß die Transzendentalien bei dem Objekt ruhen" (genau das ist bei Kant nämlich nicht der Fall, weil er transzendentales und empirisches Subjekt und damit Subjekt und Objekt der Erkenntnis unterscheidet, während der "Mensch" empirisches und transzendentales Subjekt zugleich ist), und »die Tatsache, daß diese Transzendentalien die aposteriorischen Systeme betreffen« (OD 301) - es handelt sich also um empirische Transzendentalien. Die empirischen Formen der Erkenntnis (Arbeit, Leben, Sprache) sind zugleich die »Bedingungen der Erkenntnisse"; das Empirische ist das Transzendentale. Darin besteht die humanwissenschaftliche "Dublette«, besteht die Eigenschaft des Menschen als "Ort einer empirisch-transzendentalen Reduplizierung«. (OD 389)

Daß das Empirische das Transzendentale ist, liegt in einem neuen Verständnis der Endlichkeit begründet oder gründet ein neues Verständnis der

37 Philipp Sarasin: Michel Foucault zur Einführung, S. 85.

38 Ebd. 
Endlichkeit. Bei Kant ist die Erkenntnis endlich, weil das menschliche Erkenntnissubjekt nicht nur der Welt der Dinge an sich, sondern auch der empirischen Welt der Erscheinungen angehört. Bei Foucault dagegen gehört die humanwissenschaftliche Erkenntnis selbst der empirischen Welt an. "Das heißt, daß jede dieser positiven Formen, in denen der Mensch erfahren kann, daß er endlich ist, ihm nur auf dem Hintergrund seiner eigenen Endlichkeit gegeben ist.« (OD 380)

Die Erfahrung, die sich am Anfang des neunzehnten Jahrhunderts bildete, stellt die Entdeckung der Endlichkeit nicht mehr ins Innere des Denkens über das Unendliche [wie noch bei Descartes und Kant; Gw.E.], sondern genau in das Zentrum jener Inhalte, die durch ein endliches Wissen als die konkreten Formen der endlichen Existenz gegeben werden. Daher rührt das unbeendbare Spiel eines reduplizierten Bezugs. Wenn das Wissen des Menschen endlich ist, dann weil es ohne mögliche Befreiung in den positiven Inhalten der Sprache, der Arbeit und des Lebens gefangen ist. Umgekehrt, wenn das Leben, die Arbeit und die Sprache sich in ihrer Positivität ergeben, dann weil die Erkenntnis endliche Formen hat. (OD 382)

Foucault legt hier eine erkenntnistheoretische Kritik der Humanwissenschaften und des humanwissenschaftlichen Erkenntnissubjekts, des "Menschen", vor. Es ist diese spezifische epistemische Konfiguration, die er in seiner These vom "Ende des Menschen" verabschiedet; so gesehen behauptet er weder direkt das Ende des cartesischen noch das des kantischen Erkenntnissubjekts. Allerdings schließt die These vom Ende des "Menschen", auch im beschriebenen rein erkenntnistheoretischen Verständnis, die Historizität von (Erkenntnis-)Subjektkonzeptionen überhaupt notwendig mit ein oder setzt sie voraus; das eigentliche Skandalon der Ordnung der Dinge besteht demnach in der Historisierung der Wissensformen oder Epistemen, in die die moderne Episteme der Humanwissenschaften, sunserer Episteme, ausdrücklich miteingeschlossen ist. Als Konsequenz dieser spezifischen Historisierung erweisen sich das Subjekt und seine Erkenntnis als je historisch bedingte Konstruktion, was auch die Dekonstruktion des klassischen Erkenntnissubjekts bedeutet.

An dieses transzendentale Subjekt Kants wiederum sind Freiheit und Autonomie des handelnden Subjekts gebunden, die damit ebenfalls dekonstruiert werden; so gesehen ist Geyers Kopplung von modernem autonomen Subjekt und Mensch der Humanwissenschaften (in ihrer Unbestimmtheit) doch zutreffend. Mit dem bevorstehenden "Tod des Menschen« der Humanwissenschaften ist daher doch auch das Selbstverständnis moderner Subjektivität in Frage gestellt, und daher auch richtete sich die Kritik an der Ordnung 
der Dinge u.a. gegen einen 'Antihumanismus Foucaults. ${ }^{39}$ Obwohl also Foucaults dortige These vom "Tod des Menschen" spezieller ist als die viel weiter gefaßte These vom postmodernen Tod des Subjekts überhaupt, und obwohl von `Antihumanismus hier eigentlich nur in einem epistemischen, ethisch neutralen Sinn gesprochen werden kann, ist die Folgerung eines ethischen Antihumanismus zumindest nicht ausgeschlossen. Dies um so weniger, als Foucault darüber hinaus seine primär erkenntnistheoretische These in Form und Stil der Darstellung polemisch auflädt. Insbesondere in der Wendung vom "Tod des Menschen« greift er den von Nietzsche proklamierten Tod Gottes auf, der nun tatsächlich auf die metaphysische Begründung der Freiheit und Autonomie des Menschen und die Universalität ethischer Werte abzielt, und provoziert damit Reaktionen wie den Vorwurf des Antihumanismus. ${ }^{40}$

Ein Ende nicht des "Menschen« der Humanwissenschaften, sondern des klassischen Erkenntnissubjekts erklärt Foucault explizit zu Beginn der siebziger Jahre. Zwar verzichtet er bereits in der Archäologie des Wissens (1969) auf "ein Cogito" und »eine transzendentale Subjektivität«, fordert aber nicht direkt deren Aufgabe. Es geht ihm dort vor allem darum, einen Diskurs ohne Subjekt zu beschreiben; das sprechende Subjekt ist für seine Aussagenanalyse »nicht nötig «. ${ }^{41}$ Die Forderung nach einer regelrechten Abschaffung

39 Vgl. dazu Hayden White: Foucault's Discourse. The Historiography of Anti-Humanism, in: ders.: The Content of the Form, Baltimore/London 1987, S. 104-141; Ute Frietsch: Die Ordnung der Dinge, S. 39. Zu einer Diskussion des 'Antihumanismus bei Foucault vgl. Achim Geisenhanslüke: Antihumanismus? Michel Foucault und die Folgen, in: Richard Faber (Hg.): Streit um den Humanismus, Würzburg 2003, S. 235-46; Philipp Sarasin: Michel Foucault zur Einführung, S. 87f. Ein Beispiel für prägnante santihumanistische` Äußerungen Foucaults bietet das Interview »Wer sind Sie, Professor Foucault?«, in: S I, S. 770-793, hier S. 787-793.

40 Kritiker spezifisch von Foucaults bewußtseinstheoretischer Position sparen ihrerseits nicht mit Ausdrücken, die polemisch über das Feld der Erkenntnistheorie hinausweisen; vgl. etwa Manfred Frank, der schreibt, während das Subjekt »den Ausgangspunkt des vormodernen (z.B. cartesischen) und besonders des modernen (z.B. kantianischen-Fichteschen-Sartreschen) Denkens" bedeute, laufe die Foucaultsche Auffassung des modernen Wissens auf die "Euthanasie" modernen Denkens und seines Subjektbegriffs hinaus. Manfred Frank: Was ist Neostrukturalismus?, Frankfurt a.M. 1984, S. 245.

41 Die Aufgabe der Aussageanalyse setzt "voraus, daß dieses Aussagefeld nicht auf ein individuelles Subjekt, nicht auf etwas wie ein kollektives Bewußtsein, eine transzendentale Subjektivität bezogen wird, sondern daß man es als ein anonymes Feld beschreibt, dessen Konfiguration den möglichen Platz der sprechenden Subjekte definiert. Es ist nicht nötig, die Aussagen im Verhältnis zu einer souveränen Sub- 
des Erkenntnissubjekts erfolgt erst da, wo Foucault gezielt Machtstrukturen in den Blick zu nehmen beginnt und die Form der Erkenntnis von sich selbst auch als Ergebnis von Machtstrukturen identifiziert. Im 1969 entstandenen und 1971 veröffentlichten Aufsatz Nietzsche, die Genealogie, die Historie, der Programmschrift zu seiner genealogischen Methode, formuliert er als eines ihrer Ziele die "Zerstörung des Erkenntnissubjekts" ${ }^{42}$ und in einer unter dem Titel Die Wahrheit und die juristischen Formen posthum publizierten Vortragsreihe aus dem Jahre 1973 konstatiert er, wiederum mit Bezug auf

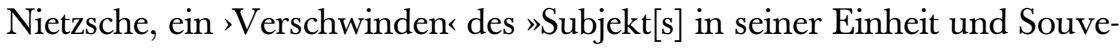
ränität«. (WjF 21) Statt dessen kündigt er dort eine "Neufassung einer Theorie des Subjekts" an, die nicht mehr "cartesisch und kantisch «43 wäre. $(\mathrm{WjF} 10)$ Er geht dabei von Nietzsches Kritik an der Erkenntnistheorie aus, ${ }^{44}$ gelangt dann aber über dessen Verbindung von Wissen und Macht nicht nur zum Ergebnis, daß es kein vorgängiges souveränes Erkenntnis-

jektivität zu plazieren, sondern in den verschiedenen Formen der sprechenden Subjektivität dem Aussagefeld eigene Wirkungen zu erkennen." (Michel Foucault: Archäologie des Wissens, Frankfurt a.M. ${ }^{12} 2005$, S. 177. Im folgenden per Sigle AW im laufenden Text zitiert.) "Die Analyse der Aussagen vollzieht sich also ohne Bezug auf ein Cogito. Sie stellt nicht die Frage dessen, der spricht, der sich manifestiert oder in dem, was er sagt, verbirgt, der, indem er spricht, seine souveräne Freiheit ausübt oder sich, ohne es zu wissen, den Zwängen unterwirft, die er schlecht wahrnimmt. Sie stellt sich tatsächlich auf die Ebene des sman sagt‘, und darunter braucht man keine Art gemeinsamer Meinung, kollektiver Repräsentation zu verstehen, die sich jedem Individuum auferlegte. Man darf darunter keine große anonyme Stimme verstehen, die notwendig durch die Diskurse eines jeden spräche, sondern die Menge der gesagten Dinge, die Relationen, die Regelmäßigkeiten und Transformationen, die darin beobachtet werden können, das Gebiet, das mit bestimmten Figuren, mit bestimmten Schnittpunkten den besonderen Platz des sprechenden Subjekts anzeigt, das den Namen eines Autors erhalten kann. 'Egal, wer spricht‘, doch was er sagt, sagt er nicht von irgendwo aus. Er ist notwendig in das Spiel einer Äußerlichkeit gefangen." (AW 178) Gans argumentiert diesbezüglich, »daß die Aussage wie die historisch diskursive Praxis die eigentliche menschliche Subjektivität selbst darstellt und somit von dieser nicht abstrakt ausgeklammert werden kann, sondern mit dieser zusammenfällt." (Michael Gans: Das Subjekt der Geschichte, S. 252); vgl. auch Michael Ruoff, der den Diskurs als "Subjektfunktion« bezeichnet (Michael Ruoff: Foucault-Lexikon, S. 201).

42 Michel Foucault: Nietzsche, die Genealogie, die Historie [1971], in: ders.: S II, S. 166-191, hier S. 191 (im folgenden per Sigle NGH im laufenden Text zitiert).

43 "[G]artesisch und kantisch [...] - denn auf der allgemeinen Ebene, auf der ich ansetze, mache ich keinen Unterschied zwischen kantischen und cartesischen Konzeptionen." $(\mathrm{WjF} 10)$

44 "Bei Nietzsche findet man tatsächlich einen Diskurs, der eine historische Analyse der Entstehung des Subjekts und einer bestimmten Art von Wissen unternimmt, ohne dabei die vorgängige Existenz eines Erkenntnissubjektes vorauszusetzen.« (WjF 15) 
subjekt gibt, sondern auch zu der Entdeckung eines ganz anderen, nämlich sehr konkreten Subjekts politisch-gesellschaftlich-rechtlicher Wissens- und Machtstrukturen - für das er allerdings, und darin liegt die Schwierigkeit, weiterhin die Bezeichnung »Erkenntnissubjekt« verwendet.

Ich möchte nun zeigen, [...] dass soziale Praktiken [...] gänzlich neue Formen von Subjekten und Erkenntnissubjekten [hervorbringen]. Auch das Erkenntnissubjekt hat eine Geschichte; auch die Beziehung zwischen Subjekt und Objekt, also die Wahrheit hat eine Geschichte. (WjF 10)

Auffällig ist hierbei Foucaults etwas unbestimmte Formulierung von "Subjekten und Erkenntnissubjekten«. Sie verrät, daß mehr auf dem Spiel steht als nur das Erkenntnissubjekt, so sehr Foucault auch bemüht ist, sein Vorgehen methodisch in einer Kritik der Erkenntnistheorie zu gründen. In dieser begrifflichen Überblendung von Erkenntnissubjekt und Subjekt sozialer Praktiken zeigt sich in Die Wahrheit und die juristischen Formen der theoretisch-methodische Übergang von einer zunächst noch der Konzentration auf epistemische Konstruktionen verpflichteten und am Begriff des Erkenntnissubjekts orientierten Subjektkonzeption (bzw. der Absage an sie) hin zu einer machtanalytischen Subjektkonzeption, zu einem Subjekt der Macht. Foucault schreibt weiter:

Insbesondere möchte ich auf diese Weise zeigen, wie im 19. Jahrhundert ein bestimmtes Wissen über den Menschen, die Individualität, das normale oder anomale Individuum innerhalb oder außerhalb der Regel entstehen konnte, ein Wissen, das in Wirklichkeit aus den Praktiken der sozialen Kontrolle und Überwachung hervorgegangen ist. Und ich möchte zeigen, dass dieses Wissen sich nicht einem vorhandenen Erkenntnissubjekt aufdrängte oder aufprägte, sondern eine vollkommen neue Art von Erkenntnissubjekt entstehen ließ. Die Geschichte der Wissensgebiete in ihrem Verhältnis zu den sozialen Praktiken, aber ohne den Primat eines ein für alle Mal vorgegebenen Erkenntnissubjekts bildet die erste Achse der Untersuchung, die ich Ihnen vorschlage. ( $\mathrm{WjF} 10)$

Damit ist umrissen, was Foucault zwei Jahre später in Überwachen und Strafen durchführen wird. Auch ist hier erstmals deutlich die Idee formuliert, daß soziale Praktiken Subjekte "hervorbringen«, daß also Machtmechanismen nicht nur restriktiv, sondern auch oder vielmehr vor allem produktiv wirken. $\mathrm{Zu}$ Beginn von Überwachen und Strafen nimmt Foucault dieselbe Überblendung von Erkenntnissubjekt und Subjekt gesellschaftlicher Machtmechanismen vor wie schon in Die Wahrheit und die juristischen Formen, indem er "das erkennende Subjekt, das zu erkennende Objekt und die Erkenntnisweisen« 
als "Effekte« von »Macht/Wissen-Komplexen« bezeichnet. (ÜS 39) Das erkennende Subjekt, das gleichzeitig zu erkennendes Objekt ist, charakterisiert das Reflexionsmodell der Subjektivität, ${ }^{45}$ mithin die cartesische ebenso wie die kantische Erkenntnissubjektkonzeption. Auf diese Weise bildet Foucault eine Art Analogie: Er erteilt dem reflexionstheoretischen Subjektmodell eine Absage (»das Modell der Erkenntnis und der Primat des Subjekts" sind "aufzugeben«, ÜS 40), beschreibt dann aber ein Subjekt, in dem sich dieses Reflexionsmodell auf einer konkreten und praktischen Ebene gesellschaftlicher Machtstrukturen gewissermaßen materialisiert wiederholt: ein Subjekt, das zugleich Subjekt und Objekt der Macht/Wissen-Strukturen ist. So sehr Foucault jedoch hier die Ablehnung des cartesisch-kantischen Erkenntnissubjekts betont, haben die dann folgenden Ausführungen tatsächlich viel größere Bedeutung für Geyers »autonomes Subjekt der Moderne« und Bublitz' »souveränen Protagonisten«. Denn freies, selbstbestimmtes Handeln ist einem so konzipierten Subjekt tatsächlich unmöglich.

Eine eigentliche Dekonstruktion des freien und selbstbestimmten Subjekts unternimmt Foucault also in seinen Arbeiten der siebziger Jahre. Überwachen und Strafen entlarvt die vermeintlich humanistischen Bemühungen um die "Humanisierung der Strafen« als Bestandteil einer Strategie fortschreitender Subjektivierung (im doppelten Wortsinne von Unterwerfung und Subjektkonstitution). Mit den machtanalytischen Schriften tritt daher die Frage nach einem Erkenntnissubjekt in den Hintergrund; hier geht es um das konkrete Subjekt gesellschaftlicher Machttechniken, das Wissensdiskursen und disziplinaren Praktiken unterworfen ist und durch diese Unterwerfung zugleich überhaupt erst hervorgebracht wird, als ein Konstrukt und reales Produkt von Machttechniken. In der Diskussion um das Subjekt bei Foucault spielt diese Absage an das freie und selbstbestimmte Subjekt eine größere Rolle als die epistemologische "Dezentrierung « des klassischen Erkenntnissubjekts.

Neben dem "Tod des Menschen« am Ende der humanwissenschaftlichen Episteme betrifft die Rede vom 'Ende des Subjekts bei Foucault also zum einen Descartes' Cogito und Kants transzendentales Subjekt bzw., allgemeiner, das Erkenntnissubjekt und zum anderen das selbstbestimmte und frei handelnde Subjekt der Moderne. Beide überblendet Foucault gezielt und ersetzt sie durch das Subjekt der Macht/Wissen-Konzeption. Hier zeigt sich

45 Vgl. hierzu Manfred Frank: Die Unhintergehbarkeit von Individualität, S. 33, 65. 
auch noch einmal, warum die Rede vom Ende des Subjekts bei Foucault nicht durch den Hinweis darauf widerlegt werden kann, daß das Subjekt bei ihm immer eine Rolle gespielt hat - einfach, weil es um zwei völlig verschiedene Subjektbegriffe geht, und weil gerade dasjenige Subjekt, das Gegenstand seiner Untersuchungen ist (das Subjekt der Macht) ja die Verabschiedung des Subjekts im bisherigen Verständnis bedingt und bedeutet. Mit Bezug auf Foucaults späte Texte seit Beginn der achtziger Jahre, ${ }^{46}$ den Arbeiten zur Sorge um sich und den Selbsttechniken, hat sich in der Forschung die Rede von einem "Wandel« oder einer "Kehre" in Foucaults Werk, und zwar in Form einer 'Wiederkehr oder 'Rückkehr' des Subjekts, durchgesetzt. ${ }^{47}$ Dementgegen wird zwar immer wieder auf Foucaults eigene rückblickende Zusammenfassung seiner Forschungen in seinem Aufsatz Subjekt und Macht aus dem Jahre 1982 verwiesen, ${ }^{48}$ wonach das "umfassende Thema" seiner Arbeit »in den letzten zwanzig Jahren" das Subjekt gewesen sei. ${ }^{49}$ So sei Martin Saar zufolge jene "Diskontinuitätslesart « widerlegt und herrsche inzwischen weitgehend Konsens darüber, daß von einer »Wiederkehr des Subjekts« bei Foucault nicht gesprochen werden könne, weil es ihm "schon lange um die Verfahren, in denen Erfahrung, Selbstbeziehung und Subjektivität entstehen", ging. ${ }^{50}$ Das ist richtig, doch kann die Rede vom "Auftauchen des Subjekts " ${ }^{51}$ ebensowenig wie die Rede von seinem Ende durch den Hinweis auf eine Kontinuität der Beschäftigung Foucaults mit >dem< Subjekt entkräftet werden, wie Veyne und Saar es versuchen und wie es Foucaults rückblickende Bemerkung nahelegt. Denn dasjenige, dem Foucault sich dort zuwendet, ist wieder ein anderes Subjekt. ${ }^{52}$ Eine berech-

46 Vgl. Foucaults Vorlesungen von 1980/81, "Subjektivität und Wahrheit« (»Subjectivité et vérité«; im Editionsprozeß); Michel Foucault: Hermeneutik des Subjekts. Vorlesung am Collège de France 1981/82, Frankfurt a.M. 2004; ders.: Der Gebrauch der Lüste. Sexualität und Wahrheit 2, Frankfurt a.M. 82004 [Paris 1984]; ders.: Die Sorge um sich. Sexualität und Wahrheit 3, Frankfurt a.M. ${ }^{8} 2004$ [Paris 1984].

47 Vgl. oben, Einleitung, Anm. 8.

48 Vgl. Matthias Rüb: Das Subjekt und sein Anderes. Zur Konzeption von Subjektivität beim frühen Foucault, in: Eva Erdmann/Rainer Forst/Axel Honneth (Hg.): Ethos der Moderne. Foucaults Kritik der Aufklärung, Frankfurt/New York 1992, S. 187-201, hier S. 187; Martin Saar: Genealogie und Subjektivität, in: ders./Axel Honneth (Hg.): Michel Foucault, S. 157-177, hier S. 159.

49 Michel Foucault: Subjekt und Macht, S. $269 f$.

50 Martin Saar: Genealogie und Subjektivität, S. 159.

51 Philipp Sarasin: Michel Foucault zur Einführung, S. 185, 190ff.

52 Vgl. Judith Butler: Noch einmal: Körper und Macht, in: Martin Saar/Axel Honneth (Hg.): Michel Foucault, S. 52-67, hier S. 66. 
tigte Kritik an der Rede von der 'Wiederkehr oder der 'Rückkehr des Subjekts` müßte daher lauten, daß sie fälschlicherweise die Identität von verschwundenem und auftauchendem Subjekt impliziert: Das, was der späte Foucault hier unter dem Begriff des Subjekts untersucht, ist weder der verabschiedete Mensch der Humanwissenschaften noch das verabschiedete (cartesische oder transzendentale) Erkenntnissubjekt noch auch das verabschiedete moderne autonome Subjekt. Zwar erlauben die "Selbsttechniken « eine Form der Subjektkonstitution jenseits von Unterwerfungs- und Machttechniken, und zwar ist das Subjekt der "Sorge um sich" ein ethisch ausgerichtetes Selbstverhältnis, das sich selbst zu dem macht, was es ist. Foucault geht es hier durchaus um die Möglichkeit einer Freiheit des Subjekts, doch hält Manfred Frank zu Recht fest: »Das ist nicht die Geschichte des neuzeitlichen Subjekts, sondern die einer neu erschlossenen Antike « ${ }^{53}$ Nicht nur, daß dieses Selbstverhältnis sich auf die Tradition der klassischen griechischen Antike bezieht, ist der Grund dafür, daß es sich dabei nicht um eine »Wiederkehr« des von der Postmoderne verabschiedeten Subjekts handelt. Der Hauptunterschied besteht darin, daß die Selbsttechniken vor allem individuelle Techniken sind und ihr Subjekt daher auch ein individuelles Subjekt ist - und nicht das Subjekt der Aufklärung, nicht das Subjekt einer universellen Humanität. Korrekt wäre daher, von einer "Hinwendung " ${ }^{54}$ zu einem Subjekt oder dem "Auftauchen« eines Subjekts zu sprechen. Andererseits konstatiert Manfred Frank: »Es bleiben Fragen. Denkt Foucault, der Gang der Geschichte sei umkehrbar und antike Individualethiken ließen sich in alter Frische an die Stelle des neuzeitlichen Wahrheitsuniversalismus stellen? «55 Vielleicht.

An einem Ende des freien und selbstbestimmten Subjekts der Moderne in Foucaults machtanalytischen Schriften der siebziger Jahre ändert all das nichts. Foucault bleibt in dieser Hinsicht ein Theoretiker des Endes des Subjekts.

53 Manfred Frank: Das Subjekt kommt zurück.

54 Frank zitiert eine briefliche Äußerung Foucaults aus dem Jahre 1983, in der dieser seine "jüngste Hinwendung zum Subjekt« erwähnt. (Ebd.)

55 Ebd. Liebsch vertritt die Auffassung nicht einer Foucaultschen »Rückkehr zu einer antiken Philosophie der Sorge um sich", sondern ihrer Aktualisierung. Burkhard Liebsch: Das menschliche Selbst in Geschichte und Gegenwart. Eine Bilanz der "Hermeneutik" Michel Foucaults, in: Zeitschrift für Kulturphilosophie 1 (2008), S. 113-135, hier S. $120 f$. 


\section{Subjekt und Tragödie bei Foucault}

Die Bedeutsamkeit der Subjektthematik für Foucaults Werk, sei es in Form einer Absage an das Erkenntnissubjekt oder an das autonome moderne Subjekt, sei es in Form machtanalytischer Subjektivierungstechniken, sei es in Form einer Hinwendung zu einem individuellen ethischen Subjekt, ist unbestritten. Gleichzeitig ist immer wieder ein gewisses Interesse an Foucault als Tragiktheoretiker oder zumindest an seinem Umgang mit dem Konzept des Tragischen und der Tragödie zu beobachten. Angesichts der spätestens seit Hegel klassischen Verbindung von Subjekttheorie und Tragödientheorie mag es daher erstaunen, daß bisher nicht nach einer solchen Verbindung bei Foucault gefragt worden ist. Andererseits liegt diese Frage natürlich auch nicht nahe, im Gegenteil: Warum auch sollte man beim bekanntesten Vertreter eines 'Endes des Subjekts` nach quasiidealistischen Verbindungen zwischen Subjekt und Tragödie fragen?

Hinzu kommt, daß Foucault vornehmlich in seinen frühesten Texten mit einem Tragikbegriff operiert, also vor dem berüchtigten `Ende des Subjekts`. Das einschlägige Vorwort zu Wahnsinn und Gesellschaft streicht er dann aber für die Neuauflage 1972 - zu einer Zeit, wo er sich mit den machtanalytischen Konzeptionen von Subjekt und Subjektivierung zu beschäftigen beginnt. Vor dem Hintergrund der seit Hegel klassischen Verbindung von Subjektkonstitution und Tragödie erscheint das konsequent: Wo kein autonomes Subjekt mehr angenommen wird, findet auch keine Rückbindung an das Tragische mehr statt. Mit seiner Absage an die moderne Konzeption eines freien Subjekts scheint Foucault also - folgerichtig - auch die Idee eines Bedingungsverhältnisses zwischen Subjektkonstitution und Tragödie zu verabschieden. Das Tragische bleibt eine Episode im Frühwerk, so im allgemeinen der Forschungskonsens. Angelika Pillens überzeugende Erklärung dafür lautet:

Mit der Kategorie des Tragischen, die Foucault nach Wahnsinn und Gesellschaft aufgibt, verschwindet nicht nur eine ursprungsmythische Konstruktion, sondern auch die totalisierende Perspektive, die der in seiner ersten Studie beschriebenen historischen Entwicklung ihre Kohärenz verliehen hat. Gleichzeitig hört die in den Gestaltungen des Tragischen gegenwärtig werdende authentische Wahrheit des Menschen auf, ein Referenzpunkt seiner Recherchen zu sein. ${ }^{56}$

56 Angelika Pillen: Referenzautoren, S. 171. Unterthurner hält es für wahrscheinlich, daß Foucault "apokalyptisch-verfallsgeschichtliche Züge" des Vorworts nachträglich zugunsten der Betonung der diskurstheoretischen Bedeutung des Textes tilgen wollte. Er weist außerdem auf den Wandel in der "Art und Weise, wie Foucault Genesis und Ursprung denkt«, hin (vgl. Gerhard Unterthurner: Foucaults Archäologie als Kritik der Erfahrung, S. 152). 
Im letzten Punkt stellt Pillen dabei andeutungsweise die Verbindung zwischen Subjekt und Tragik und den Zusammenhang zwischen Ende des Subjekts und Ende des Tragischen her. Die Wendung von der "authentische[n] Wahrheit des Menschen" mag hier zwar nicht mit der Idee eines universellen autonomen Subjekt übereinstimmen, aber zumindest macht Pillen deutlich, daß Foucaults frühe Tragikkonzeption mit einem emphatischen Begriff des Menschen zusammenhängt - und daß beide gemeinsam aufgegeben werden.

Christoph Menke, der sich in Tragödie im Sittlichen ausgiebig mit der Individuumskonstitution in Hegels Antigonelektüre beschäftigt, weist dort zwar auf eine Auseinandersetzung Foucaults mit dem Begriff des Tragischen hin, beläßt es aber dabei, ohne Foucault noch einmal zu erwähnen und ohne eine Verbindung zum Subjekt zu knüpfen. ${ }^{57}$ In einem späteren Aufsatz reiht er Foucault in die "über zweihundertjährige Tradition" ein, »der sich in der Frage nach dem Eigentümlichen der Moderne stets die Frage nach der Tragödie aufgedrängt hatte«: »eine Tradition, die von Schelling und Hegel bis zu Simmel, Weber und Freud, von Lessing und Schiller bis zu Benjamin, Gehlen und Foucault reicht " 58 führt dies aber nicht aus und kommt nicht noch einmal auf Foucault zu sprechen. In Die Gegenwart der Tragödie rezipiert Menke zwar ausgiebig Foucaults Ödipuslektüre in Die Wahrheit und die juristischen Formen, aber nicht im Hinblick auf die Frage nach dem Subjekt spezifisch bei Foucault. ${ }^{59}$

Wie Menke stellt auch Gabriella Basterra Foucault dezidiert in die Tradition moderner Tragikkonzeptionen. ${ }^{60}$ Während Menke aber zwar Foucaults Tragödienrezeption, nicht aber deren Zusammenhang mit dem Subjekt in den Blick nimmt, stellt Basterra, umgekehrt, für Foucault zwar die Verbindung von Tragik und Subjekt her, dies allerdings im Rahmen eines allgemeinen Tragik- und nicht eines Tragödienbegriffs und also ohne Bezug auf die Tragödie als literarische Gattung. So weit ich sehe, ist Basterra die einzige, die Foucault ${ }^{61}$ als Denker einer tragischen Subjektivität profiliert,

57 Vgl. Christoph Menke: Tragödie im Sittlichen, S. 19.

58 Ders.: Ethischer Konflikt und ästhetisches Spiel, S. 16.

59 Vgl. ders.: Die Gegenwart der Tragödie. Versuch über Urteil und Spiel.

60 Vgl. Gabriella Basterra: Seductions of Fate: Tragic Subjectivity, Ethics, Politics, New York 2004.

61 Neben Hegel, Freud und Althusser; Basterra zeichnet damit eine ähnliche Linie wie Judith Butler in: Psyche der Macht. Das Subjekt der Unterwerfung, Frankfurt a.M. 2001. 
wobei sie, ähnlich wie Menke, von der These einer allgemein tragischen Moderne und Gegenwart ausgeht. Sie schreibt: "[T] he modern self constitutes itself in subjection to coercive forces that function like tragic destiny" und bezeichnet "this modern and contemporary pattern of self-identity as tragic subjectivity." "[B]ecause in modern times tragic destiny no longer applies, the subject replaces it with essentializing constructs such as law, power, history or the state « ${ }^{62}$ - dies im Grunde Napoleons aus der Unterredung mit Goethe bekannte Idee, die auch Hegel zitiert. ${ }^{63}$ Basterras Argumentation zugunsten einer tragischen Subjektivität bei Foucault stützt sich dabei ausschließlich auf dessen relativ späten Text Subjekt und Macht aus dem Jahr 1982. Anders als in seinen mittleren, machtanalytischen Schriften, die gerade keine Konzentration der Macht in einer Instanz wie etwa dem Staat annehmen, sondern im Gegenteil zeigen, daß das Hauptcharakteristikum der Macht in ihrer Zerstreuung liegt, lenkt Foucault hier (wie erstmals in Ansätzen in der Vorlesung Zur Verteidigung der Gesellschaft [1975/76] und in Der Wille zum Wissen [1976], mit der Ausbildung des Konzepts der Biopolitik, und dann auch in den Vorlesungen über die Geschichte der Gouvernementalität [1977/78 und 1978/79]) den Blick auf den Staat als Zentrum der Macht. ${ }^{64}$ Er schreibt über den westlichen Staat seit dem 16. Jahrhundert,

62 Gabriella Basterra: Seductions of Fate, S. 2.

63 Vgl. G.W.F. Hegel: Vorlesungen über die Philosophie der Geschichte (= Werke, Bd. 12), Frankfurt a.M. 72005, S. 339: "Napoleon, als er einst mit Goethe über die Natur der Tragödie sprach, meinte, daß sich die neuere von der alten wesentlich dadurch unterscheide, daß wir kein Schicksal mehr hätten, dem die Menschen unterlägen, und daß an die Stelle des alten Fatums die Politik getreten sei. Diese müsse somit als das neuere Schicksal für die Tragödie gebraucht werden, als die unwiderstehliche Gewalt der Umstände, der die Individualität sich zu beugen habe.«

Ders.: In Verteidigung der Gesellschaft. Vorlesungen am Collège de France 1975/76, Frankfurt a.M. 22004; ders.: Der Wille zum Wissen. Sexualität und Wahrheit 1, Frankfurt a.M. ${ }^{15} 2005$ [Paris 1976] (im folgenden per Siglen VG bzw. WW im laufenden Text zitiert); ders.: Sicherheit, Territorium, Bevölkerung. Geschichte der Gouvernementalität I, Vorlesung am Collège de France 1977/78, Frankfurt a.M. 2006; ders.: Die Geburt der Biopolitik. Geschichte der Gouvernementalität II, Vorlesung am Collège de France 1978/79, Frankfurt a.M. 2006. Das ist etwas vereinfacht dargestellt; Foucault gibt damit nicht die Idee diffuser und nichtverortbarer Machttechniken auf. Saar macht beide Tendenzen aus; vgl. Martin Saar: Macht, Staat, Subjektivität. Foucaults Geschichte der Gouvernementalität im Werkkontext, in: Susanne Krasmann/Michael Volkmer (Hg.): Michel Foucaults Geschichte der Gouvernementalität in den Sozialwissenschaften, Bielefeld 2007, S. 23-45, hier S. 33f. 
dass die Macht des Staates [...] eine zugleich globalisierende und totalisierende Form von Macht ist. Nirgendwo sonst in der Geschichte der menschlichen Gesellschaften [...] findet sich [...] innerhalb der politischen Strukturen eine so komplexe Verbindung zwischen Techniken der Individualisierung und totalisierenden Verfahren. ${ }^{65}$

Basterras Argumentation basiert auf dieser Konzeption einer vom Staat ausgeübten und also lokalisierbaren Macht; nur so kann sie den Staat im Sinne Hegels als Substanz und damit als einen potentiell tragischen Gegenpol, als das Andere einer dann tragischen modernen Subjektivität konstruieren. ${ }^{66}$

Dagegen werden die folgenden zwei Kapitel der vorliegenden Arbeit zeigen, daß auch Foucaults machtanalytischer Subjektbegriff, das werkchronologisch mittlere, ${ }^{67}$ durch delokalisierte und diffuse gesellschaftliche Machttechniken und Disziplinen konstituierte und sich konstituierende Subjekt, wie es in Vorformen bereits in Wahnsinn und Gesellschaft angedeutet ist und schließlich prominent in Überwachen und Strafen auftritt, eine Korrelation mit Tragik und Tragödie erlaubt, dergestalt, daß auch Foucaults völlig neuartige Subjektkonzeption auf ihre Weise das spätestens seit Hegel sklassisch zu nennende Beziehungsverhältnis zwischen Subjekt und Tragödie aufgreift (und perpetuiert). Es wird dabei deutlich werden, daß Foucaults Tragikbegriff seine umfassende Bedeutung insbesondere in seinem Bezug auf diese Mechanismen der Subjektkonstitution vollständig entfaltet.

65 Michel Foucault: Subjekt und Macht, S. $276 f$.

66 Vgl. ähnlich Kap. V, Unterkap. "Der Zuschauer betritt die Bühne« und Kap. IX, Unterkap. "Der Staat als Subjekt«.

67 Martin Saar datiert Foucaults "mittlere[ ] Werkphase« auf »ca. 1970-1976/77« (Genealogie und Subjektivität, S. 158). 


\section{Die Tragik der Individuierung}

\section{Der tragische Ausschluß des Wahnsinns (Foucault und Nietzsche)}

Gleich auf den ersten Seiten des Vorworts zu seinem ersten großen Buch, Wahnsinn und Gesellschaft (1961), führt Foucault eine deutlich an Nietzsches Geburt der Tragödie (1871) anknüpfende Begrifflichkeit von Tragik und Tragödie ein, die den gesamten Text durchziehen wird. Auf diese Weise stellt er Tragik und Tragödie gleich zu Beginn in einen engen Zusammenhang mit dem Untersuchungsgegenstand des Buches - der "Geschichte des Wahns im Zeitalter der Vernunft«. Foucault formuliert als Ziel seiner Untersuchung, eine »Archäologie« des »Schweigens« des Wahnsinns zu schreiben, d.h. seine Geschichte als die Geschichte seines Ausschlusses. Es geht um den Wahnsinn als um etwas, das durch seine Ausgrenzung aus der Kultur bestimmt wird und dabei gleichzeitig diese Kultur bestimmt: »Ursprünglich ist die Zäsur, die die Distanz zwischen Vernunft und Nicht-Vernunft herstell««1 (WG 7) - und zwar »ursprünglich« nicht nur für die Geschichte des Wahnsinns, sondern für die abendländische Geschichte der Neuzeit überhaupt.

Man könnte die Geschichte der Grenzen schreiben - dieser obskuren Gesten, die, sobald sie ausgeführt, notwendigerweise schon vergessen sind -, mit denen eine Kultur etwas zurückweist, was für sie das $\ddot{A} u / s e r e$ sein wird; und während ihrer ganzen Geschichte bezeichnet diese geschaffene Leere, dieser freie Raum, durch den sie sich isoliert, sie ebensosehr wie ihre Werte; denn ihre Werte erhält und wahrt sie in der Kontinuität der Geschichte; aber in dem Gebiet, von dem wir reden wollen, trifft sie ihre entscheidenden Wahlen. Sie vollzieht darin die Abgrenzung, die ihr das Antlitz ihrer Positivität verleiht. Da liegt die eigentliche Dichte, in der sie sich formt. ${ }^{2}$ (WG 9)

1 Korrektur der Übersetzung: [dabei] gestrichen, Gw.E.; vgl. Michel Foucault: Folie et déraison. Histoire de la folie à l'age classique, Paris 1961, S. If. (im folgenden per Sigle HF [1961] zitiert).

2 Übersetzung verändert, Gw.E. Das Original lautet: „On pourrait faire une histoire des limites, - de ces gestes obscurs, nécessairement oubliés dès qu'accomplis, par lesquels une culture rejette quelque chose qui sera pour elle l'Extérieur; et tout au long de son histoire, ce vide creusé, cet espace blanc par lequel elle s'isole la désigne tout autant que 
Foucault ruft hier zunächst den Topos einer allgemeinen >Tragödie der Kultur auf, dem zufolge jeder Kultur ein "Zerreißen « ${ }^{3}$ (WG 9), eine "tragische Abtrennung « zugrunde liegt (WG 10); »eine Absplitterung, die wie die Geburt ihrer Geschichte ist«. (WG 9) Diese Idee der tragischen Absplitterung konkretisiert Foucault dann für die abendländische Kultur, fragt also nach ihrem Äußeren als nach ihrem Konstituens und sieht eine der für sie »entscheidenden Wahlen" in der Herausbildung des Konzepts eines Anderen der Vernunft, d.h. des Wahnsinns. ${ }^{4}$ So "stellt das Verhältnis von Vernunft und Unvernunft für die Kultur des Abendlandes eine der Dimensionen ihrer Ursprünglichkeit dar«. (WG 9) Indem das Äußere, das der Wahnsinn ist, eine Kultur ebenso »bezeichnet« wie ihre Werte sie bezeichnen, ist die Geschichte des Wahnsinns insbesondere für das klassische Zeitalter oder für die Aufklärung als dem Zeitalter der Vernunft von Interesse. Pointierter formuliert: Die Geschichte des Zeitalters der Vernunft ist nichts anderes als die Geschichte des Wahnsinns.

Ein Gegenstand der konstitutiven »Abtrennung[en]« der abendländischen Kultur ist also der Wahnsinn. Tragisch ist aber nicht nur die "Abtrennung", sondern auch dasjenige, was abgetrennt wird; es liegt als "tragische Struktur« »an den Toren der Zeit» und »an den Grenzen der Geschichte« einer Kultur. (WG 9) Nicht nur der Ausschluß des Wahnsinns ist demnach tragisch, sondern auch der Wahnsinn selbst. ${ }^{5}$

ses valeurs. Car ses valeurs, elle les reçoit, et les maintient dans la continuité de l'histoire; mais en cette région dont nous voulons parler, elle exerce ses choix essentiels, elle fait le partage qui lui donne le visage de sa positivité; là se trouve l'épaisseur originaire où elle se forme." (HF [1961] III)

3 Übersetzung verändert, Gw.E. Ulrich Köppen übersetzt »Absplitterung«; Foucault schreibt aber »déchirement« (HF [1961] IV), `Zerreißen«.

4 Daneben nennt Foucault an dieser Stelle den Orient, den Traum und die Sexualität (vgl. WG 10). Sarasin nennt, wohl im Vorausblick auf Foucaults spätere Werke, Wahnsinn, Verbrechen und Sexualität. Philipp Sarasin: Michel Foucault zur Einführung, S. 17.

5 Genaugenommen hat man es hier mit einem doppelten Tragik- und einem doppelten Wahnsinnsbegriff zu tun: Die Dopplung des Tragikbegriffs besteht darin, daß sowohl der Wahnsinn als ein der Trennung von Wahnsinn und Vernunft vorgängiger ursprünglicher Einheitszustand als auch die Trennung dieser Einheit als die Trennung von Wahnsinn und Vernunft im klassischen Zeitalter tragisch ist. Die Dopplung des Wahnsinnsbegriffs besteht darin, daß der Wahnsinn sowohl der der tragischen Trennung vorgängige Einheitszustand als auch, als Gegenstand neuzeitlicher Wissenschaft, das Ergebnis der tragischen Trennung ist (vgl. auch Gerhard Unterthurner: Foucaults Archäologie als Kritik der Erfahrung, S. 121, 147). 
Dieser doppelte Tragikbegriff als Zustand einer ursprünglichen Einheit einerseits und als Prozeß der Trennung andererseits geht direkt auf Nietzsche und dessen mythischen Rauschzustand des Dionysischen zurück. In Nietzsches Tragikkonzept ist einerseits die mythische dionysische Ureinheit selbst und andererseits deren Trennung tragisch. Die Zerstückelung des Dionysos Zagreus ist Gegenstand der Urtragödie, und bis in die Tragödien Aischylos' und Sophokles' bleibt Dionysos ihr »eigentlicher Held" und bleibt die »Marter des Gottes", seine »Zerstückelung«, seine »Individuation«, ihr Gegenstand. (Vgl. GT 71ff.) Die griechische Tragödie ist durch ihre Teilhabe an der Einheitserfahrung im mythischen Rauschzustand des Dionysischen charakterisiert, einzig in der Kunst der Tragödie gelingt die Synthese von dionysischem Rausch und apollinischem Schein. Auch der von Foucault beschriebenen Trennung geht ein mythischer Einheitszustand voraus: eine "noch undifferenzierte", "noch nicht durch eine Trennung gespaltene Erfahrung (WG 7), ein Gebiet, auf dem »Wahnsinn und Nichtwahnsinn, Vernunft und Nichtvernunft konfus miteinander verwickelt« sind (WG 8), und auch Foucault bezieht sich hier auf die Griechen, die ihm zufolge keinen Gegenbegriff zu ihrem logos, nichts dem logos "Gegenteiliges« besaßen. (WG 9) Die (darauffolgende) Geschichte des Abendlandes vollzieht dann einen Ausschluß des Wahnsinns und der Unvernunft. So bestand zunächst »seit dem frühen Mittelalter eine Beziehung zu etwas«, das "vage« mit »Wahnsinn, Demenz, Unvernunft« benannt wurde. Die Renaissance erlebt dann noch einmal eine Einheit von Wahnsinn und Vernunft, eine »tragische und kosmische Erfahrung des Wahnsinns« (WG 49), die sich in Erasmus' Lob der Torheit und Brants Narrenschiff, den Gemälden Breughels und Boschs manifestiert, doch bedeutet diese Manifestation zugleich schon eine Form der Auseinandersetzung mit dem Wahnsinn, die schließlich in die »kritische Erfahrung desselben Wahnsinns« überleitet. (WG 46) Durch diese frühneuzeitliche intensive Auseinandersetzung mit dem Wahnsinn ist dieser - anders als im Mittelalter - als Wahnsinn zwar bereits benannt, wird zunächst jedoch noch als die Kehrseite der Vernunft in diese aufgenommen, eine Kehrseite, in die er stets umschlagen kann. Wie Foucaults Wahnsinn "an den Toren der Zeit« eng verwandt mit Nietzsches mythischem dionysischen Rausch ist, ist Foucaults Einheitszustand von Wahnsinn und Vernunft, der in der Renaissance noch einmal auflebt, mit Nietzsches Einheit von Dionysischem und Apollinischem verwandt, die einzig in der Tragödie Aischylos' und Sophokles' verwirklicht wurde. 


\section{Tragik der Individuierung}

Das Ende dieser Tragödie und ihrer Aufführung des dionysischen Rausches wird Nietzsche zufolge durch Euripides bzw. Sokrates eingeleitet. Die dionysische "Mysterienlehre der Tragödie« beschreibt Nietzsche als

die Grunderkenntniss von der Einheit alles Vorhandenen, die Betrachtung der Individuation als des Urgrundes des Uebels, die Kunst als die freudige Hoffnung, dass der Bann der Individuation zu zerbrechen sei, als die Ahnung einer wiederhergestellten Einheit. (GT 73)

"Jenes ursprüngliche und allmächtige dionysische Element aus der Tragödie auszuscheiden [...] - dies ist die jetzt in heller Beleuchtung sich uns enthüllende Tendenz des Euripides." (GT 82) Dessen Tragödie folgt einer "sokratischen Tendenz" (vgl. GT 83) und ist ein "Product jenes eindringenden kritischen Prozesses" der "rationalistische[n] Methode" des "Sokratismus«. (GT 85) Er trennt, im Wortsinne von 'kritisch`, die dionysische Einheit und setzt das principium individuationis endgültig durch. ${ }^{6}$

6 Nietzsches Gedanken vom Tod der Tragödie durch das Aufkommen des sokratischen Prinzips der Individualität finden sich übrigens bereits bei Hegel. In den Vorlesungen zur Geschichte der Philosophie markiert Sokrates den Punkt, an dem die griechische Sittlichkeit in Moralität sumschlägt‘ (G.W.F. Hegel: Vorlesungen zur Geschichte der Philosophie I (= Werke, Bd. 18), Frankfurt a.M. 1986, S. 468) und zu Ende geht - und mit ihr die Tragödie. Indem sich Sokrates nach seinem Prozeß weigert, sein Strafmaß selbst zu bestimmen und darin seine Schuld anzuerkennen (vgl. ebd., S. 508f.), mißachtet er den Schuldspruch im Namen des athenischen Volkes, und erst diese Weigerung führt zu seinem Todesurteil. Sie bedeutet die Nichtanerkennung des Rechts des Staates, die Nichtanerkennung jenes Prinzips, dem Sophokles' Antigone sich (Hegels Lesart zufolge) in ihrem Tod unterworfen hatte. Hegel zitiert hier, wie in der Phänomenologie, wieder das "weil wir leiden, anerkennen wir, das wir gefehlt", mit dem Antigone ihre sittliche Individualität, das Recht der Familie, dem Recht des Staates unterwirft und dieses in ihrem Tod anerkennt. Sokrates dagegen unterwirft sich diesem Recht des Staates nicht und bestreitet damit dieses Recht ebenso wie Antigones sittliches Bewußtsein. Wie Sokrates hatte ja auch Antigone ihre Individualität gegen den Staat gesetzt, doch war ihre Individualität noch eine substantielle und sittliche, indem sie dem göttlichen Recht der Familie entsprach. Dagegen verkörpert Sokrates kein sittliches Recht; das Gesetz, das er vertritt, ist radikal individualisiert und verinnerlicht: Er findet es durch seine Auslegung des $>$ Erkenne dich selbst des Delphischen Orakels in sich selbst, im "eigene[n] Selbstbewußtsein des Menschen", im "allgemeine[n] Bewußtsein des Denkens eines jeden«. (Ebd., S. 503) Sokrates bedeutet »die Einführung eines neuen Gottes, der das Selbstbewußtsein zum Prinzip machte« (ebd., S. 507) - ein Prinzip, das "später zu seiner wahrhaften Gestalt 
Auch diese Konzeption der Individuumskonstitution als Trennung der Einheit mitsamt ihrer tragischen Konnotation greift Foucault auf: Im 17. Jahrhundert nämlich beginnt sich das tragische Ineinander von Vernunft und Wahnsinn aufzulösen; Descartes tritt dort paradigmatisch für die strikte Trennbarkeit von Vernunft und Wahnsinn ein (vgl. WG 69ff.). Das Ende des »kosmischen" und »tragischen« Bewußtseins und seine Ablösung durch das "kritische Bewußtsein" des Wahnsinns (WG 46ff.) wird durch ein bestimmtes Wissen herbeigeführt, das Wissen Descartes', und ist durch die Abgrenzung des Wahnsinns von der Vernunft gekennzeichnet. Descartes' Ausräumung des hyperbolischen Zweifels steht paradigmatisch für die entscheidende "Zäsur, die die Distanz zwischen Vernunft und Nicht-Vernunft herstellt«. (WG 7)

Foucault verschiebt gewissermaßen Nietzsches Konzeption der tragischen Individuation historisch um etwa 2000 Jahre: Während Nietzsche die Individuation in der griechischen Antike des Sokrates verortet, verlegt Foucault diese tragische Trennung an den Beginn der Aufklärung im 17. Jahrhundert - beides sind sogenannte Humanismen der Weltgeschichte - und ersetzt dabei Nietzsches Sokrates durch sein modernes Pendant, nämlich Descartes. Auch Nietzsches Sokrateskritik richtet sich natürlich letztlich auch gegen den Rationalismus der Neuzeit, wie sich etwa an seiner Parallelisierung von Euripides und Descartes zeigt (vgl. GT 86). Foucault zufolge vollzieht sich die Trennung von Wahnsinn und Vernunft in Descartes' Cogito; Ergebnis des epistemischen Ausschlusses des Wahnsinns ist also das neuzeitliche Erkenntnissubjekt. Die tragische Trennung von Vernunft und Unvernunft, die tragische Abspaltung des Wahnsinns als die sichere Erkenntnis, nicht wahnsinnig zu sein, bringt demnach das moderne Selbstbewußtsein hervor.

sich erheben wird« (ebd., S. 512), nämlich im Christentum. Die Parallelisierung von Sokrates und Jesus findet sich ebenfalls bei Nietzsche. Wie bei Hegel also Sokrates das Prinzip der Individualität verkörpert und »das einzelne Bewußtsein als selbständig von dem allgemeinen Geiste sich abtrennt und für sich wird« (ebd., S. 514), und wie er das und das Ende der Tragödie herbeiführt, so auch bei Nietzsche - wobei natürlich Hegels Bewertung anders ausfällt als die Nietzsches. Während Hegel das Ende der Tragödie und den Beginn des Christentums unter ästhetischen Gesichtspunkten zwar implizit bedauert, unter ethischen dagegen begrüßt, ist das Ende der Tragödie in der sokratischen Individualität bei Nietzsche sowohl ein ästhetischer Verlust als auch der Beginn der lebensfeindlichen christlichen Moral. Auch Foucault koppelt die neuzeitliche "kritische" Erfahrung des Wahnsinns mit einer "moralischen" Erfahrung des Wahnsinns und stellt diese der »kosmischen" und »tragischen" gegenüber (vgl. WG 46ff.). 
Foucault geht aber über eine bloße Ausführung von Nietzsches Überlegungen hinaus. Das Neue an seiner Verlegung der tragischen Trennung in die Neuzeit, und hier setzt seine eigentliche Untersuchung an, besteht in der Verknüpfung epistemischer und gesellschaftlicher Entwicklungen: Die Konstruktion eines Erkenntnissubjektes durch den theoretischen Ausschluß des Wahnsinns als des Anderen der Vernunft zu Beginn der Aufklärung verläuft nämlich parallel zu und untrennbar von einer Reihe tatsächlicher gesellschaftlicher Ausschlußmechanismen, die ihrerseits dem Muster tragischer Strukturen folgen: Das zentrale Beispiel stellt der Ausschluß des Wahnsinnigen durch Hospitalisierung dar, d.h. die räumliche Trennung von Vernunft und Unvernunft. Als eine gesellschaftliche Entsprechung zum cartesischen theoretischen Konzept des Selbstbewußtseins oder des Wissens des Selbst als einem Gegenbegriff zum Wahnsinn erfolgt also die praktische, gesellschaftlich-institutionelle Schaffung eines Individuums, das sich über die Abgrenzung vom und Ausschluß des dadurch ebenfalls erst geschaffenen Wahnsinnigen definiert wird. "Durch einen eigenartigen Gewaltakt bringt dann das Zeitalter der Klassik den Wahnsinn [...] zum Schweigen." (WG 68) Dieser "Gewaltakt« ist ein zweifacher: Er ist Descartes' Ausschluß des Wahnsinns in seinen Meditationes von 1641, und er ist die Internierung der Wahnsinnigen im Hôpital Général im Jahre 1657. Foucault bezeichnet ihn als »dramatisch «: »[D]er ebenso theoretische wie praktische Moment der Trennung, das ist die Wiederaufnahme des alten Dramas des Ausschlusses«. (WG 167) Der Ausschluß der Wahnsinnigen durch Internierung ist der praktische, der »institutionelle Ausdruck « der cartesischen "großen wesentlichen Trennung von Vernunft und Unvernunft «. ${ }^{7}$ Damit findet die Individuierung bei Foucault auf zwei - gleichermaßen historischen - Ebenen statt: einer theoretischen, epistemischen, für die Descartes einsteht (wie Sokrates bei Nietzsche), und einer praktischen, gesellschaftlich-institutionel-

7 Meine Übersetzung, Gw.E.; vgl. Michel Foucault: Histoire de la folie à l'age classique. Folie et déraison, Paris 1972, S. 136: "la grande coupure essentielle de la raison et de la déraison - dont l'internement n'est que l'expression institutionnelle« (im folgenden per Sigle HF [1972] zitiert). Das ganze dritte Kapitel des ersten Teils der Histoire de la folie, "Le monde correctionnaire" (HF [1972] 110-147), ist in der deutschen Übersetzung nicht enthalten. Weitere, nicht angegebene Kürzungen der deutschen Ausgabe betreffen die Seiten HF [1972] 80-90, 186-190, 208, 209-212, 375-388, 440-442, 574f., 638-640, 644-652, 654-663. 
len, durch Maßnahmen, die von der Anwendung eines Wissens auf das Individuum, von der zunehmend wissenschaftlichen Qualifizierung eines Individuums als wahnsinnig bis zum körperlichen Ausschluß durch Internierung reichen. ${ }^{8}$ Dies sind »dramatische Formen der Trennung«, so daß es sich auf einer dritten, gattungstheoretischen Ebene bei der Individuierung um eine "dramatische Konstitution" handelt. (WG 168)

Diese dramatische, genauer: tragische Trennung weist Foucault auch an konkreten literarischen Texten nach, namentlich natürlich den klassischen Tragödien Corneilles und Racines. Der Trennung von Wahnsinn und Vernunft entspricht die Tag/Nacht-Dichotomie, die Foucault zufolge charakteristisch für das klassische Zeitalter ist und sich sowohl in philosophischen Texten, paradigmatisch bei Descartes, als auch in der Bildersprache der Tragödien etwa Racines niederschlägt. Darüber hinaus ordnet die Trennung in Tag und Nacht, als sogenannte Einheit der Zeit, die einen Dramenverlauf »innerhalb eines einzigen Sonnenumlaufs « vorgibt, ${ }^{9}$ auch die Struktur der klassischen Tragödie, so daß der epistemischen Trennung eine tragödientheoretische Bedeutung - oder andersherum - zukommt:

Die dramatische Regel der Einheit der Zeit hat einen positiven Inhalt. Sie zwingt die tragische Dauer, sich um den eigenartigen, aber universellen Wechsel von Tag und Nacht zu balancieren. Die ganze Tragödie muß sich in dieser Zeiteinheit erfüllen, denn sie ist im Grunde nichts als der Zusammenstoß zweier Königreiche, die durch die Zeit selbst miteinander im Unversöhnlichen verbunden sind. (WG 248)

Auf diese Weise wird die Zeit im Theater Racines von der "große[n] tragische[n] Zäsur beherrscht" (WG 248), der Zäsur zwischen Tag und Nacht, zwischen Licht und Schatten, zwischen Helle und Dunkelheit, die zugleich eine Variante der individuumskonstitutiven Zäsur zwischen Wahnsinn und Vernunft ist:

8 Grundsätzlich ist zwar festzustellen, daß Wahnsinn und Gesellschaft auch Foucaults spätere Machtanalytik bereits in nuce enthält, wonach die Macht nicht von außen auf das Individuum einwirkt, sondern durch die Unterwerfung des Individuums unter die Machtmechanismen auch von ihm selbst und gegen sich selbst ausgeübt wird, so daß zwischen Innen und Außen gar nicht mehr unterschieden werden kann; die Tendenz stimmt aber.

9 Aristoteles: Poetik, übers. und hg. von Manfred Fuhrmann, Stuttgart 1982, S. 17 (1449b 13). 
Der Kreis von Tag und Nacht ist das Gesetz der klassischen Welt. [...] Dieses Gesetz schließt jede Dialektik und jede Versöhnung aus, gründet folglich zugleich die bruchlose Einheit der Erkenntnis und die kompromißlose Teilung der tragischen Existenz. ${ }^{10}$ (WG 248)

Den »Wechsel von Tag und Nacht« hatte bereits Hegel in der Enzyklopädie im Zusammenhang mit dem "Unterscheiden der Individualität" verwendet. ${ }^{11}$ Der tragischen Individuumskonstitution als Trennung, die die Phänomenologie beschreibt, Antigones individuierender Tat (»dies Entzweien [...] ist eben das Setzen der Individualität«), entspricht in der Enzyklopädie die Unterscheidung in Tag und Nacht, Wachen und Traum - und Vernunft und Wahnsinn. ${ }^{12}$ Foucault kannte die entsprechenden Paragraphen; er zitiert am Ende von Wahnsinn und Gesellschaft aus ihnen (vgl. WG 546). Die Tag/Nacht-Dichotomie gründet mit der Einheit der Erkenntnis das cartesische Erkenntnissubjekt. Wissen und Nichtwissen stehen einander gegenüber. Die Versöhnung von Wahnsinn und Vernunft wird ausgeschlossen; die beide vereinende tragische Existenz bleibt kompromißlos geteilt, und zwar auf zweierlei Weise: Wahnsinn und Vernunft treten ebenso auseinander wie Wahnsinn und Tragik, was sich neben dem körperlichen Ausschluß durch Hospitäler etc. und dem medizinisch-wissenschaftlichen Diskurs auf literarischer Ebene z.B. darin niederschlägt, daß der Wahnsinn aus den klassischen Tragödien verbannt wird (vgl. WG 250).

Die Ebene der subjekt- bzw. individuumstheoretischen Untersuchung überschneidet sich also im Laufe des Textes immer wieder auch mit einer tragödientheoretischen Ebene. Foucault stellt in Wiederaufnahme und Weiterführung der Überlegungen Nietzsches zur Geburt der Tragödie einen dezidierten Rückbezug auf die Tragödie als literarische her, knüpft hierin zugleich an Hegel an und rückt dadurch in die Nähe des systematischen Ineinanders geschichtlicher, subjektphilosophischer und ästhetischer Ent-

10 Korrigierte Übersetzung, Gw.E. Köppen übersetzt: »[...] gründet folglich zugleich die bruchlose Einsicht der Kenntnis und die kompromißlose Teilung der tragischen Existenz", das Original lautet aber: »[...]qui fonde par conséquent à la fois l'unité sans rupture de la connaissance, et le partage sans compromis de l'existence tragique." (HF [1972] 312)

11 G.W.F. Hegel: Enzyklopädie der philosophischen Wissenschaften III, S. 91, 87.

12 Vgl. ebd., S. $163 f f$. 
wicklungen, wie man es bei Hegel findet. Foucault schreibt über den Ausschluß des Wahnsinns: "Was wir auf der einen Seite als ein Ereignis beschrieben haben, werden wir auf der anderen Seite als Form begrifflicher Entwicklung wiederfinden." (WG 167) Ein Ineinander von historischer und begrifflicher Entwicklung also - inhaltlich könnte dieser Satz auch von Hegel stammen. Hier muß man natürlich sogleich einwenden, daß Foucaults Vorgehen ja eben darin besteht, Diskurse und Praktiken einer Zeit zueinander in Beziehung zu setzen; die Beziehungen, die er zwischen ihnen herstellt, sind daher weniger idealistischer als diskursanalytischer Natur. Auch könnte man sagen, daß Foucault zwar einen idealisierten Einheitszustand und eine ursprüngliche Erfahrung annimmt, jedoch bezweifelt werden müsse, daß er diesem Einheitszustand historische Existenz oder psychische Realität zuspricht. Es gibt allerdings Textstellen, die auf das Gegenteil hinweisen, etwa wenn Foucault von »les deux mouvements de conversion poétique et d'évolution psychologique «13 spricht, also von einem "poetischen Wandel«, der ein Wandel der literarischen Form, vielleicht sogar der Gattung ist und in Beziehung zu einer psychologischen Entwicklung steht. Daß Foucault alldem noch ein Tragikkonzept zugrunde legt, rückt ihn zumindest in die Nähe von Hegels idealistischer Systematik. ${ }^{14}$ Zwar ist Foucaults direktes theoretisches Vorbild hier Nietzsche, doch hatte auch dieser ja in Ecce Homo im Rückblick auf Die Geburt der Tragödie seinerseits konstatieren müssen, sie "riech[e] anstössig Hegelisch «. ${ }^{15}$ Es erscheint daher nur konsequent, daß Foucault das Vorwort für die Neuauflage von Wahnsinn und Gesellschaft im Jahre 1972 durch ein sehr kurzes neues Vorwort ersetzte, in dem von Tragik und Tragödie keine Rede mehr ist.

13 HF [1972] 440. Diese Stelle fehlt in der deutschen Übersetzung.

14 Die Hegelianische Dialektik in Foucaults Tragikbegriff betont Achim Geisenhanslüke: Foucault und die Literatur.

15 Friedrich Nietzsche: Ecce Homo, in: Werke. Kritische Studienausgabe, Bd. 6, München/Berlin 1980, S. 310. In Ecce Homo bezieht sich das "anstössig Hegelisch[e]« zum einen auf die dialektische Beziehung zwischen Dionysischem und Apollinischem, zum anderen aber auch, und das ist wichtiger, auf die idealistische Verknüpfung von Metaphysik und Geschichte: "Eine >Idee - der Gegensatz dionysisch und apollinisch - ins Metaphysische übersetzt; die Geschichte selbst als die Entwicklung dieser 'Idee`; in der Tragödie der Gegensatz zur Einheit aufgehoben..." Nietzsche ist darüber hinaus auch darin "anstössig Hegelisch«, daß auch er die Gattungsthematik mit der Subjekt-/Individuumsthematik verknüpft - ebenso wie Foucault. 


\section{Die Tragödie der Subjektivierung im Rechtsdiskurs und ihr Ende}

\section{Subjektkonstitution im Rechtsdiskurs}

Daß Foucault das Vorwort zu Wahnsinn und Gesellschaft für die Neuausgabe 1972 streicht und durch ein neues ersetzt, wurde verschiedentlich als eine Abkehr von seinem Tragikbegriff gedeutet. Richtig ist, daß er sich allmählich von Nietzsches früher Konzeption einer ursprünglichen tragischen Trennung abwendet; ein Vokabular von Tragik und Tragödie indes verwendet er weiterhin oder vielmehr aufs neue, denn mit der Verschiebung seines Fokus vom Wahnsinn zum Recht, zu den juristischen Praktiken und Strafsystemen, rückt das Subjekt als Subjekt des Rechtsdiskurses in sein Blickfeld - und mit ihm die Tragödie. In seiner Vorlesung In Verteidigung der Gesellschaft aus dem Jahre 1976 sagt Foucault: "Mir scheint, daß es eine grundlegende und entscheidende Zusammengehörigkeit von Tragödie und Recht, von Tragödie und öffentlichem Recht gibt «, ${ }^{1}$ eine Beobachtung, die sich weniger explizit bereits in etwas früheren Texten findet, etwa in Die Wahrheit und die juristischen Formen (1973). In gewissem Sinne laufen auch Foucaults früher Tragikbegriff und seine Konzeption des Wahnsinns letztlich in ihrer Beziehung zum Rechtsdiskurs zusammen. Der Wahnsinn wird im 19. Jahrhundert zum Gegenstand der Rechtsprechung (vgl. WG 468ff.; ÜS 30); Recht, Rechtsetzung und Rechtsprechung ihrerseits sind Gegenstand der Tragödie. So gesehen findet sich, noch bevor Foucault sich der Untersuchung des Justizsystems zuwendet, im Tragikbegriff aus Wahnsinn und Gesellschaft der tragische Zusammenhang von Subjekt und Recht bereits angedeutet. Während aber dieser frühe Tragikbegriff kein eigentlich gattungstheoretischer, sondern, ähnlich wie bei Nietzsche, ein weltanschaulicher ist, in dem es weniger um die Tragödie als um das Tragische geht, tritt in den Texten der siebziger Jahre ein stärker gattungstheoretisches Verständnis des Tragischen als Tragödie in den Vordergrund, womit Foucault näher an Hegel rückt.

1 Michel Foucault: In Verteidigung der Gesellschaft, S. 208. Diese Beobachtung an sich ist nicht neu, sondern Forschungskonsens; vgl. Hans-Thies Lehmann: Theater und Mythos. Die Konstruktion des Subjekts im Diskurs der antiken Tragödie, Stuttgart 1991, Kap. »Recht, Geschichte, Philosophie«, S. 157-167; Thomas Weitin: Recht und Literatur, Münster 2010, S. 20 u.v.a.m. 
In Die Wahrheit und die juristischen Formen untersucht Foucault »juristische Praktiken« in ihrer Bedeutung für die »Entstehung neuer Formen des Subjekts" ( $\mathrm{WjF}$ 12) und stellt so die enge Beziehung zwischen der Ausbildung von Rechtsformen und der Subjektkonstitution heraus. Aus der angenommenen Beziehung zwischen Recht und Tragödie folgt auf diese Weise auch eine Verbindung von Subjekt und Tragödie, und tatsächlich rückt Foucault die Beziehung von Rechtsformen und Subjektkonstitution in einen Tragödienkontext, indem er sie an Sophokles' König Ödipus veranschaulicht. Damit greift er einen der klassischen`Zusammenhänge von Subjektkonstitution und Tragödie auf, nämlich die Struktur der Rechtsetzung oder, allgemeiner, rechtliche Strukturen überhaupt. Die Mechanismen der Subjektwerdung, die Foucault hier beschreibt, juridischer Diskurs und Wahrheitsdiskurs, entsprechen also den zentralen Themen der Tragödie, nämlich Recht und Selbsterkenntnis.

Oben (Kap. II) wurden die Ausschlußmechanismen in Wahnsinn und Gesellschaft als >Tragik der Individuierung« bezeichnet. Hier nun zeichnen sich Machttechniken ab, die sich als `Tragödie der Subjektivierung ‘ beschreiben lassen. Die allgemeine Tragik der Individuumskonstitution wird durch eine gattungstheoretisch näher bestimmte Tragödie der Subjektkonstitution abgelöst.

Foucault beschreibt drei verschiedene Typen juristischer Wahrheitsfindung, die jeweils zugleich Machtpraktiken sind und bestimmte Subjektformen hervorbringen: erstens die archaische griechische bzw. mittelalterliche Probe (épreuve), ${ }^{2}$ in der der Ausgang eines Zweikampfes oder andere Zeichen über die (juristische) Wahrheit entscheiden, zweitens die Untersuchung (enquête), ${ }^{3}$ in der Zeugen befragt werden, und drittens die Prüfung (examen), ${ }^{4}$ die sich auf Überwachung stützt. ${ }^{5}$ Im Rahmen der Argumentation zugunsten tragischer Strukturen in der Subjektkonstitution soll hier zunächst nur die Untersuchung betrachtet werden; Probe und Prüfung kommen im Folgenden noch zur Sprache. Als Beispiel für die Ermittlungstechnik der Untersuchung führt Foucault die Beweisführung in Sophokles' König

2 Vgl. WjF 32f., 55, 58-61.

3 Vgl. WjF 40, 53, 62.

4 Vgl. WjF 86.

$5 \mathrm{Zu}$ diesen drei Begriffen und ihrer Übersetzung vgl. WjF 53f., Anm. 28. 
Ödipus an. Seine These lautet, daß sich in dieser Tragödie exemplarisch das juristische Verfahren der Untersuchung herausbildet, ein Verfahren, das bis heute Gültigkeit besitzt. Er möchte

zeigen, dass die Tragödie des Ödipus [...] repräsentativ und in gewisser Weise auch grundlegend für eine bestimmte Beziehung zwischen Macht und Wissen, zwischen politischer Macht und Erkenntnis ist, von der unsere Gesellschaft sich bis heute nicht befreit hat. (WjF 30f.)

Indem sich in Ödipus erstmals Formen eines Rechtsdiskurses manifestieren, die bis in die Gegenwart wirksam sind, besitzt die Tragödie auch für Foucault exemplarischen Charakter für die Entstehung des Subjekts. Und Foucault geht noch weiter: Ihm zufolge stellt Sophokles' Ödipus mit der Technik der Untersuchung nicht nur bestimmte Macht- und Wahrheitsbeziehungen dar, sondern ist »in gewisser Weise auch grundlegend « für sie; die Tragödie erzeugt also erst bestimmte Beziehungen von Wahrheit und Macht, erzeugt, in der Konsequenz, erst bestimmte Subjektivitätsstrukturen oder eine bestimmte Form des Subjekts. Damit räumt Foucault der Tragödie des Ödipus eine weitreichende Bedeutung für die Subjektkonstitution ein. Dies darf als ein weiterer Beleg für die enge Beziehung von Subjekt und Tragödie gelten, denn die Entwicklung oder der Wandel von Rechtsformen und der Urteilsfindung ist Gegenstand weiterer sophokleischer Tragödien, wie Foucault selbst betont: "König Ödipus ist gleichsam eine Zusammenfassung der griechischen Rechtsgeschichte. Mehrere Theaterstücke des Sophokles, zum Beispiel Antigone und Elektra, bilden gewissermaßen eine theatralische Ritualisierung der Rechtsgeschichte." (WjF 52f.) Der Begriff der Ritualisierung zeigt hier an, daß diese Tragödien jeweils nicht nur Ausdruck, sondern auch Formung des Rechts und damit des Subjekts sind.

Was für ein Subjekt konstituiert wird, ist indes auch hier wieder schwer zu bestimmen. Zunächst besteht die Beziehung zwischen juristischen Formen und dem Subjekt darin, daß Rechtsformen und Wahrheitsformen einander bedingen, daß "soziale Praktiken", wie die "juristischen Formen" es sind, "Wissensbereiche erzeugen, die [...] gänzlich neue Formen von Subjekten und Erkenntnissubjekten [hervorbringen]«. (WjF 10) Gegenstand der Untersuchung ist also die historische Verfaßtheit des Subjekts als Erkenntnissubjekt: "Auch das Erkenntnissubjekt hat eine Geschichte; auch die Beziehung zwischen Subjekt und Objekt, also die Wahrheit, hat eine Geschichte." (WjF 10) Gleichzeitig deutet die Wendung "Formen von Subjekten und Erkenntnissubjekten« an, daß es nicht allein um das Erkenntnissubjekt geht, 
sondern auch um andere Begriffsbereiche von sSubjekt $<$, die sich allerdings mit dem Erkenntnissubjekt teilweise überschneiden, wie es auch schon im obigen Kapitel zum Subjekt bei Foucault beschrieben worden ist. Der von Foucault in Die Wahrheit und die juristischen Formen verwendete Begriff des Erkenntnissubjekts ist um juristische und gesellschaftliche Bedeutungskomponenten erweitert bzw. von diesen nicht zu trennen, so daß Foucault die Bedeutung von 'Erkenntnissubjekt ganz nebenbei vollkommen umbesetzt. ${ }^{6}$ Auch Überwachen und Strafen wird Parallelen zwischen Episteme, Strafrecht und Individualisierung bzw. Subjektivierung ziehen.

Nun ist es zwar so, daß Foucault den Begriff der Tragödie hier nur im Zusammenhang mit Sophokles' Ödipus selbst gebraucht, also als nähere Textbezeichnung und in Abgrenzung zu anderen Versionen des Ödipusmythos. Doch so wenig er allgemeine Aussagen über die Tragödie als Gattung trifft, so entschieden betrachtet er einen Text als nicht nur charakteristisch, sondern auch konstitutiv für heutige Machtstrukturen, die ein Subjekt - im oben beschriebenen doppelten Verständnis von Erkenntnissubjekt und gesellschaftlich-rechtlichem Subjekt - hervorbringen; und eben dieser Text ist eine Tragödie. Zudem wird die gattungstheoretische Bedeutung dadurch verstärkt, daß die Argumentation dem Verfahren der Untersuchung in Sophokles' Ödipus das Verfahren der Probe in einem Gesang von Homers Ilias gegenüberstellt. Auf diese Unterschiede zwischen Tragödie und Epos wird Kapitel IV noch zu sprechen kommen. Vorerst bleibt folgendes festzuhalten: Auf seine Weise perpetuiert Foucault hier, wiewohl implizit, die These der Korrelation von Subjektkonstitution und Tragödie, und zwar im distinkten Sinne der Tragödie als literarischer Gattung und nicht nur im Sinne einer allgemeinen Tragödie der Kultur.

Überwachen und Strafen: Die Geschichte des Strafdiskurses als Tragödie

Der Zusammenhang von Recht, Subjekt und Tragödie, wie ihn Foucault in Die Wahrheit und die juristischen Formen geknüpft hatte, erfährt in Überwachen und Strafen (1975) weitere Ausgestaltung. Die Konzeption einer als >Tragik der Individuierung`, als Trennung verstandenen Subjektkonstitution aus

6 Vgl. dazu oben, Kap. I, Unterkap. »Das Subjekt bei Foucault«. 
Wahnsinn und Gesellschaft modifiziert und erweitert Foucault hier, wie in seinen werkchronologisch mittleren, machtanalytischen Arbeiten der siebziger Jahre überhaupt, in wesentlichen Punkten. Das negative Konzept der tragischen Trennung aus Wahnsinn und Gesellschaft, deren Ergebnis das Individuum war, wird durch ein positives Konzept der Produktion ersetzt, deren Ergebnis das Subjekt ist.

Mit Überwachen und Strafen schreibt Foucault eine Geschichte der juristischen Strafpraxis und untersucht, wie sie sich seit der Frühen Neuzeit verändert hat. Dabei ist die Genealogie der Strafpraxis zugleich eine Genealogie des modernen Subjekts; im Rechtsdiskurs sind die modernen Formen der Subjektwerdung am Werk: »Thema dieses Buches ist eine Korrelationsgeschichte der modernen Seele und einer neuen Richtgewalt. Eine Genealogie des heutigen Wissenschaft/Justiz-Komplexes", eine "Geschichte der modernen Seele im Gerichtsurteik. (ÜS 33) Mit dieser Konzeption der Subjektwerdung im Sinne eines Rechtssubjekts knüpft Foucault auch hier wieder, wie bereits in Die Wahrheit und die juristischen Formen, an die sklassischer Tradition von der Subjektkonstitution im Umfeld des Rechts an, wie die Tragödie sie vorführt. Der Themenkomplex von Überwachen und Strafen ist damit, so läßt sich auf Grundlage der von Foucault beobachteten "grundlegende[n] und entscheidende[n] Zusammengehörigkeit von Tragödie und Recht« (VG 208) rückwärts schließen, ein charakteristischer Gegenstand der Tragödie.

Tatsächlich läßt sich die Geschichte des Justizdiskurses und des Justizvollzugs, die Foucault in Überwachen und Strafen schreibt, insgesamt als tragischer Prozeß lesen. Foucault zufolge besteht eine zentrale Entwicklung in dieser Geschichte in dem, was gemeinhin als eine Humanisierung der Strafen bewertet wird, nämlich in einer fortschreitenden Abkehr von körperlichen Strafen. Ausgehend von der Marter wird diese Abkehr mit der Aufklärung im Laufe des 18. Jahrhunderts durch strafrechtsreformatorische Schriften eingeleitet, die auf Abschreckungs- und Besserungsstrafen setzen und sich im Code pénal von 1791 und im Code des délits et des peines von 1795 niederschlagen, und mündet schließlich in die Gefängnisstrafe. ${ }^{7}$ Dabei verläuft der Übergang von der Marter über die Bestrafung zum Gefängnis wie eine Tragödie und zeichnet den Übergang vom Mythos zum Logos.

Es ist verschiedentlich darauf hingewiesen worden, daß Foucault Ernst Cassirer rezipiert und einige seiner zentralen Gedanken aufgenommen

7 Vgl. WjF 78f., 121; ÜS 82ff., 113-149. 
hat. ${ }^{8}$ Die mythische Grundstruktur etwa, der Foucaults Marter folgt, weist deutliche Parallelen zu Cassirers »Denken des Mythos" auf. Cassirer zufolge wist es dem Mythos eigentümlich, daß er, bei aller `Geistigkeit‘ seiner Objekte und Inhalte, in seiner 'Logik , in der Form seiner Begriffe, verhaftet an den Körpern klebt. « ${ }^{9}$ Rechtlicher Hintergrund der Marter ist das Recht der Souveränität, und dieses sgeistige Recht der Souveränität bleibt dem Körper des Souveräns "verhaftet«, es »klebt« am Körper des Souveräns. Die Vernichtung des Verbrecherkörpers in der Marter stellt also den durch das Verbrechen verletzten Königskörper und mit diesem das Recht des Königs wieder her. Das Recht der Souveränität ist mythisches Recht, und die Marter folgt mythischen Strukturen.

Diese direkte, körperliche und mythische Verbindung zwischen Verbrechen und Strafe in der Marter werden die strafrechtlichen Reformbewegungen des 18. Jahrhunderts lösen. Deren rechtstheoretischer Hintergrund ist die Entwicklung der Vertragstheorie, die das Recht der Souveränität durch das Recht bzw. den Schutz der Gesellschaft ersetzt (vgl. ÜS 114). Es muß nicht mehr die Integrität des Königskörpers durch die Marter des Verbrecherkörpers wiederhergestellt werden, sondern der Gesellschaftsvertrag durch die Demonstration seiner Geltung am Rechtsbrecher. Der Körper des Verurteilten steht daher nicht mehr im Zentrum der Strafe, und folgerichtig werden die bislang üblichen Martern in Frankreich 1791 mit dem ersten Strafgesetzbuch der Revolution abgeschafft und durch einfache Todesstrafe ersetzt. Der Verurteilte ist nicht mehr in erster Linie Körper, sondern vergleichsweise abstraktes Rechtssubjekt, tritt also, wie der tragische Held, vom Geltungsbereich des mythischen Rechts der Souveränität in den Bereich des positiven, kodifizierten Rechts des Gesellschaftsvertrags

8 Ernst Cassirer: Philosophie der symbolischen Formen I (= Gesammelte Werke, Bd. 11), Hamburg 2002, S. 19. Philipp Sarasin betont die Bedeutsamkeit Cassirers für Foucaults Denken (vgl. dazu auch Michel Foucault: S I, S. 703ff.), bezieht sich dabei aber nicht, wie es hier geschieht, auf Parallelen zwischen Ähnlichkeit und Mythos, sondern auf die Historisierung von Diskurs und Denken (vgl. Philipp Sarasin: Michel Foucault zur Einführung, S. 101f.). Paul Geyer weist auf nicht durch Zitate ausgewiesene "Anleihen" Foucaults bei Cassirer hin, allerdings mehr in bezug auf die historische Phasierung von mythischem Denken und Episteme der Ähnlichkeit denn auf inhaltliche Parallelen (vgl. Paul Geyer: Foucaults "Les mots et les choses", S. 248, 250).

9 Ernst Cassirer: Philosophie der symbolischen Formen II (= Gesammelte Werke, Bd. 12), Hamburg 2002, S. 73. 
über - analog zum in der Tragödie inszenierten Übergang von Gewalt zu Recht ${ }^{10}$ oder von mythischem $\mathrm{zu}$ 'menschlichem Recht.

Gegen die von den Strafreformern ursprünglich geplanten und dann auch festgeschriebenen Strafen wie Zwangsarbeit, Deportation, Schande und Demütigung setzt sich seit dem 19. Jahrhundert schließlich die Gefängnishaft als allgemein gebräuchliche Strafe durch. ${ }^{11}$ Im Gefängnis nun geht es nicht mehr um den Körper des Verbrechers noch um das abstrakte Rechtssubjekt, sondern um das konkrete einzelne Individuum und seine Psyche. Wie der Übergang vom Mythos zum Logos und vom mythischen zum menschlichen Recht in der Tragödie mit einer Selbstbewußtseinswerdung des Helden verbunden ist, tritt damit auch in die Geschichte der Strafen die Subjektivität: »Die Seele tritt auf die Bühne der Justiz«. (ÜS 34)

\section{Die Guillotine (I): Zwischen Mythos und Logos}

Wie die reformierten Strafen nimmt seit der französischen Revolution auch die Guillotine eine Zwischenstellung zwischen Marter und Gefängnisstrafe ein; der Übergang von der Marter zur Guillotine stellt eine Vorstufe oder eine Variante des tragischen Übergangs vom Mythos zum Logos und vom Körper zur Seele dar. Während die Marter noch über die alten, mythischen Ähnlichkeitsbeziehungen funktioniert, läßt sich die Guillotine, auch sie eine Folge der Forderung nach humaneren Strafen, als ein erster Schritt hin zur Abstraktion des Zeichens verstehen: Die - körperliche - Todesstrafe soll auf möglichst unkörperliche Weise erfolgen, idealerweise ohne den Körper überhaupt zu berühren. Dadurch, daß die Guillotine in Sekundenbruchteilen den Hals durchtrennt, dabei aber Kopf, Rumpf und Glieder praktisch unangetastet läßt, ist der Tod durch die Guillotine gewissermaßen keine körperliche Strafe mehr. Sie ist zwar noch blutig, aber nicht mehr eigentlich auf den Körper gerichtet:

10 Vgl. etwa Sophie Klimis: Archéologie du sujet tragique, Paris 2003, S. 191: "Le mythe de passage de la violence à la justice«, u.v.a.m.

11 Foucault bezieht sich in seinen Ausführungen auf Frankreich. Im Allgemeinen Landrecht für die Preufsischen Staaten von 1794 dagegen zählt die "Festungs«-, "Zuchthaus«- oder "Gefängnißstrafe« bereits zu der am häufigsten vorgesehenen Strafe (vgl. ebd., Zweiter Teil, Zwanzigster Titel: Von den Verbrechen und deren Strafen). 
Beinahe ohne den Körper zu berühren, löscht die Guillotine das Leben aus, so wie das Gefängnis die Freiheit nimmt oder eine Geldbuße Besitztum. Sie soll das Gesetz weniger an einem wirklichen, schmerzempfindlichen Körper vollstrecken als vielmehr an einem juristischen Subjekt, das unter anderem das Recht auf Existenz innehat. Sie muß so abstrakt sein wie das Gesetz selber. (ÜS 21f.)

Damit steht die Guillotine an der Schwelle zwischen der Souveränitätsmacht und der Disziplinarmacht. Man könnte sie sogar als Symbol des neuzeitlichen Rationalismus und seiner Körper/Seele-Dichotomie auffassen; in ihr manifestieren sich gleichermaßen die materielle Trennung von Körper und Kopf wie die ideelle Trennung von Körper und Seele.

\section{Tragische Individuierung der Gefangenen}

Das Gefängnis entspricht in seinen Strukturen und seiner Funktionsweise zunächst der Individuumskonstitution durch praktischen Ausschluß, wie sie bereits in der Hospitalisierung der Wahnsinnigen erfolgt, und ist damit eine Variation der Internierungstechniken des 18. Jahrhunderts, deren Bedeutung für die Individuumskonstitution oben kurz beschrieben wurde. ${ }^{12}$ So wie die Internierung in Wahnsinn und Gesellschaft »institutioneller Ausdruck" der "großen wesentlichen Trennung von Vernunft und Unvernunft « ist, die Foucault als wesentlich tragische Trennung versteht, erweist sich auch das Gefängnis als Folge und Instrument jener tragischen Individualisierung durch und als Trennung: Der körperliche Ausschluß des Hospitals bzw. des Gefängnisses steht in Verbindung und wechselseitiger Bedingung zum epistemischen Ausschluß durch psychologische Kategorisierung des Patienten bzw. Delinquenten.

\section{Die Seele des Verbrechers: Der Delinquent}

Das Gefängnis geht aber über die bloße Individuierung durch Trennung weit hinaus. Die Ablösung des ius talionis durch eine Strafe, die nicht mehr Vergeltung, aber auch nicht mehr Belehrung des Volks durch Abschrekkung im Sinne der Generalprävention anstrebt, sondern Besserung des je

$12 \mathrm{Zu}$ den strukturellen Ähnlichkeiten zwischen (tragischem) Ausschluß in Wahnsinn und Gesellschaft und Gefängnis in Überwachen und Strafen vgl. WjF 113, ÜS 269. 
einzelnen Täters, also Spezial- oder Individualprävention bezweckt, betrifft auch die Ebene der Rechtsprechung. Denn nicht nur die Strafe selbst, sondern auch die Strafbemessung verlagert sich vom Körper auf die Seele: Während vormals das Verbrechen Bemessungsgrundlage des Strafmaßes war, rückt nun der Verbrecher in den Fokus. Geurteilt wird nicht mehr über seine Tat, sondern über seine Beweggründe, seine Begehren und Lüste, seine Vernunft oder seinen Wahnsinn. "Die Strafe soll, wenn ich so sagen darf, eher die Seele treffen als den Körper.« (ÜS 26) ${ }^{13}$

Grundlage für diese Verschiebung des Strafziels vom Körper auf die Seele ist eine Übertragung des mit dem Ausschluß des Wahnsinns gegründeten Wissens über den Wahnsinn auf den juridischen Bereich: Es findet eine Psychologisierung des Verbrechers statt, wodurch er zum Delinquenten wird. Der Delinquent unterscheidet sich vom Verbrecher dadurch, »daß weniger seine Tat als vielmehr sein Leben für seine Charakterisierung entscheidend ist ( [...], sondern daß er an sein Verbrechen durch ein Bündel von komplexen Fäden geknüpft ist (Instinkte, Triebe, Tendenzen, Charakter)«. (ÜS 325) Hiermit bedeutet die Individualisierung nicht mehr nur ausschließende Trennung, sondern, spezifischer, Psychologisierung. Dabei bleibt aber zugleich die Tragik der Individuumskonstitution wirksam, denn Voraussetzung der Psychologisierung des Verbrechers ist die Entwicklung des Umgangs mit dem Wahnsinn, dessen Geschichte Foucault 15 Jahre vor Überwachen und Strafen geschrieben hatte, ist also auch hier die - ursprüngliche und tragische - Trennung von Vernunft und Wahnsinn. Das Gefängnis basiert auf einer Konzentration auf die Psyche, und die Idee einer Psyche, die es zu bessern gilt, setzt die Trennung von Wahnsinn und Vernunft voraus.

Hierin stellt der Übergang von der Marter zum Gefängnis eine weitere Variante des Übergangs vom Mythos zum Logos dar, der sich nicht, wie der Übergang von der körperlichen zur seelischen Strafe, auf das Strafobjekt bezieht, sondern auf die Strafbemessung: Der Übergang zur psychologischen Beurteilung des Verbrechers, zur Anwendung psychologischen Wissens auf ihn, ist der Übergang von einem rächenden Mythos zu einem Logos als einer auf medizinisches Wissen gegründeten Vernunftpraxis.

13 Foucault zitiert hier aus Gabriel Bonnot de Mablys De la législation, ou: Principes de Loix aus dem Jahre 1776. 
Im medizinisch-juridischen Diskurs über die Schuldfähigkeit des Verbrechers wird diesem eine Seele geschaffen und über diese Seele gerichtet. Überwachen und Strafen beschreibt also, wie die Seele im Zuge der Psychologisierung der Strafbemessung und des Strafziels erst hervorgebracht wird.

Tragödie der Selbsterkenntnis:

Verinnerlichung der Machtstrukturen im Panopticon

Das Gefängnis stellt folglich die Ablösung des Zugriffs auf den Körper durch Erschaffung der und Zugriff auf die Seele dar: Wie in der Tragödie findet eine Subjektwerdung statt. Das Gefängnis in Überwachen und Strafen entspricht damit auf einer ersten Stufe zunächst der Hospitalisierung der Wahnsinnigen, also der Individuumskonstitution durch tragische Trennung, wie sie bereits in Wahnsinn und Gesellschaft dargestellt wird. Auch der dort angedeutete Zusammenhang von Internierung und Psychologisierung erfährt hier weitere Ausgestaltung und geht in einem zweiten Schritt über den nur ausschließenden Mechanismus der Internierung aus Wahnsinn und Gesellschaft hinaus, indem er gegenüber dem dortigen Subjektbegriff um ein produktives Moment erweitert wird. ${ }^{14}$ Dieses produktive Moment ist der dialektischen Selbstkonstitution Hegels nicht unähnlich: Es erfolgt eine Verknüpfung und Gleichzeitigkeit aus passivem Unterworfenwerden und aktivem Sichunterwerfen. In Jeremy Benthams Panopticon, das bei Foucault exemplarisch für die Subjektivierung des modernen Menschen steht, geschieht das folgendermaßen:

Die Individuierung resultiert zunächst daraus, überhaupt Gefangener zu sein. Das ist die Individuierung durch Ausschluß, wie sie soeben für Hospitäler, Gefängnisse etc. beschrieben wurde. Die Besonderheit des Panopticons besteht darin, daß der Gefangene durch dessen besondere Architektur "der Sichtbarkeit unterworfen" ist. Die Subjektivierung erfolgt dann im nächsten Schritt: im Wissen darum, der ständigen Sichtbarkeit unterworfen zu sein.

14 Vgl. auch die zwei Varianten der Disziplin (einmal bloß ausschließend und einmal produktiv): $\mathrm{WjF}$ 113, ÜS 269. 
Derjenige, welcher der Sichtbarkeit unterworfen ist und dies weiß, übernimmt die Zwangsmittel der Macht und spielt sie gegen sich selber aus; er internalisiert das Machtverhältnis, in welchem er gleichzeitig beide Rollen spielt; er wird zum Prinzip seiner eigenen Unterwerfung. (ÜS 260)

Der Gefangene, das durch Erfassung und Disziplinierung, hier durch Inhaftierung unterworfene und so konstituierte Individuum, muß im Panopticon jederzeit annehmen, vom zentralen Wachturm aus beobachtet zu werden, kann aber nie wissen, ob er tatsächlich beobachtet wird. Er wird sich also immer so verhalten, als würde er beobachtet; er verinnerlicht auf diese Weise den Blick des Aufsehers, den Blick des Anderen, und kehrt ihn gegen sich selbst, verinnerlicht also die ihm zuvor äußerlichen Machtstrukturen. Der Gefangene weiß sich als Objekt des Strafvollzugs und damit als objektiviertes Individuum und sieht sich selbst mit dem Blick des - tatsächlich anwesenden oder auch abwesenden - Aufsehers. Wie das Hegelsche Bewußtsein geht das Individuum aus sich heraus und kehrt mit dem Blick des Anderen in sich zurück, vollzieht also eine Art Anerkennungsbewegung - allerdings eine pervertierte Anerkennungsbewegung, weil der Blick des Anderen gar nicht stattfinden muß: Die Anerkennung durch den Anderen funktioniert ohne den Anderen. Das Individuum unterwirft sich auf diese Weise im Wirkungsfeld weitergehender Strategien und Mechanismen, nämlich im Wissen um den Anderen, um den Beobachter (bzw. im Nichtwissen um seine An- oder Abwesenheit), selbst - unterwirft sich sich selbst, seinem eigenen Bewußtsein, das sich gleichzeitig erst dadurch konstituiert. Wiederum in Anlehnung an Hegel und in Abgrenzung zur in Wahnsinn und Gesellschaft beschriebenen einseitigen Ausschlußbewegung, die das Individuum hervorbringt, ist dann erst für das Ergebnis dieser doppelten Konstitutionsbewegung vom eigentlichen Subjekt zu sprechen. Zu der trennenden Ausschlußbewegung aus Wahnsinn und Gesellschaft, durch die das Individuum konstituiert wird, kommt also eine weitere, tiefer gehende Komponente hinzu: Sie wird durch eine Unterwerfung ergänzt, die sowohl von außen als auch von innen, vom Individuum selbst vollzogen wird, indem dieses sich als Objekt des Wissens des Anderen, des Beobachters, erkennt und anerkennt. ${ }^{15}$

$15 \mathrm{Zu}$ Anerkennungsstrukturen bei Foucault vgl. Judith Butler: Noch einmal: Körper und Macht, S. 63f. Es ließe sich einwenden, daß Foucault das anerkennende Moment der Selbstunterwerfung bereits in Wahnsinn und Gesellschaft andeutet, etwa, wenn er zeigt, wie der internierte Wahnsinnige gezwungen wird, die (medizinische) Wahrheit 
Hiermit hält eine Bewegung der Selbsterkenntnis Einzug in Foucaults Subjektkonzeption. Obwohl das Subjekt bei Foucault keine Substanz, kein immer schon Zugrundeliegendes ist, vollzieht es eine Bewegung der reflexiven Selbsterkenntnis. Damit findet sich bei Foucault auch die zweite mögliche Bedeutung der eingangs erwähnten geläufigen These einer Verknüpfung von Subjektwerdung und Tragödie, nämlich die der Subjektwerdung als Selbsterkenntnis. Nicht nur die Trennung (Individuation) ist tragisch, sondern auch die darauffolgende Subjektivierung folgt tragischen Strukturen, so wie auch bei Hegel das Wissen als Einsicht in das Recht des anderen Rechts und in die eigene Schuld, d.h. die Selbsterkenntnis, dasjenige ist, das das Individuum zum Subjekt werden läßt.

\section{Ende der Tragödie}

Die sukzessive Abschaffung der körperlichen Strafe von der Marter über die reformierte Bestrafung zum Gefängnis läßt sich demnach insgesamt analog zum eingangs als für die Tragödie charakteristisch bezeichneten Übergang vom Mythos zum Logos lesen, vom Körperlichen, als einer direkten wörtlichen Ordnung, über das Abstrakt-Rechtliche, als einer vermittelten sprachlichen, symbolischen Ordnung, bis hin zum Seelischen, bis hin zum Subjekt. Die beiden letztgenannten Punkte bezüglich der tragischen Strukturen des panoptischen Gefängnisses, die Individuierung durch körperlichen Ausschluß und die Verinnerlichung der Machtstrukturen, führen aber zu einem Ende dieser Tragödie.

Zum einen ist gesagt worden, das Gefängnis stehe, in der Nachfolge der Hospitäler aus Wahnsinn und Gesellschaft, bis zu einem gewissen Grade noch im Zeichen der tragischen Trennung von Vernunft und Wahnsinn. Dies ist die eine, frühere Spielart der Disziplin, "die Disziplin als Blockade, als geschlossene Anstalt, die innerhalb bestimmter Grenzen auf negierende Funktionen ausgerichtet ist«, das »Modell der Ausnahmedisziplin«. Im Pan-

über sich und die Wahrheit über seinen Wahnsinn zu sagen, d.h. ihn als Wahnsinn anzuerkennen, wie dort überhaupt stellenweise auch bereits Foucaults spätere Macht/ Wissen-Konzeption und die Produktivität der Macht vorweggenommen sind. In der Tendenz bleibt die getroffene Unterscheidung von Individuumskonstitution durch Trennung und Subjektkonstitution durch anerkennende und verinnerlichende Selbsterkenntnis aber zutreffend. 
opticon dagegen tritt die Disziplin nicht mehr bloß in ihren "negierende[n] Funktionen" auf, sondern "als Funktionszusammenhang, der die Ausübung der Macht verbessern, d.h. beschleunigen, erleichtern, effektiver machen soll." (ÜS 269) Foucault unterscheidet auf diese Weise zwischen der Internierung des 18. und der des 19. Jahrhunderts, d.h. "Zwischen der Einschließung des 18. Jahrhunderts, deren Hauptaufgabe der Ausschluss der marginalisierten Person oder die Verstärkung der Marginalisierung war, und der Sequestrierung des 19. Jahrhunderts, deren Ziel Einbindung und Normalisierung ist«. (WjF 113) Der Ausschluß des 18. Jahrhunderts ist ein vornehmlich körperlicher, während der des 19. Jahrhunderts sich in größerem Maße auf die Seele bezieht, auf die Seele abzielt. Das Panopticon etwa ermöglicht durch die Verinnerlichung des äußeren Blicks die körperliche Loslösung der Gefangenen von ihren Ketten. Innerhalb ihrer Zellen können sie sich frei bewegen, da sie sich unter andauernder Beobachtung wissen. Der körperliche Ausschluß als direkter Zugriff auf den Körper wird durch den Zugriff auf die Seele verzichtbar. So wird die ausschließende Tragik der Trennung und Individuation im Laufe des Prozesses der Subjektwerdung von Entwicklungen überformt, die wesentlich untragisch sind und nicht mehr in die Figur der ursprünglichen tragischen Trennung integriert werden können. Offenbar ist die Psychologisierung des Subjekts, also der Punkt der Entwicklung, ab dem die Subjektivierung nicht mehr bloß durch Ausschluß des Wahnsinns, sondern auch durch Produktion einer Seele erfolgt, nicht mehr mit der Figur der ursprünglichen tragischen Trennung vereinbar - dies eine Variante der seit Hegel gängigen Begründung für die Unvereinbarkeit von Moderne und Tragödie, des Gegensatzes von Psychologie und Tragik. ${ }^{16}$

Zum anderen setzt mit der - tragischen - Verinnerlichung der Machtmechanismen im Panopticon, ihrer Kehrung gegen sich selbst und der auf diese Weise vollzogenen (anerkennenden) Selbsterkenntnis bei Foucault ein Ende des tragischen Prozesses ein; in diesem Stadium der Subjektwerdung gelangen Tragik und Tragödie an das Ende ihrer Möglichkeit, und zwar aus zwei miteinander verbundenen Gründen.

Erstens ist Hegel zufolge »der Zweck und Inhalt einer Handlung dramatisch nur dadurch, daß er [...] in anderen Individuen andere entgegenstehende Zwecke und Leidenschaften hervorruft." (Ä III, 479f.) Soll er

16 Vgl. dazu ausführlicher Kap. V, Unterkap. "Die Trennung der tragischen Einheit von Täter und Tat«. 
dramatisch erscheinen, so muß er sich in seiner Besonderung als unterschiedene Zwecke entgegentreten, so daß überhaupt die Handlung Hindernisse von seiten anderer handelnder Individuen zu erfahren hat und in Verwicklungen und Gegensätze gerät, welche das Gelingen und Sichdurchsetzen einander wechselseitig bestreiten. (Ä III, 480)

"Die dramatische Handlung beruht deshalb wesentlich auf einem kollidierenden Handeln«. ( im Panopticon aber kann es keine äußere und also dramatische Handlung, kein 'Entgegentreten « "unterschiedene[r] Zwecke«, keine Austragung des tragischen Konflikts geben, weil der Gefangene die »entgegenstehende[n] Zwecke« in sich vereint. Nicht nur fehlt im Panopticon ein entgegenstehendes Individuum, mit dem im Widerstreit sich der tragische Konflikt entzünden könnte (der an- oder auch abwesende Aufseher), sondern dieses entgegenstehende Individuum ist in das eine Individuum, in den Gefangenen hineingelegt. Und diese Verinnerlichung ist genau das Argument, das Hegel gegen die moderne Tragödie und ihre Figuren anführt: daß nämlich,

wenn auch die tragische Handlung auf der Kollision beruhen muß, dennoch das Hineinlegen des Zwiespalts in ein und dasselbe Individuum immer viel Mißliches mit sich bringt. [...] Es sind gedoppelte Menschen, die nicht zu fertiger und dadurch fester Individualität gelangen können. (Ä III, 563)

Zum Argument der Unmöglichkeit der Dramatisierung des tragischen Konflikts kommt also, zweitens, hinzu, daß der Charakter genau die Eigenschaft verliert, die ihn zum tragischen Handeln erst befähigt: seine tragische Einheit. ${ }^{17}$

17 Vgl. etwa G.W.F. Hegel: Vorlesungen über die Ästhetik I (= Werke, Bd. 13), Frankfurt a.M. ${ }^{8} 2003$, S. 312 (im folgenden per Sigle Ä I im laufenden Text zitiert): "In Corneilles Cid z.B. ist die Kollision der Liebe und Ehre eine glänzende Partie. Solch in sich selbst unterschiedenes Pathos kann allerdings zu Konflikten führen; wenn es aber als innerer Widerstreit in ein und denselben Charakter hineinverlegt wird, so gibt dies zwar Gelegenheit zu brillanter Rhetorik und effektvollen Monologen, doch die Entzweiung ein und desselben Gemüts, das aus der Abstraktion der Ehre in die der Liebe und umgekehrt hinüber- und herübergeworfen wird, ist der gediegenen Entschlossenheit und Einheit des Charakters in sich zuwider."Vgl. auch Ä III, $485 f$. etc. sowie, einschlägig, das Kap. zur "sittlichen Handlung" in der Phänomenologie des Geistes, PG 342-354. 
Überwachen und Strafen beschreibt demnach einen dem Verlauf der Tragödie analogen Übergang vom Körperlichen zum Seelischen und zum Subjekt, zeichnet die Tragödie damit aber zugleich als an ihr Ende gelangt; der Panoptismus führt zum Ende des Tragischen. Aus dem Gesagten geht dabei deutlich hervor, daß Foucaults Konstruktion vom Ende der Tragödie sich eng an Hegels Begründungen für das Ende der Tragödie anschließen läßt. Trotz aller Andersartig- oder Gegensätzlichkeit seiner Subjektkonzeption stellt Foucault wie Hegel und wie Nietzsche die Entwicklung des modernen Subjekts in unmittelbaren Zusammenhang zum Ende des Tragischen. Die Verknüpfung von Subjektgenese und Tragödie schließt daher das Ende der Tragödie immer schon mit ein: Parallel zur Subjektkonstitution im Verlauf der Tragödie vollendet sich die tragische Form und endet die Tragödie, als einzelne wie als Gattung. Damit ist sowohl für Hegel als auch für Foucault ein historisches (wiewohl bei Foucault kontingentes) Ende der Tragödie zu konstatieren; es sieht demnach auch für Foucault ganz nach einer untragischen Gegenwart aus. 
Zweiter Teil: Subjekt und Gattung

Tragödie, Komödie, Roman 
Foucaults eigener Anregung folgend, die Beziehung zwischen Recht und Tragödie "näher [zu] betrachten« (VG 208), haben die bisherigen Ausführungen gezeigt, daß Foucaults frühes Tragikkonzept individuierender Trennung noch ausgeführt und auch auf seine smittleren Texte übertragen werden kann, indem die Konzeption der Individuierung durch passiven tragischen Ausschluß um die einer Subjektivierung durch aktive tragische Konstitution eines Subjekts im Rahmen des Rechtsdiskurses und der ihm eigenen Machttechniken erweitert wird. Diese Anschlußfähigkeit auch Foucaults machttheoretischer Schriften an sein frühes Tragikkonzept basiert nicht zuletzt (mit Szondis Identifikation von Tragik und Dialektik im Hinterkopf) auf dem Nachweis quasidialektischer Strukturen in seiner machttheoretischen Subjektkonzeption. Nur so läßt sich die Genese des Subjekts des juridischen Diskurses insgesamt als tragische Konstitution eines Rechtssubjekts und als tragische Selbsterkenntnis lesen. Daß diese Lesart letztlich in ein Ende des Tragischen mündet und auch darin der seit Hegel klassischen Figur des Endes der Tragödie folgt, wurde soeben gezeigt. Läßt man dagegen Foucaults erklärte Ablehnung aller Dialektik und auch seine Abkehr vom Tragikkonzept gelten, stößt man auf eine neue Überraschung: Foucault eröffnet in Überwachen und Strafen einen Gattungsdiskurs über Tragödie, Komödie und Roman.

Auch hierin folgt er gewissermaßen Hegel. Im Sittlichkeitskapitel seiner Phänomenologie des Geistes hatte dieser beschrieben, wie sich in der Tragödie einerseits eine stufenweise Entwicklung des Selbstbewußtseins vollzieht, die sich damit als eine tragische Entwicklung erweist, und wie andererseits erst das Ende der Tragödie den eigentlichen Beginn des modernen Selbstbewußtseins bedeutet. Während die Tragödie, wohl in der Tradition der klassischen Bewertung der Tragödie als höchster Kunstform, im allgemeinen als das paradigmatische Modell schlechthin (für die conditio humana, für die Kultur, für die Moderne, ...) angesehen wird und auch Untersuchungen zu Hegel immer wieder die Tragödie und lange Zeit vornehmlich Hegels Antigonelektüre im Geistkapitel und damit fast ausschließlich seine Tragödientheorie in den Blick nahmen, ${ }^{1}$ rückte in jüngerer Zeit verstärkt das

1 Vgl. Christoph Menke: Tragödie im Sittlichen. 
Religionskapitel und namentlich das Unterkapitel zur "Kunstreligion« in ihren Fokus. ${ }^{2}$ Menke bezeichnet es als das »kunsttheoretische Kapitel der Phänomenologie«, ${ }^{3}$ doch ist es auch ein entschieden subjekttheoretisches. Im Abschnitt zum "geistige[n] Kunstwerk « beschreibt Hegel die Subjektkonstitution nicht, wie noch im Sittlichkeitskapitel, am Beispiel der Tragödie, sondern entlang der Gattungstrias Epos, Tragödie und Komödie. ${ }^{4}$ Ausgehend vom Epos entwickelt sich das Selbstbewußtsein über die Tragödie weiter zur Komödie und schließlich bis zum Ende der Kunst. Jede einzelne dieser Gattungen entspricht dabei einer Entwicklungsstufe des Selbstbewußtseins, womit sich die Struktur der Subjektkonstitution in der Tragödie, wie Hegel sie in seiner Antigonelektüre beschreibt, auf einer übergeordneten Ebene in der Gattungsabfolge wiederholt. ${ }^{5}$ Wie in den Kunstformen überhaupt manifestieren und realisieren sich auch in den literarischen Gattungen jeweils Stufen der Subjektivität, nämlich episches, tragisches und komisches Bewußtsein. ${ }^{6}$ Hier steht nicht die Tragödie, sondern die Komödie systematisch an letzter und also höchster Stelle; in bewußtseinstheoretischer oder subjektphilosophischer Hinsicht bedeutet das, daß sich in der Komödie die höchste Form von Subjektivität ausdrückt und verwirklicht. Die späteren Vorlesungen über die Ästhetik werden mit einem kurzen Hinweis auf den Roman schließen; dieser ist in gewisser Weise die Fortsetzung der attischen Komödie in der Gegenwart. ${ }^{7}$ Hegels idealistisches System zeigt sich hier in seiner vollkommenen Geschlossenheit: Es

2 Vgl. Werner Hamacher: (Das Ende der Kunst mit der Maske), in: Karl Heinz Bohrer (Hg.): Sprachen der Ironie - Sprachen des Ernstes, Frankfurt a.M. 2000, S. 121-155; Lars Friedrich: Der Achill-Komplex. Versuch einer dekonstruktiven Gattungspoetik, München 2009, S. 220-238; Stephan Kraft: Zum Ende der Komödie. Eine Theoriegeschichte des Happyends, Göttingen 2011, S. 274-284. Menke bezieht sich zwar auf dieses Kapitel, läßt Epos und Komödie allerdings außer acht und beschränkt seinen Blick auf das Geschehen in der Tragödie (vgl. Christoph Menke: Tragödie im Sittlichen, S. 178-187).

3 Ebd., S. 178.

4 Vgl. PG 529-544.

5 Eins zu eins expliziert: Das epische Bewußtsein entspricht dem ununterschiedenen Ansich, das tragische dem gespaltenen (oder vielmehr spaltenden) Fürsich, das komische schließlich dem vermittelten und versöhnten Anundfürsich.

6 Tragisches und komisches Bewußtsein werden in Kap. V, Unterkap. "Schauspieler und Maske in Hegels Phänomenologie des Geistes« näher beschrieben.

7 Vgl. dazu Stephan Kraft: Zum Ende der Komödie, S. 310f. 
handelt sich um eine systematische Verknüpfung von Gattungstheorie, Subjekttheorie und Geschichtsphilosophie.

Das vorangegangene Kapitel zur Tragödie der Subjektivierung im Rechtsdiskurs argumentierte, ganz im Einklang mit dem gemeinhin vertretenen Primat der Tragödie bei der Subjektkonstitution, daß Foucaults Geschichte des Strafrechts - und die Konstitution des Subjekts - insgesamt als eine Tragödie gelesen werden kann. Dagegen soll nun gezeigt werden, daß Foucault selbst diese Geschichte als Abfolge von Tragödie, Komödie und Roman beschreibt. Der zweite Teil der vorliegenden Arbeit nimmt damit einen neuen Argumentationsfaden auf. Überwachen und Strafen beschreibt nämlich nicht nur Genese und Verlauf des Rechtsdiskurses, sondern auch dessen Ende. Das panoptische Gefängnis, vordergründig eine Institution des Rechts, fällt in Wirklichkeit nicht mehr in den juridischen Bereich und seine Diskurse, sondern ist Ergebnis eines neuen Diskurses: des Diskurses der Norm. Die Norm nun aber ordnet Foucault in der bereits zitierten Vorlesung In Verteidigung der Gesellschaft nicht etwa der Tragödie, sondern dem Roman zu:

\begin{abstract}
Mir scheint, daß es eine grundlegende und entscheidende Zusammengehörigkeit von Tragödie und Recht, von Tragödie und öffentlichem Recht gibt, genau wie es wahrscheinlich eine entscheidende Zusammengehörigkeit von Roman und Normproblemen gibt. Tragödie und Recht, Roman und Norm: Das müßte man näher betrachten. (VG 208)
\end{abstract}

Damit wandelt sich Foucaults Tragikdiskurs zu einem Gattungsdiskurs, der die gattungstheoretisch übliche Abfolge von Epos, Tragödie und Komödie bzw. Tragödie, Komödie und Roman aufgreift.

Die Gattungsbezeichnungen Tragödie und Komödie führt Foucault in Überwachen und Strafen gleich eingangs ein. Zunächst spricht er allgemein vom "Verschwinden der Martern" als einem "Ende des Schauspiels" (ÜS 17f.), einem »Verschwinden des Strafschauspiels«. (ÜS 15) Diesen Hauptgedanken weiter ausdifferenzierend, zeichnet er im Zusammenhang des Übergangs der Strafe vom Körper des Verbrechers zur Seele des Delinquenten ein Ende der Tragödie und ihre Ablösung durch die Komödie:

Zu Beginn des 19. Jahrhunderts geht also das große Schauspiel der peinlichen Strafe zu Ende; man schafft den gemarterten Körper beiseite; man verbannt die Inszenierung des Leidens aus der Züchtigung. (ÜS 22f.) 
Dies ist ein wichtiger Augenblick. Die alten Mitspieler des Straf-Prunks, der Körper und das Blut, räumen den Platz. Auf die Bühne tritt eine neue Figur - maskiert. ${ }^{8}$ Eine gewisse Tragödie ist zu Ende, es beginnt eine Komödie mit schattenhaften Silhouetten, gesichtslosen Stimmen, unbetastbaren Wesen. Der Apparat der Strafjustiz hat es nun mit dieser körperlosen Realität zu tun. (ÜS 26)

Foucault bewegt sich hier nicht lediglich im engen Rahmen der verbreiteten Metaphorik der Hinrichtung als Schauspiel, wie sie auch in seinen Quellen immer wieder auftaucht. ${ }^{9}$ Auch handelt es sich keineswegs um ein bloßes und einmaliges Anzitieren des Gattungsdiskurses. Vielmehr, das soll im Folgenden herausgearbeitet werden, grundiert Foucault seine Geschichte der "Geburt des Gefängnisses" geradezu programmatisch mit Gattungsbezügen. Die zitierten Sätze umschließen nicht nur alle Bedeutungsebenen und Facetten der Verknüpfung von Tragödie und Subjektkonstitution, wie sie bisher für Foucault herausgearbeitet wurde, sondern leiten einen regelrechten Gattungsdiskurs ein. Die Begrifflichkeit von Schauspiel bzw. Tragödie und Komödie sowie die Figur der Ablösung der Tragödie durch die Komödie weisen auf zentrale Zusammenhänge des gesamten darauffolgenden Textes von Überwachen und Strafen hinaus.

Diese Zusammenhänge schließen auch Foucaults Untersuchungen aus Die Ordnung der Dinge mit ein. Bezüglich der »Geschichte des Strafrechts« und der "Geschichte der Humanwissenschaften" wirft er einleitend die Frage auf, »ob es nicht eine gemeinsame Matrix gibt und ob nicht beide Geschichten in

8 Übersetzung verändert, Gw.E.; vgl. Michel Foucault: Surveiller et punir. Naissance de la prison, Paris 1975, S. 24 (im folgenden per Sigle SP zitiert): "Les vieux partenaires du faste punitif, le corps et le sang, cèdent la place. Un nouveau personnage entre en scène, masqué."Seitter übersetzt »Straf-Fest« statt »Straf-Prunk «, »Person« statt "Figur» und "verschleiert" statt "maskiert». Insbesondere die beiden letzten sind wichtig für den theatralen Zusammenhang (vgl. dazu auch Kap. V), und auch der "Prunk « wird im folgenden noch einmal auftauchen: als Attribut der souveränen Repräsentation. Die Kapitelüberschrift »Fest der Martern« ist sehr frei; Foucault schreibt "éclat des supplices «, was so Unterschiedliches bedeuten kann wie u.a. ’lauter Knalk, ’Aufblitzen`

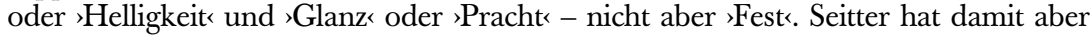
insofern einen Punkt, als »Fest" auf Foucaults implizite Identifikation der Marter mit den Ursprüngen der Tragödie im Dionysoskult hinweist; vgl. dazu das folgende Kap.

9 Zur "Analogie von Theater und Gericht« überhaupt, die seit den Römern üblich war, siehe Manfred Fuhrmann: Person. Von der Antike bis zum Mittelalter, in: Historisches Wörterbuch der Philosophie, hg. von Joachim Ritter u.a., Bd. 7, Basel 1989, S. 269-283, hier S. 270. 
einen einzigen repistemologisch-juristischen Formierungsprozeß hineingehören", und er gibt auch sogleich die Antwort, um was für eine Matrix es sich dabei handelt: "Die Technologie der Macht soll also als Prinzip der Humanisierung ${ }^{10}$ der Strafe wie der Erkenntnis des Menschen gesetzt werden."(ÜS 34) Mit Blick auf seine kurz zuvor getroffene Unterscheidung von Tragödie und Komödie läßt sich diese Antwort jedoch noch modifizieren bzw. spezifizieren: Die gesuchte "gemeinsame Matrix « sowohl der verschiedenen Epistemen als auch der verschiedenen Strafformen, diese Technologie der Macht, ist ein Gattungsdiskurs. Den jeweiligen Epistemen und Strafformen korrespondieren, so die zentrale These dieser Arbeit, literarische Gattungen, und zwar Tragödie, Komödie und Roman. Foucault parallelisiert die Episteme der Ähnlichkeit mit der Marter und der Tragödie, die Episteme der Repräsentation mit den reformierten Strafen und der Komödie sowie schließlich die Episteme der Humanwissenschaften mit Gefängnis und Disziplin und dem Roman.

10 Seitter übersetzt »humanisation« (SP 31) mit »Vermenschlichung«. 


\title{
IV. Die Tragödie der Marter und ihr Ende
}

\author{
Tragödie der Marter: Körper, Blut, Ähnlichkeit
}

Indem Foucault das Ende der Tragödie dadurch bestimmt, daß man in den Strafen »den gemarterten Körper beiseite [schafft]« und daß Körper und Blut »den Platz [räumen]«, ordnet er die Tragödie dem Körperlichen und der Marter zu. ${ }^{1}$ Diese Zuordnung begründet sich zunächst darin, daß ein körperlich blutiges Schauspiel, das mit dem Tod des Helden endet, eine Tragödie sein muß und keine Komödie sein kann; das leuchtet unmittelbar ein. Sie stützt sich außerdem auf die im Vorwort zu Wahnsinn und Gesellschaft erklärte Zusammengehörigkeit von Mythos und Tragik, denn das mythische Denken als das Denken der Ähnlichkeit ist seiner Struktur nach an die Kategorie des Körperlichen gebunden (anders als der Logos als geistige Kategorie). Durch ihre Teilhabe am mythischen Einheitszustand gehört dann auch die Tragödie dem skörperlichen Denken an, das seinerseits die Funktionsweise der Marter bestimmt.

Dies bestätigt auch der Ursprung der griechischen Tragödie. Wie Nietzsche nachdrücklich betont, ist sie aus einem Kultus zu Ehren des Gottes Dionysos hervorgegangen, und ebenso nimmt Foucaults Tragödie des Strafens ihren Ausgang in einem Ritual: Im Strafschauspiel der Marter wird der Verurteilte "zerstückelt« wie Dionysos Zagreus; die tragische Individuation "als de[r] Quell und Urgrund alles Leidens" (GT 72), die Nietzsche auch "die Marter des Gottes « ${ }^{2}$ nennt, wiederholt sich. Bei Nietzsche eröffnet der frühgriechische Dionysoskult in der Zerstückelung zugleich die Hoffnung auf die Wiederherstellung der Einheit, was bei Foucault in der Marter tatsächlich gelingt: Durch die Zerstückelung des Verbrechers wird der Körper des Königs wiederhergestellt. Foucault legt damit eine Identifikation des Gemarterten mit Dionysos Zagreus nahe, identifiziert ihn zugleich aber auch mit dem König, der durch die rituelle Marter wiederhergestellt, der wie

1 Die Zuordnung von Körper und Tragischem bemerkt auch Geisenhanslüke, allerdings ohne daraus weiterführende Schlüsse zu ziehen. Vgl. Achim Geisenhanslüke: Tragödie und Infamie, S. 92f.

2 Friedrich Nietzsche: Nachgelassene Fragmente 1869-1874 (= Werke. Kritische Studienausgabe, Bd. 7), München/Berlin 1980, S. 151f. Nietzsche spricht dort auch von "Zagreus als Individuation". 
Dionysos Zagreus "noch einmal« geboren wird. (GT 72) Überwachen und Strafen hebt immer wieder den kultischen Ritualcharakter der Martern hervor, ${ }^{3}$ dessen Hintergrund und Ziel nicht, wie bei Nietzsche, der zerstükkelte Gott Dionysos und seine Wiedergeburt, sondern der verletzte Körper des Königs und die Restauration seiner Integrität ist: "Die Marter hat also eine rechtlich-politische Funktion. Es handelt sich um ein Zeremoniell zur Wiederherstellung der für einen Augenblick verletzten Souveränität." (ÜS 64) Wie mit dem Tod des Helden in der Tragödie wird mit dem Tod des Verbrechers in der Marter ein Recht wiederhergestellt.

Mit den kultischen Ursprüngen der antiken Tragödie hat die Marter also ihren rituellen Charakter gemein. Foucault schreibt: "Diese alte Rechtsprechung war, wie Vico sagte, reine ganze Poetik « (ÜS 60) - und zwar, wie man sogleich hinzufügen kann, eine ganze Poetik der Tragödie. Wie die attische Tragödie in ihrer entwickelten Form ist sie außerdem theatralen Charakters, und zwar aus drei Gründen. Erstens muß sie öffentlich, »vor den Augen aller« vollzogen werden, damit das Ritual der Wiederherstellung des Königskörpers und des Rechts wirksam ist. Zweitens trägt die inszenierte Auseinandersetzung zwischen Körper des Verurteilten und Körper des Königs dramatische Züge, indem der "gemarterte Körper« als "Gegenspieler" des Souveräns auftritt. (ÜS 63) Drittens stellt sie eine dramatische Mimesis im Sinne Aristoteles' dar:

[D]ie Hinrichtung des Schuldigen [wird] zu einer theatralischen Wiedergabe des Verbrechens [...]: dieselben Instrumente, dieselben Gesten. In den Martern wiederholt die Justiz vor den Augen aller das Verbrechen, das sie damit in seiner Wahrheit kundtut und gleichzeitig im Tod des Schuldigen vernichtet. (ÜS 60) ${ }^{4}$

Damit ist zugleich die Funktionsweise der Marter beschrieben. Die Vernichtung des Verbrechers erfolgt in Imitation des Verbrechens und ist die Vernichtung des Verbrechens selbst. Es ist diese direkte Beziehung zwischen Verbrechen und Strafe, die die Wirksamkeit der Marter ermöglicht und garantiert: Das Verbrechen, das in der Marter bestraft wird, ist eine

3 Vgl. etwa ÜS 47, 63, 71, 119, 148, 170, 278f.

4 Vgl. Ernst Cassirer: Philosophie der symbolischen Formen II, S. 267: »Der eigentliche Akzent des sakralen Aktes aber liegt darauf, daß die Gemeinschaft als Ganzes ihn vollzieht. In den Genuß des Fleisches des Totemtieres stellt sich die Einheit des Clans und der Zusammenhang mit dem totemistischen Ahnherrn als unmittelbare, als sinnlich-körperliche Einheit wieder her: In ihm wird sie gewissermaßen aufs neue besiegelt.« 
Rechtsverletzung und damit zugleich eine körperliche Verletzung des dieses Recht verkörpernden Königs. Diese Rechtsverletzung und die Verletzung des Königskörpers werden am Körper des Verurteilten vergolten, und der Tod des Verbrechers hebt das Verbrechen selbst auf. Die Marter »kehrt das Verbrechen gegen den sichtbaren Körper des Verbrechers und wiederholt es an ihm; in ein und demselben Schrecken macht sie das Verbrechen kund und zunichte." (ÜS 73) Die Logik der Marter funktioniert demnach nach dem epistemischen Ähnlichkeitsprinzip der Renaissance, wie Foucault es in Die Ordnung der Dinge beschreibt. Die Episteme der Ähnlichkeit zeichnet sich dadurch aus, daß die Dinge untereinander ebenso wie die Wörter und Dinge als einander ähnlich bzw. einander entsprechend begriffen werden. Die Ähnlichkeit verbindet die Dinge in der Welt. Indem in der Vernichtung des Körpers des Verbrechers das Verbrechen selbst vernichtet und der Körper des Königs wiederhergestellt wird, "entspricht" die Marter also keineswegs, wie Petra Gehring meint, "präzise dem System der Repräsentation" und "fungiert" durchaus nicht "als Zeichen [...] der Sühne und Wiederherstellung des Rechts. $\aleph^{5}$ Die Marter ist gerade nicht "Zeichen" der Wiederherstellung, sondern ist diese Wiederherstellung selbst, ganz faktisch, ganz körperlich, ganz blutig.

In bezug auf Die Ordnung der Dinge spricht Ute Frietsch zu Recht von einer "verklärenden Darstellung des Wissens der Renaissance«. ${ }^{6}$ In Überwachen und Strafen liegt eben dieses "Wissen[] der Renaissance" dem Prinzip der Marter zugrunde, die Verbrechen und Strafe direkt miteinander verbindet. Diese ,Verklärung` der Episteme der Ähnlichkeit bedeutet damit auch eine Verklärung oder Idealisierung der körperlichen Marter. Indem Foucault die Marter mit der Tragödie identifiziert, läuft das Argument für die Bevorzugung der Marter gegenüber den späteren Straftechniken implizit über die Prämisse von der klassischen Bewertung der Tragödie als höchste Kunstform; die Logik der Ähnlichkeit und das Verfahren der Marter sind daher auch ästhetisch höherwertig. In der Tragödie der Marter findet sich nicht

5 Petra Gehring: Foucault - Die Philosophie im Archiv, Frankfurt a.M./New York 2004, S. 85. Der Irrtum, daß die Marter den Regeln der Repräsentation folge, mag daher rühren, daß zum einen die Episteme der Klassik, die Repräsentation, geschichtlich in das Zeitalter der Souveränität fällt und zum anderen die Marter die Strafpraxis der Souveränität ist. Auch Philipp Sarasin unterliegt diesem Irrtum (Michel Foucault zur Einführung, S. 130), wie auch Fernando Suárez-Müller die Marter fälschlicherweise mit der Repräsentation identifiziert in: Skepsis und Geschichte. Das Werk Michel Foucaults im Lichte des absoluten Idealismus, Würzburg 2004, S. 464.

6 Ute Frietsch: Die Ordnung der Dinge, S. 45. 
nur Nietzsches "Dionysische[s], mit seiner selbst am Schmerz percipierten Urlust « (GT 152), sondern auch eine Vermengung dieses Dionysischen mit dem klassizistischen Schönheitsideal: Foucault spricht von den "schönen, [den] strengen und zwingenden Figuren der Ähnlichkeit«. (OD 84) ${ }^{7}$ Als Idee der Einheit konvergiert die Ähnlichkeit offenbar mit dem seit Winckelmann geltenden Konzept klassischer Schönheit - das sich natürlich auch bei Hegel wiederfindet, dem zufolge die "Strenge« Kennzeichen des »idealischen Stils" klassischer griechischer Schönheit ist. ${ }^{8}$ (Ä II, 378) Foucaults Einschätzung der Marter steht damit einerseits noch ganz im Zeichen seines frühen nietzscheanischen Tragikkonzepts, der Tragödie als Ausdruck des Verlusts der tragischen Einheit, und schließt andererseits an die idealisierende Antikerezeption der Aufklärung und deren Tragödienbild an und macht sich deren Bewertung der Tragödie als höchste Kunstform als Argument zunutze. Seine Kritik an den die Marter ablösenden Straftechniken der Strafreformen und insbesondere der Disziplin und seine implizite Bevorzugung der blutigen Marter stützen sich demnach indirekt auch auf eine ästhetische Argumentation, was mindestens fragwürdig ist.

Das Ende der Tragödie: Körper und Blut verlassen die Bühne - die Seele tritt auf

Mit dem Abtreten des blutigen Körpers von der Strafbühne endet dieses "große Schauspiel der peinlichen Strafe« (ÜS 22f.), endet die Tragödie. Daß der Körper durch die Seele abgelöst wird, betrifft nicht nur die Vollstrekkung des Urteils selbst, sondern auch den Prozeß der Urteilsfindung. Oben ist bereits gesagt worden, es werde nicht nur der Körper als Objekt der Strafe abgelöst, sondern auch die Strafbemessung gehe auf die Seele über. Die moderne Strafbemessung, die sich nicht mehr am Verbrechen, sondern am Verbrecher orientiert, setzt voraus und führt zu dessen Psychologisie-

7 In der Syntax des Originals sind `streng` und `zwingend die Attribute der `schönen Figuren (»belles figures rigoureuses et contraignantes de la similitude« (Michel Foucault: Les mots et les choses. Une archéologie des sciences humaines, Paris 1966, S. 65), daher meine Einfügung.

8 Dieses Zitat bezieht sich auf die griechische Skulptur, die aber "Hegels Paradigma des schönen Ideals« überhaupt ist (Christoph Menke: Tragödie im Sittlichen, S. 178), was sich nicht zuletzt daran zeigt, daß Hegel die Aufführung der griechischen Tragödie als 'Belebung` von Statuen bezeichnet (vgl. Ä III, 511). 
rung. Dies drückt der Satz aus: "Die alten Mitspieler des Straf-Prunks, der Körper und das Blut, räumen den Platz. Auf die Bühne tritt eine neue Figur«. (ÜS 26) »Die Seele tritt auf die Bühne der Justiz« (ÜS 34); »[d]er Apparat der Strafjustiz hat es nun mit dieser körperlosen Realität zu tun." (ÜS 26) Diese Entwicklung erweist sich als durchaus unvereinbar mit der Tragödie. Das Ende der Tragödie der Marter liegt daher darin, daß in der reformierten Strafjustiz nicht mehr der Körper, sondern die Seele im Zentrum steht, daß in der Urteilsfindung nach der Seele des Täters statt nach seiner Tat gefragt wird. Das richterliche Urteilen verwandelt sich damit von Grund auf.

\begin{abstract}
Seitdem das Mittelalter langsam und mühselig das große Verfahren der Untersuchung aufgebaut hatte, bedeutete das Richten die Feststellung der Wahrheit eines Verbrechens, die Bestimmung seines Urhebers, die Verhängung einer gesetzlichen Sanktion. [...] Jetzt [...] ist im Urteil eine ganz andere Wahrheitsfrage enthalten: Nicht mehr bloß die Frage: »Ist die Tat festgestellt und handelt es sich um ein Vergehen?«, sondern auch die Frage: »Was ist denn eigentlich diese Tat [...]? Nicht mehr einfach: "Wer ist der Täter?«, sondern: "Wie kann man den Kausalprozeß, der zur Tat geführt hat, einordnen? Wo ist sein Ursprung im Täter selbst?« (ÜS 29)
\end{abstract}

Das "Verfahren der Untersuchung" hatte Foucault in Die Wahrheit und die juristischen Formen der Tragödie, genauer: der Tragödie des Ödipus zugeordnet. Dort geht es um die Identifikation des Täters. Der Wandel der juristischen Wahrheitsfrage, der gegen Ende des 18. Jahrhunderts stattfindet, bedeutet ein Ende dieser stragischen $<$ Untersuchung. Von nun an wird nicht mehr nach der Tat und dem objektiven Täter gefragt, wie in Ödipus, sondern nach den Hintergründen der Tat in der Seele des Täters, nach dem Zusammenhang zwischen Seele und Tat. Es geht nicht mehr um ein direktes Entsprechungsverhältnis von Verbrechen und Strafe, sondern um eine abstrakte, psychologische Beziehung von Tat und Täter.

\title{
Die Trennung der tragischen Einheit von Täter und Tat - der Verlust der Einheit des tragischen Charakters
}

Daß Foucault die Verschiebung der Strafen vom Körper auf die Seele als Ende der Tragödie bezeichnet, läßt sich tatsächlich auch tragödientheoretisch begründen. Durch die Psychologisierung des Verbrechers werden Tat und Täter voneinander getrennt, eine Differenzierung, die nicht mit der klassischen Tragödie vereinbar ist. Im berühmten Sittlichkeitskapitel der 
Phänomenologie des Geistes etwa beschreibt Hegel die griechische Sittlichkeit anhand der Tragödie. Das einzelne sittliche Bewußtsein gehört entweder dem göttlichen oder dem menschlichen Gesetz an und ist "für eins derselben entschieden«. (PG 343) Diese Entschiedenheit für eine Seite manifestiert sich in der Tat, in der sich das Bewußtsein gegen die jeweils andere Seite und gegen das andere Recht setzt. Zugleich setzt es sich selbst nach außen; »die Tat [...] ist das wirkliche Selbst«. (PG 342) Hegel identifiziert also den tragischen Charakter mit seiner Tat; der tragische Charakter ist die Einheit der Tat, ist nichts als die Tat. Dementsprechend sagt Hegel in den Vorlesungen über die Ästhetik über Ödipus, seine Tat und seine Schuld:

Das Recht unseres heutigen, tieferen Bewußtseins würde darin bestehen, diese Verbrechen, da sie weder im eigenen Wissen noch im eigenen Wollen gelegen haben, auch nicht als die Taten des eigenen Selbst anzuerkennen; der plastische Grieche aber steht ein für das, was er als Individuum vollbracht hat [...]. (

In den Grundlinien der Philosophie des Rechts bezieht sich Hegel für die Unterscheidung zwischen Vorsatz und Schuld ebenfalls auf Ödipus und die griechische Tragödie überhaupt:

Das heroische Selbstbewußtsein (wie in den Tragödien der Alten, Ödipus usf.) ist aus seiner Gediegenheit noch nicht zur Reflexion des Unterschiedes von Tat und Handlung, der äußerlichen Begebenheit und dem Vorsatze und Wissen der Umstände sowie zur Zersplitterung der Folgen fortgegangen, sondern übernimmt die Schuld im ganzen Umfange der Tat. ${ }^{9}$

Die moderne Idee einer subjektiven Unschuld bei objektiver Schuld steht also der Idee der tragischen Schuld entgegen. Die Berücksichtigung der Umstände der Tat läßt die Tragödie des Ödipus unmöglich werden; die »Gediegenheit" und die 'Plastizität des Charakters in der klassischen Tragödie geht verloren, die Einheit des tragischen Charakters zerbricht. Hegel zufolge läßt die Tragödie mithin keinen Raum für eine »Trennung des Subjekts als solchen und seines Inhalts«, d.h. für eine Trennung von Täter und Tat, wie sie die moderne Urteilsfindung praktiziert: Die tragischen Charaktere »sind das, was sie sind, und ewig dies, und das ist ihre Größe«. (Ä III, 546) Dagegen besteht die fehlende Tragik in den modernen Tragödien in ihrem »Mangel an innerer substantieller Gediegenheit des Charakters«. (Ä I, 314)

9 G.W.F. Hegel: Grundlinien der Philosophie des Rechts (= Werke, Bd. 7), Frankfurt a.M. 1986, §§ 115-118, hier $\S 118$, S. 219. 
Bei Foucault findet sich dieser Gedanke bereits in Wahnsinn und Gesellschaft: Er beschreibt dort, daß»das Verbrechen aufhörte[], nur autochthone Werte zu haben und nur in Beziehung zu sich selbst zu bestehen«, und man statt dessen versuchte, "[d]ie Verkettung von Erbschaften, der Vergangenheit, der Motivationen zu erkennen«. Das »Verbrechen [hat] seine wirkliche Dichte verloren «; die "Kriminalität verliert den absoluten Sinn und die Einheit, die sie in der vollzogenen Geste, in der begangenen Schuld annahm«. (WG 469) Mit Blick auf Hegel könnte man formulieren: Die Kriminalität verliert ihre tragische Einheit, ihre Tragik. Auf diese Weise führen die oben beschriebenen Varianten des tragischen Übergangs vom Körper zur Seele und vom Mythos zum Logos - psychologische Gutachten, mildernde Umstände und Strafunfähigkeit ${ }^{10}$ - zum Ende der Tragödie. Wenn Foucault also vom Ende der Tragödie der Marter spricht, dann tut er das mit durchaus gezieltem Bezug auf den Diskurs vom Ende der Tragödie und auf die diesem eigene Argumentation. Wie der tragische Charakter ist auch der gemarterte Verbrecher im Rechtssystem der Souveränität nichts als seine Tat; er ist der Königsmörder, ${ }^{11}$ ist der Königsmord. Und wie die Tragödie beziehen sich auch die Martern auf den ganzen oder, wie Hegel im Zusammenhang mit der griechischen Tragödie stets schreibt, den "gediegenen" oder "plastischen" Charakter ${ }^{12}$ und d.h. auf die Tat. Ganz so, wie in der Tragödie eine der beiden Konfliktparteien vernichtet werden muß, um den tragischen Konflikt zu lösen, muß daher in der Marter mit dem Körper des Verbrechers auch seine Tat vernichtet werden. Die Martern also entsprechen in ihrer Struktur und Funktionsweise der Tragödie. Psychologisierung und Individualisierung der Figuren dagegen leiten das Ende der Tragödie ein, ${ }^{13}$ ebenso wie mit der Seele, die die "Bühne der Justiz« betritt, d.h. mit der Psychologisierung des Verbrechers, auch die Marter, die Tragödie des Strafens zu Ende geht.

10 Vgl. etwa WG 462, 546, 548; HF [1972] 650; WjF 83; ÜS 27, $29 f$.

11 „Man muß die Marter in ihrer Ritualisierung bis ins 18. Jahrhundert als politischen Faktor verstehen. Sie fügt sich logisch in ein Strafsystem ein, in welchem direkt oder indirekt der Souverän selbst Anklage erhebt, das Urteil fällt und die Strafen vollstrekken läßt, da über das Gesetz er selbst durch das Verbrechen angegriffen worden ist. In jedem Vergehen steckt ein crimen majestatis, und noch im geringsten Verbrecher ein kleiner potentieller Königsmörder.« (ÜS 71)

12 Vgl. PG 354; ̈̈ I, 312, 314; Ä III, 527, 545; PhR S. 219.

13 Vgl. dazu Kap. V, Unterkap. "Die komische Maske (III): Kodifizierung und Typisierung, Individualisierung und Psychologisierung«. 


\section{Die Komödie der reformierten Strafen und das Ende des Dramas}

All dies führt zu einem weiteren Schritt: Die Psychologisierung des Verbrechers und der damit verbundene Verlust der Einheit von Täter und Tat sind in Überwachen und Strafen nämlich ein Grund nicht nur für das Ende der Tragödie des Strafens, sondern auch, konkreter, für ihre Ablösung durch die Komödie. Noch einmal:

Die alten Mitspieler des Straf-Prunks, der Körper und das Blut, räumen den Platz. Auf die Bühne tritt eine neue Figur - maskiert. Eine gewisse Tragödie ist zu Ende, es beginnt eine Komödie mit schattenhaften Silhouetten, gesichtslosen Stimmen, unbetastbaren Wesen. (ÜS 26)

Schlagwortartig und wie nebenbei ruft Foucault den Topos vom Ende der Tragödie und ihrer Ablösung durch die Komödie sowie eine ganze Reihe zentraler Punkte des tragödien- und komödientheoretischen Diskurses auf, ohne sie näher zu verfolgen - jedenfalls nicht explizit. Darüber hinaus liest sich diese kurze Passage wie ein indirektes und etwas eklektisches Zitat von Gattungsbezügen nicht nur bei Hegel, sondern auch bei Marx und - etwas entfernter - Nietzsche. Im Folgenden wird gezeigt, daß die Unterscheidung von Tragödie und Komödie, bei allem Eklektizismus, eine gezielte Unterscheidung ist. Zwar bestimmt Foucault die Komödie nicht explizit und systematisch, sondern implizit und verstreut, und die Elemente der Bestimmung überschneiden sich und gehen ineinander über. Dennoch weist er der Komödie spezifische Eigenschaften, Funktionen und Techniken zu. Er ordnet sie historisch ein, bestimmt sie als didaktische Gattung, betrachtet sie unter zeichentheoretischen Gesichtspunkten, weist ihr eine rechtstheoretische und praktische rechtliche Funktion zu und bestimmt sie inhaltlich über ihr Figureninventar sowie dramaturgisch über ihre Blickführung.

Die Komödie in den Dramentheorien und die Bestrafung in den Straftheorien der Aufklärung

Zunächst einmal ist der Übergang, den Foucault unter Zuhilfenahme der Kategorien von Tragödie und Komödie beschreibt, historisch verortbar. Er findet mit der Aufklärung und infolge der auf Cesare Beccaria und andere zurückgehenden strafrechtsreformatorischen Überlegungen des 18.Jahr- 
hunderts statt. Mit der Reform des Strafrechts verwandelt sich Foucaults tragische Justizbühne in eine komische Justizbühne.

In der dramentheoretischen Diskussion der Aufklärung ist der Nutzen des Schauspiels und insbesondere der der Komödie von zentraler Bedeutung. Johann Christoph Gottsched schreibt 1730 in seinem Versuch einer Critischen Dichtkunst: "Die Comödie ist nichts anders, als eine Nachahmung einer lasterhaften Handlung, die durch ihr lächerliches Wesen den Zuschauer belustigen, aber auch zugleich erbauen kann. ${ }^{1}$ Denis Diderot, auf den sich Foucault in seinen Texten wiederholt bezieht, schreibt 1758 in Von der dramatischen Dichtkunst: "Ein jedes Volk hat Vorurteile zu bestreiten, Laster zu verfolgen, Lächerlichkeiten verächtlich zu machen. Ein jedes Volk muß also Schauspiele [...] haben." Aus der Notwendigkeit moralischer Besserung leitet Diderot also die Notwendigkeit von Schauspielen ab. In seiner Unterscheidung der dramatischen Gattungen ${ }^{2}$ hat die »ernsthafte Komödie« »die Tugend und die Pflichten des Menschen zum Gegenstande $\aleph^{3}$ und die Aufgabe, »uns die Tugend liebenswürdig und das Laster verhaßt zu machen«;4 Diderot spricht also insbesondere ihr die Fähigkeit zum Bewirken moralischer Besserung zu. Auch die von Diderot herausgegebene und mitverfaßte Encyclopédie bezeichnet als »'objet ou la fin de la comédie« »de faire servir la malice humaine à corriger les autres vices de l'humanité«. ${ }^{5}$ Wie Diderot, dessen »Unterredungen« über den Natürlichen Sohn er ins Deutsche über-

1 Johann Christoph Gottsched: Versuch einer Critischen Dichtkunst. Anderer Besonderer Theil (= Ausgewählte Werke, hg. von Joachim Birke und Brigitte Birke, Berlin/ New York 1968-1987, Bd. 6.2), Berlin 1973, S. 348.

2 Diderot schlägt Abstufungen der dramatischen Gattung zwischen Tragödie und Komödie vor. Zwischen Tragödie und Komödie soll die "ernsthafte Gattung" stehen, zwischen »ernsthafter Gattung « und Tragödie das "Trauerspiel « und zwischen "ernsthafter Gattung und Komödie die »ernsthafte Komödie«. Es ist nicht eindeutig, ob Diderot damit fünf dramatische Untergattungen vorsieht oder vier, wobei in letzterem Fall »Trauerspiel« und »ernsthafte Komödie« gemeinsam unter die »ernsthafte Gattung « fielen. Denis Diderot: Von der dramatischen Dichtkunst, in: Ästhetische Schriften, übers. von Friedrich Bassenge und Theodor Lücke, Bd. 1, Frankfurt a.M. 1968, S. 239-333, hier S. 245f.

3 Ebd., S. 246.

4 Ebd., S. 250.

5 Jean-François Marmontel: Comédie, in: Encyclopédie ou Dictionnaire raisonné des sciences, des arts et des métiers, hg. von Denis Diderot u.a., Bd. 3, Paris 1753, S. 665-669. Hier geht es nicht um die comédie in der im Französischen weiteren Bedeutung des Schauspiels überhaupt, sondern spezifisch um die Komödie im Gegensatz zur Tragödie: »Elle differe particulierement de la tragédie dans son principe, dans ses moyens \& dans sa fin.« (Ebd., S. 665) 
setzte, ${ }^{6}$ stellt Lessing in seinen Abhandlungen von dem weinerlichen oder rührenden Lustspiele (1754) der Tragödie bzw. dem Trauerspiel und der Komödie bzw. dem Lustspiel zwei neue »Untergattung[en] ${ }^{7}$ zur Seite: das »bürgerliche Trauerspiel« und das "rührende« bzw. "weinerliche Lustspiel«. ${ }^{8}$ Das "rührende Lustspiel « "will nur rühren", so wie, als anderes Extrem, das »Possenspiel« »nur zum Lachen bringen will«. Zwischen diesen beiden aber steht die "wahre Komödie«. Sie "will beides", also rühren und zum Lachen bringen. "Die wahre Komödie allein" - und hier greift Lessing den zeitgenössischen Diskurs über die nützliche Funktion der Komödie auf - »ist für das Volk, und allein fähig einen allgemeinen Beifall zu erlangen, und folglich auch einen allgemeinen Nutzen zu stiften." Dieser »allgemeine[ ] Nutzen« besteht in »Beßrung «. ${ }^{9}$ In der Hamburgischen Dramaturgie (1767-1769) hält Lessing dementsprechend fest: "Die Komödie will durch Lachen bessern «. ${ }^{10}$ Und vermag sie nicht zu »bessern", so ist ihre Aufgabe, vorzubeugen: "Ihr ist genug, wenn sie keine verzweifelte Krankheit heilen kann, die Gesunden in ihrer Gesundheit zu befestigen. [...] Ein Präservativ ist auch eine schätzbare Arznei; und die ganze Moral hat kein kräftigers, wirksamers, als das Lächerliche. ${ }^{11}$ In der Aufklärung verfolgt die poetologische Theoriebildung zum französischen Rührstück und seinen Verwandten, zu Diderots "ernsthafter Komödie«, Lessings "wahrer Komödie« und anderen Untergattungen, demnach weitgehend wirkungs- und rezeptionsästhetische Argumente. ${ }^{12}$ Dasselbe tut die juristische Theoriebildung dieser Zeit: Wirkungs- und

6 Vgl. Gotthold Ephraim Lessing: Theater des Herrn Diderot. Vorrede des Übersetzers, in: Werke, hg. von Herbert G. Göpfert, München 1973, Bd. 4, S. 147-151; Denis Diderot: Dorval und ich [frz.: Entretiens sur le fils naturel], in: Ästhetische Schriften, Bd. 1, S. 159-238. Der Titel Dorval und ich stammt von den Übersetzern.

7 Gotthold Ephraim Lessing: Abhandlungen von dem weinerlichen oder rührenden Lustspiele, in: Werke, Bd. 4, S. 12-58, hier S. 57.

8 Ebd.

9 Ebd.

10 Ders.: Hamburgische Dramaturgie, in: Werke, Bd. 4, S. 231-707, hier S. 363.

11 Ebd.

12 Der poetologischen Beschreibung und Entwicklung neuer dramatischer Untergattungen entspricht die strafrechtstheoretische Differenzierung und Festschreibung der Gattungen und Untergattungen von Verbrechen und Strafen im 18. Jahrhundert. Die Gattungstheorien der Aufklärung versuchen u.a., das rührende Lustspiel bzw. die ernste Komödie innerhalb der Gattungspoetik als Untergattungen zu ’legitimieren (vgl. Ulrich Profitlich: Von der frühen Aufklärung bis zur Weimarer Klassik, in: ders. [Hg.]: Komödientheorie. Texte und Kommentare. Vom Barock bis zur Gegenwart, Reinbek bei Hamburg 1998, S. 35-42, hier S. 35, 40), und zwar mit Blick auf ihre 
Rezeptionsästhetik der Komödie haben ihr Pendant im Zweck der Belehrung und Besserung der reformierten Strafen, die »auf den Geist der Straffälligen wirken" sollen (ÜS 150) und die den Regeln des belehrenden Schauspiels und »ernsthaften Theaters" (»théâtre sérieux") (ÜS 146; SP 133) folgen. Das »Theater der Züchtigungen« (ÜS 135) stimmt in dieser Hinsicht also mit Diderots "genre sérieux" bzw. seiner »ernsthaften Komödie«, der "comédie sérieuse« überein. Wie Diderot das Schauspiel als eine »Art[ ] des öffentlichen Unterrichts" betrachtet, ${ }^{13}$ schreibt Foucault über die reformierten Strafen, in Abgrenzung zu den Martern: »Die Züchtigungen sollten eher eine Schule sein als ein Fest«. (ÜS 143) Lessings »Präservativ« der Komödie entspricht der Prävention der reformierten Strafen. Komödientheorien und Straftheorien des 18. Jahrhunderts sind eng verwandt.

\section{Die Lektion der reformierten Strafen}

In diese implizite diskursgeschichtliche Argumentation, der zufolge der komödienpoetische Diskurs und der strafrechtstheoretische Diskurs der Aufklärung konvergieren, gehört noch ein drittes Element: der epistemische Diskurs. Zuvor wurde die These formuliert, daß die in Die Ordnung der Dinge beschriebenen Epistemen den in Überwachen und Strafen untersuchten Strafformen korrespondieren. Daß die Martern der Episteme der Ähnlichkeit folgen, ist bereits gezeigt worden. Das Ende der Tragödie der Marter bedeutet damit auch das Ende der smythischen schen Verbrechen und Strafe, also den Übergang vom Mythos zum Logos, vom Blut zum Zeichen, vom Körper zur Seele, von der Episteme der Ähnlichkeit zu der der Repräsentation. ${ }^{14}$

nützliche Wirkung. Das gleiche gilt für die Strafrechtstheorien der Aufklärung: Sie versuchen, die neue Form der Bestrafung zu legitimieren - ebenfalls unter Verweis auf ihre nützliche Wirkung. Es handelt sich also zum einen um den Versuch einer Legitimierung der rührenden Komödie innerhalb der Gattungspoetik und zum anderen um den Versuch einer Legitimierung der Strafgewalt innerhalb des Strafrechts (als Nachweis ihrer Gesetzmäßigkeit).

13 Denis Diderot: Von der dramatischen Dichtkunst, S. 308f.

14 Dieser Übergang (vom Mythos zum Logos, vom Blut zum Zeichen, vom Körper zur Seele) als die Ablösung der Marter durch die Guillotine und schließlich durch das Gefängnis ist oben als Beleg für die tragische Struktur der Subjektwerdung in Überwachen und Strafen insgesamt angeführt worden, und es wurde gesagt, die Tragödie inszeniere eben diesen Übergang - woraus folgen würde, daß die Tragödie erst mit 
Während in der Renaissance Wörter und Dinge einander ähnlich sind bzw. einander entsprechen, haben die Wörter in der Klassik keine direkte Verbindung mehr zu den Dingen und bilden ein eigenes, in sich geschlossenes Feld. Dies gilt auch für die Strafpraxis: Während Verbrechen und Strafe einander in den Martern entsprechen, stehen die Strafen in den Reformkonzepten des späten 18. Jahrhunderts nicht mehr in direkter und körperlicher Beziehung zum Verbrechen. Das bedeutet auch, daß der Körper des Verurteilten nicht mehr spiegelbildlich zu dem Schaden, den er dem Körper des Souveräns durch seinen Rechtsbruch zugefügt hat, bestraft wird. Er ist nicht mehr durch Ähnlichkeit mit dem Verbrechen verbunden, so daß durch die Vernichtung dieses Körpers nicht mehr das Verbrechen selbst vernichtet werden kann. Es geht in den Strafen nämlich nicht mehr um den Körper des Verbrechers und den des Königs, nicht mehr um das Recht des Souveräns, sondern um das Recht der Gesellschaft. Dieses neue Recht der Gesellschaft basiert auf dem Gesellschaftsvertrag, und es ist dieser Gesellschaftsvertrag, den der Rechtsbrecher verletzt. In der reformierten Bestrafung soll daher nicht der Körper des Königs, sondern die Geltung des Gesellschaftsvertrags und der damit verbundenen Gesetze wiederhergestellt werden. "In der Bestrafung ist nicht mehr der Souverän gegenwärtig, die Gesetze selber werden lesbar." (ÜS 141) Die körperliche Wirksamkeit der Marter wird durch eine zeichenhafte Lesbarkeit der reformierten Strafen ersetzt. Zum Zwecke dieser "Zeichentechnik« (ÜS 127) wird die Strafgesetzgebung gemäß dem epistemischen Prinzip der Repräsentation entworfen und basiert auf der Aufstellung einer »Taxonomie der Arten« von Verbre-

dem vollzogenen Übergang zu Ende wäre. Genau diesen tragischen Übergang selbst bezeichnet Foucault hier nun aber als das Ende der Tragödie. Wenn es also heißt, mit dem Abtreten des Körpers sei die Tragödie zu Ende, greift auch hier wieder die bereits aus Wahnsinn und Gesellschaft bekannte und oben im Zusammenhang mit Nietzsches Geburt der Tragödie beschriebene widersprüchliche Doppeldeutigkeit der Tragik als tragischer Zustand einer- und tragischer Trennung andererseits. Das Tragische, als Zustand, ist an die Körperlichkeit gebunden, während die Ablösung von der Körperlichkeit ein Ende des Tragischen bedeutet, dabei zugleich aber selbst erst der Vollzug des seinerseits tragischen Übergangs vom Mythos zum Logos ist, vom mimetischen Abbild zum Zeichen (vgl. Cassirers Übergang von einer "naiven Abbildtheorie der Erkenntnis « zu einer 'Symboltheorie in: Ernst Cassirer: Philosophie der symbolischen Formen I, S. 3), vom Körper zur Seele. Genaugenommen müßte man sogar drei Ebenen unterscheiden: Zum einen steht das Tragische auf der Seite des Mythos, als dem Körperlichen, zum anderen vollzieht die Tragödie selbst den Übergang vom Mythos zum Logos, und zum dritten bedeutet erst die Ablösung der Tragödie diesen Übergang als vollzogenen. Zum tragischen Ende der Tragödie vgl. GT 75. 
chen und Strafen. (ÜS 127) Foucault zitiert aus einem strafrechtsreformatorischen Text aus dem Jahre 1784, wonach das »Tableau aller Gattungen von Verbrechen [...] so beschaffen sein [muß], daß es auf ein anderes Tableau, nämlich das der Strafen, abgestimmt ist und die beiden einander genau entsprechen." (ÜS 127) Die »Semiotik des Strafsystems" (ÜS 125) und seine »Kodifizierung "(ÜS 126) gewährleistet also die Ablesbarkeit des Gesetzes in der Strafe. Dabei spielt Foucault mit dem Begriff des Codes und macht sich dessen zweifache Bedeutung als Regel der Verknüpfung von Zeichen einerseits und als Strafgesetzbuch andererseits zunutze, um klassische Episteme und reformiertes Strafrecht zu parallelisieren. ${ }^{15}$ Die Kodifizierung des Strafrechts bedeutet damit zweierlei: zum einen eine Rechtsetzung durch Verschriftlichung und zum anderen die strukturelle Anpassung dieser Verschriftlichung an die Episteme des klassischen Zeitalters, die Repräsentation. Schrift statt Körper, Zeichen statt Blut. Die Struktur, die den strafrechtlichen Code in eine "Taxonomie" ordnet und als »Tableau « faßt (ÜS 127) - das Projekt der Strafrechtsreformer -, ist die Grundlage für die "Zeichentechnik der Bestrafungen" (ÜS 131), die die Ablesbarkeit des Gesetzes in der Strafe regelt. Die Schriften der Strafrechtsreformer heben die direkte materielle Beziehung zwischen Verbrechen, Strafe und Körper weitgehend auf und knüpfen statt dessen eine Zeichenbeziehung zwischen Verbrechen, Strafe und Gesetz, genauer: Gesetzestext. Sie errichten eine Ordnung der Strafzeichen, in der die Strafe nicht mehr dem Verbrechen entspricht oder ähnlich ist, sondern das Gesetz repräsentiert. Wie die Sprache der Klassik nicht mehr mit den - körperlichen Dingen verbunden ist, bezieht und richtet sich die reformierte Strafe nicht mehr direkt auf den Körper, und wie in der Sprache der Klassik Dinge und Wörter oder Zeichen getrennt sind, die Sprache also reines Zeichen ist, sind auch die neuen Strafen reine Zeichen, die der Schuldige »von sich gibt«. (ÜS 141) Verbrechen und Strafe sind nun nicht mehr durch eine Ähnlichkeitsbeziehung miteinander verbunden, sondern über ein Repräsentations- und Zeichenverhältnis aufeinander bezogen - das sich allerdings weiterhin gewisser Ähnlichkeiten bedient, wie das auch für die Episteme der Klassik überhaupt gilt (vgl. OD 102f.). Insbesondere die körperlichen Strafen weisen zum Teil weiterhin Ähnlichkeit mit dem jeweiligen Verbrechen auf, so daß Verbrechen und Strafe zwar noch durch »eine Verbindung von Gleich-

15 Eine Doppeldeutigkeit, die Seitter in seiner Übersetzung gelegentlich deutlich macht, indem er das französische »Code« durch "Codex/Code« übersetzt. (ÜS 142, 145) 
heit, Analogie, Ähnlichkeit« verknüpft sind (ÜS 134), diese Ähnlichkeit jedoch keine körperliche mehr ist, sondern eine zeichenhafte. "Die ideale Bestrafung wird auf das von ihr sanktionierte Verbrechen hin vollkommen transparent sein. Für den, der sie betrachtet, wird sie unfehlbar das Zeichen des bestraften Vergehens sein." (ÜS 134) Das ist die Tableaustruktur, die Foucault in Die Ordnung der Dinge beschreibt.

Jetzt ist der Träger des Exempels die Lektion, der Diskurs, das lesbare Zeichen, die Inszenierung und Abbildung [la mise en scène et en tableau; Gw.E.] der öffentlichen Moralität. Die Zeremonie der Züchtigung beruht nicht mehr auf der schreckenerregenden Wiederherstellung der Souveränität, sondern auf der Wiedereinsetzung des Strafgesetzbuches [du Code; Gw.E.], auf der kollektiven Festigung des Bandes zwischen der Idee des Verbrechens und der Idee der Strafe. In der Bestrafung ist nicht mehr der Souverän gegenwärtig, die Gesetze selber werden lesbar. [...] Sobald nun ein Verbrechen begangen worden ist, tritt unverzüglich die Bestrafung ein, die den Diskurs des Gesetzes verwirklicht und beweist, daß der Code, der die Ideen verbindet, auch die Wirklichkeit verbindet. Der unmittelbaren Verknüpfung im Text muß eine unmittelbare Verknüpfung in den Taten entsprechen. [...] Die öffentliche Bestrafung ist die Zeremonie der unmittelbaren Recodierung. ${ }^{16}$ (ÜS 141f.; SP 130)

Es geht nicht mehr um den Souverän, sondern um die Gesetze, und nicht mehr um körperliche Gegenwärtigkeit, sondern um Lesbarkeit - um die Lesbarkeit des Strafgesetzbuches oder besser: des Codes. Das Gesetz ist, in seiner Kodifizierung, in der Strafe lesbar, und zwar ganz nach den epistemischen Regeln der Repräsentation. Zwar haben auch die Martern "zeichenhafte Bedeutung «, doch ist der Schmerz des Verurteilten »vieldeutig und kann sowohl die Wahrheit des Verbrechens wie den Irrtum der Richter, die Güte oder die Bosheit des armen Sünders, die Übereinstimmung oder den Gegensatz zwischen dem menschlichen und dem göttlichen Urteil bedeuten."(ÜS 62) Das Urteil, das in der Marter vollstreckt wird, muß also interpretiert werden - wie die Ähnlichkeiten in der Welt der Renaissance. Dagegen offenbart sich das Gesetz, in der Eindeutigkeit des Gesetzestextes, in der reformierten Strafe. Wie gesagt: Es ist nicht die Marter, die "präzise dem System der Repräsentation" entspricht (Gehring), sondern vielmehr die reformierte Strafe des 18. Jahrhunderts. Die Parallelisierung funktioniert insbesondere durch die erwähnte Doppeldeutigkeit des Code-Begriffs. Der Code als Sprach- oder Wissenscode verknüpft die Ideen; der Code als

16 Übersetzung des letzten Satzes verändert, Gw.E. (»La punition publique est la cérémonie du recodage immédiat.« [SP 130]). 
Gesetzbuch verknüpft die Wirklichkeit des Verbrechens mit der Wirklichkeit der Strafe.

In den Abschreckungsstrafen also »ist der Träger des Exempels die Lektion, der Diskurs, das lesbare Zeichen, die Inszenierung und Abbildung der öffentlichen Moralität.« (ÜS 141) Die »Lektion« als zu lernende moralische Lektion, die das Strafschauspiel erteilt, trifft mit der »Lektion" als lectio, als Lesen, zusammen, und tatsächlich werden die reformierten Strafen von schriftlichen Erläuterungen begleitet:

Anschlagzettel, Schrifttafeln, Zeichen, Symbole müssen in großer Zahl jedem die Bedeutung des Geschehens erklären. Die Öffentlichkeit der Bestrafung darf keine physische Schreckenswirkung verbreiten; sie muß ein Buch aufschlagen, das zu lesen ist. [...] Diese lesbare Lektion, ${ }^{17}$ diese rituelle Recodierung, muß so oft wie möglich wiederholt werden. Die Züchtigungen sollten eher eine Schule sein als ein Fest, eher ein ständig aufgeschlagenes Buch als eine Zeremonie. (ÜS 142f.)

Mit "Exempel« und »Lektion« der reformierten Strafen ${ }^{18}$ fallen Stichwörter, die auch wieder auf die Komödie der Aufklärung verweisen. Diese soll nützen, belehren, bessern; sie inszeniert eine Lektion und "präsentier[t] «, so Ulrich Profitlich, "moralische Exempel«. ${ }^{19}$ Und in der Tat erweist sich die »Zeichentechnik « (ÜS 131) der reformierten Strafen, die dafür sorgt, daß in ihnen das Gesetz "ablesbar" (ÜS 141) ist, nun zugleich als eine dramatische Technik. In der Komödie der Bestrafung liest der Zuschauer das Tableau der Gesetze und der Strafen. Auf diese Weise laufen nicht nur reformierte Strafen und Repräsentation sowie, wie zuvor gezeigt wurde, reformierte Strafen und Komödie zusammen, sondern, folgerichtig, auch Repräsentation und Komödie.

17 Seitter übersetzt »sichtbare Lektion«, Foucault schreibt »leçon lisible«. (SP 131)

18 Foucault erweist sich in dieser Hinsicht als ein Vorläufer der sogenannten Law-andLiterature-Bewegung. In diesem Punkt stellt sich die Problematik möglicher subjektoder geschichtsphilosophischer Implikationen des Gattungsdiskurses (siehe dazu Teil III dieser Arbeit) nicht, weil die Parallelen zwischen Dramentheorie und Rechtstheorie hier eindeutig nicht spekulativer, subjekt- oder geschichtsphilosophischer, sondern diskursanalytischer Natur sind.

19 Ulrich Profitlich: Von der frühen Aufklärung bis zur Weimarer Klassik, S. 35. 


\section{Die Komödie der Repräsentation}

Foucaults Beschreibung der reformierten Strafen als "Inszenierung und Abbildung der öffentlichen Moralität«, im Original: "la mise en scène et en tableau" (SP 130), spielt daher noch auf eine andere Bedeutung von 'Tableau an: nicht nur auf das wissenschaftliche Tableau, sondern auch auf das dramatische Tableau, das Diderot in seiner Dramentheorie entwikkelt. ${ }^{20}$ Bei Diderot geht es dabei um das Tableau als Gemälde und als Bühnengemälde, also um die Verknüpfung von Malerei und Schauspielkunst. ${ }^{21}$ Hierauf ebenso wie auf die Mode der Tableaux vivants im 18. Jahrhundert überhaupt verweist Foucault, wenn er die zahlreichen Exempel, die in der "Straf-Gesellschaft" "vorgestellt" werden, als »lebende[ ] Bilder[ ] ("scènes vivantes«) (ÜS 145; SP 133) oder »lebende Lektion" (»leçon vivante«) (ÜS 144; SP 132) bezeichnet. Foucault verknüpft also das Paradigma der Episteme der Repräsentation, das Tableau des Wissens, mit der Inszenierung im Wortsinne des Schauspiels, der Bühnenaufführung: "Jetzt ist der Träger des Exempels die Lektion, der Diskurs, das lesbare Zeichen, die Inszenierung und Abbildung [la mise en scène et en tableau; Gw.E.] der öffentlichen Moralität." Mit dieser Ineinssetzung von epistemischem Tableau und dramatischem Tableau schließt sich der Kreis der komödientheoretischen Argumentation, die Foucaults Darstellung der reformierten Strafen implizit zugrunde liegt. Dabei macht Foucault sich die Mehrdeutigkeit des französischen Wortes représentation zunutze, das neben der spezifischen Bedeutung, die er ihm zur Bezeichnung der epistemischen Strukturen des klassischen Zeitalters und der Aufklärung gibt (und die in der deutschen Übersetzung mit "Repräsentation" wiedergegeben wird), auch die szenische Aufführung, die Theatervorstellung bedeutet. ${ }^{22}$ Auf

20 Denis Diderot: Dorval und ich, S. 172f., 217f. Vgl. dazu Peter Szondi: Die Theorie des bürgerlichen Trauerspiels im 18. Jahrhundert, Frankfurt a.M. 1977, Kap. II: »Denis Diderot: Theorie und dramatische Praxis», S. 91-147; zum Tableau S. 100, $114 \mathrm{ff}$.

21 Vgl. dazu Annette Graczyk: Das literarische Tableau zwischen Kunst und Wissenschaft, München 2004, Kap. II: "Stillgestellte Szenen: Diderots Transfer des Tableaus von der Malerei ins Theater", S. 77-116.

22 Seit Erika Fischer-Lichtes Semiotik des Theaters, Tübingen 1983, sind zahlreiche Publikationen zu Repräsentation und Performativität des Theaters erschienen; vgl. etwa dies. (Hg.): Theatralität und die Krisen der Repräsentation, Stuttgart/Weimar 2001. Trotz einiger Verweise auf Foucault wird dort die Beziehung von Repräsentation im Sinne Foucaults und dem Theater nicht näher in den Blick genommen. 
der Bühne der reformierten Strafen wird also ein dramatisch-epistemisches Tableau in Form der Komödie gespielt. Wie funktioniert diese im zweifachen Sinne verstandene Repräsentation, und wieso entspricht sie der Komödie?

Diderots Konzeption des Tableaus bezieht sich auf das Schauspiel im allgemeinen und nicht auf die Komödie im besonderen. Foucault dagegen konzipiert das - epistemische und dramatische - Tableau und seine Repräsentation als Komödie, und das Komische liegt dabei in der Struktur der Repräsentation selbst, wie Foucault sie in der Ordnung der Dinge beschreibt: Das Wissen der Renaissance ist ternär organisiert; es gibt Zeichen, Bezeichnetes und, als drittes, die Ähnlichkeit, die Zeichen und Bezeichnetes miteinander verbindet. Das epistemische Repräsentationssystem des klassischen Zeitalters dagegen funktioniert binär; es gibt Zeichen und Bezeichnetes, doch keine Verbindung zwischen diesen beiden. Das Zeichen wird nur dadurch zu dieser »reine[n] Dualität«, »daß es unter anderem die Beziehung manifestiert, die es mit dem verbindet, was es bezeichnet. Es muß repräsentieren, aber diese Repräsentation muß ihrerseits in ihm repräsentiert sein." Diese Eigenschaft nennt Foucault verdoppelte oder "reduplizierte Repräsentation«. (OD 98)

Am Anfang des siebzehnten Jahrhunderts [...] hört das Denken auf, sich in dem Element der Ähnlichkeit zu bewegen. [...] Es ist die privilegierte Zeit des trompe-l'œil, der komischen Illusion, des Theaters, das sich verdoppelt und ein Theater repräsentiert, des Quiproquo, der Träume und Visionen. (OD 83)

Foucault stellt hier eine direkte Beziehung zwischen der für die Episteme der Repräsentation charakteristischen Dopplung, dem Komischen und dem Theater her. Das Komische der »komischen Illusion" besteht dabei darin, daß sie ihren Illusionscharakter offenlegt und die Illusion bricht, ähnlich wie in der Komödie die Parabase oder das Spiel im Spiel:23 ein »Theater[], das

23 Ralf Simon bezeichnet das Spiel im Spiel als "Gattungskonstituens« der Komödie. Ralf Simon: Vorwort. Theorie der Komödie - Poetik der Komödie, in: ders. (Hg.): Theorie der Komödie - Poetik der Komödie, Bielefeld 2001, S. 7-12, hier S. 8. Vgl. Bernhard Greiner: Die Komödie. Eine theatralische Sendung: Grundlagen und Interpretationen, Tübingen 1992, S. 6ff. 
sich verdoppelt und ein Theater repräsentiert«. ${ }^{24}$ In dieser Transparenz ihres Zeichencharakters und dem verdoppelnden Herausstellen ihrer eigenen Verweisungsstruktur (Spiel im Spiel) erweist sich die Episteme der Repräsentation als strukturell selbstreflexiv und funktioniert wie eine Komödie. Auch das "Quiproquo« ist, als komische Verwechslung von Figuren, ein typisches Element der Komödie. Diesen Anspielungen auf die Repräsentation als Komödie stellt Foucault sogleich kontrastierend die "schönen, strengen und zwingenden Figuren der Ähnlichkeit« (OD 84) entgegen, die der klassischen Ästhetik der Tragödie angehören.

\section{Der Schauspieler als Zeichen statt als Körper}

Die strukturell komische Dopplungsstruktur der Repräsentation spiegelt sich auch im Schauspielcharakter der Komödie der reformierten Strafen wider, der sich von dem der Tragödie der Marter wesentlich unterscheidet. Zwar hatte Foucault zu Beginn von Überwachen und Strafen geschrieben: »Das Verschwinden der Martern ist also das Ende des Schauspiels, es ist aber auch die Lockerung des Zugriffs auf den Körper.« (ÜS 17f.) Die Aussage vom Ende des Schauspiels schränkt er aber an späterer Stelle ein und präzisiert: "Der Körper verschwindet als Subjekt der Strafe, aber nicht unbedingt als Element in einem Schauspiel."(ÜS 121) Für die Strafen des reformjuristischen Konzepts ist ihr Schauspielcharakter also weiterhin von zentraler Bedeutung. Nicht nur die Todesstrafe wird nach wie vor öffentlich vollzogen, sondern auch die anderen reformierten Strafen (Schande, Demütigung) sind entschieden öffentlichen Charakters, und zwar weil ihre praktische Zielsetzung die Abschreckung und Belehrung der Bevölkerung ist. Es geht in der reformierten Bestrafung zwar nicht mehr um den Körper des Verbrechers, sondern um das Publikum, das belehrt wird, doch bedarf es zur dramatischen Vermittlung dieser "Lektion« weiterhin des Körpers, der körperlichen Anwesenheit, des Verbrechers. Die Wirkung des Strafschauspiels auf das Publikum setzt die wirkliche Bühnenpräsenz des Schauspielers

24 Eine ganz ähnliche Strukturbeziehung zwischen Komödie und Dopplung sieht Greiner in seiner Monographie über die Komödie. Zwar sagt er, "[i]m Prinzip der Dopplung erschließt sich das Wesen des Theaters" (ebd., S. 5), also das Wesen von Tragödie und Komödie gleichermaßen, doch gelte das für die Komödie in höherem Maße als für die Tragödie. Vgl. dazu genauer ebd., S. $6 f$. 
voraus. Die erforderliche Lesbarkeit der zu lernenden Lektion begründet daher die Eigenschaft des Bestraften, Schauspieler und als solcher Zeichen zu sein. "Nicht die körperliche Wirklichkeit ${ }^{25}$ der Strafe also muß auf ein Höchstmaß gesteigert werden, sondern die Vorstellung davon." (ÜS 121) "Vorstellung« übersetzt hier das französische "représentation«, womit eine weitere Bedeutung von rreprésentation ins Spiel kommt, so daß gleichzeitig zeichenhafte Repräsentation, szenische Aufführung und, drittens, gedankliche Vorstellung, Imagination, also der wirkungsästhetische Vorgang im Zuschauer, aufgerufen werden. Für die Steigerung dieser Vorstellung der Strafe bedarf es, wie gesagt, weiterhin des Theaters - jedoch nicht mehr des tragischen Theaters der Marter, sondern des komischen Theaters der reformierten Strafen, in dem der Schauspieler bzw. der Verbrecher selbst zum Signifikat des Strafzeichens wird (vgl. weiter unten; ÜS 165f.). Entscheidend für die reformierten Strafen ist also die Beziehung zwischen Körper und Zeichen: "[W]enn sich die Züchtigung seines [d.i. des Individuums; Gw.E.] Körpers bemächtigt [...], so geschieht dies in dem Maße, in welchem der Körper - für den Sträfling und für die Zuschauer - ein Gegenstand der Vorstellung ist." (ÜS 166)

In den Martern also ist der Körper des Verbrechers das zentrale Element, da in ihm und seiner Vernichtung das Verbrechen vernichtet wird. In den reformierten Strafen dagegen bedarf es zwar der körperlichen Präsenz des Schauspielers bzw. des Bestraften auf der Bühne, zentral ist aber sein Zeichencharakter: Der bestrafte Körper ist lesbares Zeichen der Verbindung von Gesetz und Strafe. Während die Marter die körperliche Wiederherstellung der Gerechtigkeit ist und also performativ funktioniert, ist die reformierte Bestrafung Zeichen der Strafe und funktioniert semiotisch.

\section{Die komische Maske (I): Als Zeichen der Zeichenhaftigkeit}

Das zeigt sich auch darin, daß die Figuren der komischen Bühne "maskiert" sind: "Auf die Bühne tritt eine neue Figur - maskiert." (ÜS 26) Seitter übersetzt »verschleiert« statt »maskiert ${ }^{26}$ und führt die `Maskierung`damit

25 Korrektur der Übersetzung, Gw.E. Seitter übersetzt "Wirksamkeit«, Foucault schreibt "réalité« (vgl. SP 112).

$26 »[\mathrm{M}]$ asqué«, SP 24. 
direkt auf die Verschleierung der zum Tode Verurteilten zurück, die bei Hinrichtungen eine Zeitlang üblich war und die Foucault wenige Seiten zuvor beschreibt (vgl. ÜS 22). Obwohl dies Foucaults ursprünglicher inhaltlicher Bezugspunkt sein mag, hat es durchaus seinen Grund, daß er hier nicht "verschleiert«, sondern "maskiert" verwendet. Die Maskierung macht deutlich, daß der Bestrafte nicht mehr in erster Linie Körper, als tragische Einheit von Schauspieler und Charakter, sondern Zeichen ist. Die Maske repräsentiert den Repräsentationscharakter des komischen Strafschauspiels, womit dieses Foucaults Definition der epistemischen Repräsentation und des Tableaus entspricht: Der Zeichencharakter ist im Zeichen, die Repräsentation in der Repräsentation repräsentiert.

Die Maskierung des Schauspielers ist bei Foucault klar der Komödie zugeordnet. Für seine Tragödie der Marter gilt, daß der Schauspieler bzw. Verbrecher tatsächlich der Held ist, den er vorstellt. Der Verbrecher trägt also insofern keine Maske, als er mit seiner Maske oder seiner Rolle identisch ist. Er ist der Verbrecher, der Königsmörder, und nur dies - so wie Hegels tragische Charaktere das sind, "was sie sind, und ewig dies«. (Ä III, 546) $\mathrm{Daß}$ in der Komödie der reformierten Strafe "maskiert[e]" Figuren auftreten, bedeutet daher, daß in ihr die Dopplung aus Schauspieler oder Mensch und Maske herausgestellt wird. Dementsprechend erfolgt in der griechischen Komödie, anders als in der Tragödie, ein Abnehmen der Maske durch die Schauspieler, wodurch der gleiche Effekt der Distanznahme oder die Betonung der Zweiheit von Schauspieler und Maske/Figur erreicht wird, die Betonung des Repräsentationscharakters (in allen erwähnten Bedeutungen). Mit der Maske ruft Foucault also einen zentralen Bestandteil der antiken Bühnendramatik auf und integriert ihn in seine Darstellung der modernen Strafjustiz als Komödie.

\section{Schauspieler und Maske in Hegels Phänomenologie des Geistes}

In der Theoretisierung der Maske hat Foucault einen Vorläufer in - auch hier wieder - Hegel, der die Funktion der dramatischen Maske im Kunstreligionskapitel der Phänomenologie des Geistes betrachtet. Episches, tragisches und komisches Selbstbewußtsein unterscheiden sich dort - wie auch sonst die verschiedenen Stufen in der Phänomenologie - nach dem Grad ihres Bewußtseins. Demnach zeichnet sich der dramatische Held, unabhängig davon, ob er in einer Tragödie oder einer Komödie spielt, gegenüber 
dem besungenen Helden des Epos durch die Dopplung aus Mensch und Rolle, Schauspieler und Maske, wirklichem Selbst und (dramatischer) Person aus:

So wesentlich es der Bildsäule ist, von Menschenhänden gemacht zu sein, ebenso wesentlich ist der Schauspieler seiner Maske, - nicht als äußerliche Bedingung, von der die Kunstbetrachtung absehen müsse; oder insofern davon in ihr allerdings zu abstrahieren ist, so ist eben dies damit gesagt, daß die Kunst das wahre eigentliche Selbst noch nicht in ihr enthält. (PG 535)

»[N]icht als äußerliche Bedingung, von der die Kunstbetrachtung absehen müsse«: Die Tatsache, daß der Schauspieler auf der Bühne nicht wirklich der vorgestellte Held ist, ist nicht etwa ein hinzunehmender Mangel, sondern vielmehr dasjenige, das den höheren Bewußtseinsgrad des Dramas gegenüber dem Epos ausmacht - das Wissen darum, »daß die Kunst das wahre eigentliche Selbst noch nicht in ihr enthält." In der Tragödie kommt dieses gedoppelte Bewußtsein jedoch nur dem Schauspieler zu: "[D]er Held, der vor dem Zuschauer auftritt, zerfällt in seine Maske und in den Schauspieler, in die Person und in das wirkliche Selbst." Die Zuschauer hingegen erliegen der Illusion der Identität von Schauspieler und Maske und fürchten um den dargestellten Helden und leiden mit ihm - ein Ergebnis der "Hypokrisie« des Schauspielers. Die Konsequenz des Bewußtseins des Tragödienschauspielers um seine Dopplung ist die Auflösung dieser seiner »Hypokrisie«: "Das Selbstbewußtsein der Helden muß aus seiner Maske hervortreten «. (PG 541) Dies geschieht aber nicht in der Tragödie, sondern erst in der Komödie. ${ }^{27}$ In der Tragödie "zerfällt« der Held - passiv - in

27 Christoph Menke (Tragödie im Sittlichen, S. 184f.) liest diese Stelle anders. Ihm zufolge geschieht das Ablegen der Maske bereits am Ende der Tragödie, womit die "Subjektkonstitution" vollzogen wird. Text und Textbild der Phänomenologie sprechen aber für eine andere Lektüre. Hegel schreibt:

"[D]er Held, der vor dem Zuschauer auftritt, zerfällt in seine Maske und in den Schauspieler, in die Person und in das wirkliche Selbst.

Das Selbstbewußtsein der Helden muß aus seiner Maske hervortreten und sich darstellen, wie es sich als das Schicksal der Götter sowohl des Chors als der absoluten Mächte selbst weiß und von dem Chore, dem allgemeinen Bewußtsein, nicht mehr getrennt ist.

Die Komödie hat also vorerst die Seite, daß das wirkliche Selbstbewußtsein sich als das Schicksal der Götter darstellt." (PG 541)

Das "also" macht deutlich, daß sich der vorstehende kurze Abschnitt bereits nicht mehr auf die Tragödie, sondern auf die Komödie bezieht. Schulte positioniert sich in dieser Frage nicht eindeutig, doch ist seine Lesart dieses Abschnitts hiermit immerhin 
Maske und Schauspieler, allerdings, den Zuschauern nicht sichtbar, nur in seiner eigenen Erfahrung, während er für die Zuschauer die Einheit von Charakter und Maske bildet. In der Komödie dagegen stritt< er - aktiv - »aus seiner Maske hervor «. ${ }^{28}$ Das Abnehmen der Maske in der Komödie macht die Spaltung von Schauspieler und Maske offenbar und auch dem $\mathrm{Zu}-$ schauer sichtbar. Dennoch, oder vielmehr gerade dadurch, fällt in der Komödie "das eigentliche Selbst des Schauspielers [...] mit seiner Person [und d.h.: mit seiner Maske; Gw.E.] zusammen, so wie der Zuschauer[, der] in dem, was ihm vorgestellt wird, vollkommen zu Hause ist und sich selbst spielen sieht.«29 (PG 544) Gerade durch das Hervortreten aus der Maske

vereinbar, wenn er das Hervortreten aus der Maske als »Übergang, der von der Tragödie zur Komödie führt", bezeichnet. (Michael Schulte: Hypokrisie und Maske. Zum Verhältnis von Tragödien- und Komödientheorie in Hegels rechtsphilosophischer Schrift "Über die Behandlungsarten des Naturrechts« und im Religionskapitel der "Phänomenologie des Geistes «, in: Klaus Detering [Hg.]: Wahrnehmungen im poetischen All, Heidelberg 1993, S. 207-253, hier S. 240) Schulte sieht richtig, daß bei Hegel "die Geburt des Selbst, die Geburt freier Subjektivität« im »komischen Bewußtsein« und nicht im Bewußtsein der Tragödie stattfindet (vgl. ebd. S. 243). Dagegen gründet Menkes gesamte Argumentation von der "Gegenwart der Tragödie" auf der Prämisse von der wesentlichen Reflexivität der Tragödie im Spiel (Schlegels für die Komödie beschriebene Parekbase), die Menke auf Hegel zurückführt: »Es war Hegel, der diese romantische Figur ästhetischer Selbstreflexion in der Komödie in der Phänomenologie des Geistes auch auf die Tragödie angewendet hat«. (Christoph Menke: Die Gegenwart der Tragödie. Versuch über Urteil und Spiel, S. 238. Vgl. auch ders.: Tragödie im Sittlichen, S. 53-73; sowie ders.: Ethischer Konflikt und ästhetisches Spiel)

28 Es ist interessant - und paradigmatisch für die Systematik der Phänomenologie -, wie Hegel hier das Bewußtsein des Schauspielers der Tragödie als eine kontinuierliche Einheit mit dem Bewußtseins des Schauspielers der Komödie betrachtet: Weil in der Tragödie »der Held, der vor dem Zuschauer auftritt, [...] in seine Maske und in den Schauspieler, in die Person und in das wirkliche Selbst [zerfällt]«, "muß« das »Selbstbewußtsein der Helden [...] aus seiner Maske hervortreten« - und zwar in der Komödie. (PG 541) Das Bewußtsein des Komödienschauspielers setzt das Bewußtsein des Tragödienschauspielers fort.

29 Die Herausgeber Michel und Moldenhauer entscheiden sich hier gegen die Version des Erstdrucks der Phänomenologie von 1807, der ihre Ausgabe ansonsten folgt, und für die überarbeitete Version der Werke von 1832 (hg. von Johannes Schulze). Sie schreiben: »[...] das eigentliche Selbst des Schauspielers fällt mit seiner Person zusammen, so wie der Zuschauer in dem, was ihm vorgestellt wird, vollkommen zu Hause ist und sich selbst spielen sieht.« (PG 544) Der Erstdruck lautet, wie bereits im obigen Fließtext hinzugefügt: "[...] das eigentliche Selbst des Schauspielers fällt mit seiner Person zusammen, so wie der Zuschauer, der in dem, was ihm vorgestellt wird, vollkommen zu Hause ist und sich selbst spielen sieht." Der Unterschied ist wesentlich. Denn anders als in der überarbeiteten Fassung läßt sich im Erstdruck der Satz früher beenden: »[...] das eigentliche Selbst des Schauspielers fällt mit seiner Person zusam- 
also wird der Schauspieler mit ihr eins - indem er das, wofür die Maske steht, die göttliche Substanz, nicht ernst nimmt, dadurch aber die Maske selbst, in ihrer Eigenschaft als Maske, ernst nimmt: Indem er sie in dem Wissen anlegt, daß sie bloß eine Maske ist, bejaht er sie in ihrer ihr wesentlichen Maskenhaftigkeit. Auch die Identifikation der Zuschauer mit dem Schauspieler (und nicht mit dem Charakter, den er darstellt, d.h. seiner Maske) funktioniert über dieses Durchbrechen der dramatischen Illusion: "Das Selbstbewußtsein der Helden muß aus seiner Maske hervortreten und sich darstellen, wie es [...] von dem Chore, dem allgemeinen Bewußtsein, nicht mehr getrennt ist." (PG 541) Das heißt auch: von den Zuschauern nicht mehr getrennt ist. Statt des Helden sehen die Zuschauer den Schauspieler, den Menschen in seiner "Nacktheit« und "Gewöhnlichkeit« auf der Bühne, ununterschieden von sich selbst (PG 542), und sehen damit in seinem Spiel mit der Maske auch sich selbst spielen. Das komische Bewußtsein des Komödienschauspielers ist damit, anders als das tragische des Tragödienschauspielers, der hinter seiner Maske verbleibt, ebenso das Bewußtsein der Zuschauer.

Das Verhältnis des Schauspielers zu seiner Rolle einerseits und des Publikums zur Bühnenfigur andererseits, jeweils veranschaulicht im Verhältnis von Schauspieler und Maske, gelten Hegel also als die entscheidenden dramaturgischen wie subjektphilosophischen Unterschiede zwischen Tragödie und Komödie. Weiter schreibt Hegel über die Komödie, in Abgrenzung zur Tragödie:

Die Komödie hat also vorerst die Seite, daß das wirkliche Selbstbewußtsein sich als das Schicksal der Götter darstellt. Diese elementarischen Wesen sind, als allgemeine Momente, kein Selbst und nicht wirklich. Sie sind zwar mit der Form der Individualität

men, so wie der Zuschauer«, was die Syntax der überarbeiteten Fassung nicht zuläßt und womit ihr eine wichtige Aussage verlorengeht: Wie das Selbst des Schauspielers mit seiner Person zusammenfällt, so fällt, angesichts des Schauspiels, auch der Zuschauer mit seiner Person zusammen. (Bei Michel und Moldenhauer hingegen lautet die Aussage, daß der Schauspieler mit seiner Maske zusammenfällt und der $\mathrm{Zu}$ schauer sich selbst im Schauspieler spielen sieht, sich also, vermittelt, mit seiner Maske zusammenfallen sieht, aber nicht selbst mit ihr zusammenfällt.)

Im vorliegenden Interpretationszusammenhang und übertragen auf Foucaults Komödie der Bestrafung bedeutet das, daß nicht nur der Verbrecher wieder zum Rechtssubjekt, sondern auch die Zuschauer dieses Strafschauspiels wieder zu Rechtssubjekten gemacht werden oder ihr Status als Rechtssubjekte gefestigt wird - dies die Bedeutung der >Aktualisierung` der Repräsentation, der >Aktualisierung` des "Signifikantensystem[s] des Gesetzes« (ÜS 166), von der im folgenden noch die Rede sein wird. 
ausgestattet, aber diese ist ihnen nur eingebildet und kommt ihnen nicht an und für sich selbst zu; das wirkliche Selbst hat nicht ein solches abstraktes Moment zu seiner Substanz und Inhalt. Es, das Subjekt, ist daher über ein solches Moment als über eine einzelne Eigenschaft erhoben, und angetan mit dieser Maske spricht es die Ironie derselben aus, die für sich etwas sein will. Das Aufspreizen der allgemeinen Wesenheit ist an das Selbst verraten; es zeigt sich hier in seiner Wirklichkeit gefangen und läßt die Maske fallen, eben indem es etwas Rechtes sein will. Das Selbst, hier in seiner Bedeutung als Wirkliches auftretend, spielt es mit der Maske, die es einmal anlegt, um seine Person zu sein; aber aus diesem Scheine tut es sich ebenso bald wieder in seiner eigenen Nacktheit und Gewöhnlichkeit hervor, die es von dem eigentlichen Selbst, dem Schauspieler, sowie von dem Zuschauer nicht unterschieden zu sein zeigt. (PG 541f.)

Das "wirkliche Selbstbewußtsein« ist der Schauspieler der Komödie. Er sstellt sich "als das Schicksal der Götter" >darı, die "Zwar mit der Form der Individualität ausgestattet« sind, welche ihnen aber "nicht an und für sich selbst zu[kommt]«. Die »Form der Individualität« besteht darin, daß sie, wie Hegel im Abschnitt zum Epos geschrieben hatte, "bestimmte Elemente, besondere Götter« sind. (PG 533) Daß sich der Komödienschauspieler »als das Schicksal der Götter darstellt«, bedeutet, daß er deren individualisierte Maske trägt, die ihn als ein `besonderes` und ’bestimmtes Element Das »wirkliche Selbst« aber, der Schauspieler, »hat nicht ein solches abstraktes Moment zu seiner Substanz und Inhalt«; es »ist daher über ein solches Moment als über eine einzelne Eigenschaft erhoben, und angetan mit dieser Maske«, d.h. mit der Maske, die eine einzelne Eigenschaft darstellt, "spricht es die Ironie derselben aus, die für sich etwas sein will.«/Für sich etwas sein zu wollen ist das "Aufspreizen der allgemeinen Wesenheit«, oder, wie es zuvor über die Götter im Epos hieß, deren »zufälliges leeres Aufspreizen«. (PG 533) Dieses "Aufspreizen« ist nun auf der komischen Bühne »an das Selbst «, d.h. an den komischen Schauspieler, "verraten; es zeigt sich hier in seiner Wirklichkeit gefangen" und läßt die Maske fallen, eben indem es etwas Rechtes sein will.« Das "Aufspreizen« in der »Form der Individualität«, das Hegel immer wieder mit dem Komischen assoziiert, ${ }^{30}$ ist also Gegenstand des ironischen Maskenspiels des Komödienschauspielers. Die göttliche Substanz ist in der Wirklichkeit der körperlichen Darstellung durch den Schauspieler "gefangen und läßt die Maske fallen", um sich dementgegen als Substanz zu zeigen, ist dabei aber an den Schauspieler

30 Vgl. etwa auch Ä I, 251f. 
"verraten«, weil dieser eben damit das komische Maskenspiel beginnt und die Götter gerade dadurch in ihrer Substanzlosigkeit bloßstellt.

Die komische Maske (II): Als Rechtsperson

Das "Aufspreizen« besteht aber nicht nur darin, »für sich etwas sein« zu wollen. Noch einmal:

Das Aufspreizen der allgemeinen Wesenheit ist an das Selbst verraten; es zeigt sich hier in seiner Wirklichkeit gefangen und läßt die Maske fallen, eben indem es etwas Rechtes sein will. Das Selbst, hier in seiner Bedeutung als Wirkliches auftretend, spielt es mit der Maske, die es einmal anlegt, um seine Person zu sein; aber aus diesem Scheine tut es sich ebenso bald wieder in seiner eigenen Nacktheit und Gewöhnlichkeit hervor, die es von dem eigentlichen Selbst, dem Schauspieler, sowie von dem Zuschauer nicht unterschieden zu sein zeigt. (PG 541f.)

Kommentare zu dieser Textstelle ignorieren in aller Regel das grammatische Objekt »es" im zweiten Satz (»spielt es mit der Maske») und enthalten sich seiner Interpretation. ${ }^{31}$ Dabei ist das Satzobjekt durchaus von Bedeutung: Es verweist auf »etwas Rechtes« aus dem vorherigen Satz, so daß der vollständige Satz lauten würde: `Das Selbst, hier in seiner Bedeutung als Wirkliches auftretend, spielt das Rechte mit der Maske, die es einmal anlegt, um seine Person zu sein ${ }^{32}$ Der Schauspieler spielt das Rechte, "um seine

31 Schulte zitiert die Textstelle gar nicht. Friedrich zitiert sie zwar und greift dieses "Rechte« auch noch einmal auf, erläutert es aber nicht bzw. faßt es nicht in seinem spezifischen Wortsinn auf. Andere Kommentare ignorieren das Satzobjekt »es« und argumentieren, als lautete der Satz >Das Selbst, hier in seiner Bedeutung als Wirkliches auftretend, spielt mit der Maske<, so etwa bei Hamacher und auch bei Kraft, wo der vorangehende Satz nicht zitiert wird und also der Bezugspunkt des Satzobjekts "es« wegfällt. Vgl. Michael Schulte: Hypokrisie und Maske; Lars Friedrich: Der Achill-Komplex, S. 234; Werner Hamacher: (Das Ende der Kunst mit der Maske), S. 133f.; Stephan Kraft: Zum Ende der Komödie, S. 281.

32 Auch Lars Friedrich: Der Achill-Komplex, S. 234, liest diese Stelle so. Das Satzobjekt "es« kann zwar ebenso auf das "Aufspreizen« verweisen. Damit würde auch die ironische Haltung des Schauspielers gegenüber der "allgemeinen Wesenheit" der Götter in der »Form der Individualität« gestützt, die »für sich etwas sein [...] wollen«, so wie das Selbst mit der Maske spielt, »indem es etwas Rechtes sein will«. So bei Christoph Menke: Tragödie im Sittlichen, S. 185, der den Teilsatz »es zeigt sich hier 
Person zu sein « - und zwar mit der Maske, d.h. mit Hilfe der Maske. ${ }^{33}$ Wenn also das Rechte zu spielen, der Weg ist, Person zu sein, wird deutlich, daß es sich bei dieser Person um die Rechtsperson handelt. Das in der Komödie verspottete "Aufspreizen", "für sich etwas sein" zu wollen, bezieht sich also auf das "Aufspreizen«, "etwas Rechtes sein« zu wollen. Im komischen Spiel mit der Maske, dem An- und Ablegen der Rechtsperson, ironisiert das komische Bewußtsein den Anspruch, etwas Rechtes zu sein, ironisiert überhaupt das Rechte, oder das Recht, als Substanz. Es ist »über ein solches Moment als über eine einzelne Eigenschaft«, wie es die tragische Zugehörigkeit zu einer sittlichen Substanz war und wie es die Götter sind, »erhoben«. (PG 542) Scheinbar problematisch wird Hegels Text dann dort, wo es heißt, daß das komische Bewußtsein, »das eigentliche Selbst des Schauspielers", mit seiner Maske, "seiner Person" und also seiner Rechtsperson 'zusammenfälltr. (PG 544) Denn die komische Ironie besteht ja gerade im Spiel, die Maske an- und abzulegen; in dem Moment jedoch, wo der Schauspieler mit ihr szusammenfälltı, endet dieses Spiel. Tatsächlich aber ist das Zusammenfallen mit der Maske die notwendige Konsequenz des ironischen Spiels mit ihr, weil, wie bereits gesagt, diese Ironie die Maske als - bloße - Maske ernst nimmt. Das ironische Maskenspiel trägt sein Ende also notwendig in sich. Das komische Bewußtsein kann sich den "Leichtsinn" erlauben, mit der Maske zusammenzufallen, weil es weiß, daß nichts Substantielles dahintersteckt (die göttlichen Substanzen wurden ja raufgelöst‘ [PG 542]) - bzw. vielmehr weil es weiß, daß nur es selbst, als "wirkliches Selbst«, dahintersteckt. In diesem Zusammenfallen als der »Rückkehr alles Allgemeinen in die Gewißheit seiner selbst" (PG 544) ist daher der "vollkommen glückliche» Zustand des "Wohlsein[s] und Sichwohlseinlassen[s] « erreicht. (PG 544) Doch gleichzeitig bedeutet das Zusammenfallen mit der Maske das Ende dieses heiteren Maskenspiels. Trotz allen Ironisierens des Bestrebens, etwas Rechtes sein zu wollen, und trotz allen Wohlseins im 'Zuhause der "Gewißheit seiner selbst « führt dieses Maskenspiel, indem es im Zusammenfallen des Selbst mit seiner Maske endet, letztlich in den Rechtszustand. Infolge des

in seiner Wirklichkeit gefangen und läßt die Maske fallen, eben indem es etwas Rechtes sein will« aus seinem Zitat gleich gänzlich ausklammert. Die Verbindung von Maske und Rechtsperson, die in der vorliegenden Argumentation im folgenden noch weiter belegt wird, geht auf diese Weise verloren.

33 Zur Tradition des "Spiel[s] mit den Termen >Maske` und >Person« $«$ vgl. Werner Hamacher: (Das Ende der Kunst mit der Maske), S. 133f. - hier allerdings ohne Hinweis auf den Zusammenhang von Maske und Rechtsperson. 
komischen Spiels mit der Maske wird der Schauspieler, der natürliche Mensch (rechtlich gesprochen: die natürliche Person), zur Rechtsperson. Im Rechtszustand nämlich findet kein Maskenspiel mehr statt, sondern das Selbst wird zur Maske und bleibt diese Maske, dergestalt, daß es nur noch Maske, nur noch Rechtsperson ist, und sein "wirkliche[s] Selbst" 'verliert. Hatten die Entleerung der Maske, also der Verlust der göttlichen Substanz, die sich vormals hinter der Maske verbarg, und infolgedessen die Verabsolutierung des Selbst zum "vollkommen glücklichen« komischen Bewußtsein geführt, zieht dieses nun das "unglückliche« Bewußtsein« nach sich (PG 547): Das "unglückliche Bewußtsein« ist das Bewußtsein des Verlusts der Götter ebenso wie des Verlusts des Selbst. Komisches und unglückliches Bewußtsein gemeinsam machen das Bewußtsein des Rechtszustands aus: "Im Rechtszustande ist also die sittliche Welt und die Religion derselben in dem komischen Bewußtsein versunken und das unglückliche das Wissen dieses ganzen Verlustes." (PG 547) Dieser "vollkommene[ ] Verlust" (PG 547) des 'Wirklichen komischen Bewußtseins, "das Selbst ist das absolute Wesen« (PG 545), wird im Rechtszustand zu dem Satz: "[D]ie abstrakte Person ist absolutes Wesen«. (PG 546) Ebenso hatte Hegel im Kapitel über den Rechtszustand das Rechtsbewußtsein als "abstrakte Form", "abstrakte[] Wirklichkeit" und als "gestaltlos" bezeichnet, als »das leere Eins der Person" (PG 356) »ohne eigentümlichen Inhalt«, als »abstrakte Allgemeinheit« und »wesenlose Wirklichkeit«. (PG 357) ${ }^{34}$

Historisch entspricht der Rechtszustand in Hegels System dem Römertum. Dieses zeichnet sich gegenüber der griechischen Sittlichkeit dadurch aus, daß keine vermittelte Einheit mehr von Familie und Staat (oder Weiblichkeit und Männlichkeit oder göttlichem und menschlichem Recht) besteht. In der Verabsolutierung des Selbst im komischen Bewußtsein (»das Selbst ist das absolute Wesen «) und seiner Abstraktion im positiven Recht, das sich historisch als römisches Privatrecht ausbildet, besteht der Einzelne nur noch als Rechtsperson und findet seine Anerkennung allein im Privateigentum eine Anerkennung, die, jeden lebendigen und natürlichen sittlichen Verhältnisses bar, rein formell und unerfüllt bleibt. ${ }^{35}$ In seinen Vorlesungen zur Phi-

34 Die Idee der Abstraktion des Rechtssubjekts zieht sich durch Hegels Werk; im Naturrechtsaufsatz ist "wesenlos" beinahe stets das Attribut zu "Abstraktion".

35 Vgl. G.W.F. Hegel: Kapitel »Die römische Welt«, in: Vorlesungen über die Philosophie der Geschichte, S. 339-412, insbes. S. 350f., 383f., $387 f$. 
losophie der Geschichte sagt Hegel über die "Persönlichkeit im Privatrecht«, sie sei »die individuelle Abstraktion, die Person, welche die Bestimmung enthält, daß das Individuum an sich etwas sei, nicht nach seiner Lebendigkeit, nach einer erfüllten Individualität, sondern als abstraktes Individuum.«36 Darin unterscheidet sich das `Rechtsbewußtsein v vom sittlichen Bewußtsein der Tragödie:

Im sittlichen Leben ist das Selbst in dem Geiste seines Volkes versenkt, es ist die erfüllte Allgemeinheit. Die einfache Einzelheit aber erhebt sich aus diesem Inhalte, und ihr Leichtsinn reinigt sie zur Person, zur abstrakten Allgemeinheit des Rechts. In dieser ist die Realität des sittlichen Geistes verloren, die inhaltsleeren Geister der Völkerindividuen sind in ein Pantheon versammelt, [...] in ein Pantheon der abstrakten Allgemeinheit, des reinen Gedankens, der sie entleibt und dem geistlosen Selbst, der einzelnen Person, das Anundfürsichsein erteilt. Aber dies Selbst hat durch seine Leerheit den Inhalt freigelassen; das Bewußtsein ist nur in sich das Wesen; sein eigenes Dasein, das rechtliche Anerkanntsein der Person, ist die unerfüllte Abstraktion [...]. (PG 546)

Hier wird noch einmal deutlich, daß der Weg von der (griechischen) Sittlichkeit zum (römischen) Rechtszustand die Komödie ist. Denn sie ist es, ihr komischer »Leichtsinn «, ${ }^{37}$ der das Individuum "zur Person, zur abstrakten Allgemeinheit des Rechts [reinigt]«. Die komische "Reinigung« 38 und die zunächst nur ironische Vereinigung mit der Maske mündet in eine Entleerung und 'Entleibung des sittlichen Selbst. Von ihm und seiner wirklichen Körperlichkeit bleibt nur die abstrakte Form, die Maske - die Rechtsperson. Werner Hamacher spricht daher auch von der »Rechtsperson als absoluter Maske«. 39

Eine "absolute[ ] Maske« in diesem Sinne trägt auch die "Figur", die Foucaults komische Strafbühne betritt. Oben ist gesagt worden, daß die Maskierung der Figuren in der reformierten Strafe deren Dasein als Schauspieler, getrennt von ihren Masken, herausstellt, die Maske also Zeichen der Zeichenhaftigkeit oder Repräsentation der Repräsentation ist. Sie steht aber auch mit der Rechtsperson im soeben beschriebenen Sinne in Zusammen-

36 Ebd., S. 384.

37 Zum »Leichtsinn« der Komödie vgl. Werner Hamacher: (Das Ende der Kunst mit der Maske), S. 138f.

38 Vgl. G.W.F. Hegel: Vorlesungen über die Philosophie der Geschichte, S. 342: "Die Entwicklung besteht in der Reinigung der Innerlichkeit zur abstrakten Persönlichkeit, welche im Privateigentum sich die Realität gibt«.

39 Werner Hamacher: (Das Ende der Kunst mit der Maske), S. 148. 
hang; Hegels Verknüpfung von komischer Maske und abstraktem Rechtssubjekt findet sich daher bei Foucault wieder.

Wie Hegels komisches Bewußtsein bzw. das Rechtsbewußtsein, in dem es aufgeht, »entleibt« und »inhaltsleer« (PG 546), »die vollkommene Entäußerung der Substanz «(PG 547) ist, so ist auch Foucaults komische Figur eine »körperlose[] Realität«. (ÜS 26) Und wie das Bewußtsein in Hegels Rechtszustand der Verlust des "wirkliche[n] Selbst[s] « ist und zu einer "abstrakte[n] Person " wird (PG 546), also nicht mehr der wirkliche Schauspieler, sondern nur noch seine Maske auf der Bühne steht, so verliert auch die tragische Figur von Foucaults tragischer Bühne der Marter ihren Körper und wird zur »maskiert[en]« Figur der komischen Bühne der reformierten Strafe, zur »schattenhaften Silhouette[ ], gesichtlosen Stimme[ ] und zum "unbetastbaren Wesen«. (ÜS 26) Diese seine Körperlosigkeit (oder, mit Hegel gesprochen, seine "Unwesentlichkeit«, "wesenlose Wirklichkeit« [PG 357], »Unwesenheit« [PG 359]) liegt, wie bereits gezeigt wurde, im Zeichencharakter und der Repräsentation des Gesetzes in der reformierten Strafe begründet, deren Zielsetzung Abschreckung und Besserung ist. Mit dem Repräsentationscharakter hängt nun auch bei Foucault noch eine weitere "Zielsetzung" zusammen, nämlich die Restitution des Gesellschaftsvertrags durch Restitution des Verbrechers als "Rechtssubjekt«: Es geht um die »Wiederherstellung eines Rechtssubjekts innerhalb eines Gesellschaftsvertrags«. (ÜS 167) "Zielpunkt" der reformierten Strafjustiz ist damit das abstrakte "Rechtssubjekt eines idealen Vertrags" (ÜS 291) und dessen »Wiedereinbürgerung [...] durch die Strafe«. (ÜS 287) "Die individuelle Besserung muß [...] das Individuum wieder zu einem Rechtssubjekt machen: durch die Wiederaufwertung der Zeichensysteme und der durch sie in Umlauf gesetzten Vorstellungen." (ÜS 166) Dies erfolgt durch das komische Strafschauspiel und die Maskierung. Das straffällige Individuum, das durch seinen Gesetzesbruch aus dem Gesellschaftsvertrag herausgetreten ist, wird im komischen Strafschauspiel wieder zum Subjekt dieses Gesellschaftsvertrags - und zwar, wie in Hegels Komödie, in der »das eigentliche Selbst des Schauspielers [...] mit seiner Person zusammen[fällt]« (PG 544), indem es eine Maske trägt - die persona, auch hier in spezifischer Bedeutung der Rechtsperson. Die Maske ist die Rechtsperson, die der Verbrecher wieder anlegen muß, um in den Gesellschaftsvertrag reintegriert zu werden: In der Parabase der "Schafott-Diskurse" tritt der Verbrecher an den Rand der Schafottbühne und wendet sich an die Zuschauer, dabei als Mensch ununterschieden von den Menschen im Publikum, um dann in der darauf- 
folgenden Bestrafung mit seiner Maske wiedervereint und erneut zu einem Rechtssubjekt des Gesellschaftsvertrags zu werden. Wie bei Hegel wird auf Foucaults komischer Bühne der Mensch in den Status als Person, als Rechtssubjekt, überführt. ${ }^{40}$

Anders jedoch als bei Hegel »ällt« der Verbrecher nicht »leichtsinnig" mit dieser Maske zusammen, sondern wird in der Bestrafung (gewaltsam) mit ihr vereint. Ein ironisches Spiel mit der Maske findet hier nicht statt, wie Foucaults Komödie der reformierten Strafen überhaupt die Ironie des Bühnengeschehens fehlt. Der Status der Maske entspricht hier also demjenigen der »absoluten Maske« bei Hegel, zu der sich die komische Maske im Übergang zum Rechtszustand verhärtet, womit Foucaults Komödie sozusagen der Spätform oder dem Ende der Komödie, im oder nach dem Übergang zum Rechtszustand, entspricht.

\section{Zwischenbilanz: Komödie und Bestrafung}

In Überwachen und Strafen faßt Foucault die Technik der reformierten Bestrafung wie folgt zusammen:

Worauf zielt die Strafe, wodurch verschafft sie sich ihren Zugriff aufs Individuum? Es sind die Vorstellungen: Vorstellungen seiner Interessen, Vorstellungen seiner Vorteile, Vorstellungen von Nachteilen, Vorstellungen seines Vergnügens und Mißvergnügens. Und wenn sich die Züchtigung seines Körpers bemächtigt, wenn sie ihn mit Techniken bearbeitet, die den alten peinlichen Strafen nicht nachstehen, so geschieht dies in dem Maße, in welchem der Körper - für den Sträfling und für die Zuschauer - ein Gegenstand der Vorstellung ist. Mit welchem Instrument wirkt man auf die Vorstellungen ein? Mit anderen Vorstellungen oder vielmehr mit Vorstellungspaaren (Verbrechen/Strafe, eingebildeter Vorteil des Verbrechens/wahrgenommener Nachteil der Züchtigungen); diese Paarungen können nur im Element der Öffentlichkeit ihre Funktion erfüllen: Straf-Szenen machen sie dem Blick aller deutlich und eindringlich; Diskurse setzen sie in Umlauf und werten jederzeit das Spiel der Zeichen auf. Die Rolle des Verbrechers in der Bestrafung ist es, gegenüber den Codes/den Gesetzen und den Verbrechen wieder die wirkliche Gegenwart des

40 Über die Guillotine im reformierten Strafrecht hatte Foucault zu Beginn von Überwachen und Strafen geschrieben, sie "soll das Gesetz weniger an einem wirklichen, schmerzempfindlichen Körper vollstrecken als vielmehr an einem juristischen Subjekt, das unter anderem das Recht auf Existenz innehat. Sie muß so abstrakt sein wie das Gesetz selber.« (ÜS 21f.) Man könnte ergänzen: Nicht nur die reformierte Strafe muß "so abstrakt sein wie das Gesetz selber", sondern auch das Rechtssubjekt, an dem sie vollzogen wird. 
Signifikats einzuführen - das heißt jene Strafe, die laut Code unlösbar mit dem Vergehen verknüpft sein muß. ${ }^{41}$ Ausgiebig und unübersehbar dieses Signifikat vorstellen, damit das Signifikantensystem des Gesetzes immer wieder aktualisieren, die Idee des Verbrechens als ein Zeichen der Bestrafung zur Geltung bringen - das ist die Währung, mit welcher der Missetäter der Gesellschaft seine Schuld abzahlt. Die individuelle Besserung muß also das Individuum wieder zu einem Rechtssubjekt machen: durch die Wiederaufwertung der Zeichensysteme und der durch sie in Umlauf gesetzten Vorstellungen. (ÜS 165f.)

Es lassen sich hier drei Charakteristika der reformierten Bestrafung unterscheiden, die im vorangehenden Kapitel bereits erläutert wurden und die sich gleichermaßen als Charakteristika der Komödie erwiesen: erstens das 'Ziek der Bestrafung (»Worauf zielt die Strafe [...] ?«), das im »Zugriff aufs Individuum", also in der Einwirkung der Strafe auf die Seele des Verbrechers ebenso wie auf die der Zuschauer besteht. Wie in den Komödientheorien der Aufklärung geht es um Abschreckung und Besserung. Zweitens die Funktionsweise der Bestrafung (»[W]odurch verschafft sie sich ihren Zugriff aufs Individuum?«): »Es sind die Vorstellungen« (représentations), über die die Strafe auf das Individuum seinwirken« soll. »Vorstellung« meint hier zum einen die konkrete Imagination des Zuschauers (»Vorstellungen seiner Interessen, Vorstellungen seiner Vorteile, Vorstellungen von Nachteilen, Vorstellungen seines Vergnügens und Mißvergnügens«) - das entspricht der Seite der psychologischen Mechanismen der Wirkungsästhetik der Komödie. "Vorstellung " meint zum anderen die epistemische Repräsentation des Gesetzes, die Zeichenbeziehung zwischen Strafe und Gesetz. Die jeweiligen Elemente der »Vorstellungspaare "Verbrechen/Strafe, eingebildeter Vorteil des Verbrechens/wahrgenommener Nachteil der Züchtigungen" sind aufeinander hin "vollkommen transparent" (ÜS 134) - das entspricht der Seite des Prinzips der Repräsentation als »Instrument«

41 Übersetzung verändert, Gw.E. Seitter übersetzt: »Angesichts des Gesetzes und der Verbrechen hat der Verbrecher in der Bestrafung die wirkliche Gegenwart des Signifikats vorzuführen, die wirkliche Gegenwart der Strafe, die nach den Buchstaben des Gesetzes mit dem Vergehen unmittelbar verknüpft sein muß«; das Original lautet: "Le rôle du criminel dans la punition c'est de réintroduire, en face des codes et des crimes, la présence réelle du signifié - c'est-à-dire de cette peine qui selon les termes du code doit être infailliblement associée à l'infraction." (SP 151) Man beachte hier wieder die Doppeldeutigkeit des französischen code/Code, deutsch Code/Codex, auf die oben bereits hingewiesen wurde und die noch einmal die Zusammengehörigkeit von Episteme der Repräsentation einerseits und reformierten Strafen und deren Gesetzes- und Schriftbezug andererseits deutlich macht. 
der `Einwirkung auf die "Vorstellung«. Weiterhin setzt dieses »Instrument« der Vorstellungspaarungen das "Element der Öffentlichkeit« voraus. Hiermit ist noch einmal der Zusammenhang von Wissenstableau und Schauspieltableau angesprochen; das Funktionieren der Repräsentation in den reformierten Strafen ist an deren Schauspielcharakter gebunden, daran, daß ein wirklicher Körper auf der Bühne, der Körper des Verurteilten, "Gegenstand der Vorstellung" (»objet de représentation" [SP 151]) und Zeichen ist. Drittens der Zweck der Bestrafung: die Restitution eines Rechtssubjekts. Auch diese Restitution erfolgt über Repräsentation der Zeichen, und auch dies wieder in den Vorstellungen der Zuschauer wie des Bestraften. Zum zusammenfassenden Vergleich seien hier noch einmal die jeweiligen Gegenstücke in der Marter genannt: erstens die Einwirkung auf den Körper (statt auf die Seele), zweitens die körperliche Beziehung zwischen Verbrechen und Strafe (statt einer repräsentativen Beziehung der Vorstellungen) und der Schauspielcharakter, der über die Ähnlichkeit von Darstellendem und Dargestellten funktioniert (statt über Tableau und Repräsentation), drittens die Restitution des Rechts und des Körpers des Königs (statt des abstrakten Rechtssubjekts). Foucault präsentiert die reformierte Strafjustiz des 18. Jahrhunderts also in didaktischer Hinsicht als belehrende und bessernde Komödie der Aufklärung, in zeichentheoretischer Hinsicht als schauspielerisch-epistemisches Tableau und in rechtstheoretischer Hinsicht als Komödie des modernen Rechtssubjekts.

\section{Die neuen Figuren auf der Bühne der Justiz: Die »kleine Delinquenz«}

Neben diesen funktionalen oder strukturellen Gemeinsamkeiten zwischen den reformierten Strafen und der Komödie gibt es auch inhaltliche Parallelen, und zwar bei den Figuren. Foucault beschreibt ihr Auftreten, es sei hier noch einmal zitiert, wie folgt:

Die alten Mitspieler des Straf-Prunks, der Körper und das Blut, räumen den Platz. Auf die Bühne tritt eine neue Figur - maskiert. Eine gewisse Tragödie ist zu Ende, es beginnt eine Komödie mit schattenhaften Silhouetten, gesichtslosen Stimmen, unbetastbaren Wesen. Der Apparat der Strafjustiz hat es nun mit dieser körperlosen Realität zu tun. (ÜS 26)

Hier ist zunächst deutlich, daß Foucault die Ablösung der Tragödie durch die Komödie als einen Niedergang betrachtet: »Der Apparat der Strafjustiz 
hat es nun mit dieser körperlosen Realität zu tun", er muß sich mit ihr herumschlagen - das Original lautet "L'appareil de la justice doit mordre maintenant sur cette réalité sans corps." (SP 24) Auch trägt Foucaults Komödie mit ihren "schattenhaften Silhouetten, gesichtslosen Stimmen, unbetastbaren Wesen « alle Attribute, die seit Platon mit der bloßen Scheinhaftigkeit und Unwahrheit der Kunst verbunden sind. Die Komödie als im Vergleich zur Tragödie niedere Gattung zu betrachten, hat eine lange Tradition. Neben dem "mehrmals" geführten Streit über die Höherwertigkeit von Tragödie oder Komödie ${ }^{42}$ wurden seit der sogenannten Querelle des Anciens et des Modernes aber auch antike und moderne (namentlich die klassische französische) Komödie vergleichend diskutiert, wobei nicht die aristophanische, sondern stets die neu(er)e griechische Komödie (Menander) und in deren Folge die römische Komödie (Plautus, Terenz) Bezugspunkt der Diskussion war, die der aristophanischen gemeinhin als überlegen galt. ${ }^{43}$ Die Komödie des Aristophanes tritt erst bei Friedrich und August Wilhelm Schlegel prominent auf und gilt fortan, u.a. bei Schelling und Hegel, als die wahre Komödie. ${ }^{44}$ Theorien der Komödie unterscheiden von da an in der Regel alte, d.h. aristophanische Komödie einerseits und neue, d.h. neue griechische, römische und moderne Komödie andererseits, die nicht mehr als Fortschritt, sondern als Ausdruck eines Verfalls der Gattung begriffen wird; eine Wertung, die auch Hegel in seinen Vorlesungen über die Ästhetik vornimmt. ${ }^{45}$ Die Differenzierungen, die seit Ende des 18. Jahrhunderts in die Diskussionen um Tragödie und Komödie sowie alte und moderne Komödie eingeführt wurden, lassen jedoch nicht die üblicherweise vorgenommene allgemeine Höherbewertung der Tragödie

42 Friedrich Schiller: Über naive und sentimentalische Dichtung, in: ders.: Sämtliche Werke, hg. von Peter-André Alt u.a., Bd. 5, München 2004, S. 694-780, hier S. 724: "Es ist mehrmals darüber gestritten worden, welche von beiden, die Tragödie oder die Komödie, vor der andern den Rang verdiene."

43 Vgl. Peter-André Alt: Barock. Einleitung, in: Ulrich Profitlich (Hg.): Komödientheorie, S. 19-21, hier S. 19; Michael Schulte: Von der Romantik bis zum Realismus. Einleitung, in: Ulrich Profitlich (Hg.): Komödientheorie, S. 87-96, hier S. 88.

44 Vgl. ebd., S. 89f.

45 Dort reiht er die Komödie Shakespeares sowie den modernen satirischen/komischen Roman (Hippel, Sterne [Jean Paul hingegen goutiert Hegel weniger]) in die Tradition der alten Komödie ein, wogegen er die moderne Komödie in der Nachfolge der neuen griechischen bzw. der römischen Komödie (sowie der römischen Satire) sieht - und ebenso schlecht bewertet. Eine Ausnahme bildet Raupachs Die Bekehrten; vgl. dazu das Kap. mit dem schönen Titel "Ein vergessener Flirt: Hegel und die Komödie seiner Zeit«, in: Stephan Kraft: Zum Ende der Komödie, S. 244-261. 
gegenüber der Komödie verschwinden. Zudem führen sie dazu, daß in der Rede über oder in Bezugnahmen auf die Komödie oftmals unterschiedliche Argumente der jeweils unterschiedlichen Diskussionen (Tragödie vs. Komödie, alte Komödie [verstanden als neue griechische und römische] vs. moderne Komödie, alte Komödie [verstanden als aristophanische] vs. moderne Komödie) durcheinandergeraten bzw. zum Zwecke der jeweiligen Argumentation gezielt aus ihrem Zusammenhang herausgelöst werden. In der Folge ist häufig nicht ganz klar, wovon die Rede ist, wenn über die Komödie gesprochen wird. ${ }^{46}$ Das gilt auch für Foucaults Komödienbezüge. Klar bleibt aber ein Hauptunterschied zwischen Tragödie und Komödie: das Figureninventar.

Aristoteles bestimmt die Komödie als "Nachahmung von schlechteren Menschen" und die Tragödie als »Nachahmung guter Menschen «;47 außerdem nennt er als Gegenstand der Tragödie Figuren, »die großes Ansehen und Glück genießen, wie Ödipus und Thyestes und andere hervorragende Männer aus derartigen Geschlechtern.«48 Er unterscheidet die Figuren also zum einen in moralischer Hinsicht und zum anderen, wiewohl nicht ganz getrennt davon, in sozialer Hinsicht, im engeren Sinne des Standes. Auch Hegel zufolge "sind die Zustände und Charaktere aus diesen Kreisen [d.h. »aus untergeordneten Ständen«; Gw.E.] geeigneter für das Lustspiel und das Komische überhaupt." (Ä I, 252) ${ }^{49}$ Seine Kritik an der Komödie richtet sich also nicht darauf, daß darin Bürger und einfaches Volk anstelle

46 Weniger klar auch als bei der Tragödie; was zum einen daran liegt, daß dort die Differenzierung zwischen antiker und moderner Tragödie eindeutiger ist, zum anderen aber auch daran, daß die Theoriebildung zur Tragödie ausführlicher stattfindet und die Komödie meist nur als Kontrastfolie zur Tragödie diskutiert wird. Bei Hegel erfolgt die Vermischung zweier Argumentationsstränge reflektiert, als strukturelle Wiederholung: "Dasselbe Prinzip, welches uns den Grund für die Scheidung der dramatischen Kunst in Tragödie und Komödie gab, liefert nun auch die wesentlichen

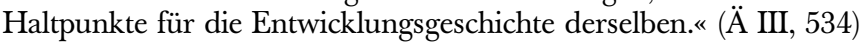

47 Aristoteles: Poetik, S. 17 (1449a 31f.); vgl. auch S. 9 (1448a 18f.).

48 Ebd., S. 39 (1453a 10f.).

49 Seine Begründung ist interessant. Er argumentiert keineswegs, daß Personen des untersten Standes der tragischen Bühne nicht würdig oder per se zu großen Taten nicht fähig wären, sondern, daß die Umstände ihnen keine Möglichkeit zu eigentlichem Handeln geben: »Den Figuren aus untergeordneten Ständen dagegen, wenn sie innerhalb ihrer beschränkten Verhältnisse zu handeln unternehmen, sehen wir überall die Gedrücktheit an; denn in ausgebildeten Zuständen sind sie in der Tat nach allen Seiten hin abhängig, eingeengt und kommen mit ihren Leidenschaften und Interessen durchweg ins Gedränge und in die Not der ihnen äußeren Notwendigkeit, 
von Helden und Fürsten auftreten, sondern wie sie und welche ihrer Eigenschaften und Tätigkeiten dargestellt werden. "Die Laster der Menschen z.B. sind nichts Komisches." »[E]igennützige Bürger«, "streitsüchtig, leichtsinnig, aufgeblasen, ohne Glauben und Erkenntnis, schwatzhaft, prahlerisch und eitel«, sind daher Hegel zufolge Gegenstand der Satire, nicht aber der wahren Komödie. ( $\ddot{A}$ III, 527) Deswegen kritisiert er auch die moderne Komödie, die

überhaupt Privatinteressen und die Charaktere dieses Kreises [d.h. Bedienten oder Kammerzofen; Gw.E.] in zufälligen Schiefheiten, Lächerlichkeiten, abnormen Angewöhnungen und Torheiten für den Zuschauer teils in Charakterschilderung, teils in komischen Verwicklungen der Situationen und Zustände dar[stellt]. (Ä III, 571)

Auf ähnliche Weise wirft Nietzsche Euripides als dem letzten der drei großen griechischen Tragiker vor, die Tragödie u.a. dadurch zugrunde gerichtet und zugleich der neueren attischen Komödie den Weg bereitet zu haben, daß er den "Mensch[en] des alltäglichen Lebens" und »das allgemeine, allbekannte, alltägliche Leben und Treiben«, überhaupt "Alltäglichkeit" und »bürgerliche Mittelmäßigkeit» auf die Bühne brachte. (GT 76f. $)^{50}$ Euripides' Figuren haben »nichts Schweres zu verantworten, nichts Grosses zu erstreben«. (GT 78) Analog dazu zeichnet sich Foucaults neue, nunmehr komische "Bühne der Justiz" gegenüber der tragischen u.a. dadurch aus, unbedeutende, einzelne Schicksale zu zeigen: »Eine sorgfältigere und genauere Justizpraxis beginnt nun, auch eine kleine Delinquenz zu erfassen ". ${ }^{51}$ (ÜS 97) Die reformierte Strafjustiz befaßt sich fortan nicht mehr mit bedeutenden "Heldentaten" (ÜS 248) und großer Schuld, die ebenso groß gesühnt werden muß, wie das noch in den Martern - und der Tragödie - der Fall ist. Was Foucault eine Ablösung der Tragödie durch die Komödie nennt, bedeutet, daß »niedrige, alltägliche Kämpfe« (ÜS 87), »das alltägliche Verhalten der Individuen, ihre Identität, ihre Tätigkeit, ihre scheinbar be-

da hinter ihnen gleich die unüberwindliche Macht der bürgerlichen Ordnung steht, gegen welche sie nicht ankommen können und selbst der Willkür der Höheren, wo diese gesetzlich berechtigt ist, ausgesetzt bleiben. An dieser Beschränkung durch

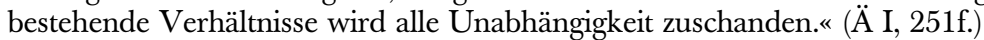

50 Auch Hegel bemerkt über die Dramen des Euripides, daß sie, verglichen mit denen Aischylos' und Sophokles', "nicht mehr denselben plastischen sittlichen Charakter an sich tragen" und sich in ihnen "schon mehr das Prinzip des Verderbens zu erkennen gibt.« G.W.F. Hegel: Vorlesungen über die Philosophie der Geschichte, S. 318.

51 Seitter setzt »kleine« in Anführungszeichen; im Original stehen keine, vgl. SP 91. 
deutungslosen Gesten« (ÜS 99), »geringfügige[ ] Dinge« (ÜS 274), daß statt Königsmördern »kleine[ ] Kriminelle[ ] (ÜS 367) in den Fokus der Justiz treten, "absolut ruhmlose[ ] Leute«, »das Banale«. Von nun an »[erscheinen] Bettler, arme oder einfach nur mittelmäßige Leute auf einer seltsamen Bühne.$^{52}$ Die Alltäglichkeit greift damit auf das Justizsystem insgesamt über, der "Straf-Prunk" der Martern wird zum »Theater der alltäglichen Züchtigung " (ÜS 146), das ehrwürdige Schauspiel der Souveränität zum "Theater des Alltäglichen ", 53 der tragische Verbrecher wird durch den komischen Delinquenten ersetzt. In dieser Komödie nimmt »das Normale den Platz des Altehrwürdigen ein«. (ÜS 249) Das »Normale« ist dabei, auf einer zweiten Bedeutungsebene, nicht nur das Alltägliche, sondern auch Ausdruck eines Normbewußtseins, das üblicherweise als eine Voraussetzung der Komödie angesehen wird, indem das Komische u.a. in der Abweichung von einer (sozialen, moralischen etc.) Norm besteht. ${ }^{54}$ Es wird noch zu sehen sein, daß die fortschreitende Orientierung am Normalen und der Norm Foucault zufolge schließlich das Ende des Dramas und den Übergang zum Roman einleitet.

Neben dem Figureninventar selbst läßt sich bei Aristoteles noch ein weiterer Unterschied zwischen Tragödie und Komödie ausmachen, der ebenfalls die Figuren betrifft: Die Tragödie ist Nachahmung einer Handlung, während die Komödie, wiewohl ebenfalls Nachahmung einer Handlung, überwiegend Nachahmung von Charakteren ist. Die Figuren spielen in der Komödie also eine größere Rolle als in der Tragödie. ${ }^{55}$ Unter Rückgriff auf

52 Michel Foucault: Das Leben der infamen Menschen (1977), in: S III, S. 309-332, hier S. 328.

53 Ebd., S. 319.

54 Rainer Warning: Komik/Komödie, in: Fischer Lexikon Literatur, hg. von Ulfert Ricklefs, Frankfurt a.M. 1996, Bd. 2, S. 897-936, hier S. 925. Vgl. auch Eckehard Catholy: Das deutsche Lustspiel vom Mittelalter bis zum Ende der Barockzeit, Darmstadt 1968, S. 8-12; Karl Hillebrand: Die klassische Komödie und ihre Voraussetzungen, in: Norbert Altenhofer (Hg.): Komödie und Gesellschaft, Frankfurt a.M. 1973, S. 25-126, hier S. 90; Bernhard Greiner: Die Komödie, S. 97ff. (unter Bezug auf Hans Robert Jauß' »Komik der Herabsetzung «); Andrea Bartl: Die deutsche Komödie. Metamorphosen des Harlekin, Stuttgart 2009, Kap. I.a: »Kulturelle Selbstwahrnehmung und Abweichung von der Norm: Was heißt komisch?«, S. 11-22.

55 Vgl. Aristoteles: Poetik, Kap. 5 und 6, S. 17-25 (1149a 30-1450b 20). Vgl. dazu Ralf Simon: Theorie der Komödie, in: ders. (Hg.): Theorie der Komödie - Poetik der Komödie, S. 47-66, hier S. 47f.; Stephan Kraft: Zum Ende der Komödie, S. 19. Dies zumindest die übliche Lesart. Differenzierter neuerdings Arbogast Schmitt in seinem Kommentar zu Aristoteles: Poetik, Berlin 2008. 
Aristoteles schreibt auch Lessing in seiner Hamburgischen Dramaturgie über das Verfassen von Dramen, in der Komödie seien »die Charaktere das Hauptwerk, die Situationen aber nur die Mittel«. Es geht demnach weniger um das, was die Protagonisten getan haben (Hegels tragische Einheit von Tat und Täter), als um das, was sie sind. Daß man Lessing zufolge in der Komödie »die Charaktere in Betrachtung ziehen« muß, ${ }^{56}$ gilt nun ebenso für das Fällen von Urteilen der reformierten Strafjustiz. Während sich Tragödie und Marter auf die Tat richten und in ihnen also "die Charaktere weniger wesentlich « sind, ${ }^{57}$ beginnen sich Komödie und reformierte Strafen auf den Charakter bzw. den Täter und seine Seele zu richten. Daher sind mit dem Wandel des Figureninventars von Tragödie zu Komödie auch Individualisierung und Psychologisierung der Figuren verbunden.

Die mit der genaueren »Charakterschilderung[ ] ( gehende Zwiespältigkeit und fehlende Geschlossenheit der Charaktere, die Hegel an der modernen Tragödie kritisiert hatte, kehrt auch in Nietzsches Kritik an Euripides' Tragödie und, in deren Folge, der neueren Komödie wieder. ${ }^{58}$ So bemängelt Nietzsche nicht nur, daß Euripides eine Art Ständeklausel verletzt, indem er das Volk auf die Bühne bringt, sondern darüber hinaus, und das ist wichtiger, daß er ein verstärkt psychologisiertes und damit zersplittertes Bild seiner Figuren zeichnet. Diese Individualisierung und Psychologisierung ist auch ihm zufolge nicht mit der Tragödie und der "Deutlichkeit und Festigkeit« (GT 64) ihrer Figuren vereinbar; sie führt zur Komödie:

Es hat ich weiss nicht wer behauptet, dass alle Individuen als Individuen komisch und damit untragisch seien: woraus zu entnehmen wäre, dass die Griechen überhaupt Individuen auf der tragischen Bühne nicht ertragen konnten. In der That scheinen sie so empfunden zu haben. (GT 71)

"[W]ährend noch Sophokles ganze Charactere malt« (GT 113), setzt mit Euripides, der »die treue Maske der Wirklichkeit« (GT 76) und »heftige[ ] Leidenschaften" abbildet, ein "Ueberhandnehmen der Charakterdarstellung und des psychologischen Raffinements" ein. "Der Charakter soll [...] durch künstliche Nebenzüge und Schattirungen, durch feinste Bestimmtheit

56 Gotthold Ephraim Lessing: Hamburgische Dramaturgie, S. 470.

57 Ebd.

58 Auch Hegel sieht in Euripides bereits eine frühe Form jenes Mangels an "Festigkeit« der Charaktere: "Euripides verläßt auch bereits die abgerundete Plastik der Charaktere«. ( $\ddot{\mathrm{A}}$ III, 562) 
aller Linien individuell wirken«. (GT 113) »[D]er Spiegel, in dem früher nur die grossen und kühnen Züge zum Ausdruck kamen, zeigte jetzt jene peinliche Treue, die auch die misslungenen Linien der Natur gewissenhaft wiedergiebt." (GT 76) $)^{59}$ Das geschieht auch in den reformierten Strafprozessen, wie Foucault sie beschreibt: Hatten die Martern noch rganzer Verbrecher, sozusagen »die grossen und kühnen Züge» der "Helden" vorgeführt, beginnen die Strafreformen durch Psychologisierung der Individuen »die beliebige, die gemeine Individualität« (ÜS 246) hervorzubringen, die »kleine[ ] Seele des Kriminellen« (ÜS 327), die "Niedrigkeit der Angelegenheiten «60 und die »kleinliche Schamhaftigkeit der Absichten ${ }^{61} \mathrm{zu}$ beleuchten und banale, kleine und kleinliche Taten zu zeigen, die aus Lüsten, Trieben und Begierden hervorgegangen sind. Man

urteilt [...] über Leidenschaften, Instinkte, Anomalien, Schwächen, Unangepaßtheiten, Milieu- oder Erbschäden; man bestraft Aggressionen, aber durch sie hindurch Aggressivitäten; Vergewaltigungen, aber zugleich Perversionen; Morde, die auch Triebe und Begehren sind. (ÜS 27) ${ }^{62}$

Sophokles' Zeichnung "ganze[r] Charactere" (Nietzsche) bzw. "plastische[r] « oder "gediegene[r] Charaktere" (Hegel) zersplittert im modernen Urteilsverfahren zu Psychogrammen der Delinquenten. Vorhin ist gezeigt worden, wie die Tragödie durch die Psychologisierung ihrer Figuren zu Ende geht, dadurch, daß weniger nach der Tat denn nach der Seele des Täters gefragt wird. Eben dies tun die mit den Strafreformen aufkommenden Disziplinartechniken, und Foucaults Komödie der reformierten Strafjustiz besteht genau darin, daß durch Psychologisierung und Individualisierung des Verbrechers der Delinquent und damit die "Seele [...] auf die Bühne der Justiz [tritt]«. (ÜS 34) Seiner Charakterisierung dieser »neue[n] Figur« (ÜS 26) liegen daher wiederum konkrete gattungstheoretische Überlegungen zum

59 Auch bei Hegel kommt in der modernen Komödie, »als Ersatz «ür die ihr fehlende Komik, »die fein ausgebildete Geschicklichkeit in genauer Zeichnung der Charaktere« zum Zug. (

60 Michel Foucault: Das Leben der infamen Menschen, S. 319.

61 Ebd., S. 326.

62 Zum "Trieb« vgl. auch Hegel, dem zufolge in der modernen Komödie der "sittliche Trieb « und nicht, wie in der alten Komödie, »die bewußte absolute sittliche Natur [...] spielt«. G.W.F. Hegel: Über die wissenschaftlichen Behandlungsarten des Naturrechts, seine Stelle in der praktischen Philosophie und sein Verhältnis zu den Rechtswissenschaften, in: Werke, Bd. 2, Frankfurt a.M. ${ }^{42000, ~ S . ~ 434-530, ~ h i e r ~ S . ~} 498$ (im folgenden per Sigle $\mathrm{N}$ im laufenden Text zitiert). 
Ende der Tragödie in der Moderne und zur Komödie zugrunde: Der komische Delinquent unterscheidet sich vom tragischen Verbrecher genau darin, daß in ihm die Einheit von Tat und Täter aufgelöst ist. Foucault macht sich auch hier wieder Nietzsches und Hegels ästhetische Argumentation zu eigen und drückt seine Kritik an den Techniken moderner Strafjustiz indirekt über das klassische ästhetische Argument fehlender Einheit aus: In den psychologisierenden Gerichtsverfahren geht die Ganzheit des Verbrechens als Tat verloren; sie können es in dieser Hinsicht nicht mit dem blutigen Strafschauspiel der Martern aufnehmen.

Die komische Maske (III): Kodifizierung und Typisierung, Individualisierung und Psychologisierung

Hierüber erklärt sich die `Maskierung` der »neue[n] Figur[en] « auf Foucaults Justizbühne der Komödie, anders als oben, wo die Maske als Zeichen des Zeichencharakters bzw. als abstrakte Rechtsperson interpretiert wurde, auf noch eine dritte Weise: als Ausdruck von Individualisierung und Psychologisierung des Delinquenten (hängt dabei aber gleichzeitig noch mit der Rechtsmaske zusammen, indem sie Ergebnis der Kodifizierung des Strafrechts und der dazu notwendigen Typisierung und Individualisierung von Verbrechen und Strafen ist).

In der Geburt der Tragödie unterscheidet Nietzsche zwei Arten von Maskierung. Die Maskierung der alten Tragödie geht auf die »Urtragödie« (GT 60) zurück, auf die »Tragödie in ihrer ältesten Gestalt«, in der Dionysos der »einzig vorhandene Bühnenheld « war. Bei Aischylos und Sophokles sind die Figuren "nur Masken jenes ursprünglichen Helden Dionysos", der weiterhin als der eigentliche »tragische Held« »hinter allen diesen Masken [...] steckt«. (GT 71) Das Dionysische wird durch den schönen Schein und durch »das Apollinische der Maske« verhüllt dargestellt (GT 65), das Bühnengeschehen zeigt die schreckliche »dionysische Wahrheit« apollinisch maskiert. Anders verhält es sich mit der Maskierung bei Euripides und in der neueren Komödie:

[W]ährend noch Sophokles ganze Charactere malt und zu ihrer raffinirten Entfaltung den Mythus ins Joch spannt, malt Euripides bereits nur noch grosse einzelne Charakterzüge, die sich in heftigen Leidenschaften zu äussern wissen; in der neuern attischen Komödie giebt es nur noch Masken mit einem Ausdruck, leichtsinnige Alte, geprellte Kuppler, verschmitzte Sclaven in unermüdlicher Wiederholung. (GT 113) 
Die Maske bei Euripides ist nur mehr leere Nachahmung: Seine "Helden haben nur nachgeahmte maskirte Leidenschaften und sprechen nur nachgeahmte maskirte Reden" (GT 75), denen kein Dionysisches mehr zugrunde liegt. Anders als hinter den Masken der alten tragischen Helden verbirgt sich hinter den Masken der alltäglichen Figuren des Euripides nicht mehr Dionysos, und die apollinische Maske des schönen Scheins wird durch die "treue Maske der Wirklichkeit" (GT 76) ersetzt. Diese hebt einzelne, besondere Charakterzüge hervor, statt wie bei Aischylos und Sophokles weniger charakteristische Züge zu zeigen, die sich dadurch zum »ewigen Typus« (GT 113) erweitern lassen.63 Nietzsche beobachtet ein »Ueberhandnehmen der Charakterdarstellung und des psychologischen Raffinements in der Tragödie von Sophokles ab«; »[d]er Charakter soll [...] durch künstliche Nebenzüge und Schattirungen, durch feinste Bestimmtheit aller Linien individuell wirken«. (GT 113) Er stellt diese Entwicklung als das Ergebnis einer analytischen Verwissenschaftlichung dar:

\begin{abstract}
Auch hier gewahren wir den Sieg der Erscheinung über das Allgemeine und die Lust an dem einzelnen gleichsam anatomischen Präparat, wir athmen bereits die Luft einer theoretischen Welt, welcher die wissenschaftliche Erkenntnis höher gilt als die künstlerische Wiederspiegelung einer Weltregel. Die Bewegung auf der Linie des Charakteristischen geht schnell weiter (GT 113),
\end{abstract}

die Psychologisierung der euripideischen Figuren führt zu einer Typisierung der Figuren der neuen Komödie, in der es »nur noch Masken mit einem Ausdruck« gibt. Nietzsche beklagt sowohl das "psychologische[ ] Raffinement[ ] u und die "Schattirungen" und "feinste Bestimmtheit aller Linien« der euripideischen Masken einerseits als auch den »eine[n] Ausdruck" der Masken der neueren Komödie (GT 113f.), die also wiederum nicht fein genug gezeichnet sind, andererseits. ${ }^{64}$ Er zeichnet eine Entwicklungslinie vom umfassenden smythischen Allgemeinen der alten Tragödie über das psychologisierte Besondere der euripideischen Tragödie hin zum reduzierten typisierten Allgemeinen der neuen attischen Komödie. Diese Linie mag gattungsgeschichtlich nicht korrekt sein, doch weist sie auf eine

63 Tatsächlich zeigten die Masken der alten griechischen Tragödie zunächst eine neutrale Mimik, weder lachende noch weinende oder greinende Gesichtszüge. Typisierte Charaktermasken kamen erst später auf.

64 Diese Spannung zwischen Individualisierung und Typisierung ist ein Problem wissenschaftlicher Klassifizierung überhaupt, mit der Nietzsche die Maske ja auch in Zusammenhang bringt. 
Problematik hin, der auch die Strafrechtsreformen bei Foucault unterliegen: die der wissenschaftlichen Klassifikation.

Nietzsche begreift die Abkehr von der Darstellung des mythischen "Allgemeine[n] « durch die typisierte Maske der neueren Komödie als Ausdruck einer analytischen Verwissenschaftlichung, deren Bemühen seinerseits einem nun nicht mehr mythischen, sondern wissenschaftlich-objektiven Allgemeinen gilt. Die Klassifikation der Figuren ist gattungsgeschichtlich in der Tat ein Merkmal der Komödie - man denke an die Charaktermaske der Typenkomödie: "Figurenklassifikationen waren von der Typenkomödie her bekannt«;65 diese stellt sozusagen Charaktertableaus auf. Die der Komödie demnach eigene schematische swissenschaftliche Klassifikation< von Figuren und ihren Handlungsweisen läßt sich daher bei Foucault mit der von den Strafreformern angestrebten Klassifikation und Taxonomisierung von Verbrechen und Verbrecher kurzschließen. In den reformierten Strafen richtet sich der Blick auf die Seele des Verbrechers, seine individualisierende Psychologisierung, im Dienste der taxonomischen Klassifizierung bzw. juridischen Kodifizierung von Verbrechen und Strafen. Auch die Strafreformen der Aufklärung "athmen [...] die Luft einer theoretischen Welt«, und die Maske der reformierten Strafen ist Element einer Rationalisierung und Verwissenschaftlichung des Strafverfahrens: »Mit der Notwendigkeit einer parallelen Klassifizierung von Verbrechen und Strafen entsteht gleichzeitig die Notwendigkeit einer Individualisierung der Strafen, die dem besonderen Charakter eines jeden Verbrechers gerecht wird." (ÜS 126) Untrennbar von der Individualisierung und taxonomischen Klassifizierung der Strafen ist daher die Individualisierung und taxonomische Klassifizierung der Straftäter, die in ihrer Maskierung Ausdruck finden. Im Zusammenhang der Bemühungen der Strafreformer um ein allgemeingültiges System der Bestrafungen ist die wissenschaftlich typisierte Maske ein notwendiges Element des aufzustellenden Straftableaus - und also des Strafschauspiels.

Die Verbindung zwischen Kodifizierung und Individualisierung [und d.h. auch: zwischen Typisierung und Individualisierung; Gw.E.] wird in den wissenschaftlichen Modellen der Zeit gesucht. Das geeignetste Schema wurde zweifellos von der Naturgeschichte angeboten: die Taxonomie der Arten in einer kontinuierlichen Abstufung. Gesucht wird ein Linné der Verbrechen und Strafen dergestalt, daßjede einzelne Gesetzesübertretung und jedes straffällige Individuum ohne irgendeine Willkür unter ein allgemeines Gesetz fallen können. (ÜS 127)

65 Fotis Jannidis: Figur, literarische, in: Metzler Lexikon Literatur- und Kulturtheorie, hg. von Ansgar Nünning, Stuttgart/Weimar 1998, S. 149. 
Ergebnis der Strafrechtsreformen und deren Streben nach Allgemeingültigkeit und Objektivität ist demnach der genaue Blick auf »jedes straffällige Individuum" - das Erscheinen also der »kleinen Delinquenz", der alltäglichen Figuren auf der Justizbühne. Das Auftreten eben dieser »kleinen Delinquenz" stellt die Rechtstheorie dann aber vor ein Problem. Der Allgemeinheitsanspruch der juridischen Kodifizierung bzw. der wissenschaftlichen Klassifizierung der Straftäter gerät in Konflikt mit dem Streben nach größtmöglicher Genauigkeit und der dazu notwendigen Individualisierung der Verbrechen und der Verbrecher. Der Anspruch auf Universalität des Gesetzes und Allgemeingültigkeit der Verbrechen und Strafen führt zu einer immer feineren Typisierung und Individualisierung der Verbrecher, die schließlich mit genau diesem Universalitätsanspruch kollidieren. Sie mündet in eine Psychologisierung, die letztlich nicht mehr mit den "legalistischen" Prinzipien der Universalität des Rechts vereinbar ist. Die Maskierung läßt sich daher ähnlich wie bei Nietzsche als der Beginn einer Psychologisierung der ddramatischen Figur auf der Bühne der Strafen lesen. Wie Euripides und die neuere Komödie ihre Figuren mit psychologisierten bzw. typisierten Masken versehen, klassifizieren die modernen Strafverfahren den Delinquenten gemäß psychologisch typisierten Analyserastern. Die von Foucault beschriebenen Phänomene der Individualisierung und Psychologisierung finden damit wiederum auf den drei Ebenen der Episteme, des Strafrechts und der Dramen-/Komödien-/Gattungstheorie statt - auf epistemegeschichtlicher Ebene Individualisierung und Psychologisierung der Wissenschaften und Diskurse, auf strafrechtsgeschichtlicher Ebene die des Delinquenten und auf dramentheoretischer Ebene die der dramatischen Figuren. Die Maske steht dann für die "Seele« des Delinquenten, d.h. für die Anwendung psychologischer Erkenntnisse auf oder für das erlangte psychologische Wissen über ihn. Die abstrakte Rechtsmaske verwandelt sich über die, ursprünglich der Kodifizierung dienenden, individualisierte und typisierte Charaktermaske hin zu einer psychologisierten Darstellung der Figur, der letztlich keine Maske mehr genügen kann. ${ }^{66}$ Sie führt zum Ende der legalistischen Theorie ebenso wie zum Ende der Komödie, zum "Ende der Kunst mit der Maske«. Die komische Figur verliert durch fort-

66 Vgl. Hegel über das "moderne[] Schauspiel«: "Hier nämlich fallen die Masken und die Musikbegleitung fort, und an deren Stelle tritt das Mienenspiel, die Mannigfaltigkeit der Gebärde und die reichhaltig nuancierte Deklamation." (̈̈ III, 513f.) 
schreitende Individualisierung und Psychologisierung ihren dramatischen Figurencharakter. ${ }^{67}$

\section{Komische Schatten und Gespenster}

Maskierung und Psychologisierung gehen daher mit einer Geisterhaftigkeit der Figuren auf der neuen »Bühne der Justiz« einher. Die "schattenhaften Silhouetten, gesichtslosen Stimmen, unbetastbaren Wesen« (ÜS 26) wirken gespenstisch - auch dies eine indirekte Anspielung auf Hegels Ende der Tragödie und deren Ablösung durch die Komödie bzw. die Unterscheidung von antiker und moderner Tragödie. So bemängelt Hegel in seiner Ästhetik das "Jenseitige[ ] und Gespensterhafte[ ] moderner dramatischer Figuren, wie er überhaupt die fehlende "Einheit und Festigkeit des Charakters" und "die Nichtigkeit und Halbheit im Schwanken und Übergehen" "gespenstig“ nennt. ( $\ddot{\mathrm{A}} \mathrm{I}, 315 \mathrm{f}$.) 》Gespenstig« ist also eine Figur, die keine Einheit mit ihrer Tat bildet, die nicht in ihrer Tat aufgeht, die verschiedene und womöglich widerstreitende Eigenschaften aufweist und in Hegels Sinne charakterlos und daher untragisch ist. ${ }^{68}$ Die gespenstische Schattenhaftigkeit und Wesenlosigkeit der komischen Figur auf der reformierten Strafbühne verweisen mithin nicht nur auf die Abstraktheit des Rechtssubjekts, sondern auch auf die Unkörperlichkeit und Ungreifbarkeit der auftretenden Seele, auf das, was Hegel als mangelnde Plastizität der modernen dramatischen Figuren bezeichnet. Hier wie auch anderswo wiederholt sich bei Hegel der Unterschied zwischen Tragödie und Komödie, variiert, als Unterschied zwischen antiker und moderner Schauspielkunst. Bei den Griechen »verbindet sich [...] die redende Kunst mit der Skulptur; das handelnde Individuum tritt als objektives Bild in totaler Körperlichkeit heraus«; »die Statue belebt [sich]«. Dagegen legt die moderne Schauspielkunst Wert auf die Darstellung der "Eigentümlichkeit des Charakters in den feinsten Schattierungen«, und zwar, neben Gebärden und Mienenspiel, »im Ton und Ausdruck der Stim-

67 Rückgebunden an die Gattungsgeschichte der Komödie bedeutet das das Verschwinden der Typenkomödie zugunsten der psychologisierten ernsten Komödie und ihrer Verwandten im 18. Jahrhundert, die schließlich, so könnte man sagen, dem noch entschiedener psychologisierenden Roman weicht.

68 Vgl. oben, Kap. IV, Unterkap. "Die Trennung der tragischen Einheit von Täter und Tat«. 
me«. (Ä III, 511) Die statuenhafte Körperlichkeit wird durch die Modulierung der körperlosen Stimme ersetzt, das »objektive Bild « des tragischen Charakters durch die gespenstischen "Schattierungen" des untragischen oder komischen Individuums - man denke hier auch noch einmal an die "Schattirungen" der Charaktere, die Nietzsche an der Tragödie des Euripides bemängelt. (GT 113) Die "schattenhaften Silhouetten«, die die Bühne betreten, sind also Ausdruck und Ergebnis der Psychologisierung der Figuren, deren Zersplitterung und Unkörperlichkeit sich, wie gesagt, nicht mit der Tragödie vertragen.

Auch Marx bringt die Komödie und ihre Figuren mit Gespenstern in $\mathrm{Zu}$ sammenhang. Er schreibt über die Revolution von 1848, die er insgesamt als Komödie bzw. Farce charakterisiert: "Menschen und Ereignisse erscheinen als umgekehrte Schlemihle, als Schatten, denen der Körper abhanden gekommen ist. « ${ }^{69}$ Nicht nur die dramatischen Figuren (»Menschen«) der Komödie, sondern auch der dramatische Konflikt ("Ereignisse») ist also schattenhaft und substanzlos. Wieder ist es Hegel, der hierfür das Vorbild liefert, wenn er in seinem Naturrechtsaufsatz in bezug auf die Konflikte der Komödie von "Schattenbildern« spricht. (N 499) Die "alte oder göttliche«, d.h. aristophanische, Komödie zeigt "Schattenbilder von Konflikten«, die moderne Komödie »Schattenbilder von Selbständigkeit und Absolutheit«. (N 496) ${ }^{70}$ Hegels Komödienkonzeption verändert sich in der Folge in mancherlei Hinsicht, doch bleibt die Schattenhaftigkeit oder die »Wesenlosigkeit« der »Zwecke« ( ein Charakteristikum der Komödie, deren "Zwecke und Charaktere an und

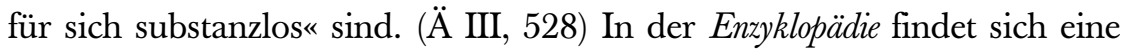
entsprechende Gegenüberstellung der "substantiellen Zwecke« der Tragödie und der »nichtigen Zwecke« der Komödie. ${ }^{71}$ Während also die Konflikte der Komödie schattenhaft, wesen- und substanzlos sind, verkörpern die Pro-

69 Karl Marx: Der achtzehnte Brumaire des Louis Bonaparte, in: ders./Friedrich Engels: Werke, Bd. 8, hg. vom Institut für Marxismus-Leninismus beim ZK der SED, Berlin 31972, S. 115-207, hier S. 119 (im folgenden per Sigle MEW sowie Band- und Seitenangabe zitiert). Die MEW folgen der zweiten, von Marx überarbeiteten Ausgabe des Achtzehnten Brumaire von 1869. In der MEGA ist der entsprechende Band (I, 21) noch nicht erschienen; dort liegt bisher nur die Erstveröffentlichung von 1852 vor (Bd. I, 11).

70 Siehe dazu Michael Schulte: Tragödie im Sittlichen. Zur Dramentheorie Hegels, München 1992; ders.: Hypokrisie und Maske, S. 216-219; Stephan Kraft: Zum Ende der Komödie, S. 217ff.

71 G.W.F. Hegel: Enzyklopädie der philosophischen Wissenschaften III, S. 114. 
tagonisten der Tragödie die "beiden Zonen des Sittlichen" und stehen »in leibhafter Beziehung" zueinander. (N 499) Diese »leibhafte[] Beziehung" ist für den frühen Hegel der Jenaer Zeit ein Grund dafür, daß »das absolute Verhältnis" »im Trauerspiel aufgestellt« ist (N 499); gegenüber der sschattenhaften Beziehung der Komödie ist sie in dieser (ästhetischen) Hinsicht höherwertig. ${ }^{72}$ Ebenso werden in Foucaults Komödie nicht nur die Figuren, sondern wird auch das dramatische Geschehen seiner Tragik beraubt:

Es sind diese Schatten hinter den Tatsachen des Verfahrens, die in Wirklichkeit beurteilt und bestraft werden. Beurteilt werden sie vermittels der smildernden Umständer, die in den Wahrspruch ja nicht nur die ,Umstände` der Tat eintreten lassen, sondern etwas ganz anderes, rechtlich gar nicht Kodifizierbares: die Erkenntnisse und Einschätzungen betreffend den Verbrecher, [...] all die Begriffe [...], die unter dem Vorwand, eine Tat zu erklären, ein Individuum qualifizieren. (ÜS 27)

Fortan stehen im Zentrum des Verfahrens der Urteilsfindung nicht mehr der Konflikt, sondern sein Schatten, d.h., nicht mehr die Tat, sondern ihre Umstände. Eine »leibhafte Beziehung" dagegen besteht in der Marter und ihrer direkten und körperlichen Konfrontation des Verurteilten mit dem König. Ähnlich wie bei Hegel ist diese tragische Konfrontation der Marter der komischen Konfrontation der reformierten Strafe unter ästhetischen Gesichtspunkten implizit überlegen.

72 Die Forschung diskutiert, wie es sich mit dem Status von Tragödie und Komödie bei Hegel insgesamt verhält. Lange ging man von einer eindeutigen Höherwertigkeit der Tragödie aus, wogegen in jüngerer Zeit vielfach die gegenteilige Meinung vertreten wurde. Gustav-H. H. Falke bezeichnet die Höherwertigkeit der Tragödie gegenüber der Komödie bei Hegel als »unselige[ ] Annahme«. (Gustav-H. H. Falke: Begriffne Geschichte. Das historische Substrat und die systematische Anordnung der Bewusstseinsgestalten in Hegels Phänomenologie des Geistes. Interpretation und Kommentar, Berlin 1996, S. 43) Zumindest für den Naturrechtsaufsatz ist sie aber nicht falsch. Es mag helfen, zwischen ästhetischer und spekulativer oder systematischer Bedeutung der Gattungen zu unterscheiden. In ästhetischer Hinsicht ist die Tragödie vollkommener als die Komödie, in systematischer und spekulativer Hinsicht dagegen ist die Komödie, als Ausdruck eines entwickelteren Bewußtseins, die im Vergleich zur Tragödie fortgeschrittenere Gattung. 
In der Körperlosigkeit und Schattenhaftigkeit der Figuren auf der Bühne kündigt sich ebenso wie in der fortschreitenden Individualisierung und Psychologisierung das Ende der Komödie an. Körperlose Schatten sind eigentlich nicht bühnentauglich, und durchpsychologisierte Figuren eignen sich nicht als dramatische Charaktere.

Bei Hegel beginnt das Ende der Komödie da, wo ihre Charakteristika sich "in ihre Extreme" (N 497) entwickeln, wo also das, was die Komödie ausmacht, in einem Maße ausgestaltet wird, daß es ihren Rahmen sprengt. Das wäre bei Hegels Tragödie nicht möglich; eine Verstärkung ihrer Charakteristika würde nicht in Extreme und entstellende Übertreibung führen, sondern zu noch engerer Geschlossenheit und »Gediegenheit«. Bei der Komödie dagegen ist die Ausbildung ihrer Charakteristika »in ihre Extreme« bereits in den Charakteristika selbst, insbesondere der Individualisierung, angelegt. Die Komödie trägt immer bereits ihr Ende und das Ende des Dramas überhaupt in sich, und ihre Entwicklung führt in ihre Auflösung. Das erhellt aus der Analogie zwischen Komödie und attischer Demokratie, die Hegel im Naturrechtsaufsatz herstellt: Die Polis kann sich erlauben, "mit absolute[m] Leichtsinn« »ihre mannigfaltigen Seiten und Momente sich zur vollkommenen Individualität ausgebären« zu lassen, weil sie »eine zum Bewundern starke Natur« hat. (N 496)

Eine solche sittliche Organisation wird so z.B. ohne Gefahr und Angst oder Neid einzelne Glieder zu Extremen des Talents in jeder Kunst und Wissenschaft und Geschicklichkeit hinaustreiben und sie darin zu etwas Besonderem machen, - ihrer selbst sicher, daß solche göttlichen Monstruositäten der Schönheit ihrer Gestalt nicht schaden, sondern komische Züge sind, die einen Moment ihrer Gestalt erheitern. Als solche heitere Erhöhungen einzelner Züge werden wir, um ein bestimmtes Volk anzuführen, den Homer, Pindar, Aischylos, Sophokles, Platon, Aristophanes usw. ansehen können, [werden] aber auch sowohl in der ernsthaften Reaktion gegen die ernsthafter werdende Besonderung des Sokrates und vollends in der Reue darüber, als [auch] in der pullulierenden Menge und hohen Energie der zugleich aufkeimenden Individualisierungen nicht verkennen, daß die innere Lebendigkeit damit in ihre Extreme herausgetreten [war], in der Reife dieser Samenkörner ihre Kraft, aber auch die Nähe des Todes dieses Körpers, der sie trug, ankündigte und die Gegensätze, die sie überhaupt hervorrief und vorher selbst in ihrem ernsthafteren und weitgreifenderen Aussehen, wie Kriege, als Zufälligkeiten und mit gleichem Leichtsinn erregen und betreiben konnte, nicht mehr für Schattenbilder, sondern für ein übermächtig werdendes Schicksal nehmen mußte. (N 497f.) 
Wie die Komödie individualisierte Figuren ausbildet, treibt die Polis "einzelne Glieder zu Extremen des Talents« hinaus, zu »komische[n] Züge[n] [...], die einen Moment ihrer Gestalt erheitern". Diese »Individualisierungen« der Polis sind Homer (der zeitlich nicht eigentlich dazugehört), Pindar, dann Aischylos, Sophokles, Platon, Aristophanes und, schließlich, Sokrates. Auch er ist ein Ergebnis der leichtsinnig-heiteren Ausbildung des Besonderen, doch seine "Besonderung " erweist sich als »ernsthafter" als die der Vorgenannten. Hegel kommt im Naturrechtsaufsatz nicht noch einmal auf Sokrates zu sprechen, führt dessen Rolle aber an anderen Stellen vielfach aus. Sokrates verkörpert »die aufgehende innere Welt der Subjektivität«, und dieses "Prinzip des Sokrates erweist sich als revolutionär gegen den athenischen Staat", indem es die Trennung des Einzelnen von der Polis und also die Trennung der charakteristischen Einheit von Bürger und Staat bewirkt: »Viele Bürger schieden jetzt vom praktischen Leben, von Staatsgeschäften $\mathrm{ab}$, um in der idealen Welt zu leben.«73 Mit Sokrates hält ein Wissen Einzug, das das Bestehende und Bekannte in Frage stellt, indem es sich ihm gegenüber ironisch verhält. Daher bedeutet Sokrates den Höhepunkt der attischen Demokratie sowie der Komödie (man denke an seinen Auftritt in Aristophanes' Wolken, auf die Hegel an entsprechender Stelle in der Phänomenologie anspielt [vgl. PG 543]) und zugleich den Umschlagspunkt in ihrer beider Niedergang.

Innerlichkeit, Fleischlosigkeit, Ironie und Positivität

In nuce findet sich das Bild des modernen komischen Subjekts bei Foucault bereits in Psychologie und Geisteskrankheit von $1962 .{ }^{74}$ Dort spricht er von einem "neuen psychologischen Drama[ ]«, das durch die "psychoanaly-

73 G.W.F. Hegel: Vorlesungen über die Philosophie der Geschichte, S. 329.

74 Psychologie und Geisteskrankheit ist Foucaults überarbeitete Fassung eines seiner frühesten Texte, Maladie mentale et personnalité (1954). Diese erste Fassung ist nicht ins Deutsche übersetzt. Die ersten zwei Drittel der zweiten Fassung, Maladie mentale et psychologie (1962), sind bis auf kleinere Änderungen und Korrekturen mit der ersten Fassung identisch; dagegen wurden Kapitel 5 und 6 sowie der Schluß (durch Umnumerierung in der deutschen Übersetzung entsprechend den Kapiteln 4 und 5 sowie dem Schluß) vollständig durch neuen Text ersetzt. Dabei tauchen insbesondere die Bezüge zum Drama und Dramatischen sowie zum Tragischen erst in der Neufassung auf. Vgl. Michel Foucault: Psychologie und Geisteskrankheit, S. 115, 118, 132. 
tische[] Intervention" hervorgebracht wird ${ }^{75}$ und dem Tragischen entgegengesetzt ist, ${ }^{76}$ also dem "Drama des Ausschlusses" aus Wahnsinn und Gesellschaft. (WG 167) Liest man die folgende kurze Passage mit den entsprechenden Stellen aus Überwachen und Strafen zusammen, läßt sich dieses "neue[ ] psychologische[ ] Drama[ ] näher bestimmen, nämlich als Komödie, als Komödie der Psychologisierung des modernen Menschen. Sie besteht im

Verhältnis, das vor fast zweihundert Jahren der Mensch des Okzidents zu sich selbst hergestellt hat. Dieses Verhältnis ist [...] das Hervortreten - in den Formen des $\mathrm{W}$ issens - eines homo psychologicus, dem es aufgegeben ist, die innere, fleischlose, ironische und positive Wahrheit alles Selbstbewußtseins und aller möglichen Erkenntnis in sich zu versammeln. ${ }^{77}$

Der moderne Mensch tritt in ein Verhältnis zu sich selbst. Das setzt eine Distanznahme voraus, wie sie laut Hegel in der Komödie erfolgt, im komischen Selbstbewußtsein, das um seine Dopplung aus Schauspieler und Figur weiß. Die vier Charakteristika dieses modernen Selbstbezugs, die Foucault hier nennt - Innerlichkeit, Fleischlosigkeit, Ironie und Positivität - sind Charakteristika, mittels deren er in Überwachen und Strafen die Komödie von der Tragödie des Strafens abgrenzt.

Das Wort "innere« deutet auf die Verinnerlichung von Machtstrukturen hin, die Verinnerlichung einer Erkenntnis, eines wissenschaftlichen Wissens oder Diskurswissens, als dessen Ergebnis sich das moderne Selbstbewußtsein erweist. Eben diese Innerlichkeit machte ja Hegel zufolge den Unterschied zwischen Tragödie und Komödie (bzw. zwischen der antiken und der modernen Tragödie) aus. ${ }^{78}$ »Innere« meint aber auch spsychisch im

75 Ders.: Psychologie und Geisteskrankheit, S. 130.

76 Vgl. ebd., S. 132.

77 Ebd., S. 131.

78 Vgl. Ä III, 555. Ludwig Siep schreibt in seinem Stellenkommentar zur Phänomenologie: "Hegel parallelisiert offenbar die Zerstörung der naiven Polis-Sittlichkeit durch den Sokratischen `Individualismus« mit der Komödie bzw. dem Satyrspiel.« (Ludwig Siep: Der Weg der Phänomenologie des Geistes. Ein kooperativer Kommentar, Frankfurt a.M. 2000, S. 309) Er bezieht sich dabei auf die folgende Hegelpassage: „Die Vollendung der Sittlichkeit zum freien Selbstbewußtsein und das Schicksal der sittlichen Welt ist daher die in sich gegangene Individualität, der absolute Leichtsinn des sittlichen Geistes«. (PG 513; Hervorhebung Gw.E.) Leider erläutert Siep seinen Kommentar nicht weiter; er stimmt aber mit der obigen Lesart überein, die Hegel nah an Nietzsche und dessen Kritik an der neueren Komödie rückt, die ja ebenfalls Ausdruck der sokratischen Individuierung ist. 
Gegensatz zu ‘körperlich‘, meint die Psychologisierung der Figuren. Daher hängt mit der Innerlichkeit sowie der Verinnerlichung des dramatischen Konflikts auch die "fleischlose" Wahrheit dieses Selbstbewußtseins zusammen, die Foucault später an der bereits mehrfach zitierten Stelle in Überwachen und Strafen wieder aufgreift - in bezug auf den Übergang von der Tragödie zur Komödie der Justiz, die es mit "schattenhaften Silhouetten, gesichtslosen Stimmen, unbetastbaren Wesen«, kurz, mit "körperlose[r] Realität« zu tun hat und damit ebenso "fleischlos" ist. Zum einen ist das Fleischlose das Unblutige und von daher nicht mehr zur Tragödie (und zur Marter) gehörig. Zum anderen klingt in der Fleisch- und also Körperlosigkeit auch die Schattenhaftig- und Substanzlosigkeit der komischen Figuren an, also das, was Hegel "gespenstig" nennt. Diese `Gespenstigkeit ist Hegel zufolge Ergebnis des "Prinzip[s] der neueren Ironie» in der Dramatik. Gemeint ist die Ironie der Frühromantiker, namentlich Schlegels und Tiecks: "Diese falsche Theorie hat die Dichter verführt, in die Charaktere eine Verschiedenheit hineinzusetzen, welche in keine Einheit zusammengeht, so daß sich jeder Charakter als Charakter zerstört.« (Ä I, 315) Jenseits dieses engen und pejorativen Ironiebegriffs bei Hegel ist die ironische Haltung überhaupt ein zentrales Merkmal der Komödie, das in Techniken ironischer Selbstbezüglichkeit wie Hervortreten aus der Rolle etwa durch Abnehmen der Maske, Parabase, Illusionsdurchbrechung, Spiel im Spiel Ausdruck findet. ${ }^{79}$ Drittens schließlich ist die sokratische Ironie angesprochen, die Hegel mit der Komödie - bzw. ihrem Ende - verknüpft. Entscheidender dürfte hier aber Nietzsches Identifikation des Sokratischen - und also der sokratischen Ironie - mit der modernen Vernunft und Wissenschaft sein, die sich bei Euripides ankündigt, das Ende der Tragödie besiegelt und in die geringgeschätzte neuere Komödie überleitet. So bezeichnet Nietzsche Euripides' Stücke und deren "naturalistische« Tendenz als Ergebnisse des "aesthetischen Sokratismus" und als "Product jenes eindringenden kritischen Prozesses, jener verwegenen Verständigkeit«, als »Beispiel für die Productivität jener rationalistischen Methode.« (GT 85)

Über Sokrates ist das Ironische mit dem Positiven verknüpft. Das, was Foucault "positiv" nennt, entspricht dem, was Nietzsche in der Geburt der Tragödie "optimistisch" nennt, wenn er von der "in ihrem tiefsten Wesen optimistische[n] Wissenschaft, mit ihrem Ahnherrn Sokrates an der Spitze", spricht. (GT 103) Die "positive« Wahrheit des modernen Selbstbezugs ist

79 Vgl. Bernhard Greiner: Die Komödie, S. $6 \mathrm{ff}$. 
die Wahrheit der modernen Wissenschaft als der Humanwissenschaft, in diesem Falle der Psychologie. Ironisch ist sie zum einen, weil der Mensch sich darin selbst zum Gegenstand seines eigenen Wissens wird (wie der Zuschauer sich selbst auf der Bühne sieht), und zum anderen, weil sie Anspruch auf eine Positivität erhebt, die es nicht geben kann - weil man eben, mit Sokrates, nichts wissen kann. Vor dem Hintergrund des Gattungsdiskurses erweist sich die "innere, fleischlose, ironische und positive Wahrheit alles Selbstbewußtseins" als das Selbstverhältnis des modernen Menschen, zu dem sich das Selbstverhältnis des komischen Subjekts entwickelt. Foucaults "homo psychologicus", die moderne Seele, geht damit aus der ironischen Subjektivität der Komödie, dem ironischen komischen Subjekt hervor.

Der Zuschauer betritt die Bühne: Die Komödie der Hoffräulein und das Ende des Dramas

Foucaults Argumentation knüpft noch in anderer Hinsicht an die gattungstheoretische Unterscheidung zwischen Tragödie und Komödie an. Die inhaltliche Neuerung der Komödie gegenüber der Tragödie, die darin liegt, daß das Volk die Bühne betritt, bedeutet auf struktureller und dramaturgischer Ebene eine weitere Veränderung, nämlich die Umkehrung der Blickverhältnisse. Es steht nicht mehr der einzelne Held auf der Bühne, sondern der Durchschnittsbürger, und damit rückt sozusagen die ganze Gesellschaft, rücken die Vielen ins Zentrum des Blicks, blicken ihrerseits ins Publikum und sehen sich selbst auf der Bühne. Daß sich die (aristophanische) Komödie bei Hegel dadurch auszeichnet, daß der Zuschauer "sich selbst spielen sieht" (PG 544), wurde oben gezeigt; das machte die Weiterentwicklung des komischen gegenüber dem tragischen Bewußtsein aus. Auch Nietzsche nimmt diese Entwicklung in den Blick, allerdings nicht in bezug auf Aristophanes, sondern auf die durch Euripides vorbereitete "neuere Komödie«und daher mit anderer Bewertung. Er schreibt, daß »der Zuschauer von Euripides auf die Bühne gebracht worden ist. [...] Der Mensch des alltäglichen Lebens drang durch ihn aus den Zuschauerräumen auf die Scene«. (GT 76) »Im Wesentlichen", so Nietzsche, "sah und hörte jetzt der Zuschauer seinen Doppelgänger auf der euripideischen Bühne«.80 (GT 77)

80 Statt sich, wie in der »Urtragödie«, im Satyrchor gespiegelt zu sehen (vgl. GT 59f.). 
Bei Foucault ist dieses Charakteristikum der Komödie der Beginn dessen, was im Panopticon und der modernen Gesellschaft überhaupt geschieht. U.a. vor dem Hintergrund dieser Blickverschiebung schreibt Foucault, den Mediziner und Gefängnisreformator Nikolaus Heinrich Julius (1783-1862) zitierend:

Die Antike war eine Zivilisation des Schauspiels. "... der Menge den Anblick und die Überschauung Weniger verschaffen« - diesem Problem wurde die Architektur der Tempel, der Theater, der Zirkusse gerecht. Mit dem Schauspiel dominierten die "öffentliche Lebensweise«, die Intensität der Feste, die sinnliche Nähe. In diesen von Blut triefenden Ritualen gewann die Gesellschaft ihre Kraft und bildete für einen Augenblick gleichsam einen einzigen großen Körper. Die neuere Zeit stellt das umgekehrte Problem: »Wenigen oder einem Einzelnen die Übersicht Vieler zu gewähren«. In einer Gesellschaft, in der die Hauptelemente nicht mehr die Gemeinschaft und das öffentliche Leben sind, sondern die privaten Individuen einerseits und der Staat andererseits, können die Beziehungen nur in einer Form geregelt werden, die dem Schauspiel genau entgegengesetzt ist. [...] Unsere Gesellschaft ist nicht eine des Schauspiels, sondern eine Gesellschaft der Überwachung. ${ }^{81}$ [...] Die schöne Totalität des Individuums ${ }^{82}$ wird von unserer Gesellschaftsordnung nicht verstümmelt, unterdrückt, entstellt; vielmehr wird das Individuum darin gemäß einer Taktik der Kräfte und der Körper fabriziert. Wir sind weit weniger Griechen, als wir glauben. Wir sind nicht auf den Rängen und nicht auf der Bühne, sondern in der panoptischen Maschine, die wir selber in Gang halten, indem wir ein Rädchen davon sind. ${ }^{83}$ (ÜS 278f.)

81 Diese Beobachtung macht Foucault bereits in Die Wahrheit und die juristischen Formen, wo er ebenfalls N.H. Julius zitiert und vom »Problem einer Architektur nicht mehr des Schauspiels, wie bei den Griechen, sondern der Überwachung« (WjF 104) sowie von einer »Wende vom Schauspiel zur Überwachung« (WjF 105) spricht.

82 Bei Hegel findet sich die »schöne Individualität» des "griechischen Charakters" (G.W.F. Hegel: Vorlesungen über die Philosophie der Geschichte, S. 293f.) und die "freie Totalität« des Klassischen (G.W.F. Hegel: Vorlesungen über die Ästhetik II (=Werke, Bd. 14), Frankfurt a.M. ${ }^{6} 2004$, S. 13, 18 [im folgenden per Sigle Ä II im laufenden Text zitiert]), nicht aber die "schöne Totalität«. Man darf annehmen, daß Foucault sich hier vermittelt über seinen Lehrer Jean Hyppolite auf Hegel bezieht (vgl. Jean Hyppolite: Introduction à la philosophie de l'histoire de Hegel, Paris 1968, S. 68; ders.: Genèse et structure de la Phénoménologie de l'Esprit de Hegel, Paris 1946, S. 528). Hyppolite schreibt hier, kursiviert, von der "belle totalité de l'individu«, ohne diesen Begriff direkt bei Hegel nachzuweisen.

83 Übersetzung verändert, Gw.E.; vgl. SP 253: „Nous ne sommes ni sur les gradins ni sur la scène, mais dans la machine panoptique, investis par ses effets de pouvoir que nous reconduisons nous-mêmes puisque nous en sommes un rouage." 
Foucault überspringt hierbei allerdings einen Schritt seiner eigenen Argumentation. Er geht vom "Anblick und [der] Überschauung Weniger" zur »Übersicht Vieler« durch »Wenige[ ] oder eine[n] Einzelnen« über, von der antiken "Zivilisation des Schauspiels" zur heutigen "Gesellschaft der Überwachung«. Tatsächlich ist aber die »Übersicht Vieler« durch »Wenige[ ] oder eine[n] Einzelnen" noch nicht die panoptische Gesellschaft, wie Foucault hier schreibt, sondern die Gesellschaft, die sich am Übergang vom Absolutismus zum Panoptismus befindet: Es ist der Souverän, aber nicht mehr der, auf den alle Blicke gerichtet sind, sondern der, der als einzelner den Überblick über die Vielen hat - es wird gleich noch zu sehen sein, daß Napoleon diese Figur verkörpert. Im Empire sind die Blickverhältnisse tatsächlich »dem Schauspiel genau entgegengesetzt«; der Staat, verkörpert im einzelnen Souverän, überblickt die Vielen, »die privaten Individuen«. Im Panopticon schließlich wird der Blickwechsel noch weiter entwickelt: Der Gefangene »internalisiert das Machtverhältnis, in welchem er gleichzeitig beide Rollen spielt; er wird zum Prinzip seiner eigenen Unterwerfung.« (ÜS 260) Indem der Gefangene den Blick des Aufsehers verinnerlicht und von innen gegen sich selbst kehrt, "spielt« er »beide Rollen«. Diese panoptische Identität von Beobachtetem und Beobachter, von Schauspieler und $\mathrm{Zu}-$ schauer führt das dramatische Konzept des Schauspiels überhaupt ad absurdum.

Auf das Ende der Tragödie folgt also die Komödie, und die Komödie geht ihrerseits zu Ende, indem die gesamte Gattung des Dramas zu Ende geht. Denn die komische Umkehrung der Blickverhältnisse durch das Betreten der Bühne durch den Bürger geht noch weiter und führt geradezu zu einer Auflösung der Blickverhältnisse insofern, als alles Blick wird und dadurch die Blicke selbst aufgehoben werden. Im Panopticon finden gar keine wirklichen Blicke mehr statt, es gibt nur noch die antizipierten, angenommenen, verinnerlichten und gegen sich selbst gekehrten Blicke. Hierin erst besteht die panoptische Disziplinargesellschaft. Hier sind »die Hauptelemente nicht mehr die Gemeinschaft und das öffentliche Leben", aber auch nicht mehr, wie Foucault nahelegt, »die privaten Individuen einerseits und der Staat andererseits«. (ÜS 278) In der Folge wird nämlich auch der Staat als »Hauptelement" der Gesellschaft abgelöst, was zu einer unüberschaubaren Diversifizierung der Blicke und Blickrichtungen führt. Die Gesellschaft strukturiert sich nicht mehr über die Polarität von Individuen und Staat, sondern formiert sich aus dem unentwirrbaren Gemenge von Individuen und Disziplin, in dem jeder Einzelne »der Sichtbarkeit unterworfen« (ÜS 260) ist 
und sich ihr unterwirft. Diese differenziertere oder abgestufte Argumentation erst läßt sich auf Foucaults Begrifflichkeit vom Schauspiel und auf seine Unterscheidung von Tragödie und Komödie sowie - wie zu sehen sein wird - Schauspiel und Roman rückspiegeln. Foucault klassifiziert auf diese Weise sowohl die griechische Antike als auch das klassische Zeitalter als Gesellschaft des Schauspiels. Der Schauspielcharakter des Absolutismus zeigt sich im Prunk der monarchischen Repräsentation, aber auch im "Straf-Prunk « der Martern; gleichzeitig beginnen sich disziplinare Strukturen herauszubilden, die gegen Ende des 18. Jahrhunderts zu dem führen, was Foucault eine »Komödie« des Strafens nennt. Die Komödie vereint also den alten Schauspielcharakter der absolutistischen Gesellschaft mit ihren panoptischen Anfängen - indem das banale Individuum die Bühne betritt. Noch blicken hier die Vielen auf die Wenigen, doch sind diese Wenigen keine Helden mehr, sondern Durchschnittsmenschen. Indem sich der Bürger nun aber plötzlich selbst auf der Bühne stehen sieht, blickt er auch von dieser Bühne zurück ins Publikum; und je mehr sich auf diese Weise die Blickrichtungen diversifizieren und die Blicke vervielfachen, desto weniger läßt sich dieses Blickgeschehen noch als Schauspiel, auch nicht mehr als Komödie, fassen. Daß der Körper abtritt und statt dessen die körperlose Seele die Bühne betritt, macht die Bühne selbst schließlich obsolet und beendet das Drama.

Der gleiche Übergang vollzieht sich auf dem Gebiet der Epistemen. Im ersten Kapitel von Die Ordnung der Dinge beschreibt Foucault Velázquez' Hoffräulein als Repräsentation der Repräsentation (vgl. OD 45), als Darstellung also der Episteme der Klassik. Mit der Interpretation dieses Gemäldes (tableau) taucht, wie bei Diderot, auch bei Foucault die Verbindung von Schauspiel und Gemälde auf: Die Blicke im und auf das Gemälde bezeichnet er als "Schauspiel« (spectacle), den oder die Betrachter in der Regel als "Zuschauer" (»spectateur[s]«). (OD 31ff.) ${ }^{84}$ Hier sei noch einmal an die Doppeldeutigkeit des französischen Begriffs représentation erinnert: Imagination und Theateraufführung. Und auch hier ist der Schauspielcharakter der Blickführung zunächst an den Souverän gebunden, daran, daß der Souverän im Zentrum des Blicks und also auf der Bühne steht: »Dieses Schauspiel, das da im Blick ist, bilden [...] die Herrscher." (OD 43) Dieser Blick auf das Königspaar entspräche noch der Tragödienstruktur des ’Blicks auf die Wenigen . Die Besonderheit an den Hoffräulein ist aber ja, daß das Königspaar auf dem Bild eigentlich gar nicht zu sehen ist, sondern sich außerhalb

84 Vgl. Michel Foucault: Les mots et les choses, S. $19 \mathrm{ff}$. 
des repräsentierten Bildraums befindet, dort, wo auch der Betrachter des Bildes steht. Diese Tatsache selbst findet sich im Spiegel repräsentiert, der im Zentrum des Bildes zu sehen ist. Nur durch den Spiegel ist Velázquez' Gemälde »reduplizierte Repräsentation« (OD 98) und damit Repräsentation der Repräsentation. Er zeigt die "Gestalten«, »die der Maler betrachtet (der Maler in seiner repräsentierten, objektiven Wirklichkeit als der eines arbeitenden Malers) «, d.h. der auf dem Bild repräsentierte Maler. Diese Gestalten sind das Königspaar. Der Spiegel zeigt maber auch die Gestalten, die den Maler anschauen (in jener materiellen Realität, die die Linien und Farben auf der Leinwand niedergelegt haben)«, d.h. den Betrachter des Gemäldes. (OD 36) Das "Spiel der Repräsentation besteht [darin], von den beiden Formen der Unsichtbarkeit die eine in einer beweglichen Überlagerung an die Stelle der anderen zu setzen«. (OD 37) »Der Platz, auf dem der König mit seiner Gattin thront, ist ebenso der des Künstlers und der des Zuschauers.» (OD 44) Einerseits findet damit im Schauspiel der Hoffräulein die Einnahme des Platzes des Königs durch den Zuschauer statt, gewissermaßen das Betreten der Bühne durch den Zuschauer - ganz so, wie Hegel und Nietzsche es als ein Charakteristikum der Komödie beschreiben. Daß Zuschauer und König denselben Platz einnehmen, ist zudem so etwas wie der komische Rollentausch des "Quiproquo" (OD 83), und das Gemälde im Gemälde der Hoffräulein entspricht dem komödientypischen Spiel im Spiel, dem »Theater, das sich verdoppelt und ein Theater repräsentiert«. (OD 83) "Das Bild in seiner Gänze blickt auf eine Szene, für die es seinerseits eine Szene ist." (OD 42) Die Hoffräulein ist also eine Komödie, die Komödie der Repräsentation. "Vielleicht«, schreibt Foucault. (OD 45) Denn andererseits beginnt hier die panoptische Multiplikation der Blicke. Wie die Komödie dadurch, daß der Zuschauer von der Bühne zurückblickt, in den Panoptismus der Prosa übergeht, so findet sich im Falle der Hoffräulein in der Tatsache, daß der Betrachter des Bildes gleichzeitig Betrachteter ist, das Ende des Dramas durch Diversifikation und Multiplikation der Blicke ebenfalls bereits angekündigt - und damit auch die Ablösung der Repräsentation des klassischen Zeitalters durch die moderne Episteme, die Humanwissenschaften. ${ }^{85}$

Zusammengefaßt ist dieser Schematisierung zufolge das klassische Zeitalter, wie die griechische Antike, eine Zivilisation des Schauspiels, eine Gesell-

85 Dieser Aspekt wird in Kap. VI ausführlicher behandelt, vgl. Unterkap. »Der humanwissenschaftliche Panoptismus der Erzähltechniken«. 
schaft der Tragödie, und entspricht der Episteme der Ähnlichkeit; der Übergang von der absolutistischen zur panoptischen Gesellschaft entspricht der Komödie und der Episteme der Repräsentation; ${ }^{86}$ und die panoptische Gesellschaft bedeutet, durch die Multiplikation der Blicke und die Verinnerlichung der Machtstrukturen und d.h. der Konflikte, das Ende des Schauspiels, das Ende der dramatischen Gattung überhaupt, und entspricht der Episteme der Humanwissenschaften.

\section{Napoleon und die Guillotine (II): Grenze des Schauspiels}

Als exemplarisch für den Übergang von der absolutistischen zur panoptischen Gesellschaft führt Foucault Napoleon an. Ähnlich wie die Komödie vereint er in sich die Momente der Gleichzeitigkeit und Übergänglichkeit von Souveränität und Disziplin..$^{87}$ Napoleon

steht am Punkt, wo sich die monarchische und rituelle Ausübung der Souveränität mit der hierarchischen und steten Ausübung der unbegrenzten Disziplin trifft. Er ist derjenige, der alles mit einem einzigen Blick überragt, aber dem kein Detail, wie winzig es auch sein mag, jemals entkommt. [...] Im Augenblick ihres Hervortretens übernimmt die Disziplinargesellschaft mit dem Kaiser noch den Aspekt der Herrschaft des Schauspiels. Als Monarch, der gleichzeitig den alten Thron usurpiert und den neuen Staat organisiert, rafft er in einer symbolischen und letzten Gestalt den ganzen langen Prozeß zusammen, mit dem der Prunk der Souveränität, die notwendigerweise spektakulären Kundgebungen der Macht allmählich in eine alltägliche

86 Der Übergangscharakter der Komödie zeigt sich bei Foucault auch in ihrer Nähe zum komischen bzw. pikaresken Roman: zu Cervantes' Don Quichotte, der ebenfalls, dem Zeitalter der Repräsentation angehörend, bereits über die Repräsentation hinausweist. Auch bei Hegel gibt es bereits diese Affinität zwischen Komödie und Roman: Bei ihm tritt der moderne komische Roman (auch hier Don Quichotte, aber auch Jean Paul) die Nachfolge der alten griechischen Komödie an. Vgl. zu Hegel ausführlicher Stephan Kraft: Zum Ende der Komödie, S. $257 \mathrm{ff}$.

87 Als ein früheres Beispiel nennt Foucault zuvor bereits eine Medaille zur ersten Militärparade Ludwigs XIV., die »den Augenblick [bezeugt], da sich auf paradoxe aber bezeichnende Weise die prunkendste Gestalt der souveränen Macht mit dem Heraufkommen der für die Disziplinarmacht charakteristischen Rituale verbindet. Die kaum auszuhaltende Sichtbarkeit des Monarchen wendet sich in die unerbittliche Sichtbarkeit der sSubjekter. Und diese Umkehrbarkeit der Sichtbarkeit im Funktionieren der Disziplinen sollte die Ausübung der Macht bis in die feinsten Details hinein sicherstellen. Man tritt ins Zeitalter der unbegrenzten Überprüfung und der zwingenden Objektivierung ein.« (ÜS 243) 
Ausübung der Überwachung, in einen Panoptismus verlöschen, in dem die Wachsamkeit der einander kreuzenden Blicke den Adler wie die Sonne bald überflüssig machen wird. (ÜS 279) ${ }^{88}$

Die Zuordnung der Souveränität zum Schauspiel und, genauer, zur Tragödie wird hier noch einmal sehr deutlich. Im "Prunk der Souveränität « und ihren "notwendigerweise spektakulären" Machtkundgebungen - spektakulär hier auch im Wortsinne begriffen, als zum Spektakel, zum Schauspiel gehörig - zeigt sich die "Herrschaft des Schauspiels". Eine Form jenes »Prunk[s] der Souveränität« ist der "Straf-Prunk« (ÜS 26), den Foucault zu Beginn von Überwachen und Strafen mit der Tragödie identifiziert hatte und der ebenfalls zu Ende geht. Ersetzt wird die spektakuläre und prunkvolle Souveränität durch eine »alltägliche Ausübung der Überwachung« hier wieder ein Hinweis auf das Alltägliche der Komödie als Übergang zum Ende des Theatralen. Napoleon nimmt eine Übergangsposition zwischen Souveränitäts- und Disziplinarmacht ein; er verkörpert damit einerseits noch den Souverän und seinen mythischen Körper, steht andererseits aber bereits für die Disziplinarmacht, die alles sieht: "Der Kaiser ist das universelle Auge, das auf die gesamte Gesellschaft gerichtet ist.« (WjF 106) Dieser eine Blick des napoleonischen Adlers und der Sonne der absoluten Souveränität ist aber nicht mehr der "göttlich-gelassene[ ] Blick[ ] auf das Treiben der Menschen" aus der »Vogelperspektive" der Komödie, ${ }^{89}$ sondern bereits ein disziplinierender Blick, der in der Folge von den zahllosen panoptischen Blicken abgelöst werden wird. Wie die Komödie leitet Napoleon von der

88 Übersetzung verändert und korrigiert, Gw.E. Das Original lautet: »[1]l est au point de jonction de l'exercice monarchique et rituel de la souveraineté et de l'exercice hiérarchique et permanent de la discipline indéfinie. Il est celui qui surplombe tout d'un seul regard, mais auquel aucun détail, aussi infime qu'il soit, n'échappe jamais. [...] La société disciplinaire, au moment de sa pleine éclosion, prend encore avec l'Empereur le vieil aspect du pouvoir de spectacle. Comme monarque à la fois usurpateur de l'ancien trône et organisateur du nouvel État, il a ramassé en une figure symbolique et dernière tout le long processus par lequel les fastes de la souveraineté, les manifestations nécessairement spectaculaires du pouvoir, se sont éteints un à un dans l'exercice quotidien de la surveillance, dans un panoptisme où la vigilance des regards entrecroisés va bientôt rendre inutile l'aigle comme le soleil." (SP 253) Seitter übersetzt »Prunkherrschaft« statt »Herrschaft des Schauspiels«, dafür aber »Feste der Souveränität« statt »Prunk der Souveränität«. Insbesondere seine Übersetzung des letzten Satzes ist in ihrer großen Abweichung vom Original irritierend. Er schreibt, »im Panoptismus, in dem die Wachsamkeit der einander kreuzenden Beobachtungen den Blick des Adler-Sonnen-Auges bald überflüssig machen wird«. (ÜS 279)

89 Stephan Kraft: Zum Ende der Komödie, S. 221. 
Souveränität zu Disziplin und Panoptismus und damit vom Zeitalter des Schauspiels ins Zeitalter des Romans ${ }^{90}$ über.

Die Guillotine nimmt die gleiche Zwischenstellung ein und steht wie Napoleon und wie die Komödie an der Grenze des Schauspiels. Oben war gesagt worden, der Übergang von den Martern zur Guillotine stelle, indem diese sich nicht mehr vorrangig auf den Körper richte, eine Vorstufe oder eine Variante des tragischen Übergangs vom Mythos zum Logos und vom Körper zur Seele dar. Mit diesem vollzogenen Übergang bedeutet die Guillotine aber zugleich auch wieder das Ende der Tragödie und des Schauspiels überhaupt. Das, was an der äußeren Form der Guillotinierung noch dem Schauspiel angehört, ist von den alten Martern übernommen: das Schafott etwa und die theatrale Situation im Sinne der Blicke Vieler auf Wenige bzw. den Einzelnen. Und tatsächlich war die Hinrichtung durch Enthauptung »die Strafe der Vornehmen" (ÜS 21) und blieb lange Zeit den Adligen vorbehalten, wie es mit der Ständeklausel auch die tragische Bühne war. Erst spät wurde die Enthauptung auch für Nichtadlige üblich, und 1791 wird sie in Frankreich zur einzigen Vollstreckungsart von Todesurteilen bestimmt ${ }^{91}$ - ab 1792 durch die Guillotine. Die Guillotine ist auch deshalb ganz faktisch der Übergang von der souveränen zur Disziplinarmacht, weil ihr in der Französischen Revolution zunächst die Adligen zum Opfer fallen. Mit der terreur beginnen dann ab Juni 1793 die Guillotinierungen, denen das Volk massenhaft zum Opfer fällt. ${ }^{92}$ Der Einzelne auf dem Schafott ist damit kein tragischer Held mehr, sondern banaler Delinquent, steht also für die Vielen, so daß sich die Blicke der Zuschauenden, wie in der Komödie, eigentlich auf die Vielen und d.h. auf sich selbst richten. Das Schafott der Guillotine wird dadurch zur komischen Bühne. Doch unter theatralen und dramaturgischen Gesichtspunkten bedeutet die Guillotinierung noch einen weiteren Übergang, und zwar den von der Komödie zum Ende des Schauspiels: Zwar wird sie noch, wie die tragischen Martern, "vor den Augen aller« (ÜS 60) vollzogen, doch geschieht die Hinrichtung selbst schneller, als es der Blick verfolgen kann, sie ist "auf eine einzige Geste und einen einzigen Augenblick reduziert" (ÜS 46) und eignet sich also eigentlich nicht mehr

90 Vgl. dazu Kap. VI.

91 Vgl. ÜS 20; Code pénal (1791), 1. Teil, 1. Abschnitt, Art. 3: „Tout condamné aura la tête tranchée.«; Daniel Arasse: Die Guillotine. Die Macht der Maschine und das Schauspiel der Gerechtigkeit, Reinbek bei Hamburg 1988, S. 30-34.

9285 Prozent der Guillotinierten der terreur gehörten dem Dritten Stand an; vgl. Albert Soboul (Hg.): Dictionnaire historique de la Révolution française, Paris 2005, S. 1023. 
zum Schauspiel. Bei Foucault erfolgen das Ende der Tragödie und der Übergang zur Komödie demnach parallel zum Übergang von der souveränen zur disziplinaren Gesellschaft; die ausgebildete Disziplinargesellschaft aber gehorcht auch den Regeln der Komödie nicht mehr - weil sie den Regeln des Schauspiels nicht mehr gehorcht. Drama und Panoptismus erweisen sich als unvereinbar.

\section{Das Ende des Dramas im Ende des Rechts}

Neben der Psychologisierung der Figuren und der panoptischen Verschiebung der Blicksituation gibt es ein weiteres Argument für den Zusammenhang von Disziplin und Ende des Dramas, das auf Foucaults eingangs zitierter Beobachtung der "Zusammengehörigkeit« von Tragödie und Recht basiert. In Überwachen und Strafen hatte er konstatiert, daß »das Rechtliche im Rückgang ist«. Es verliert durch die "Formierung der Disziplinargesellschaft" (ÜS 246, 269) und das Aufkommen des Panoptismus seine zentrale Bedeutung; die Disziplinen funktionieren nicht mehr über juridische Kategorien, "[vollziehen] eine Suspension des Rechts" (ÜS 286) und lösen die Ordnung des Rechtlichen überhaupt ab. Foucault erklärt das damit, daß das Recht der Neuzeit ursprünglich und wesentlich das Recht des Souveräns war und ausgebildet wurde, um dessen Herrschaft zu legitimieren. Mit der Ablösung des Absolutismus verliert auch das Recht als Recht des Souveräns seine zentrale Bedeutung und wird, zunächst, durch das Recht der Gesellschaft ersetzt. Das ist oben bereits als Grund für die Abkehr von der Marter und den körperlichen Strafen angeführt worden. In der Idee eines Gesellschaftsvertrags trifft die Strafe nicht mehr den Körper des Verurteilten, wie dieser in seinem Verbrechen den Körper des Königs getroffen hatte, sondern es tritt »ein Individuum dem gesamten Gesellschaftskörper« (ÜS 114) gegenüber. Der Verbrecherkörper des Souveränitätsprinzips wandelt sich zum körperlosen Rechtssubjekt der Vertragstheorie - der oben beschriebene Übergang von der Tragödie der Marter zur Komödie der reformierten Strafen. Allerdings ist diese Betrachtungsweise laut Foucault auf die "politische Theorie« beschränkt und damit zu abstrakt. Der These, der zufolge eine »Gesellschaft, die wesentlich aus Individuen bestehe«, auf »die abstrakten Rechtsformen des Vertrags", also auf eine »vertragliche Vereinigung von isolierten Rechtssubjekten" zurückgehe, stellt er daher die These entgegen, das Individuum in der modernen Gesellschaft sei eben genau nicht 
mehr in erster Linie auf jenes abstrakte Rechtssubjekt zurückzuführen. Das moderne Individuum ist zwar möglicherweise auch, aber keinesfalls mehr nur »das fiktive Atom einer sideologischen Vorstellung der Gesellschaft«, sondern das praktische Erzeugnis der individualisierenden Macht der Disziplin. (ÜS 249f.)

Das Recht geht also zu Ende, und mit ihm das Rechtssubjekt, und zwar sowohl das tragische Subjekt des Rechts der Souveränität, der Körper des Verbrechers, als auch das komische, abstraktere Rechtssubjekt des Gesellschaftsvertrags. Das Rechtssubjekt wird durch das Disziplinarindividuum ersetzt, und das bedeutet sowohl das Ende der Tragödie der Marter als auch das Ende der Komödie der reformierten Strafen. Was Foucault in Überwachen und Strafen bezüglich der Verbindung von Drama und Recht nur andeutet, formuliert er kurz darauf, das wurde bereits zitiert, in seiner Vorlesung In Verteidigung der Gesellschaft (1975/76) explizit - wiewohl ohne Erwähnung der Komödie: "Mir scheint, daß es eine grundlegende und entscheidende Zusammengehörigkeit von Tragödie und Recht, von Tragödie und öffentlichem Recht gibt (VG 208), und (hier allerdings mit speziellem Bezug auf Racine): "Die Racinesche Tragödie wirft eher ein rechtliches als ein psychologisches Problem auf.«(VG 210) ${ }^{93}$

\section{Unvereinbarkeit von Recht und Psychologisierung}

Damit wird der Grundsatz, die Tragödie sei mit der Psychologisierung ihrer Charaktere nicht vereinbar, von einer zweiten Seite her argumentativ gestützt. Denn der Psychologie steht in der Tragödie nicht nur der (nach Hegel einseitige) tragische Charakter, ${ }^{94}$ sondern auch das Recht entgegen. In der mit Disziplin und Panoptismus einhergehenden Psychologisierung liegt daher ein weiterer Grund für das Ende der Tragödie. Die Psychologie nämlich, die Einzug in die Rechtsprechung hält, ist ein "rechtlich gar nicht Kodifizierbares" (ÜS 27); das psychologische Wissen wird also in ein ihm fremdes Wissen integriert und bildet auf diese Weise einen neuen, psychojuridischen Diskurs. Wenn nun die Rechtsproblematik der Tragödie zugeordnet, die Psychologie aber rechtlich nicht kodifizierbar ist (denn das Recht

93 Vgl. in diesem Zusammenhang zu Racines Phädra Friedrich Balke: Figuren der Souveränität, München 2009, Kap. VII: »Das Subjekt des Souveräns«, S. 335-396.

94 Vgl. G.W.F. Hegel: Ä III, S. 454f., 479. 
folgt universellen und allgemeinen, die Psychologie aber individuellen und besonderen Normen, vgl. weiter unten), so kann die Psychologie auch aus diesem Grund nicht in der Tragödie verhandelt werden. Dem trägt der oben beschriebene Übergang zur Komödie Rechnung, die sich, indem sie sich auf die Seele des Verbrechers und die Seele der Zuschauer richtet, der Psychologie zuzuwenden beginnt. Insofern Psychologisierung und Einführung mildernder Umstände der Strafbemessung und juristischen Urteilsfindung dienen, gelingt der Komödie der reformierten Strafen die Vereinigung von Psychologie und Recht bis zu einem gewissen Grad. Auch in der Psychologisierung im Dienste der für die Komödie charakteristischen Wirkungsästhetik, d.h. der Besserung von Straftäter und Zuschauern, scheinen Recht und Psychologie vereint zu sein. Zudem verbleibt die Komödie der reformierten Strafen im System des Rechts, weil es in ihr ja um die Restitution eines Rechtssubjekts geht (vgl. ÜS 166). Sie verfolgt also zwei sehr verschiedene Ziele: Zum einen die streng rechtliche und formale Restitution eines Rechtssubjekts - dies ihr rein performativer Charakter, worin sie noch Ähnlichkeiten zum Ritualcharakter der Tragödie der Marter aufweist -, und zum anderen die psychologische Besserung von Straftäter und $\mathrm{Zu}-$ schauern. Man könnte sagen, die Komödie scheitere schließlich an dieser zweifachen Zielsetzung - wie auch die Strafreformen am Widerspruch zwischen allgemeinen und abstrakten Rechtsnormen und den individuellen und besonderen Normen der Psychologie scheitern. Die Komödie der reformierten Strafen geht dann auch aufgrund der ihr wesentlichen und inhärenten gattungs- und rechtstheoretischen Widersprüche zu Ende. ${ }^{95}$

95 Damit wäre auch eine Antwort auf Foucaults Frage gegeben, warum das Gefängnis, das in den Strafreformen gar nicht vorgesehen war, sich schließlich durchsetzt (vgl. WjF 121, ÜS 169f.). 


\section{Die Prosa der Disziplin und das Ende der Literatur}

\section{Recht und Norm, Tragödie und Roman}

Die Ablösung des Rechts durch die Psychologie, die bereits in der Ablösung der Tragödie durch die Komödie begann, vollzieht sich vollends erst in einer anderen Gattung: dem Roman. In der bereits zitierten Vorlesung In Verteidigung der Gesellschaft sagt Foucault:

Mir scheint, daß es eine grundlegende und entscheidende Zusammengehörigkeit von Tragödie und Recht, von Tragödie und öffentlichem Recht gibt, genau wie es wahrscheinlich eine entscheidende Zusammengehörigkeit von Roman und Normproblemen gibt. Tragödie und Recht, Roman und Norm: Das müßte man näher betrachten. (VG 208)

Die Tragödie mit dem Recht zu verknüpfen, ist nun keineswegs neu; neu aber ist, wie in den vorangegangenen Kapiteln gezeigt wurde, die Übertragung dieser Verknüpfung auf den jeweils konkreten historischen Rechtsdiskurs. Dem gesellschaftshistorischen Ende der zentralen Bedeutung des Rechts entspricht damit bei Foucault noch ein weiteres Ende: das der dramatischen Gattung, und also bedeutet der Übergang vom Rechtssystem zum Disziplinarsystem den Gattungswechsel vom Drama zur Prosa. Neben der Psychologisierung und neben der Blickverschiebung innerhalb des Strafvollzugs führt damit, drittens, das Ende des Rechtsdiskurses das Ende der Tragödie und schließlich auch das Ende des Schauspiels, das Ende der dramatischen Gattung überhaupt herbei. Der Übergang vom Recht zur Norm erfolgt parallel zum Übergang von der Tragödie als dem Recht des Souveräns und der Komödie als dem Recht der Gesellschaft zum Roman als der Disziplin.

An diesem Punkt läßt sich der Gattungsdiskurs auch wieder direkt an den Subjektdiskurs rückbinden. Foucault schreibt,

daß die rechtlichen Systeme, nach allgemeinen Normen, Rechtssubjekte qualifizieren, während die Disziplinen charakterisieren, klassifizieren, spezialisieren; sie verteilen entlang einer Skala, ordnen um eine Norm herum an, hierarchisieren die Individuen untereinander. ${ }^{1}$ (ÜS 286)

1 Übersetzung verändert, Gw.E.; vgl. SP 259: »[A]lors que les systèmes juridiques qualifient les sujets de droit, selon des normes universelles, les disciplines caractérisent, classifient, spécialisent; elles distribuent le long d'une échelle, repartissent autour d'une norme, hiérarchisent les individus les uns par rapport aux autres.«. 
Die Unterscheidung von Verbrecher und Delinquent wird hier zur Unterscheidung von Rechtssubjekt und Disziplinarindividuum verallgemeinert. Das Rechtssubjekt ist durch rechtliche und d.h. allgemeine Normen bestimmt, das Disziplinarindividuum durch außerrechtliche und besondere, z.B. psychologische Normen. Der Verbrecher als Rechtsbrecher ist vor dem Hintergrund des Rechts der Souveränität, also dem Bereich der Tragödie bestimmt. Der Verbrecher als abstraktes Rechtssubjekt bestimmt sich über die - komische - Repräsentation des Gesetzes. Für die Disziplin dagegen formuliert Foucault das "Prinzip [...], daß sich die Delinquenz weniger vom Gesetz als vielmehr von der Norm her spezifiziert.«(ÜS 325) Durch diese Zuordnung der Delinquenz zur Norm und der Norm zum Roman gehören Delinquenz und Delinquent, exemplarisch für das moderne Subjekt, in den Bereich des Romans.

Damit lösen sich in Überwachen und Strafen auch die Parallelen zwischen der Rechts- und Subjektkonstitution in der Tragödie und der tatsächlichen Konstitution eines Rechtssubjekts (vgl. Kap. III) auf: Die Identifikation von Subjekt und Rechtssubjekt gilt hier nicht mehr. Hier handelt es sich nicht mehr um das dem Recht des Souveräns unterworfene (tragische) Subjekt und auch nicht mehr um das abstrakte (komische) Rechtssubjekt im klassischen juristischen oder vertragstheoretischen Sinne, sondern um das sehr konkrete Subjekt des psychojuridischen Diskurses und seiner Praktiken, die selbst nicht mehr dem ursprünglichen Rechtssystem angehören. Das Rechtssubjekt wird zum Disziplinarindividuum.

\section{Unvereinbarkeit von Disziplin und Handlung}

Recht und Norm, Rechtsbrecher und Delinquent lassen sich über noch ein weiteres Element an den Gattungsdiskurs anschließen: über das Handeln. In seiner Poetik bestimmt Aristoteles die Tragödie dadurch, daß sie, anders als das Epos, Nachahmung von Handelnden bzw. von Handlung sei. ${ }^{2}$ Die Handlung der Tragödie entspringt in der Regel einer Auseinandersetzung mit dem Recht bzw. dem das Recht verkörpernden Souverän. Zum einen fehlt im Disziplinarsystem ein solcher lokalisierbarer Gegenpol, an dem sich

2 Aristoteles: Poetik, S. 9 (1448a 26-29), 21 (1450a 15-17), 25 (1450b 24), 29 (1451a 30-34). 
eine Handlung entzünden könnte - das ist im Zusammenhang mit der Verinnerlichung der Machtstrukturen und also der Verinnerlichung des Konflikts bereits gesagt worden. Zum anderen gibt es im Disziplinarsystem deshalb kein eigentliches Handeln, weil jedes Tun auf einen Ursprung in den je individuellen biographischen und psychischen Umständen zurückgeführt wird. Diese individuellen biographischen und psychischen Umstände aber spielen, anders als die Handlung, für die Tragödie keine wesentliche Rolle, wie Aristoteles weiter schreibt: "Ferner könnte ohne Handlung keine Tragödie zustandekommen, wohl aber ohne Charaktere « ${ }^{3}$ - gemeint ist: ohne die psychologische Durchzeichnung der Charaktere. In den Disziplinen nun wird das - tragische - Handeln des Rechtsbrechers durch bloßes - prosaisches - Tun des Delinquenten ersetzt, das lediglich eine Folge seiner Biographie und seiner Psyche ist. Damit machen die Disziplinen Handeln, und d.h. selbstbestimmtes Handeln der Figuren der Tragödie, unmöglich, da sie keine Verantwortlichkeiten und keine Entscheidung zulassen. Indem sie sich der individuellen Psychologie zuwenden, heben sie die Kategorie der Handlung und also die Möglichkeit der Tragödie überhaupt auf. Hintergrund von Foucaults Zuordnung des Rechts zur Tragödie und der Norm zum Roman ist daher letztlich das ganz klassische Argument vom Ende der Tragödie, wonach das moderne Individuum nicht mit deren Strukturen vereinbar sei. Dem Disziplinarindividuum kommt nur noch der Roman bei.

Auflösung der dramatischen Einheit der Handlung, der Zeit und des Ortes

Hinzu kommt, daß an den Handlungscharakter des Dramas klassischerweise auch die Idee der Einheit der Handlung gebunden ist. ${ }^{4}$ In der Tragödie der Marter ist diese Einheit gegeben: Es gibt ein Verbrechen, die Verletzung des Königs, und eine Strafe, die Marter des Rechtsbrechers; es gibt eine Rechtsverletzung und eine Wiederherstellung des Rechts. Für die Komödie gilt die Einheit der Handlung Hegel zufolge in weniger strengem Maße als für die Tragödie: "Die Komödie z.B. bei vielseitig verwikkelten Intrigen braucht sich nicht so fest zusammenzuschließen als die

3 Ebd., S. 21 (1450a 24f.).

4 Vgl. ebd., S. 25 (1450b 24-31), 29 (1451a 30-35), 77 (1459a 17-24). 


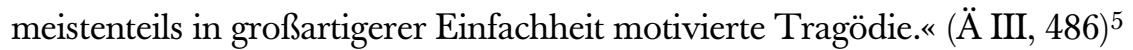
Auch in Foucaults Komödie der reformierten Strafen ist, bei aller Verallgemeinerung und Vereinheitlichung von Verbrechen und Strafen durch Kodifizierung und Taxonomisierung (vgl. ÜS 126f.), die Einheit der Handlung etwas loser geknüpft. Zum einen zielt sie in verschiedene Richtungen: Es geht nicht mehr nur um Wiederherstellung eines Rechts, sondern um die Verhinderung von Straftaten in der Bevölkerung (Generalprävention) und um die Verhinderung neuerlicher Straftaten durch den Verbrecher (Individualprävention). Dabei berücksichtigt die Individualprävention den Blick auf die Biographie des Delinquenten, so daß weitere Handlungsstränge in den Blick geraten - die sich allerdings zunehmend weniger zur Darstellung auf der Bühne eignen. Die biographische Vergangenheit und das Leben des Delinquenten nehmen eine zu zentrale Stellung ein, als daß sie etwa in einer dramatischen Exposition abgehandelt werden könnten. Auch das Vergangene müßte szenisch auf die Bühne gebracht werden, womit das Geschehen nicht nur aus der Einheit der Zeit herausfiele, sondern sie gänzlich sprengen würde.

Zur Einheit der Handlung gehört zum anderen, so hebt Aristoteles in seiner Poetik hervor, die Eigenschaft, zu enden. Genau wie die Handlung ist daher auch das Drama über "Anfang, Mitte und Ende« strukturiert. ${ }^{6}$ Foucaults Gattungsüberlegungen zum Übergang von der Tragödie zur Komödie und schließlich zum Roman stützt daher auch ein Blick auf den jeweiligen Ausgang. Anders als die Tragödie darf die Komödie eigentlich nicht mit dem Tod enden; die Zwischen- oder Übergangslösungen, die Foucault anbietet, sind, wie gezeigt worden ist, zum einen die reformierten Strafen und zum anderen die Guillotine, die zwar den Tod bringt, aber wenigstens einen vergleichsweise unblutigen. Nicht so die Disziplinen. Vorbereitet durch die Strafreformen, die statt der Todesstrafe erstmals Sklaverei auf Lebenszeit erwogen (vgl. ÜS 121), bringen sie schließlich ein Ende ohne Tod hervor:

$5 \mathrm{Zu}$ Hegel über die drei dramatischen Einheiten insgesamt vgl. Ä III, $482 \mathrm{ff}$.

6 Vgl. Aristoteles: Poetik, S. 25 (1450b 24-31): »Wir haben festgestellt, daß die Tragödie die Nachahmung einer in sich geschlossenen und ganzen Handlung ist, die eine bestimmte Größe hat; es gibt ja auch etwas Ganzes ohne nennenswerte Größe. Ein Ganzes ist, was Anfang, Mitte und Ende hat. [...] Ein Ende ist [...], was selbst natürlicherweise auf etwas anderes folgt, und zwar notwendigerweise oder in der Regel, während nach ihm nichts anderes mehr eintritt." Auch Hegel greift diese Bestimmung der Totalität als Handlung auf (vgl. Ä I, 316). 
das Gefängnis, die unendlich fortgeführten und unabschließbaren Befragungen, Kontrollen und Prüfungen - ein Ende, das keines ist.

\begin{abstract}
Was sich nunmehr der Strafjustiz als ihr Zielpunkt [...] anbietet, ist nicht mehr der gegen den Körper des Königs ausgespielte Körper des Schuldigen; und auch nicht das Rechtssubjekt eines idealen Vertrags; sondern das Disziplinarindividuum. [...] Der Idealfall des heutigen Strafsystems wäre die unbegrenzte Disziplin: eine Befragung ohne Ende; eine Ermittlung, die bruchlos in eine minutiöse und immer analytischer werdende Beobachtung überginge; ein Urteil, mit dem ein nie abzuschließendes Dossier eröffnet würde. (ÜS 291f.)
\end{abstract}

Im Gegensatz zur Tragödie der Marter, die das Ende des Verbrechers vorführt, erzählt die Geschichte des Disziplinarindividuums von der »lebenslange[n] Kontrolle des Einzelnen" (WjF 87), eine Geschichte also, die sich gerade nicht auf eine geschlossene Handlung beschränkt und die nicht endet: eine "ununterbrochene Schrift«.7 Der »rituelle Vollzug der Souveränität« in der Marter - und ein Ritus ist eine fest definierte Handlungsfolge, also eine in sich geschlossene Handlung - wird von der "steten Ausübung der unbegrenzten Disziplin« abgelöst (ÜS 279), die "sich auf eine nie abzuschließende Unterwerfung [richtet] «. (ÜS 209) Ebenso zeichnet sich der Roman gegenüber dem Drama durch seine prinzipielle Unabgeschlossenheit aus. Aristoteles schreibt, »das Epos verfügt über unbeschränkte Zeit«. ${ }^{8}$ Die in der deutschen Frühromantik unter dem Begriff der progressiven Universalpoesie postulierte Fragmentarizität des Romans findet sich in den so umfassend wie möglich angelegten, doch stets nur ausschnitthaft bleibenden medizinischen und psychologischen Fallberichten verwirklicht. Und der Roman geht über die bloße Unabgeschlossenheit noch hinaus, er weist nämlich - progressiv - in die Zukunft, ganz so wie auch das disziplinare Gerichtsurteil »Voraussagen über die Zukunft des Delinquenten enthält." (ÜS 30) $)^{9}$ In den Disziplinen also sind die Einheit der Handlung und die Einheit der Zeit aufgelöst, sie haben keinen Anfang und kein Ende und beschreiben eine einzige unendliche Folge ewig unabgeschlossener Prüfungen, Erhebungen, Protokolle und Prognosen. Wie der Geschlossenheit des Dramas die Unabschließbarkeit des Romans, so steht der Abgeschlossenheit der Marter die lebenslange Kontrolle der Disziplin gegenüber.

7 Dieser Ausdruck wurde auf S. 246 der deutschen Übersetzung von Überwachen und Strafen ausgelassen; das Original lautet: "écriture ininterrompue«. (SP 224)

8 Aristoteles: Poetik, S. 17 (1449b 14).

9 Vgl. auch ÜS $118 f f$. und ÜS 164 . 
Einzig der Einheit des Ortes scheinen die Disziplinen teilweise entgegenzukommen, nämlich unter den Idealbedingungen der Prüfung: im geschlossenen Raum des Panopticons, des Gefängnisses, der Psychiatrie. Allerdings erstreckt sich die Einheit des Ortes, wie gesagt, nicht auf die Darstellung der Anamnese oder der biographischen und psychologischen Hintergründe eines Delikts, deren Schauplatz ein anderer als der konkrete Raum der Ausübung der Disziplin ist. Hierzu bedürfte es einer endlosen monologischen Exposition. Es bleibt also dabei, daß die Disziplinen insgesamt mit klassischen dramatischen Strukturen nicht vereinbar sind - sie bedeuten das Ende des Schauspiels. ${ }^{10}$

\section{Variante: Übergang vom Epos zum Roman}

Auf Grundlage der Beobachtung, daß die Psyche ins Zentrum der Strafen rückt, zeichnet Foucault in Überwachen und Strafen noch eine dritte Linie des Gattungsarguments. Während es bisher um Tragödie und Komödie und in In Verteidigung der Gesellschaft um Tragödie und Roman ging, geht es hier um Epos und Roman. Das Aufkommen des Prinzips des Panoptismus, der Disziplin und der Norm spiegelt sich Foucault zufolge auch in Veränderungen der Epik, namentlich in der Entwicklung des Romans, wider. Anders als im Epos mit seinen »objektiven Helden" (Hegel) spielt im Roman die Psyche die zentrale Rolle - das Verhältnis von Epos und Roman ist in dieser Hinsicht analog zum Verhältnis von Tragödie und Komödie bzw. Tragödie und Roman.

[D]ie Übergänge vom Epischen zum Romanhaften, von der Großtat zur heimlichen Besonderheit, von den langen Irrfahrten zur inneren Suche nach der Kindheit, von den Kämpfen zu den Phantasmen [verweisen] auf die Formierung einer Disziplinargesellschaft. ${ }^{11}$ (ÜS 249)

$10 \mathrm{Da}$ das Fehlen der drei Einheiten ebensowenig wie die Unabgeschlossenheit grundsätzlich der dramatischen Struktur widerspricht (vgl. Volker Klotz' `offenes Drama‘), darf hier unberücksichtigt bleiben.

11 Seitter übersetzt Foucaults "passage de l'épique au romanesque« mit »Übergang vom Epos zum Roman". Le "romanesque", das "Romanhafte", findet sich allerdings bei Hegel; vgl. das folgende Zitat. 
Foucault führt das nicht näher aus, so daß ihm auch in der ein Jahr nach Erscheinen von Überwachen und Strafen gehaltenen Vorlesung In Verteidigung der Gesellschaft noch bleibt, die Forderung nach snäherer Betrachtung` des Zusammenhangs von Norm und Roman zu erheben (vgl. VG 208). Denkt man aber beispielsweise an den Entwicklungs- oder Bildungsroman, leuchtet die Verknüpfung von Norm und Roman unmittelbar ein: Der Bildungsroman ist eine Gattung der individuellen Lebensbeschreibung. Hegel beschreibt den Kampf des Individuums mit der Gesellschaft in der Form des »Romanhafte[n]« folgendermaßen:

Diese Kämpfe nun aber sind in der modernen Welt nichts Weiteres als die Lehrjahre, die Erziehung des Individuums an der vorhandenen Wirklichkeit, und erhalten dadurch ihren wahren Sinn. Denn das Ende solcher Lehrjahre besteht darin, daß sich das Subjekt die Hörner abläuft, mit seinem Wünschen und Meinen sich in die bestehenden Verhältnisse und die Vernünftigkeit derselben hineinbildet, in die Verkettung der Welt eintritt und in ihr sich einen angemessenen Standpunkt erwirbt. ( $\ddot{\mathrm{A}}$ II, 219f.) $)^{12}$

12 Diese Beschreibung Hegels erfolgt allerdings keineswegs, wie Rolf Selbmann (Der deutsche Bildungsroman, 2., überarb. und erw. Aufl., Stuttgart 1994, S. 14) es nicht ohne Empörung darstellt, in apologetischer Absicht. Der ganze Abschnitt über »Das Romanhafte" propagiert nicht »die restlose Anpassung des Subjekts, sein `Einbilden in die bestehenden Verhältnisse und ihre >Vernünftigkeit« (ebd.), sondern kritisiert in durchgängig ironischem Ton eine abgeschmackte und im Kern immergleiche Darstellung jenes modernen Kampfes des Individuums im modernen Roman. Die amüsante Stelle sei hier ausschnittweise kurz zitiert: "Mag einer auch noch soviel sich mit der Welt herumgezankt haben, umhergeschoben worden sein, zuletzt bekommt er meistens doch sein Mädchen und irgendeine Stellung, heiratet und wird ein Philister so gut wie die anderen auch; die Frau steht der Haushaltung vor, Kinder bleiben nicht aus, das angebetete Weib, das erst die Einzige, ein Engel war, nimmt sich ungefähr ebenso aus wie alle anderen, das Amt gibt Arbeit und Verdrießlichkeiten, die Ehe Hauskreuz, und so ist der ganze Katzenjammer der übrigen da. - Wir sehen hier den gleichen Charakter der Abenteuerlichkeit, nur daß dieselbe ihre rechte Bedeutung findet und das Phantastische daran die nötige Korrektion erfahren muß." (Ä II, 220) Die »nötige Korrektion«, die »erfahren [werden] muß«, bezieht sich hier auch keineswegs, wie Selbmann es darstellt, auf das Individuum, sondern auf die Form des Romans - im Gegensatz zum romantischen Ritterroman. Hier klingt auch wieder das Motiv der Alltäglichkeit an, das bei Foucault wie bei Hegel und Nietzsche von der Tragödie zur Komödie (bzw. von der alten zur neueren Komödie) überleitet. Es wird schließlich vollends im Roman entfaltet. Der Panoptismus hat zum Ziel, alles bis ins kleinste Detail zu erfassen, und d.h. bis ins kleinste psychische und biographische Detail, bis in die unscheinbarste Handlung hinein, bis in den hintersten Winkel des Alltäglichen. Die Seele tritt bei Foucault auf die - komische - Bühne, aber (noch) maskiert; im Roman dann, jenseits der Bühne, wird es keine Masken mehr geben, und die Seele erscheint bloßgelegt in ihrer ganzen banalen Alltäglichkeit. 
Das, was Foucault das Problem der Norm nennt, behandelt der Bildungsroman als die Geschichte der Entwicklung eines Individuums in der Gesellschaft oder, stärker formuliert, als die Geschichte der Bildung und Formung eines Individuums in Auseinandersetzung mit der Gesellschaft und ihren Normen. Noch stärker formuliert: als Geschichte der Anpassung des Individuums an die Normen, als Geschichte seiner Normalisierung. Daher auch schreibt Foucault über das Kerkersystem: "Es gibt da so etwas wie eine Disziplinar-Ausbildung, die sowohl an einen Bildungsweg wie an eine berufliche Laufbahn erinnert." (ÜS 388) Und: "Der Delinquent ist das Produkt einer Institution. "(ÜS 389) Den Vorgang dieser Produktion beschreibt der Institutionenroman. ${ }^{13}$

\section{Der humanwissenschaftliche Panoptismus der Erzähltechniken}

Die unterschiedlichen Erzähltechniken des Romans ermöglichen dabei die ganze panoptische Bandbreite an Blicken des Individuums, Blicken auf das Individuum und Blicken des Individuums auf sich selbst. Stanzels auktorialer Erzähler liefert genau den Einblick in die Psyche, den sich die panoptischen Techniken zu verschaffen suchen. Auf diese Verbindung zwischen Panoptismus und Roman des Realismus weist auch Mark Seltzer hin: »The technique of omniscient narration [...] gives to the narrator a providential vision of the characters and action. It is the fantasy of such an absolute panoptism", "that fantasy of surveillance which [...] lies at the heart of the realistic project." "[T] he narrative method of the novel departs from this panoptic technique. «14 Der auktoriale Erzähler kennt nicht nur Hintergrund und Umstände der Handlung, sondern verfügt über Vergangenheit, Gegenwart und Zukunft der Romanfigur und aller sie umgebenden Umstände,

Die Disziplin befaßt sich, mit Hegel gesprochen, mit der "Prosa im menschlichen Dasein« (Ä I 197), der »Welt des Alltäglichen und der Prosa « (̈̈ I 197), der »Prosa der Welt« (̈̈ I 199) und, mit spezifischem Bezug auf den sromantischen` Roman, der »Prosa der Wirklichkeit ( äußerliche Realität, das Alltägliche der Wirklichkeit und die gemeine Prosa des

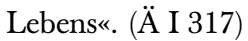

13 Campe prägt den Begriff des Institutionenromans als Nachfolger des Bildungsromans, in dem beschrieben wird, wie Institutionen Leben "formen" (vgl. Rüdiger Campe: Robert Walsers Institutionen. "Jakob van Gunten«, in: Rudolf Behrens/Jörg Steigerwald [Hg.]: Die Macht und das Imaginäre, Würzburg 2005, S. 235-250).

14 Mark Seltzer: The Princess Casamassima: Realism and the Fantasy of Surveillance, S. 531; vgl. auch Leo Bersani: The Subject of Power. 
verfügt über das vollkommene panoptische Wissen. Der Ich-Erzähler dagegen gehorcht der disziplinaren "Anreizung zu Diskursen« und der Pastoralmacht aus Der Wille zum Wissen und steht paradigmatisch für die Figur der Beichte und des Geständnisses. Die Erzähltechnik des Bewußtseinsstroms ist so etwas wie die absolute Form der Beichte und des Geständnisses, in der die ganze »Wahrheit über sich" gesagt wird.

Der Panoptismus zeichnet sich durch die Überblendung von Sehen und Gesehenwerden aus. Erkenntnistheoretisch formuliert bedeutet das, daß der Gefangene im Panopticon gleichzeitig Beobachtender und Beobachteter, Subjekt und Objekt der Beobachtung ist. Das scheint zunächst dem neuzeitlichen Reflexionsmodell des Bewußtseins seit Descartes bzw. seit Kants Lösung dieser Aporie durch die Zweiteilung in empirisches und transzendentales Subjekt zu entsprechen. Es besteht aber ein entscheidender Unterschied zwischen Kants Erkenntniskonzeption und der Blicksituation im Panopticon, indem genau diese Zweiteilung im Panopticon nicht erfolgt, denn der Gefangene spaltet sich eben gerade nicht in empirisches und transzendentales Subjekt, sondern bleibt zugleich empirisches Subjekt und Objekt. Fast könnte man meinen, das Problem der Subjekt-Objekt-Spaltung, vor dem die Erkenntnistheorie seit der Neuzeit steht, die "Aporien der Bewußtseinsphilosophie ${ }^{15}$ in der das Subjekt gleichzeitig Erkennendes und zu Erkennendes ist und die Kant durch die Differenzierung von transzendentalem und empirischem Subjekt festgeschrieben hatte, erwiesen sich in Foucaults Konzeption der panoptischen Blicke als gelöst. Im Panopticon scheint ein Subjekt widerspruchsfrei Gegenstand seiner eigenen subjektiven Beobachtung sein zu können. Doch tatsächlich entspricht diese Blicksituation eher einer neuen erkenntnistheoretischen Aporie, nämlich der humanwissenschaftlichen Dopplung, die Foucault in der Ordnung der Dinge beschreibt. Der Gefangene sieht sich unter den empirischen Bedingungen seines Gefangenseins ausschließlich als diesen Gefangenen, hat also gerade keine apriorische, sondern nur eine aposteriorisch-empirische Erkenntnis von sich. Die Bedingung des Blicks des Gefangenen auf sich selbst, d.h. das Transzendentale der Selbsterkenntnis im Panopticon, ist die empirische Gefängnissituation und ist der angenommene empirische und humanwissenschaftlicher, psychologisierende Blick des Aufsehers. So entspricht der Unterschied zwischen Kants Erkenntnismodell und der Blicksituation im

15 Jürgen Habermas: Der philosophische Diskurs der Moderne. Zwölf Vorlesungen, Frankfurt a.M. 1988 [1983], S. 345. 
Panopticon dem Unterschied zwischen Kants Transzendentalem und Foucaults Quasi-Transzendentalem (vgl. OD 307), zwischen apriorischen und empirischen Transzendentalien: Im Panopticon ist das Empirische das Transzendentale - wie in den Humanwissenschaften; ${ }^{16}$ es ist also Modell nicht der kantischen erkenntnistheoretischen Konzeption, sondern der humanwissenschaftlichen Episteme; und der Gefangene im Panopticon in seiner Doppelrolle von Subjekt und Objekt ist der »Mensch« der Humanwissenschaften, die "empirisch-transzendentale Dublette«.

Der Episteme der Ähnlichkeit und der der Repräsentation hatten dramatische Blicksituationen entsprochen, nämlich Tragödie bzw. Komödie. Ebensowenig nun, wie die Blicksituation im Panopticon noch als Schauspiel beschrieben werden kann, ${ }^{17}$ sind die Humanwissenschaften ihrer Struktur nach dramatisch; vielmehr finden sie ihre Entsprechung in narrativen Strukturen. ${ }^{18}$ Das hatte sich bereits in Velázquez' Hoffräulein angedeutet. Zu Beginn der Ordnung der Dinge interpretiert Foucault die Hoffräulein als Abbild der Episteme der Repräsentation, mithin als Komödie. Doch weist er dort bereits auf die entscheidende Einschränkung dieser Interpretation hin: auf die "essentielle Leere« nämlich, auf das "Subjekt«, das "ausgelassen worden« ist (OD 45), und damit kündigt sich das Ende des Dramas an. Diesen Gedanken erläutert Foucault am Ende der Ordnung der Dinge näher. Die Hoffräulein erweisen sich dort nicht mehr als vollkommene Repräsentation der Repräsentation, sondern deuten auf die Strukturen der modernen Humanwissenschaften voraus, denn hier tritt der Betrachter des Bildes hinzu, der "Mensch", und nimmt den "Platz des Königs" ein. Der Zuschauer, könnte man sagen, betritt die Bühne - so weit noch die Komödie. Dabei ist der »Mensch« jedoch nicht mehr Bestandteil des Repräsentationsgefüges

16 Vgl. oben, Kap. I, Unterkap. "Das Subjekt bei Foucault«.

17 Vgl. oben, Kap. V, Unterkap. "Der Zuschauer betritt die Bühne«.

18 Auch die Verfaßtheit der Humanwissenschaften selbst läßt sich übrigens erzähltheoretisch erfassen. Foucault beschreibt »das den Humanwissenschaften Eigene« als »die einfache Tatsache, daß sie in Beziehung zu den Wissenschaften, in denen das menschliche Wesen als [...] Objekt gegeben ist, in einer Position der Reduplizierung sich befinden und daß diese Reduplizierung a fortiori für sie selbst Geltung haben kann. [...] [D]ie Tatsache, [...] daß dieses Spiel auf sie selbst angewandt werden kann (man kann stets die Humanwissenschaften der Humanwissenschaften, die Psychologie der Psychologie, die Soziologie der Soziologie etc. herstellen), genüg[t], um ihre eigenartige Konfiguration zu zeigen. [...] Sie sind eher Wissenschaften des Reduplizierens in einer "metaepistemologischen« Position." (OD 424f.) Für diese »eigenartige Konfiguration« hält die Erzähltheorie mit Genette den Begriff der Intradiegese bereit, des erzählten Erzählens. 
und Mitwirkender des Schauspiels (als Zuschauer und als Schauspieler), sondern wird zu seinem Ausgangs- und Bezugspunkt. Es »erscheint»

der Mensch mit seiner nicht eindeutigen Position als Objekt für ein Wissen und als Subjekt, das erkennt. Unterworfener Souverän, betrachteter Betrachter, taucht er dort an jener Stelle auf, die ihm im voraus die Hoffräulein zuwiesen, von wo aber für lange Zeit seine reale Präsenz ausgeschlossen war. (OD 377)

Die Struktur der Hoffräulein läßt sich in ihrer ganzen Komplexität allein erzähltheoretisch erfassen. Daher auch spricht Foucault, wenn er sich auf Velázquez bezieht, vom "Autor« statt vom "Maler «, 19 was nicht nur der Differenzierung zwischen dem realen` und dem dargestellten Velázquez dient, sondern auch den narrativen Charakter des Bildes betont ${ }^{20}$ Jede der verschiedenen Möglichkeiten der Betrachtersituation und ihr "Abwechseln, reziproke[s] Ausschließen, Verflochtensein und Geflimmer«, jede Situation desjenigen, der in den Hoffräulein blickt (»das Modell, der Maler, der König, der Betrachter« [OD 377]) kann durch die Unterscheidungen zwischen homo- und heterodiegetischer Erzählebene, Fokalisierung und Stimme beschrieben werden. Daß der Mensch den Raum der Repräsentation sprengt, definiert seine Position als heterodiegetischer Erzähler (eine Position, die das Drama nicht zuläßt); zugleich und paradoxerweise aber bleibt der Mensch eine Figur in der erzählten Welt. Käte Hamburger schreibt in Die Logik der Dichtung: »Die epische Fiktion ist der einzige erkenntnistheoretische Ort, wo die Ich-Originität (oder Subjektivität) einer dritten Person als einer dritten dargestellt werden kann. ${ }^{21}$ Tatsächlich ist diese Möglichkeit auch in den Hoffräulein verwirklicht, denn auch dort sieht man den Blick »einer dritten Person als einer dritten«: den Blick des Königs nämlich. Der Maler, und zwar nicht der repräsentierte Maler, sondern der »echte« Maler, Velázquez (also laut Foucault der »Autor«), ist der Erzähler, der für den Betrachter (Leser) aus der Sicht des Königs erzählt analog zum Verhältnis, in das der Gefangene im Panopticon zu sich selbst tritt: Dieser betrachtet sich selbst durch die Augen eines dritten und stellt also seine Subjektivität als die eines dritten dar; der »erkenntnistheoretische

19 OD 34, 44, 45 (in der deutschen Übersetzung nur im letzteren Falle entsprechend übersetzt; auf OD 34, 44 ersetzt Köppen »auteur" durch »Maler«).

20 Den >Tod des Autors hat Foucault hier anscheinend noch nicht im Blick.

21 Käte Hamburger: Die Logik der Dichtung, 2., stark veränderte Aufl., Stuttgart 1968, S. 73. 
Ort« der epischen Fiktion ist damit auch der des Gefangenen im Panopticon, das sich als eine komplexe Erzählsituation erweist. "Roman und Norm", narrative Techniken und Disziplinartechniken sind also eng verwandt, und zugleich ermöglichen gewisse spezifisch narrative Techniken die Darstellung der humanwissenschaftlichen "empirisch-transzendentalen Dublette«. Wie die Tragödie der Marter der Ähnlichkeit und die Komödie der reformierten Strafe der Repräsentation entsprochen hatten, so entspricht der Roman des Panoptismus den Humanwissenschaften.

\section{Dichtung und Geschichtsschreibung, Kriminologie und Literatur}

Gegen die Identifikation von Panoptismus und Romanform ließe sich hier allerdings, wiederum in Anlehnung an Aristoteles' Poetik und diesmal mit Blick auf die dortige Unterscheidung zwischen Dichtung und Geschichtsschreibung, auch die Unvereinbarkeit von Disziplinarsystem und Literatur überhaupt behaupten. Denn im Gegensatz zur Dichtung beziehen sich die Disziplinen, wie laut Aristoteles die Geschichtsschreibung, auf das, "was wirklich geschehen ist«:22 auf das Leben und die Vergangenheit des Delinquenten; sie sind biographisch, und tatsächlich spricht Foucault in bezug auf das Disziplinarindividuum von der "Geschichtsschreibung seiner Existenz". (ÜS 247) Andererseits aber lassen sich die Disziplinen sehr weitgehend in Einklang mit der Dichtung bringen, weil es in ihnen eben genau nicht mehr in erster Linie darum geht, herauszufinden, "was geschehen war" $(\mathrm{WjF} 86)$, sondern sie sich vielmehr, wie laut Aristoteles die Dichtkunst, mit dem befassen, "was geschehen könnte, d.h. [dem] nach den Regeln der Wahrscheinlichkeit oder Notwendigkeit Mögliche[n]..23 Der Individualpräventionscharakter der modernen Strafjustiz besteht genau darin: sich nicht auf das zu richten, "was die Individuen getan haben, sondern auf das, was sie sind, sein werden, sein könnten" (ÜS 28), d.h. auf die Wahrscheinlichkeit oder Notwendigkeit eines Rückfalls, darauf, die »Gefährlichkeit« des Delinquenten auszuloten. Foucaults Definition der Gefährlichkeit weist daher Parallelen zu Aristoteles' Definition der Dichtung auf:

22 Aristoteles: Poetik, S. 29 (1451a 37).

23 Ebd., S. 29 (1451a 37-1451b 5). 
Das gesamte Strafsystem des 19. Jahrhunderts richtet sich darauf aus, nicht das tatsächliche, sondern das mögliche Handeln der Menschen zu kontrollieren; man fragt nicht, ob die Menschen sich gesetzeskonform verhalten oder nicht, sondern was sie möglicherweise tun, wozu sie fähig sein könnten, wofür sie anfällig sein mögen, was sie zu tun drohen. So war denn der zentrale Begriff der Kriminologie und des ganzen Strafsystems Ende des 19. Jahrhunderts der rechtstheoretische Begriff der Gefährlichkeit. Er besagt, dass der Einzelne von der Gesellschaft nicht auf der Ebene des tatsächlichen, sondern des potentiellen Verhaltens betrachtet werden sollte; nicht auf der Ebene tatsächlicher Verstöße gegen vorhandene Gesetze, sondern auf der Ebene möglichen Verhaltens. (WjF 83f.) ${ }^{24}$

So gesehen funktioniert die sich im 19. Jahrhundert entwickelnde Kriminologie nach den Verfahren der Dichtkunst; Disziplin und Literatur erweisen sich damit nicht als unvereinbar, sondern, im Gegenteil, als verwandt. In Überwachen und Strafen findet sich eine vielleicht nur zufällige, aber hübsche Anspielung auf diese Verwandtschaft. Foucault erwähnt dort die "moralische[] Buchführung" in Gefängnissen, die die schriftliche Dokumentation des Verhaltens der Häftlinge vorsah. (ÜS 321) »Moralische[ ] Buchführung « übersetzt hier »compte moral« des französischen Originals ${ }^{25}$ - und "compte moral" ist ein Homophon von sconte morak, von der im 18. Jahrhundert weit verbreiteten ’moralischen Erzählung, ein Gleichklang, in dem sich die inhaltliche Verwandtschaft der beiden so unterschiedlichen `Gattungen` andeutet.

24 Vgl. auch WjF 103: »Im Panoptismus erfolgt die Überwachung des Einzelnen nicht auf der Ebene des Tuns, sondern des Seins; nicht auf der Ebene der tatsächlichen, sondern der möglichen Taten. Dadurch tendiert die Überwachung zu einer immer stärkeren Individualisierung des Täters und achtet immer weniger auf die rechtliche Bedeutung, die strafrechtliche Qualifizierung der Tat. Der Panoptismus steht also im Gegensatz zu der legalistischen Theorie, die sich in den Jahren davor entwickelt hatte.«; ÜS 327: »In diesem neuen Wissen handelt es sich darum, die Tat als Delikt und vor allem das Individuum als Delinquenten swissenschaftlich zu qualifizieren. Die Möglichkeit einer Kriminologie ist gegeben. Hat es die Strafjustiz mit dem Rechtsbrecher zu tun, so entspricht dem Vollzugsapparat der Delinquent. Der Delinquent als biographische Einheit, als Kern von `Gefährlichkeit‘ [...].«

25 SP 291. 


\section{Das Ende des Romans in der Wissenschaftsprosa}

Foucault schlägt also eine Verbindung von Disziplinarsystem und Romanform vor. Die Beispiele aber, die er dann nennt, weisen über diese Gattungszuordnung noch hinaus. Foucault spricht in Überwachen und Strafen zwar über den Übergang vom Epos zum Roman, modifiziert diese Unterscheidung dann allerdings durch die gleich darauf folgenden Beispiele epischer Formen, die abgelöst werden. Hier stehen nämlich zwei mittelalterliche Versepen neben einer Kindererzählung aus dem 19. Jahrhundert - letztere nicht eben ein überzeugendes Beispiel für ein Epos. Das überraschende Nebeneinander der disparaten literarischen Werke erklärt sich über ihre jeweiligen Gegenstücke, die nun tatsächlich Gemeinsamkeiten untereinander aufweisen: Es sind psychoanalytische und autobiographische Krankenberichte.

Es sind die Unglücke des kleinen Hans und nicht mehr die von Hänschen klein, ${ }^{26}$ die das Abenteuer unserer Kindheit erzählen. Der Rosenroman wird heute von Mary Barnes geschrieben. Den Platz des Ritters Lanzelot nimmt der Gerichtspräsident Schreber ein. (ÜS 249)

Wie sich die Homophonie von sconte morak und scompte morak als Ersetzung der moralischen Erzählung des 18. Jahrhunderts durch den moralischen Rechenschaftsbericht des Gefängnisses des 19. Jahrhunderts lesen läßt, geht es auch hier nicht mehr eigentlich um den Übergang vom Epos zum Roman, sondern um den von literarischer Prosa zu wissenschaftlichem Bericht. Statt Kindererzählungen wie jener der Comtesse de Ségur werden fortan Schilderungen wie Freuds Analyse der Phobie eines fünfjährigen Knaben verfaßt; statt Versromanen über die Liebe schreibt man von der eigenen Reise durch den Wahnsinn; epische Helden werden durch Psychiatriepatienten ersetzt. ${ }^{27}$ Die Psychologie greift in einem Maße auf die Literatur über, daß von dieser nur mehr die Prosa der wissenschaftlichen oder autobiographischen Krankenberichte übrigbleibt - der Roman wird zur Fallstudie: Der

26 Im Original statt »Hänschen klein« »le bon petit Henri« (SP 227); vgl. folgende Fußnote.

27 Sophie de Ségur: Le bon petit Henri, in: Nouveaux Contes de fées, Paris 1857; Sigmund Freud: Analyse der Phobie eines fünfjährigen Knaben, in: Gesammelte Werke, hg. von Anna Freud u.a., Frankfurt a.M. 1999, Bd. 7, S. 241-377; Mary Barnes/Joseph Berke: Two accounts of a journey through madness, London 1971 (dt. München 1973); Daniel Paul Schreber: Denkwürdigkeiten eines Nervenkranken, Leipzig 1903 [Neudruck hg. von Gerd Busse, Gießen 2003]. 
Ich-Erzähler des Romans wird zum Patienten, der über sich selbst schreibt, der auktoriale Erzähler zum Psychotherapeuten, der die Anamnese aufnimmt und den Krankenbericht verfaßt, die Herausgeberfiktion zur Herausgeberwirklichkeit: Mary Barnes' Reise durch den Wahnsinn wird zusammen mit dem Kommentar ihres Arztes Joseph Berke veröffentlicht. Berke übernimmt damit die klassische Rolle des fiktiven Herausgebers, der die unter verschiedensten Umständen aufgefundenen oder ihm anvertrauten Berichte oder die ihm berichteten Geschehnisse mit einem Kommentar versieht und veröffentlicht - mit dem Unterschied, daß weder der herausgegebene Text noch die Herausgeberstellung noch auch der Herausgeber selbst fiktiv sind. Ähnliches gilt für die Analyse der Phobie eines fünfjührigen Knaben. Auch hier gibt es einen 'Erzähler`, der, zum Teil wörtlich zitierend, berichtet, was ihm der Vater des »kleinen Hans" brieflich und manchmal auch mündlich über diesen mitgeteilt hat. Doch ist auch dieser Erzähler nicht mehr fiktiv. Und auch hier folgt auf den Bericht, der nicht mehr fiktiv ist, der Kommentar eines (mit dem Erzähler identischen) Herausgebers, der nicht mehr fiktiv ist. Auf diese Weise gehen die Beispiele, die Foucault in Überwachen und Strafen nennt, sogar noch über die Gattungsentwicklung von Epos zu Roman hinaus und deuten auf ein Ende der Literatur überhaupt, auf ein Hegelsches Ende der Kunst - gipfelnd in der Psychoanalyse. Die Literatur tritt in die Wirklichkeit über und wird durch Prozeßakten und Zeitungsberichte, durch "moralische Buchführung", durch medizinische und psychoanalytische Fallstudien ersetzt. ${ }^{28}$ (Im Grunde durch die Prosa der Welt.)

28 Eine ganz ähnliche Beobachtung macht Theodor W. Adorno in: Standort des Erzählers im zeitgenössischen Roman [1954], in: ders.: Noten zur Literatur, Frankfurt a.M. 1981, S. 41-48. Er schreibt, "die Wissenschaft, zumal die Psychoanalyse Freuds« habe die "psychologischen Errungenschaften" der traditionellen Romankunst [Adorno bezieht sich hier konkreter auf die "psychologischen Errungenschaften Dostojewskys«] »längst [...] hinter sich gelassen«. "[A]lles Positive, Greifbare, auch die Faktizitäten des Inwendigen" sei "von Information und Wissenschaft beschlagnahmt«. (Ebd., S. 42f.) Statt jedoch, wie etwa Wolfgang Kayser, von hier aus auf den "Tod des Romans" zu schließen (Wolfgang Kayser: Entstehung und Krise des modernen Romans, Stuttgart ${ }^{4} 1963$ [1954], S. 33), beobachtet Adorno seine Erneuerung im zeitgenössischen Roman (wobei er hier mit Proust, Joyce, Kafka, Musil, Gide, Broch und Thomas Mann eher den Roman der klassischen Moderne nennt) und in dessen "antirealistische[m] Moment«. (Theodor W. Adorno: Standort des 
Indes scheint sich paradoxerweise gerade in der Psychoanalyse eine neuerliche Möglichkeit des Tragischen zu eröffnen, denn sie hebt die Trennung von Macht und Recht, die sich in der Ablösung der Souveränität durch die Biomacht manifestierte, auf, indem sie unternimmt,

die Thematik der Sexualität wieder in das System des Gesetzes, der symbolischen Ordnung und der Souveränität einzuschreiben. [...] In Reaktion auf den zeitgenössischen Aufstieg des Rassismus bemühte sich Freud, der Sexualität das Gesetz zugrunde zu legen - das Gesetz der Allianz, das Gesetz der verbotenen Blutschande, das Gesetz des Vater-Souveräns. Um das Begehren sollte wieder die ganze alte Ordnung der Macht zusammengerufen werden. (WW 144f.)

Die Psychoanalyse verknüpft Recht und Macht, Gesetz und Sex aufs neue. Vor dem Hintergrund der These, daß die Tragödie mit dem Recht verbunden sei, erklärt sich hierüber u.a. das Interesse der Psychoanalyse an der Tragödie, wie es etwa in Freuds Ödipus- und Lacans Antigonelektüre Ausdruck findet. Die Psychoanalyse restauriert die juridische Form der Macht, die dem Tragischen den Boden bereitet. Diese neu aufscheinende Möglichkeit der Tragödie besteht jedoch nur im begrenzten diskursiven Raum der Psychoanalyse, und nur vorübergehend, wie Foucault sogleich anmerkt:

Aber diese Position der Psychoanalyse war an eine bestimmte historische Konjunktur gebunden. Und nichts vermag zu verhindern, daß das Denken der Ordnung des Sexuellen in den Begriffen des Gesetzes, des Todes, des Blutes und der Souveränität [...] letztlich nur eine nostalgische Rückwendung in die Geschichte ist. (WW 145)

Die aufblitzende Möglichkeit einer modernen Tragödie wird also sogleich wieder verneint. Ist auf diese Weise auch das tragische Potential der Psychoanalyse ausgeräumt, bleibt es dabei, daß Überwachen und Strafen die Linie Tragödie - Komödie - Roman bzw. die Linie Epos - Roman - Wissenschaftsprosa zeichnet. Beide Linien münden schließlich in das Ende der schönen Literatur.

Erzählers, S. 43) Indes sind auch, vielleicht sogar gerade dessen "antirealistische» Techniken wenn nicht dasjenige, was ihn an die Norm koppelt (denn das dürfte wohl eher für die traditionelle Erzählweise und den auktorialen Erzähler gelten), so doch dasjenige, was ihn für den Panoptismus interessant macht. 
Eine Variante der Linie Epos - Roman - Wissenschaftsprosa/Bericht geht von dem aus, was Foucault die "Schafott-Diskurse[ ] nennt: Im 18. Jahrhundert erteilte man dem Verurteilten vor der Hinrichtung das Wort, damit er »sein Verbrechen und die Gerechtigkeit seiner Verurteilung " kommentiere und bestätige (eine Art Parabase im Strafschauspiel, in der sich bereits der komische Charakter der reformierten Abschreckungsund Besserungsstrafen ankündigt), und verbreitete diese letzten Worte in Flugblättern. (ÜS 85) Bei diesen "Schafott-Diskursen« handelte es sich "[i]n einigen Fällen [...] sicher um wirkliche Erklärungen, aber häufiger um fiktive Reden, die man zur Abschreckung und Erbauung in Umlauf setzte.« (ÜS 85) Es ist wohl dieser fiktive Charakter, aufgrund dessen Foucault sie als literarische "Gattung " bezeichnet, als die "Gattung Letzte Worte eines Verurteilten«.29 (ÜS 86) Diese "Literatur« (ÜS 86) erwies sich jedoch als ein zweifach `besetzter` (vgl. ÜS 87f.), »doppeldeutige[r] Diskurs[ ]«. (ÜS 88) Einerseits dienten die Verbrechensberichte der Abschreckung und, wenn sie noch im Vorfeld der Verurteilung verbreitet wurden, der indirekten Einwirkung auf das Strafmaß. Das Volk sollte gegen den Angeklagten aufgebracht werden, so daß die öffentliche Meinung keine zu milde Strafe zuließe. Andererseits wurden diese Zwecke nicht immer erreicht. Die »Schafott-Diskurse" verselbständigten sich und die beschriebenen Verbrechen erschienen als Kampf »düstere[r]« Helden (ÜS 90) aus dem Volk gegen die Mächtigen (vgl. ÜS 86f.). »Der Verurteilte wurde durch die ausführliche Schilderung seiner Verbrechen heroisiert [...]. Die verkündeten Verbrechen erhoben winzige Kämpfe zum Epos.« ${ }^{30}$ (ÜS 86f.) Neben dem weitgehend fiktiven Charakter der Geschichten, die "zum Lesestoff der unteren Volksschichten" (ÜS 88) werden, ist es dieser sepische< Stil, der rechtfertigt, daß Foucault sie als eigene literarische Gattung bezeichnet: Sie werden zu einer Art `Volksepos`, das direkte politische Auswirkungen zeitigen konnte. Entgegen ihrem ursprünglichen Zweck führten die Geschichten oftmals dazu, daß die Zuschauer des Strafschauspiels sich auf die Seite des Verurteilten schlugen und seine Hinrichtung tumultuarisch zu verhindern suchten. Weil

29 Seitter übersetzt »Literaturgattung«, Foucault schreibt nur "genre«. (SP 79)

30 Übersetzung verändert, Gw.E.; vgl. SP 80: "Les crimes proclamés amplifiaient jusqu'à l'épopée des luttes minuscules«. 
also das "niedrige[ ] und alltägliche[] Epos«31 (ÜS 88f.) des Verurteilten die öffentliche Ordnung zu bedrohen begann, forderten die Strafreformer das Verbot der Flugblätter, deren Tage jedoch ohnehin gezählt waren. Die "volkstümlichen Helden" verlassen das >literarischer Feld der Schafott-Diskurse, mit denen so etwas wie eine Episierung des Strafschauspiels begonnen hatte, und "[d]ie Zeitungen nehmen die unepische graue Eintönigkeit der Vergehen und Strafen in ihre vermischten Meldungen auf.«32 (ÜS 90) Gleichzeitig aber, und hier kommt ein neues Element in die Argumentation, entwickeln sich erste Formen von Kriminalliteratur, die zunächst episodisch in Zeitungen erscheint und sich dann als eigenständige Form des Kriminalromans emanzipiert. ${ }^{33}$

Die >literarischer "Gattung 'Letzte Worte eines Verurteilten«" spaltet sich also auf; in einen literarischen und fiktionalen Teil - Kriminalliteratur - und in einen berichtenden und nichtfiktionalen Teil - Zeitungsberichte über Hinrichtungen in den "vermischten Meldungen«. An den "Schafott-Diskursen« zeigt sich damit sowohl der Übergang vom - volkstümlichen - Epos zum - bürgerlichen - (Kriminal-)Roman als auch der Übergang vom Epos zum nüchternen, 'prosaischen Bericht, also die Ablösung der Literatur.

Variante: Epos - Tragödie - >lettres de cachet‘

Implizit beschreibt Foucault die Entwicklung von schöner Literatur zu ihrem Ende bereits in Die Wahrheit und die juristischen Formen, und zwar im Zusammenhang seiner Unterscheidung der drei bereits genannten juristischen Wahrheits- oder Urteilsfindungstechniken: Probe, Untersuchung und Prüfung (vgl. Kap. III). Ohne sie explizit zu stellen, behandelt Foucault hier auch die Gattungsfrage: Er vergleicht einen Rechtsfindungsprozeß in

31 Übersetzung verändert, Gw.E. Seitter übersetzt: »diesen niedrigen und alltäglichen Heldensagen«; Foucault schreibt: »'épopée mineure et quotidienne des illégalismes«. (SP 81f.) Auch an anderer Stelle übersetzt Seitter "épopée« mit "Heldensage«, wodurch die explizite Gattungszuweisung zum Epos verlorengeht (vgl. ÜS 247 bzw. SP 225).

32 Meine Übersetzung, Gw.E.; vgl. SP 82f.: "Les journaux, eux, reprendront dans leurs faits divers la grisaille sans épopée des délits et de leurs punitions."Seitters Übersetzung ("während die graue Masse der Vergehen und Strafen in die alltäglichen Zeitungsberichte eingeht«) übergeht den Hinweis auf den Verlust des Epischen.

33 Zur Kriminalliteratur vgl. die Literaturhinweise bei Mark Seltzer: The Princess Casamassima: Realism and the Fantasy of Surveillance, S. 527f., Anm. 32. 
Homers Ilias, exemplarisch für die Probe, mit der Beweisführung in Sophokles' König Ödipus, exemplarisch für die Untersuchung. In der Ilias beschuldigt Menelaos Antilochos, ihn bei den Leichenspielen für den gefallenen Patroklos im Wagenrennen um den Sieg betrogen zu haben, und verlangt von ihm den Schwur, ihn nicht absichtlich aus der Bahn gedrängt zu haben. Antilochos wagt nicht, zu schwören, und gesteht damit sein Unrecht ein. Foucault zufolge wird hier also der Rechtsstreit durch eine Probe (bzw. dadurch, daß der Probe ausgewichen wird) entschieden, was um so auffälliger ist, als vor Beginn des Rennens an der Wendemarke zwar eigens ein Zeuge aufgestellt wurde, der später aber nicht befragt wird. ${ }^{34}$ Das verdeutlicht den Unterschied zwischen Probe und Untersuchung zusätzlich: Selbst wenn es einen Zeugen gibt, greift man in der Urteilsfindung nicht auf ihn zurück, sondern läßt die göttliche Probe entscheiden. Anders im Ödipus: Im Zuge der Suche nach Laios' Mörder werden Iokaste und Ödipus als Zeugen befragt, und auch bei der Ermittlung der Wahrheit über die Prophezeiung von Vatertötung und Mutterschändung treten zum Beschuldigten Ödipus und zum Seher und Ankläger Teiresias mit dem Boten aus Korinth bzw. dem Hirten des Laios Dritte hinzu (vgl. WjF 36). Der Unterschied zwischen der Probe im Epos und der Untersuchung in der Tragödie besteht demnach darin, daß zum "allmächtigen Blick[ ] des Sonnengottes, in der Form des Blicks des Sehers", ein weiterer Blick hinzukommt: »der Blick des Zeugen«. (WjF 39) Die Tragödie also ergänzt den einen, göttlichen Blick des Epos um einen weiteren bzw. stellt ihm einen anderen entgegen: den des Boten und den des Hirten, einen "gleichsam empirisch-alltäglichen Blick« (WjF 40) den Blick des Zuschauers. Dieser Blick des Zuschauers markiert die Gattungsgrenze zwischen Epos und Tragödie bzw. Epik und Dramatik; die Differenz des juristischen Verfahrens ist eine Gattungsdifferenz - und eben, wenn man Foucaults Ausgangsthese wieder in den Blick nimmt, auch eine Differenz zwischen verschiedenen epistemischen Formen und Subjekt- oder Subjektivierungsformen.

34 Hierbei unterläuft Foucault eine Ungenauigkeit in der Lektüre. Zum einen schreibt er fälschlicherweise, der Name des Zeugen werde nicht genannt (vgl. WjF 31). Homer nennt ihn aber durchaus (er heißt Phoinix; vgl. Ilias, 23. Gesang, 360), was das Ausbleiben seiner Befragung im Sinne von Foucaults Lesart nur noch erstaunlicher erscheinen läßt. Abgesehen davon ist zwar richtig, daß dieser Zeuge an der Wendemarke postiert wurde, doch erfolgt Antilochos' Regelverstoß nicht an der Wendemarke, sondern an einer Wegenge irgendwo auf der Strecke (vgl. ebd., 419), wo der Zeuge sie möglicherweise gar nicht beobachten konnte. 
Während Foucault in Die Wahrheit und die juristischen Formen also Homers Ilias und Sophokles' Ödipus als Zeugnisse für das Verfahren der Probe bzw. der Untersuchung liest, exemplifiziert er die Prüfung nicht mehr an einem literarischen Text (anders als in Überwachen und Strafen, wo er sie, wie gezeigt wurde, der Disziplin und dem Roman zuordnet). Und doch sind auch hier wieder Texte von zentraler Bedeutung: die sogenannten >lettres de cachet‘. ${ }^{35}$ Dies waren »Befehle des Königs, die eine einzelne Person zu etwas zwangen«. Mittels ihrer konnte man »einen Menschen aus dem Land verbannen, ihn seines Amtes entheben oder ihn einsperren." (WjF 94) Die Besonderheit der slettres de cachet besteht darin, daß die Initiative zu den Befehlen in den meisten Fällen nicht vom König ausging, sondern sie auf individuelle Bitten einzelner Personen erfolgten, die in der Regel aus dem engsten Umfeld der $\mathrm{zu}$ bestrafenden (und d.h. zu entfernenden, einzusperrenden) Person stammten. In diesem Zwangssystem ist es also nicht der König, der blickt, sondern es sind die Verwandten, die Ehemänner und Ehefrauen, die Söhne und Töchter, die Nachbarn und die Gemeindemitglieder, die auf den Einzelnen blicken (vgl. WjF 95f.). Durch diesen Blick der Vielen auf »eine einzelne Person« oder auf Wenige scheinen die slettres de cachet« zunächst der Souveränität und der Funktionsweise des Dramas zugeordnet zu sein, in dem der Einzelne zum Gegenspieler des Königs wird. Doch handelt es sich tatsächlich um gegenseitige Blicke; Familien und Nachbarn nehmen je einander in den Blick, womit nicht mehr ein Einzelner, sondern die Vielen in den Blick geraten, in eine unüberschaubare Vielheit und Gegenseitigkeit an Blicken - eine Variante oder Vorform des Panoptismus, wie Foucault ihn in Überwachen und Strafen beschreiben wird. Dementsprechend bezeichnet er die ’lettres de cachet‘ als Ursprung des Gefängnisses (vgl. WjF 97). Auch hier also werden literarische von nichtfiktionalen Texten abgelöst; hier wird die Linie Epos - Tragödie - >lettres de cachet ' gezeichnet. Die slettres de cachet in Die Wahrheit und die juristischen Formen stützen damit die implizite Argumentation zum Ende der Literatur. Wie die Humanwissenschaften, deren Ende Foucault in der Ordnung der Dinge voraussagt, gehen demnach auch der Panoptismus und der Roman zu Ende.

351982 gibt Foucault zusammen mit Arlette Farge eine Sammlung der >lettres de cachet heraus: Michel Foucault/Arlette Farge (Hg.): Le désordre des familles. Lettres de cachet des archives de la Bastille, Paris 1982 [dt.: Familiäre Konflikte. Die `Lettres de cachet‘, Frankfurt a.M. 1989]. 
Dritter Teil: Gattung, Geschichte und Subjekt 


\section{Archäologie, Genealogie, Gattungstheorie}

\section{Gegen die Gattung: Die Ordnung der Dinge und die Archäologie des Wissens}

Die Ordnung der Dinge hebt mit dem »Erstaunen« über eine generische Klassifikation an. Mit der fortan berühmten und überall zitierten Taxonomie "eine[r] gewissen chinesische[n] Enzyklopädie" aus einem Essay Jorge Luis Borges' eröffnet Foucault seine Kritik »unseres Denkens«. Die Taxonomie sei auch hier noch einmal wiedergegeben. Ihr zufolge unterteilen sich die Tiere in:

a) dem Kaiser gehörende, b) einbalsamierte, c) gezähmte, d) Milchschweine, e) Sirenen, f) Fabeltiere, g) herrenlose Hunde, h) in die vorliegende Klassifikation gehörige, i) die sich wie Tolle gebärden, j) unzählbare, $k$ ) die mit einem ganz feinen Pinsel aus Kamelhaar gezeichnet sind, l) etcetera, m) die den Krug zerbrochen haben, n) die von weitem wie Fliegen aussehen. ${ }^{1}(\mathrm{OD} 17)$

Die Absurdität dieser Klassifikation, »die schiere Unmöglichkeit, das zu denken« (OD 17), gründet in der »Erfahrung der Ordnung«, die unserer Kultur als ein "historische[s] Apriori« zugrunde liegt. (OD 24) Jegliche Gattungsklassifikation, so suggeriert Foucault, unterliegt notwendigerweise diesem »historischen Apriori« (Ähnlichkeit, Repräsentation, Humanwissenschaften) und kann daher keinerlei überzeitliche Gültigkeit beanspruchen. Auch in der Archäologie des Wissens wendet sich Foucault gegen überhistorisch gültige Gattungseinteilungen. Er beschreibt zunächst unter Verweis auf Bachelard und Canguilhem eine zeitgenössische Tendenz in den Wissenschaften: "Unter den großen Kontinuitäten des Denkens, [...] unter dem Beharren einer Gattung, einer Form, einer Disziplin, einer theoretischen Aktivität, sucht man jetzt die Auswirkung der Unterbrechungen zu entdek-

1 Übersetzung angepaßt, Gw.E.; vgl. Michel Foucault: Les mots et les choses, S. 7: »a) appartenant à l'Empereur, b) embaumés, c) apprivoisés, d) cochons de lait, e) sirènes, f) fabuleux, g) chiens en liberté, h) inclus dans la présente classification, i) qui s'agitent comme des fous, j) innombrables, k) dessinés avec un pinceau très fin en poil de chameau, l) et cætera, m) qui viennent de casser la cruche, n) qui de loin semblent des mouches«. Köppen übersetzt »classification« mit "Gruppierung«. Die Unterklasse »j) innombrables" fehlt gänzlich und kann wahlweise mit "unzählbare« oder "zahllose» wiedergegeben werden. 
ken." (AW 10) Zum Zeitpunkt, zu dem er dies schreibt, sind verschiedene intellektuelle und theoretische Strömungen (die Tel-Quel-Gruppe u.a. angesichts des Nouveau Roman, der französische Strukturalismus oder die Semiotik) damit beschäftigt, die überkommenen Gattungseinteilungen der Literaturwissenschaft zu demontieren. Foucault faßt diese aktuelle Position knapp zusammen bzw. weist auf sie voraus: Auch die »literarische Analyse" müsse sich

künftig nicht das Gefühl oder die Sensibilität einer Epoche, nicht die "Gruppen«, "Schulen«, "Generationen« oder "Bewegungen«, nicht die Gestalt des Autors im Spiel des Austausches, das sein Leben und seine "Schöpfung" verknüpft hat, sondern die einem Werk, einem Buch, einem Text eigene Struktur als Einheit [nehmen]. (AW 12)

Daß Foucault hier das "Werk« (exuvre) als Gegenbegriff zur "Schöpfung« (création) eines Autors und seines Lebens anführt, ist überraschend, da gerade der Werkbegriff mit dem Autor verbunden ist, dessen »Tod« Roland Barthes erst kurz zuvor verkündet hatte und dessen "Gestalt« Foucault ja gerade nicht mehr als Gegenstand »literarischer Analyse« verstanden wissen möchte. ${ }^{2}$ Tatsächlich wird das »Werk « und seine Einheit an allen anderen Stellen seines Textes in Frage gestellt und fungiert dort eher als Exemplum alles dessen, was es theoretisch und methodisch zu vermeiden gilt. Mit "Buch" und »Text« dagegen nennt Foucault zentrale Begriffe genau dieser zeitgenössischen Diskussion, die sich gegen den Werkbegriff wendet und mit der auch die Absage an Gattungsklassifikationen verbunden ist. So schreibt Maurice Blanchot 1962 über das »Buch«:

Wichtig ist allein das Buch in seinem So-Sein, fern allen Gattungsbegriffen, außerhalb aller Einteilungen wie Prosa, Poesie, Roman, Zeugnis, denen es sich nicht einfügen will und denen es die Macht abspricht, seinen Ort festzulegen und seine Form zu bestimmen. [...] Es macht also ganz den Eindruck, als ob nach dem Verschwinden der Gattungen die Literatur allein Bestand hätte [...] - als gäbe es also wirklich ein >Wesen der Literatur. Aber es ist gerade das Wesen der Literatur, daß sie sich jeder Wesensbestimmung entzieht, jeder Behauptung, die sie festlegt oder gar zu etwas Wirklichem macht, Hohn spricht. ${ }^{3}$

2 Roland Barthes: La mort de l'auteur [engl. 1967; frz. 1968], in: ders.: Le bruissement de la langue, Paris 1984, S. 61-67. Vgl. auch Michel Foucault: Was ist ein Autor?, in: S I, S. 1003-1042.

3 Maurice Blanchot: Wohin geht die Literatur? [1962], in: ders.: Der Gesang der Sirenen. Essays zur modernen Literatur, Frankfurt a.M./Berlin/Wien 1982, S. 263-339, hier S. 272f. 
Vergleichbare Gedanken halten sich durch die sechziger Jahre hindurch; Philippe Sollers schreibt 1968:

Peut-être le symptôme le plus impressionnant de la littérature moderne est-il de voir apparaitre de plus en plus sous nos yeux un mode d'écriture nouveau, unitaire, global, où les distinctions de genres, radicalement abandonnées, laissent place à ce qu'il faut bien appeler des »livres« - mais des livres pour lesquels, dirait-on, aucune méthode de lecture n'est encore pratiquement définie. ${ }^{4}$

Barthes entwirft nicht das "Buch«, sondern die »Erzählung« bzw., radikaler und umfassender, den »Text « als Alternativkonzept zum Werk. ${ }^{5}$ Es sind wohl solche Zitate und Konzepte, die in der Forschung zu einem gewissen Konsens bezüglich einer "anti-generischen ${ }^{6}$ (Pornschlegel, s.u.) Haltung in der Postmoderne geführt haben. Birgit Neumann und Ansgar Nünning zufolge stehen "[p]oststrukturalistische Theoretiker [...] dem Konzept der Gattung bekanntlich kritisch oder gar ablehnend gegenüber«. ${ }^{7}$ Sie sprechen - ohne Textverweis - von einer "Rede vom sTodk der Gattungen in der Postmoderne ${ }^{8}$ und erklären die von ihnen behauptete postmoderne $\mathrm{Ab}$ lehnung der Gattungen damit, daß »die Einteilung der Literatur in formal und/oder inhaltlich definierte Kategorien als unproduktive Einengung der Vielfalt literarischer Ausdrucksformen « betrachtet werde. ${ }^{9}$ Dagegen ist einzuwenden, daß dies eine keineswegs spezifisch postmoderne, sondern eine genuin moderne Position wäre, die auf die zunehmend schwieriger zu klassifizierende Literatur der Moderne reagiert und die Individualität des je einzelnen Kunstwerks nachdrücklich betont - man denke an Benedetto Croces Ablehnung literarischer Gattungseinteilungen in seiner Ästhetik von 1902. Neumann und Nünning legen nicht dar, welche »[p]oststrukturalisti-

4 Philippe Sollers: Critique de la poésie, in: Logiques, Paris 1968, S. 206.

5 Roland Barthes: Introduction à l'analyse structurale des récits, in: Communications 8 (1966), S. 1-27; ders.: De l'œuvre au texte, in: Revue d'esthétique 24 (1971), S. 225-232.

6 Clemens Pornschlegel: Vögel mit Schlangen. Zur Problematik generischer Klassifikationen in der Postmoderne, in: Uwe Hebekus/Ethel Matala de Mazza/Albrecht Koschorke (Hg.): Das Politische. Figurenlehren des sozialen Körpers nach der Romantik, München 2003, S. 248-260, hier S. 250.

7 Birgit Neumann/Ansgar Nünning: Einleitung: Probleme, Aufgaben und Perspektiven der Gattungstheorie und Gattungsgeschichte, in: Marion Gymnich/Birgit Neumann/ Ansgar Nünning (Hg.): Gattungstheorie und Gattungsgeschichte, Trier 2007, S. 1-21, hier S. 6.

8 Ebd. S. 16.

9 Ebd., S. 6. 
sche[n] Theoretiker" sie im Sinn haben, doch steht zu vermuten, daß es dieselben sind, die Klaus W. Hempfer meint, wenn er schreibt:

Während sich in Italien seit den sechziger Jahren jedoch eine zunehmende Befreiung von Croceschem Denken vollzieht, ist in einigen neuesten französischen Publikationen geradezu eine Rückkehr zu 'gattungsfeindlichen< Positionen zu erkennen, die sich im wesentlichen der gleichen Argumente bedienen wie schon Croce, offensichtlich jedoch ohne sich dieses Bezugs bewußt zu sein. ${ }^{10}$

Auch Hempfer benennt die Publikationen, die er meint, nicht; sieht man sich aber die Texte aus dem Umkreis der Tel-Quel-Gruppe an, die er an anderer Stelle erwähnt (Sollers, Barthes, Blanchot), zeigt sich, daß deren Argumentation in der Tat auf dem ästhetischen Boden erfolgt, auf dem sich schon Croce bewegt hatte - der Nichtklassifizierbarkeit des je individuellen Werkes aufgrund seiner Einzigartigkeit. Barthes etwa schreibt in seinem Aufsatz De l'ouvre au texte (1971), das Karl Canvat das "manifeste des tenants du stexte face aux tenants de l'’œuvre et du ‘genre«11 nennt: »Le Texte [...] ne peut être pris dans une hiérarchie, ni même un simple découpage des genres. Ce qui le constitue est au contraire (ou précisement) sa force de subversion à l'égard des classements anciens.«12 Barthes wiederholt damit Croces Position bis hin zum Selbstwiderspruch, Gattungseinteilungen für obsolet zu erklären, weil die moderne Literatur bzw. der "Text« sich eben über das Überschreiten der Gattungsgrenzen definiere. Und Blanchots und Sollers' »Buch«- und »Werk«-Konzeptionen gehen direkt auf Mallarmé und damit ebenfalls auf eine genuin moderne Position zurück..$^{13}$ Eine spezifisch spostmoderne kritische Haltung gegenüber Gattungsklassifikationen findet sich weder hier noch in Publikationen desselben Umfelds. Zu Recht läßt David Duff daher »modern literary theory « um 1800 beginnen, in der »few concepts have proved more problematic and unstable than that of genre." $\mathrm{Zu}$ Recht schreibt er, "the notion of genre is one whose meaning, validity

10 Klaus W. Hempfer: Gattungstheorie, München 1973, S. 38. Auffällig ist hierbei der sprogenerischer Gestus, mit dem Hempfer von einer "Befreiung" von Croce spricht, die ursprünglich ihrerseits als Befreiung - von normativen Gattungsklassifikationen konzipiert war.

11 Karl Canvat: Enseigner la littérature par les genres. Pour une approche théorique et didactique de la notion de genre littéraire, Brüssel 1999, S. 35.

12 Roland Barthes: De l'œuvre au texte, S. 227.

13 Vgl. dazu Dominique Combe: Les genres littéraires, Paris 1992, darin: "Le `Livre`, l’(Euvre totak et la transgression des genres«, S. 65-69. 
and purpose have been repeatedly questioned in the last two hundred [years]«, und zu Recht nennt er die "anti-generic tendencies of Romanticism and Modernism " in einem Zuge. ${ }^{14}$ Fredric Jameson beobachtet zwar in den siebziger Jahren antigenerische Tendenzen, ordnet sie aber der Moderne zu: "The reaction against genre theory in recent times is a strategic feature of what must be called the ideology of modernism. «15 Im gleichen Sinne erwähnt Hempfer ein »Reden vom >Tod» der Gattungen in der Moderne«16 (und nicht in der Postmoderne), und auch Canvat reiht die Tel-Quel-Gruppe, Barthes und Blanchot in die "conception moderne" der Gattungen ein. ${ }^{17}$ Mit Bezug auf ähnliche Texte wie die, auf die Canvat verweist, behauptet Clemens Pornschlegel dagegen zusammen mit Neumann und Nünning einen »anti-generischen Affekt« nicht der Moderne, sondern der Postmoderne. ${ }^{18}$ Seine Erklärung dafür ist jedoch nicht, wie die Neumanns und Nünnings, eine in erster Linie ästhetische, sondern eine politische. Zwar könne "man die postmoderne Zurückweisung generischer Klassifikationen sicherlich auf historische Poetologien, zumal die der Romantik zurücklesen«, doch sei

der anti-generische Affekt, wie er die Texte Blanchots, aber auch die Texte Barthes', Derridas und Kristevas durchquert, in seiner expliziten, politisch-ästhetischen Fragestellung nirgendwo zunächst je als literarische 'Neoromantik^ in Szene gesetzt worden, um so offener indes als ethisch-politische Antwort auf die Katastrophen des 20. Jahrhunderts. ${ }^{19}$

Er bezeichnet die Texte als »Elemente eines neuen, ästhetisch-politischen Projekts«, dem ein "aktuelle[s], politische[s] Motiv« zugrunde liege, ${ }^{20}$ bleibt die entsprechenden Textbelege aber schuldig - und zwar notgedrungen,

14 David Duff: Introduction, in: ders. (Hg.): Modern genre theory, Harlow 2000, S. 1-24, hier S. 1.

15 Fredric Jameson: Magical Narratives: Romance as Genre, in: New Literary History 7.1 (1975), S. 135-163, hier S. 135.

16 Klaus W. Hempfer: Gattung, in: Reallexikon der deutschen Literaturwissenschaft. Neubearbeitung des Reallexikons der deutschen Literaturgeschichte, hg. von Klaus Weimar u.a., Bd. 1, Berlin/New York 1997, S. 651-655, hier S. 654. Ebensowenig allerdings wie Neumann und Nünning die "Rede vom >Tod der Gattungen in der Postmoderne " belegt Hempfer dieses "Reden vom `Tod der Gattungen in der Moderne" durch konkrete Textverweise.

17 Karl Canvat: Enseigner la littérature par les genres, S. 40.

18 Clemens Pornschlegel: Vögel mit Schlangen, S. 250 und passim.

19 Ebd., S. 250.

20 Ebd. 
weil diese Texte keineswegs "explizit« und »offen« politisch argumentieren. Als einzigen Gewährsmann führt er Vincent Descombes an, der die gesamte Postmoderne, wohl nicht zu Unrecht, als Reaktion auf die Geschehnisse der vierziger Jahre begreift; 21 über einen allgemeinen Kampf gegen Differenzen hinaus dagegen, der zweifellos auch grundsätzlich politisch zu lesen ist, argumentieren die genannten Texte Blanchots, Barthes', Kristevas und Derridas - und für Derrida beispielsweise nennt Pornschlegel keinen spezifischen Text - nicht gattungspolitisch.

Die naheliegendste und überzeugendste, zugleich aber ebenfalls wenig spezifische Begründung für die Gattungsskepsis der Postmoderne liefert Albert Meier, dem zufolge Gattungsbegriffe und "Begriffe wie `das Lyrische‘, >das Epische und ‘das Dramatischer dem postmodernen Generalverdacht gegen alle Ontologie zum Opfer gefallen" sind. ${ }^{22}$ Daß Gattungstheorie und Ontologie in der Tat untrennbar miteinander verbunden sind, betont auch Schaeffer, der seinen Aufsatz Du texte au genre mit folgender Feststellung beginnt:

Je poserai au départ que la plupart des théories génériques ne sont pas véritablement des théories littéraires, mais plutôt des théories de la connaissance. Je veux dire par là que leur enjeu transcende la théorie littéraire proprement dite et débouche sur des querelles d'ordre ontologique. ${ }^{23}$

Das liegt zum einen schlicht daran, daß die Gattungseinteilung, wie jede Klassifikation, dem Universalienproblem unterliegt ${ }^{24}$ und also in der Tat notwendig an Fragen ontologischer Natur teilhat. Zweitens gilt dies seit Friedrich Schlegel und Hegel, gilt seit dem, was Szondi als Ablösung der

21 Vincent Descombes: Das Selbe und das Andere. FünfundvierzigJahre Philosophie in Frankreich (1933-1978), Frankfurt a.M. 1981.

22 Albert Meier: Lyrisch - episch - dramatisch, in: Ästhetische Grundbegriffe, hg. von Karlheinz Barck u.a., Bd. 3, Stuttgart 2001, S. 709-723, hier S. 709. Strenggenommen muß man die Postmoderne dann allerdings konsequenterweise bereits mit Nietzsche beginnen lassen, wie es Habermas und Vattimo tun. Vgl. Gianni Vattimo: Das Ende der Moderne, Stuttgart 1990, S. 178f.; Jürgen Habermas: Eintritt in die Postmoderne: Nietzsche als Drehscheibe, in: ders.: Der philosophische Diskurs der Moderne, S. 104-129.

23 Jean-Marie Schaeffer: Du texte au genre. Notes sur la problématique générique, in: Gérard Genette/Tzvetan Todorov (Hg.): Théorie des genres, Paris 1986, S. 179-205, hier S. 179 (zuerst veröffentlicht in: Poétique 53 [1983], S. 3-18). Der Titel Du texte au genre ist eine programmatische Umkehrung dessen, was in den sechziger Jahren stattfand, als man sich von der Gattung ab- und zum Text bzw. zum "Buch" hinwendete (vgl. Blanchot, Sollers, Barthes).

24 Vgl. dazu ausführlich Klaus W. Hempfer: Gattungstheorie, S. 30ff. 
normativen durch die spekulative Gattungspoetik beschreibt. ${ }^{25}$ Der bekannte erste Satz von Szondis Versuch über das Tragische lautet: "Seit Aristoteles gibt es eine Poetik der Tragödie, seit Schelling erst eine Philosophie des Tragischen. ${ }^{26}$ Analog dazu kann man sagen, daß es seit Aristoteles eine Gattungspoetik, seit dem deutschen Idealismus erst eine Philosophie literarischer Gattungen gibt. Dabei bietet insbesondere Hegel einen Ausweg aus dem - noch einmal: modernen, nicht postmodernen - Problem der Allgemeinheit generischer Klassifikation einerseits und der Individualität des einzelnen Kunstwerks andererseits, aus dem Problem des »Spannungsverhältnis[ses], in dem die Lehre von den drei poetischen Gattungen zu der konkreten Mannigfaltigkeit der Poesie steht«, wie Szondi schreibt:

Aufbewahren und auflösen aber kann dieses Spannungsverhältnis, in dem die Gattungspoetik recht eigentlich ihre Bedingung hat, nur ein Denken, dem es um die Vermittlung von Allgemeinem und Besonderem, von Idee und Geschichte geht also nur die identitätsphilosophische Systematik des deutschen Idealismus. Darum kommt die Lehre von der Einteilbarkeit der Dichtung in drei Gattungen hier erst nach Hause. ${ }^{27}$

Dann muß man aber auch sagen, daß die triadische Gattungssystematik mit dem System des deutschen Idealismus steht und fällt. ${ }^{28}$ Den modernen Vorbehalten gegenüber der Gattungstheorie als »unproduktive[r] Einengung der Vielfalt literarischer Ausdrucksformen" (Neumann/Nünning) entgeht Hegel also - aber eben dank eines spekulativen Systems, gegen das dann in der Tat auch (aber keineswegs erst) die Postmoderne ihren "Generalverdacht" richtet und zu Felde zieht. Zusätzlich zur Ablehnung jeglicher Ontologie (Meier) handelt es sich daher bei der Ablehnung literarischer Gattungseinteilungen auch, genauer, um die Ablehnung idealistischer Spekulation.

Es ist auch der Grund dafür, daß die Beschäftigung mit Gattungen heute ein »anachronistisches« Unternehmen zu sein scheint, wie Tzvetan Todorov

25 Peter Szondi: Von der normativen zur spekulativen Gattungspoetik, in: ders.: Poetik und Geschichtsphilosophie II, Frankfurt a.M. 1974, S. 7-183.

26 Ders.: Versuch über das Tragische, in: ders.: Schriften I, Frankfurt a.M. 1978, S. 151-260, hier S. 151.

27 Ders.: Von der normativen zur spekulativen Gattungspoetik, S. 11.

28 Was Szondi freilich nicht davon abhält, die Einteilung der Dichtung in die drei Gattungen als »für das Problem der Gattungspoetik heute noch von größtem Interesse « zu bezeichnen. Ders.: Hegels Lehre von der Dichtung, in: ders.: Poetik und Geschichtsphilosophie I, Frankfurt a.M. 1974, S. 267-511, hier S. 471. 
bemerkt. ${ }^{29}$ Das bedeutet aber nicht, wie immer wieder zu lesen ist, daß keinerlei gattungstheoretische Überlegungen mehr angestellt würden ${ }^{30}$ oder daß »die Frage nach den literarischen Gattungen [...] zuletzt 1960 Konjunktur gehabt" habe. ${ }^{31}$ Ganz im Gegenteil erscheinen in den siebziger Jahren ganz erstaunlich viele Studien zur Gattungstheorie und durchaus, entgegen anderslautenden Behauptungen, systematische Versuche ihrer Neubegründung. ${ }^{32}$ Todorov etwa besteht 1970 auf der Notwendigkeit von Gattungseinteilungen und fordert die Ausarbeitung abstrakter Kategorien, die der gegenwärtigen Literatur gerecht würden, ${ }^{33}$ womit er sich auf echt gattungspoetischem Terrain bewegt. Das Interesse an der Klassifikation bleibt unvermindert bestehen bzw. keimt neu auf; zugegebenermaßen handelt es sich aber meistens um semiotische oder linguistische Ansätze, ${ }^{34}$ womit der ontologisch oder idealistisch-spekulativ belastete Gattungsbegriff dann in der Tat verabschiedet oder, wie es immer heißt, dem >Tod anheimgefallen zu sein scheint. (Ganz zweifellos jedenfalls ist er der Rede von der Rede von seinem Tod anheimgefallen.)

\section{Gattung und Archäologie - Gattungstheorie und Diskursanalyse}

Mit seiner Skepsis gegenüber Gattungseinteilungen, angedeutet in der Ordnung der Dinge, deutlicher formuliert in der Archäologie des Wissens, scheint Foucault sich jenem "postmodernen Generalverdacht gegen alle Ontologie»

29 Tzvetan Todorov: L'origine des genres, in: ders. (Hg.): Les genres du discours, Paris 1978, S. 44-60, hier S. 44.

30 Vgl. etwa Clemens Pornschlegel: Vögel mit Schlangen, S. 250.

31 Albert Meier: Lyrisch - episch - dramatisch, S. 709.

32 Vgl. etwa Hempfers »konstruktivistische Synthese«. Klaus W. Hempfer: Gattungstheorie, S. 122-127.

33 Tzvetan Todorov: Introduction à la littérature fantastique, Paris 1970; Kap. 1: "Les genres littéraires«, S. 7-27, hier S. 12.

34 Vgl. etwa Hempfers Vorschläge zu einer "Gattungstheorie als Teiltheorie einer allgemeinen Texttheorie", die in Teilen auf die generative Grammatik zurückgreift (Klaus W. Hempfer: Gattungstheorie, S. 226); Walter Hinck (Hg.): Textsortenlehre - Gattungsgeschichte, Heidelberg 1977; Wolfgang Raible: Was sind Gattungen? Eine Antwort aus semiotischer und textlinguistischer Sicht, in: Poetica 12 (1980), S. 320-349; siehe dazu auch Albert Meier: Lyrisch - episch - dramatisch, S. 709; später dann auch kognitive Ansätze, vgl. dazu einige Beiträge in: Madeleine Frédéric $(\mathrm{Hg}$.): Nouvelles perspectives en théorie des genres. Genre theory: new perspectives. Revue belge de philologie et d'histoire 75.3 (1997). 
bzw. gegen alle Spekulation anzuschließen. Duff, der als einziger Gattungstheorie und Foucault überhaupt irgendwie miteinander in Zusammenhang bringt, ${ }^{35}$ führt die Archäologie in einem kurzen Hinweis als Beispiel für eine Absage an Gattungsunterscheidungen an:

Distinctions of genre are [...] still liable to be displaced by other analytical categories, as for instance [...] when Foucault calls upon us to overlook superficial boundaries 'form s and 'genre in order to perceive the circulation of entire discourses such as medicine, political economy and biology. ${ }^{36}$

Aber dann fügt er hinzu: »Foucault's archaeology of knowledge still in effect competes with the ssociology of genres`« ¿ Duff führt diesen Punkt nicht aus und kommt auch nicht noch einmal darauf zurück. Jedenfalls liest er die Archäologie zwar als Ablehnung von Gattungsunterscheidungen, andererseits aber als eine konkurrierende Alternative, was andeutet, daß beide letztlich vergleichbare Ziele verfolgen. Seine Aussage ist auch noch zu präzisieren: Foucaults Anliegen ist weniger die >Wahrnehmung< ganzer Diskurse als vielmehr die Begründung ihrer jeweiligen Einheit. Er geht ja davon aus, daß man einzelne Diskurse durchaus bereits unterscheidet (Medizin, Grammatik, Politische Ökonomie etc.), doch fragt er danach, auf welcher Basis diese Unterscheidungen zustande kommen und ob sich alternative, besser begründete Einheiten bestimmen lassen. Foucault befaßt sich also damit, überkommene Klassifikationen in Frage zu stellen und gegebenenfalls außer Kraft zu setzen und neue Differenzierungskriterien zu entwerfen.

Nach welchen Kriterien soll man die Einheiten isolieren, mit denen man es zu tun hat: was ist eine Wissenschaft? Was ist ein Werk? Was ist eine Theorie? Was ist ein Begriff? Was ist ein Text? [...] [W]elches ist das angemessene Niveau der Formalisierung? welches das der Interpretation? welches das der strukturalen Analyse? welches das der Kausalitätsbestimmungen? (AW 13)

35 Allenfalls wäre noch eine Randbemerkung bei Canvat zu nennen: Karl Canvat: Enseigner la littérature par les genres, S. 105. Darüber hinaus nimmt die bisherige Forschung Foucaults Haltung zur Gattungstheorie nicht in den Blick, geschweige denn, daß sie eine Beziehung zwischen Foucaults Methodik und Gattungstheorie herstellen würde. Auf einer anderen Ebene schlägt aber Lars Friedrich eine Korrelation zwischen dem von Foucault beschriebenen epistemischen Bruch zwischen Repräsentation und Humanwissenschaft mit der "Differenz zwischen den Gattungspoetiken der Aufklärung (Diderot/Lessing) und der spekulativen Poetik (Hegel) « vor. Lars Friedrich: Der Achill-Komplex, S. 17, Anm. 29.

36 David Duff: Introduction, S. 17. 


\section{Und er fragt weiter:}

Kann man ohne weiteres die Unterscheidung der großen Diskurstypen oder jene der Formen oder der Gattungen zugeben, die Wissenschaft, Literatur, Philosophie, Religion, Geschichte, Fiktion usw. in Opposition zueinander stellen und daraus Arten großer historischer Individualitäten machen? (AW 34f.)

Die Antwort auf diese rhetorische Frage muß natürlich lauten: Nein, kann man nicht. Vielmehr sind »diese Unterteilungen [...] Diskursfakten, die neben den anderen analysiert zu werden verdienen" (AW 35), und das soll die künftige historische Wissenschaft, die Archäologie, leisten. "Werk « und "Buch", "Wissenschaft" und »Literatur« müssen ihrer "Quasievidenz« entrissen werden. (AW 40) Foucault weist also traditionelle Einheiten, zu denen er nicht nur das »Werk", sondern auch den »Text« zählt, zurück und macht sich statt dessen daran, »diskursive Einheiten« (AW 33, 36) zu identifizieren und zu untersuchen.

Was sind sie? Wie sie definieren und abgrenzen? Welchen distinkten Gesetzestypen können sie gehorchen? Für welche Gliederung sind sie empfänglich? Welchen Teilmengen können sie Raum geben? [...] Es handelt sich darum, zu erkennen, [...] daß sie eine Theorie erfordern. (AW 40)

Mit diesen Fragen steht Foucault nicht allein, wie er auch auf den ersten Seiten der Archäologie deutlich macht, allerdings bezieht er sich dort vor allem auf epistemologische Theoriedebatten und geschichtswissenschaftliche Strömungen. Indessen sind seine Fragen auch mit denen zeitgenössischer strukturalistischer Literaturtheorien verwandt. Barthes hatte die Frage nach den Einheiten der "Erzählung « bereits in seiner Introduction à l'analyse structurale des récits (1966) gestellt:

Innombrables sont les récits du monde. C'est d'abord une variété prodigieuse de genres [...]: le récit peut être supporté par le langage articulé, oral ou écrit, par l'image, fixe ou mobile, par le geste et par le mélange ordonné de toutes ces substances; il est présent dans le mythe, la légende, la fable, le conte, la nouvelle, l'épopée, l'histoire, la tragédie, le drame, la comédie, la pantomime, le tableau peint, le vitrail, le cinéma, les comics, le fait divers, la conversation. [...] International, transhistorique, transculturel, le récit est là, comme la vie. [...] Mais ces variétés même, comment les maîtriser, comment fonder notre proit à les distinguer, à les reconnaitre? Comment opposer le roman à la nouvelle, le conte au mythe, le drame à la tragédie (on l'a fait mille fois) sans se référer à un modèle commun?37

37 Roland Barthes: Introduction à l'analyse structurale des récits, S. 1. 
Ausgehend von diesen Fragen unternimmt Barthes, eine "théorie "pour décrire et classer l'infinité des récits" aufzustellen, ${ }^{38}$ wie eben auch Foucault seine Fragen in die Forderung nach einer "Theorie" (AW 40) der Gliederung der "Einheiten des Diskurses« (AW 33) münden läßt. Nun muß man hier sogleich einwenden, daß Foucault erstens unmißverständlich betont, daß er keinen Strukturalismus betreibe ${ }^{39}$ (wiewohl er später zugibt, daß es durchaus Parallelen gab), und zweitens, daß er keine literarischen Texte, sondern ganze Diskurse in den Blick nimmt, seinen Untersuchungsgegenstand also viel weiter faßt als Barthes (obwohl auch der seinen Erzählungs- und seinen Textbegriff schon über die Grenzen des Literarischen hinaus erweitert). Es ist allerdings auffällig, daß Foucault in seine Ablehnung universeller Kategorien und kultureller Totalitäten explizit auch die Einteilung in Gattungen einschließt und darüber hinaus seine Kritik gegenüber bisherigen "Einheiten" des Diskurses immer wieder exemplarisch als Kritik nicht nur an "Buch" und »Werk ", sondern auch am »Text« formuliert, d.h., in seinem Bemühen um eine Gliederung der Diskurse an die zeitgenössischen strukturalistischen Bemühungen um Alternativen zur Gattungsklassifikation anschließt und die zentralen Begriffe der "gattungsfeindlichen" Diskussion aufgreift: "Aber vor allem sind die Einheiten, die man unentschieden lassen muß, diejenigen, die sich auf unmittelbarste Weise aufdrängen: jene des Buches und des Werks." (AW 35) "Buch« und »Werk" nämlich bleiben, hier trifft sich Foucault mit Barthes, dem Autorkonzept als zweifelhaftem kontinuitäts- und kausalitätsstiftendem Prinzip verpflichtet. Indem Foucault zudem für die Archäologie und ihre Gliederung der Diskurse noch einmal betont, wie sehr sie die "Problematik [...] der Subjektivität« (AW 288) betrifft und daß sie die Idee eines »konstitutiven Bewußtseins" (AW 290) aufzugeben und den "Status des Subjekts" (AW 291) zu erschüttern bestrebt ist, bleibt er in der Nähe der Idee vom Tod des Autors und auch daher gewissermaßen in literaturwissenschaftlichem Fahrwasser. Das führt dazu, daß seine Forderung nach einer Theorie der "Einheiten des Diskurses" gewissermaßen eine literaturtheoretische und damit auch eine gattungstheoretische (bzw. antigattungstheoretische) Schlagseite erhält.

38 Ebd., S. 2.

$39 \mathrm{Vgl}$. etwa AW 27. Er wendet sich damit gegen einen ihm wiederholt gemachten Vorwurf, den er auch im Schlußteil der Archäologie des Wissens, im fiktiven Gespräch zwischen sich und seinen Lesern, abhandelt. 
Eine Theorie also der »Einheiten des Diskurses«. Zur »Beschreibung der diskursiven Ereignisse" (AW 42) bedarf es Foucault zufolge der »Aufhebung aller zugelassenen Einheiten" (AW 43) und muß »man sie von allen Gruppierungen befrei[en], die sich als natürliche, unmittelbare und universelle Einheiten geben " (AW 45) - d.h. von Buch, Werk, Bewußtsein, Autor etc., aber auch vom Text und von den Gattungen. Insbesondere in der Wendung von "natürliche[n] « und »universelle[n] « Einheiten klingen Goethes Naturformen der Dichtung und das Universalienproblem der Gattungsklassifikation an. Auch verwendet Foucault mit dem zentralen Aussagebegriff zumindest nominell eine typisch linguistisch-strukturalistische Kategorie. Ziel dieser Beschreibung der »diskursiven Formationen« (AW 48) ist, "andere Formen der Regelmäßigkeit, andere Typen der Beziehung erfassen zu können" (AW 44), und »andere Einheiten zu beschreiben [...], die nicht arbiträr wären, indessen aber ungesagt geblieben wären. « (AW 45) Foucault stellt zu diesem Zwecke vier Hypothesen zu einem möglichen Vorgehen auf: die Bestimmung der Einheiten erstens anhand des Gegenstands, auf den sie sich beziehen, zweitens anhand von »Form und Typ ihrer Verkettung «, drittens anhand der in ihnen verwendeten "permanenten und kohärenten Begriffe« und viertens anhand der »Identität und Beständigkeit der Themen ${ }^{40}$ Und er wiederholt diese Hypothesen, variiert: erstens über ein "wohl gegliedertes Gebiet von Objekten«, zweitens über »einen definierten und normativen Typ von Äußerung«, drittens über »ein wohl definiertes Alphabet ideologischer Begriffe«, viertens über die »Permanenz einer Thematik«. (AW 57) Noch einmal variiert: »Gegenstände, Äußerungsmodalität, Begriffe, thematische Wahl«. (AW 58) Vor dem Hintergrund von Foucaults Forderung nach einer Theorie der »Einheiten des Diskurses« wäre zumindest zu überlegen, ob die "Formationsregeln« in dieser Form nicht mit Kategorien klassischer deskriptiver Gattungseinteilungen vergleichbar sind, ob beispielsweise Foucaults Bestimmung der »Gegenstände« mit Aristoteles' Unterscheidung der »Gegenstände, die nachgeahmt werden«, ob Foucaults "Form und Typ der Verkettung" mit Aristoteles' »Beschaffenheit [der] Zusammenfügung der Geschehnisse« und ob Foucaults »Äußerungsmodalität« mit Aristoteles' sogenanntem Redekriterium, also der Art und Weise, wie ein Gegenstand nachgeahmt wird (gesungenes Epos vs. dargestelltes Dra-

40 Köppen übersetzt das französische "persistance« (Michel Foucault: L'Archéologie du savoir, Paris 1969, S. 50) mit "Hartnäckigkeit«; "Beständigkeit«, "Fortdauer« oder »Beharren« erscheinen mir hier passender. 
ma), in Zusammenhang gebracht werden könnte. Dann gälte für Foucaults Archäologie, was Todorov und Dominique Combe als Fortwirken der alten Kategorien auch in zeitgenössischen Versuchen zur Neufassung der bzw. zu Alternativen zur Gattungstheorie beobachten: Todorov etwa schreibt über Blanchot: "A lire d'ailleurs les écrits même de Blanchot où s'affirme cette disparition des genres, on y voit à l'œuvre des catégories dont la ressemblance avec les distinctions génériques est difficile à nier. « ${ }^{41}$ Peter Stolz erhebt denselben Vorwurf allerdings gegen Todorov, der »die klassische Definition der Gattungen mit neuem semiotischen Vokabular wiederaufzuführen" scheine. ${ }^{42}$ Und Combe zufolge unterscheiden sich auch die alternativen strukturalistischen Ansätze letztlich nicht substantiell von den klassischen Gattungseinteilungen: "Derrière l'appareil conceptuel, emprunté à la linguistique structurale (Jakobson), à la sémiotique ou à la phénoménologie (Sartre, Staiger), on retrouve toujours les mêmes catégories fondamentales de la poétique, seulement reformulées à travers d'autres méthodes. «43 Und dann läßt sich auch der Titel von Todorovs Sammelband zur Gattungstheorie, Les genres du discours (1978), als eine sozusagen korrigierende Anspielung auf Foucaults Kapiteltitel "Die Einheiten des Diskurses" (Les unités du discours) lesen, mithin als ein Hinweis darauf, daß auch Todorov jene Ähnlichkeiten zwischen Diskursanalyse und Gattungstheorie sieht. ${ }^{44}$ Der Versuch, dem Verhältnis von diskursanalytischer Methodik und deskriptiver Gattungstheorie genauer nachzugehen, scheitert dann allerdings am Text der Archäologie des Wissens. Foucaults Ausführungen zu den »Einheiten des Diskurses" sind insgesamt ein methodologisches Durcheinander. Wie weit die Ähnlichkeiten zwischen Einteilung von Diskursformationen und gattungstheoretischen Klassifizierungen gehen, läßt sich schwerlich sagen, weil die vorgeschlagene Methodik kaum verständlich und es geradezu unmöglich ist, sie in sinnvoller Weise zusammenzufassen. Die vier methodischen Hypothesen zur Einteilung von Diskursen, die systematisch

41 Tzvetan Todorov: L'origine des genres, S. 45.

42 Peter Stolz: Der literarische Gattungsbegriff. Aporien einer literaturwissenschaftlichen Diskussion. Versuch eines Forschungsberichtes zum Problem der »literarischen Gattungen«, in: Romanistische Zeitschrift für Literaturgeschichte 14 (1990), S. 209-227, hier S. 211.

43 Dominique Combe: Les genres littéraires, S. 146. Combe behauptet daher eine "constance de la tripartition aristotélicienne«. (Ebd., S. 145)

44 In seinem eigenen Beitrag zu diesem Sammelband verbindet Todorov außerdem auch den Ursprungsbegriff und die Gattungen (vgl. Tzvetan Todorov: L'origine des genres). 
gleichrangig behandelt werden, befinden sich von vorneherein auf unterschiedlichen logischen und kategoriellen Ebenen; ihr Verhältnis zueinander ist unklar; die Erläuterungen sind nicht ohne weiteres mit den Begriffen, auf die Foucault sie bringt, zu verknüpfen, und so fort. Auf die Aufstellung der Hypothesen folgen umständliche Versuche, diese Kategorien zu erläutern und sie sodann durch andere, vermeintlich zutreffendere zu ersetzen, ${ }^{45}$ um dann in den vier folgenden Kapiteln (Kap. II.2-II.6) doch wieder den erstgenannten Hypothesen zu folgen, die gleichzeitig jedoch in der wiederholenden Wiederaufnahme variiert werden. Bei aller scheinbaren Ordnung der Argumentation (aufzählende Gliederung etc.) bleiben die vorgeschlagenen Bestimmungstechniken und ihr Verhältnis zueinander unsystematisch bis zur Unnachvollziehbarkeit. ${ }^{46}$

Foucaults Methodik in der Archäologie des Wissens ist vielfach kritisiert, aber auch verteidigt worden. ${ }^{47}$ Während Philipp Sarasin den Text affirmativ als Foucaults "eigenen Discours de la méthode» bezeichnet, ${ }^{48}$ konstatiert Allan Megill "a peculiar unimaginativeness in many of Foucault's readers, that they seek to constrain within the boundaries of methodology something so obviously antimethodological «, ${ }^{49}$ und meint: "[]]t has not been understood that The Archaeology of Knowledge is a parody «, 50 eine Parodie nämlich auf ebenjenen Discours de la méthode Descartes'. Tatsächlich gibt es Ähnlichkeiten

45 So müsse statt nach den Gegenständen vielleicht eher nach dem Raum gefragt werden, in dem sie "sich profilieren und ständig sich transformieren«. (AW 50) Statt in "Form und Typ der Verkettung « von Aussagen - worunter Foucault irritierenderweise »einen bestimmten Stil, einen bestimmten Charakter der Äußerung« versteht (AW 51) müsse man das Prinzip der Einheit von Aussagen vielleicht eher in der "Gesamtheit von Regeln, die gleichzeitig oder nacheinander reine perzeptive Beschreibungen, aber auch durch Instrumente vermittelte Beobachtungen, Erfahrungsprotokolle aus Laboratorien, statistische Berechnungen" (AW 52), suchen und so weiter.

46 Frank schreibt daher: "Die Archäologie des Wissens ist ein schwieriges Buch. Und das nicht darum, weil sie intellektuell besonders strapaziös wäre, sondern weil sie abweichend von der Tradition aller vergleichbaren "Discours de la méthode« (von Descartes bis Sartre) - ihre Begriffe nicht oder sehr schlecht definiert." Manfred Frank: Was ist Neostrukturalismus?, S. 216.

47 Vgl. dazu Clemens Kammler: Archäologie des Wissens, in: ders./Rolf Parr/Ulrich Johannes Schneider (Hg.): Foucault-Handbuch, S. 51-62, hier S. 60f.

48 Philipp Sarasin: Foucault zur Einführung, S. 103. Ebenso, allerdings deutlich kritischer, bereits Manfred Frank: Was ist Neostrukturalismus?, S. 216.

49 Allan Megill: Prophets of Extremity: Nietzsche, Heidegger, Foucault, Derrida, Berkeley 1995, S. 227.

50 Ebd., S. 228. 
in der Form, etwa die immer wieder erfolgenden rhetorischen Einschränkungen des bisher Gesagten und die captatio-benevolentiae-artigen Reflexionen auf die begrifflichen und methodischen Schwächen, mit denen eine zuvor abgeschlossene Überlegung wieder aufgegriffen und in die nächste übergeleitet wird. All das ließe sich als Bestätigung dessen lesen, daß Foucault hier jeglichen Versuch zur Gliederung des Diskurses ironisiert und, im Einklang mit den "gattungsfeindlichen" Tendenzen seiner Zeit, die Unmöglichkeit von Gattungsklassifikationen behauptet. Die zahlreichen kategoriell und begrifflich unsauberen Bestimmungstechniken der diskursiven Formationen, die er vorschlägt, würden dann an Borges' chinesische Enzyklopädie erinnern, und die Archäologie des Wissens erschiene als ein ironisches "antigenerisches « Manifest. Diese These von der Archäologie als "parody of method « ist zwar verlockend, aber nicht haltbar. Zum einen stellt sich die Frage nach der Motivation, eine 300 Seiten umfassende methodologische Parodie zu verfassen (die ursprünglich mehr als doppelt so lang war ${ }^{51}$ ). Zum anderen hat Foucault durchaus ein methodologisches Anliegen (dazu gleich mehr), ebenso wie ein inhaltliches. Die Form mag stellenweise parodistisch sein, aber sie ist es nicht durchgängig, und der Inhalt ist es gar nicht - man blicke nur auf alles, wogegen sich Foucault mit seiner Archäologie so nachdrücklich richtet: gegen die »transzendentale Unterwerfung der Geschichte des Denkens" und das konstitutive Bewußtsein; gegen Kontinuität, Teleologie, Kausalität; gegen Totalitäten, Homogenisierung, Universalität; gegen Ursprung, anthropologisches Denken, humanistische Ideologien, Subjekt, Genese, System, Synchronie, Werden, Relation, Ursache, Struktur, Geschichte. ${ }^{52}$ Die Widersprüchlichkeiten als ironische aufzulösen oder die Archäologie des Wissens in ihrer Gesamtheit als Parodie zu lesen, ist jedenfalls verfehlt, und die Tatsache, daß es zumindest streckenweise gelingt, sie als Parodie aufzufassen, besagt nichts gutes für ihren Theoriestatus. Foucault, so könnte man sagen, scheitert am Versuch einer Theorie zur Einteilung der Diskurse. Darüber hinaus versucht er sich an einer Begründung dieser Einteilung, was immer wieder auf die Rede von "spezifischen Regelmäßigkeiten« hinausläuft, deren Spezifität aber offenbar nicht näher erläutert werden kann. Um die gattungstheoretischen Parallelen noch einmal zu bemühen: Foucaults Archäologie als deskriptive Gattungspoetik mündet immer wieder in quasispekulative Begriffe wie die "spezifische Regelmäßig-

51 Vgl. Clemens Kammler: Archäologie des Wissens, S. 51.

52 Vgl. AW $289 f f$. 
keit« - und damit in die Genealogie als, so die nun folgende Hypothese, spekulative Gattungspoetik.

\section{Gattung und Genealogie - Gattungstheorie und Machtanalytik}

Auf andere und entschiedenere Art und Weise als die Archäologie ist nämlich auch die Genealogie mit der Gattungstheorie in Zusammenhang zu bringen. Die vordergründige Gattungsskepsis der Archäologie des Wissens (bzw. deren hintergründige deskriptive Gattungspoetik) weicht in Überwachen und Strafen einem untergründigen (und zwar spekulativen) Gattungsdiskurs. In Nietzsche, die Genealogie, die Historie beschreibt Foucault das von ihm anvisierte methodische Vorgehen als `Genealogier. Der Begriff knüpft an Nietzsche an und trifft sich mit dessen Genealogie darin, scheinbar überhistorische Konzepte wie Moral, Erkenntnis etc. zu historisieren und dabei nicht nur als etwas Gewordenes, sondern auch Kontingentes zu entlarven. Damit verbunden ist die entschiedene Ablehnung der Suche nach einem »Ursprung«; ’Genealogie also als die Untersuchung nicht des Ursprungs, sondern der Genese, der "Herkunft" (NGH 167) und des "Werden[s]« (NGH 179) vermeintlicher Konstanten und Universalia. ${ }^{53}$ Die Idee von Genese und Werden scheint auf den ersten Blick in Widerspruch zu einer Kernidee eben dieser "genealogischen« Methode Foucaults zu stehen: dem prominenten Konzept des »Diskontinuierliche[n]« (NGH 180), wonach Geschichte nicht als Kontinuum begriffen werden soll, sondern als der "Punkt, an dem etwas hervortritt. "[A]lles, was sie [i.e. die Geschichte; Gw.E.] als ruhige, kontinuierliche Bewegung erscheinen lässt, muss systematisch zerstört werden« (NGH 179) - mittels der Genealogie. Ein "Punkt« aber, so ließe sich einwenden, hat kein »Werden ${ }^{54}$ ein »Diskontinuierliche[s]« keine

53 Das gilt aber auch schon für die Archäologie, die ebenso bereits die Suche nach Kontinuitäten (vgl. AW 38f., 290) und einem metaphysischen oder "geheimen Ursprung (AW 38) (Nietzsches »Wunder-Ursprung«) ablehnt. Ohnehin ist die Archäologie des Wissens, obzwar sie sich eindeutig "Archäologie» nennt, eher Zeugnis des Übergangs von archäologischer zu genealogischer Methode.

54 Daher auch führt Foucault in der Archäologie des Wissens (die 1969 erschien, also im selben Jahr, in dem Nietzsche, die Genealogie, die Historie entstand) "Werden" (AW 24, 26) als einen Begriff ein, der in den Bereich der überkommenen "globalen Geschichte« fällt, die Foucault durch eine »allgemeine Geschichte« zu ersetzen sucht. (AW 18f.) "Genese« und »Werden« stellt er Begriffen wie »Relation« und »Ursache« gleich, die es gleichermaßen zu meiden gelte (vgl. AW 291). Andererseits differenziert Foucault 
Genese. Dieser Widerspruch läßt sich jedoch durch den Verweis auf Serienbildung wie etwa in der Annales-Schule, vor allem aber wie in Darwins Evolutionstheorie auflösen, in der Möglichkeit, Geschichte als Serien von Diskontinuitäten zu betrachten. ${ }^{55}$ Mit dem Gattungsdiskurs in Überwachen und Strafen tritt dagegen ein handfester inhaltlicher Widerspruch auf. Ausgerechnet den Text, in dem Foucault seine in Nietzsche, die Genealogie, die Historie umrissene Methode zur Anwendung bringt, ausgerechnet die Methode, die Substanzen, Universalia und Kontinuitäten "zerstören« soll, grundiert er mit klassischen Gattungsanalogien. Und bezeichnenderweise trägt der Name, den Foucault seiner Methode gibt, den Gattungsbezug bereits in sich, fordert ihn geradezu: Genealogie als Untersuchung nicht nur der Genese, sondern auch des genos, der Gattung; daß bei Foucault mit der Genealogie auch Gattungsbezüge auftreten, ist so gesehen nachgerade folgerichtig. ’Genealogie als geschichtswissenschaftliche Methode läßt sich dann auf zweierlei Weise lesen, wobei der Unterschied darin liegt, ob ihr Untersuchungsgegenstand ein historiographischer oder ein historischer ist: Genealogie entweder als Untersuchung von Gattungen in der Geschichtsschreibung oder Genealogie als Untersuchung von Gattungen in der Geschichte. ${ }^{56}$

Ersteres, die Untersuchung von Gattungen in der Geschichtsschreibung, unternimmt in gewissem Sinne Hayden White in seiner großen Studie

dort zwischen zwei Betrachtungsweisen des Werdens: Die Geschichte des Diskurses durch Rückführung »auf die Gesetze eines unbekannten Werdens « lehnt er zugunsten eines archäologischen Erfassens der Diskurse "im Gesetz ihres wirklichen Werdens" ab. (AW 185) Nun spricht natürlich nicht per se etwas gegen eine Neudefinition dieser Begriffe unter Rückbezug auf Nietzsche. Doch auch mit diesem Rückbezug bleibt ihre Differenzierung problematisch, allerdings nicht, wie Cook und Pizer meinen (Deborah Cook: Nietzsche and Foucault on Ursprung and Genealogy, in: Clio 19.4 [1990], S. 299-309; John Pizer: The Use and Abuse of >Ursprung`. On Foucault's Reading of Nietzsche, in: Nietzsche-Studien 19 [1990], S. 462-478), weil es eine entsprechende Gegenüberstellung bei Nietzsche nicht gebe (zumal Foucault explizit darauf hinweist, daß bei Nietzsche ein spezifischer und ein unspezifischer Gebrauch des Wortes "Ursprung « auftaucht, ein Hinweis, der weite Teile von Cooks Kritik obsolet werden läßt), sondern weil die Opposition der Begriffe von »Ursprung « und »Herkunft « an sich nicht unmittelbar einleuchtet und an Trennschärfe vermissen läßt.

55 Vgl. dazu das Kap. "Serien und Ereignisse« in Philipp Sarasin: Darwin und Foucault, Frankfurt a.M. 2009, S. 133-186, insbes. 151-163. Zu methodischen Affinitäten zwischen Genealogie und Evolutionstheorie vgl. Kap. IX.

56 Eine weitere Möglichkeit, Genealogie nämlich als Untersuchung historiographischer Gattungen, d.h. von Gattungen der Geschichtsschreibung wie etwa Chronik, Annalen etc., sei hier beiseite gelassen. 
Metahistory. Die historische Einbildungskraft im 19. Fahrhundert in Europa, in der er eine Poetologie der Geschichtsschreibung entwirft und rhetorische und gattungstypologische Grundlagen geschichtswissenschaftlicher Argumentationen freilegt. Dabei muß sogleich einschränkend angemerkt werden, daß seine auf Northrop Fryes Analyse der Literaturkritik zurückgehende Unterscheidung in Romanze, Komödie, Tragödie und Satire keine im eigentlichen Sinne gattungstheoretische ist, sondern eine Kategorisierung "historiographischer Stile" mit Blick auf ihre "narrative Modellierung" (emplotment) bzw. ihre »Handlungsstruktur" (plot structure). ${ }^{57}$ Zudem durchkreuzen Fryes und folglich auch Whites Kategorien die traditionellen Gattungsunterscheidungen und erweitern und modifizieren sie hin zu einer gänzlichen Neubestimmung. Foucaults Gattungsbezüge dagegen sind, das dürfte deutlich geworden sein, im klassischen Gattungsdiskurs verwurzelt. Metahistory erschien 1973, zwei Jahre vor Überwachen und Strafen, so daß White sich darin nicht zu den dortigen Gattungsbezügen äußern konnte und dies auch später nicht getan hat, und auch auf die Wahnsinn und Gesellschaft zugrunde liegenden (tragischen) Erzählstrukturen kommt er nicht zu sprechen.

Neben den Kategorien narrativer Modellierung, die White in der Geschichtsschreibung des 19. Jahrhunderts ausmacht, entwirft er eine "Tropologie des historischen Diskurses « ${ }^{58}$ In diesem Zusammenhang merkt er an, daß er Foucault und die französischen Strukturalisten, bei allen Verdiensten, »für Gefangene tropologischer Interpretationsstrategien halte, wie es ihre Vorläufer im 19. Jahrhundert waren " ${ }^{59}$ und fährt fort: "So scheint sich zum Beispiel Foucault nicht darüber im klaren, daß die Kategorien, die er zur Analyse der Geschichte der Humanwissenschaften verwendet, kaum mehr als Formalisierungen der Tropen sind."In einem Aufsatz aus demselben Jahr führt White diese These aus und ordnet die epistemischen Strukturen, die Foucault in Die Ordnung der Dinge unterscheidet, den seit der Renaissance klassischen vier Tropen zu. Demnach entspricht die Ähnlichkeit des 16. und der ersten Hälfte des 17. Jahrhunderts der Metapher, die Repräsentation der zweiten Hälfte des 17. und des 18. Jahrhunderts der Metonymie, die Humanwissenschaften des 19. Jahrhunderts der Synekdo-

57 Vgl. Hayden White: Metahistory. Die historische Einbildungskraft im 19. Jahrhundert in Europa, Frankfurt a.M. 1991 [New York 1973], S. 21ff. und passim.

59 Ebd., S. 568. 
che und die Humanwissenschaften des 20. Jahrhunderts der Ironie. ${ }^{60}$ Doch selbst wenn diese Zuordnung zutrifft, kann von einer sei es bewußten, sei es unbewußten ${ }^{61}$ Fortführung der historiographischen Tropen durch Foucault keine Rede sein, denn Whites Behauptung fußt auf einem entscheidenden Fehler: Die epistemischen Strukturen, die Foucault unterscheidet (Ähnlichkeit, Repräsentation, Humanwissenschaften) sind keineswegs »die Kategorien, die er zur Analyse der Geschichte der Humanwissenschaften verwendet«, sondern sind dasjenige, was er beschreibt, sind also nicht Mittel, sondern Gegenstand seiner Analyse. Der hier wesentliche Unterschied zwischen den Geschichtsschreibern des 19. Jahrhunderts und Foucaults Ordnung der Dinge besteht daher darin, daß die "Tropen" Foucaults Untersuchung und Argumentation nicht zugrunde liegen und sie strukturieren, wie White das für die Geschichtsschreibung des 19. Jahrhunderts zeigt, sondern vielmehr ihr Gegenstand sind. Die Behauptung, daß Ähnlichkeit, Repräsentation und Humanwissenschaften den vier klassischen Tropen entsprechen, bedeutet demzufolge keine Infragestellung von Foucaults Methode, sondern ist eine Übertragung von Whites eigenen Untersuchungsergebnissen auf die Foucaults. Bei Whites »vorkritisch akzeptierte[m] Paradigma «62 der Geschichtsschreibung handelt es sich dann gleichsam um eine - inhaltlich und daher in ihrer Aussageweite ungleich begrenztere Variante von Foucaults »historische[m] Apriori« (OD 17; AW 184) der Erkenntnis.

Korrigiert man indes Whites Behauptung bezüglich Foucaults »Formalisierungen der Tropen" dahingehend, daß sie nicht mehr lautet, seine Analysekategorien, sondern die Epistemen, die er beschreibt, seien "Formalisierungen der Tropen«, ergibt sich ein anderer Vorwurf. In Die Ordnung der Dinge beschreibt Foucault die Epistemen als die zwar kontingente, aber nichtsdestoweniger reale Struktur oder reale "Seinsweise" (OD 24) der Erkenntnis des jeweiligen historischen Zeitraums. ${ }^{63}$ Wenn nun aber diese

60 Vgl. ders.: Foucault decodiert: Notizen aus dem Untergrund, in: ders.: Auch Klio dichtet oder Die Fiktion des Faktischen. Studien zur Tropologie des historischen Diskurses, Stuttgart 1986, S. 268-302, hier S. 292-296 [zuerst veröffentlicht in: History and Theory 12 (1973), S. 23-54].

61 Vgl. ebd., S. 295.

62 Ders.: Metahistory, S. 9.

63 Diese Auffassung der Episteme korrigiert er in der Archäologie des Wissens: "Die Episteme ist keine Form von Erkenntnis und kein Typ von Rationalität, die, indem sie die verschiedensten Wissenschaften durchdringt, die souveräne Einheit eines Subjekts, eines Geistes oder eines Zeitalters manifestierte; es ist die Gesamtheit der 
tatsächlich existierenden Epistemen »Formalisierungen der Tropen sind«, dann würde Foucault gewissermaßen die reale Strukturierung der Erkenntnis durch die Tropen behaupten. Übertragen auf die oben in den Kapiteln IV-VI beschriebene Engführung von literarischen Gattungen und historischen Epistemen und Straftechniken wäre analog dazu auch der Vorwurf einer Gattungskategorien gehorchenden realen »narrativen Strukturierung « der Geschichte nicht mehr fern - man gelänge zur zweiten möglichen Lesart von `Genealogies: Genealogie als die Untersuchung von Gattungen, die sich in der Geschichte manifestieren, oder von Manifestationsweisen der Geschichte in Gattungen - Genealogie als die Untersuchung von Gattungen von Geschichte. Eine solche Methode bestünde darin, literarische Gattungsklassifikationen auf die Geschichte zu übertragen, und zwar verstanden entweder als Formen der Betrachtungsweise bzw. als Erklärungsmuster historischer Abläufe (gattungskonzeptualistisch) oder als die Form der historischen Abläufe, als Form der Geschichte selbst (gattungsrealistisch). Letztlich ist allerdings auch der ontologisch sschwächere Gattungskonzeptualismus, dem zufolge die Betrachtungsweise der Geschichte durch Gattungen real strukturiert wäre, nur eine Form von Gattungsrealismus, ${ }^{64}$ der zufolge Gattun-

Beziehungen, die man in einer gegebenen Zeit innerhalb der Wissenschaften entdekken kann, wenn man sie auf der Ebene der diskursiven Regelmäßigkeiten analysiert." (AW 273) Vgl. dazu auch Andrea D. Bührmann: Der Diskurs als Diskursgegenstand im Horizont der kritischen Ontologie der Gegenwart, in: dies. u.a. (Hg.): Das Wuchern der Diskurse. Perspektiven der Diskursanalyse Michel Foucaults, Frankfurt a.M./New York 1999, S. 49-62.

64 Vgl. Klaus W. Hempfer: Gattungstheorie, S. 36f. Die inhaltliche Strukturierung, die Hempfer seinem Buch gibt, legt Zeugnis von der Unübersichtlichkeit der gattungstheoretischen Strömungen, vor allem aber der Schwierigkeit ihrer Unterteilung - in Gattungen, wenn man so möchte - ab. Bei allem Bemühen um klare Unterscheidungen, gelingt es ihm nicht, Widersprüche gänzlich zu vermeiden: Der mit 3.3 numerierte Abschnitt trägt den Titel "Realistische und konzeptualistische Positionen", umfaßt dann aber unter 3.3.6.3.8 noch einmal gesondert "Konzeptualistische Positionen«. Zugleich tauchen zuvor (und letzteren systematisch vorgeordnet) beispielsweise unter 3.3.6.3 "Struktural-linguistische» Gattungseinteilungen unter gattungsrealistischen Positionen auf, obwohl, wie Hempfer zeigt, die »Struktur« selbst sowohl als »eine Realität des Objekts" als auch als »ein theoretisches Konstrukt« verstanden werden kann (ebd., S. 102), also je nachdem realistischen oder auch konzeptualistischen Positionen zugeordnet werden müßte. Es geht hier nicht darum, spitzfindig Unzulänglichkeiten von Hempfers Darstellung aufzuzählen, sondern darum, zu zeigen, wie schwierig es ist, die unterschiedlichen gattungstheoretischen Ansätze zu klassifizieren - woraus sich zum Teil auch die Schwierigkeit von Aussagen über den Status gattungstheoretischer Anspielungen und Bezugnahmen überhaupt erklärt. 
gen »als Abstraktionen in unserem Geiste« existieren, ${ }^{65}$ womit man sich also doch wieder eine gattungsrealistische, mindestens aber anthropologische ${ }^{66}$ Position einhandelte. Damit wären beide Positionen entschieden metaphysische Standpunkte und also mit der Gattungsskepsis und den philosophischen Voraussetzungen der Postmoderne überhaupt unvereinbar. Durch die direkte Übertragung von Gattungsbegriffen auf die Geschichte ginge eine solchermaßen verstandene Genealogie außerdem, drittens, in ihren Konsequenzen noch über die von Hempfer als Gattungskonzeptualismus oder Gattungsrealismus beschriebenen Varianten hinaus. Es handelte sich bei einer so verstandenen Genealogie um eine genuin idealistische Gattungstheorie, um Hegels Position, um, wie man sagen könnte, Gattungsidealismus. ${ }^{67}$

65 Ebd., S. 56.

66 Vgl. ebd., S. 62-76.

67 Hempfer ordnet Hegels - wie überhaupt geschichtsphilosophische - Gattungstheorie nicht in das System von Gattungsnominalismus, -realismus und -konzeptualismus ein, sondern subsumiert sie im systematisch freischwebenden Anhang unter dem Titel »Evolutionsmodelle«. Das liegt auch daran, daß historische Gattungskonzeptionen sowohl nominalistisch als auch realistisch sein können. Schaeffer jedenfalls zählt Hegel eindeutig zu den Gattungsrealisten. Man könnte Hegels Gattungstheorie als eine Kombination aus Gattungsrealismus (Gattungen existieren, und zwar als "objektive Gegebenheiten « [ebd., S. 56]) und Gattungskonzeptualismus (Gattungen existieren, und zwar "als Abstraktionen in unserem Geiste« [ebd.] beschreiben - eben als 'Gattungsidealismus', der nicht zwischen der Seinsweise der Gattungen als geistigen Abstraktionen und als objektiven Gegebenheiten unterscheidet bzw. der sie identifiziert. 


\section{Gattungsdiskurs, Geschichtsphilosophie, Subjektphilosophie}

Des Erstaunens nicht eingedenk, das ihn zu Beginn der Ordnung der Dinge angesichts der Klassifikation in Borges' chinesischer Enzyklopädie ergriffen hatte, läßt Foucault Überwachen und Strafen mit einer Gattungsunterscheidung anheben: der Unterscheidung zwischen Tragödie und Komödie. Er führt also ausgerechnet in dem Buch, in dem er seine zuvor nur programmatisch formulierte genealogische Methode erstmals zur Anwendung bringt, Gattungsbezeichnungen ein: "Eine gewisse Tragödie ist zuende, es beginnt eine Komödie« etc. (ÜS 26) Nun möchte man wohl nicht so weit gehen, Foucault allen Ernstes Gattungsrealismus (oder Gattungsidealismus) zu unterstellen; es ist klar, daß dies den Voraussetzungen, dem Programm und der Methodik seiner Archäologie wie Genealogie gänzlich zuwiderliefe. Und zweifellos hat seine Rede vom Ende der Tragödie und dem Beginn der Komödie illustrativen Charakter. Doch bleibt die bloße Tatsache der Gattungsbezüge, selbst in illustrativer Absicht, heikel, denn diese lassen sich schlichtweg nicht rein illustrativ verwenden, ohne die idealistische gattungstheoretische Tradition mit aufzurufen. Die Kontingenz, die Foucault für die verschiedenen Epistemen ebenso wie für die verschiedenen Straftechniken beansprucht, konterkariert er durch die Gattungsbezüge, die unweigerlich Notwendigkeiten implizieren. Zweifellos war sich Foucault dessen bewußt. Zudem haben die vorangehenden Kapitel gezeigt, daß sich das Bild von der Ablösung der Tragödie durch die Komödie und schließlich den Roman in Überwachen und Strafen sehr gezielt auf gattungstheoretische Traditionen rückbeziehen läßt. Indem Foucault die Marter mit der Tragödie, die reformierte Strafe mit der Komödie und die Disziplinen und das Gefängnis mit dem Roman kurzschließt, reproduziert und aktualisiert er das Narrativ von der historischen Abfolge literarischer Gattungen und deren Gültigkeit über den Bereich des Literarischen hinaus. Allein durch die Verwendung literarischer Gattungsbegriffe rückt Foucault daher in die Nähe des Hegelschen Gattungsdiskurses und riskiert, in dessen Argumentationsstrukturen einzutreten und sich geschichtsphilosophische Notwendigkeiten einzuhandeln und subjektphilosophische Strukturen zu implizieren, an denen ihm eigentlich nicht gelegen sein kann.

Zunächst zu den geschichtsphilosophischen Implikationen. Seit der Entwicklung der spekulativen Gattungspoetik Ende des 18. Jahrhunderts, insbesondere aber seit - auch hier wieder - Hegel, ist Gattungstheorie nahezu 
untrennbar mit Geschichtsphilosophie verknüpft. Peter Szondi schreibt über das "historische Denken«: "Bei Hölderlin noch unausdrücklich, bei Fr. Schlegel und Schelling deutlicher, vollends bei Hegel, greift es auf die Poetik über, wird die Poetik historisiert. «1 Szondis Darstellung ist an dieser Stelle irreführend, da sie impliziert, daß die >Historisierung` der Gattungsbegriffe notwendigerweise deren »Unantastbarkeit « oder Apriorität aufhebt und deren Entsubstantialisierung bedeutet. Dagegen gilt gerade für die von ihm genannten Positionen, und insbesondere für Hegel, daß beides zusammengedacht wird - Historizität und Substanz. Die Poetik wird historisiert, aber nicht entsubstantialisiert. Die `Historisierung der Poetik her nicht nur die Erkenntnis, daß Gattungen historischen Konjunkturen unterliegen, daß unterschiedliche Epochen je unterschiedliche Gattungen prägen oder, stärker, daß unterschiedliche Epochen von je unterschiedlichen Gattungen geprägt sind. Vielmehr wird die Gattungstheorie in Hegels idealistische, und d.h. teleologische, Geschichtsphilosophie eingeschrieben. Deren zentraler Gedanke ist bekanntlich die »Vernunft in der Geschichte«, d.h. das Konzept einer historisch sich entwickelnden und vollziehenden Vernunft, einer Selbstbewußtseinswerdung des Geistes, ausgehend vom subjektiven über den objektiven bis hin zum absoluten Geist. Aus dieser Identifikation von Idee und Geschichte folgt für seine Gattungstheorie auch die Identifikation von Gattung und Geschichte; die Gattungen werden von Hegel in diese "geschichtsphilosophische Konzeption hineingenommen «, ${ }^{2}$ und zwar dergestalt, daß sie je unterschiedlichen geschichtlichen Epochen - und also auch, wie eingangs gesagt und wie gleich noch einmal zu sehen sein wird, unterschiedlichen geistigen Entwicklungsstufen, unterschiedlichen Stufen von Subjektivität - entsprechen. Hegel vertritt damit einen Gattungsrealismus, der sich nicht auf literarische Gattungen beschränkt, sondern diese zudem auf die Geschichte überträgt. Gattungstheorie ist seitdem nicht mehr ohne Geschichtsphilosophie zu haben. Mit der Bestimmung der Genealogie als Untersuchung von Gattungen von Geschichte gerät man also direkt ins Zentrum von Hegels gattungstheoretischem Diskurs, und Foucault rückt ihm durch die Gattungsbezüge in Überwachen und Strafen erstaunlich nahe.

Die in Frage stehende (und bereits mehrfach zitierte) zentrale Textstelle aus Überwachen und Strafen lautet:

1 Vgl. Peter Szondi: Von der normativen zur spekulativen Gattungspoetik, S. 56.

2 Ders.: Hegels Lehre von der Dichtung, S. 470f. 
Zu Beginn des 19. Jahrhunderts geht also das große Schauspiel der peinlichen Strafe zu Ende; man schafft den gemarterten Körper beiseite; man verbannt die Inszenierung des Leidens aus der Züchtigung. [...] Dies ist ein wichtiger Augenblick. Die alten Mitspieler des Straf-Prunks, der Körper und das Blut, räumen den Platz. Auf die Bühne tritt eine neue Figur - maskiert. Eine gewisse Tragödie ist zu Ende, es beginnt eine Komödie mit schattenhaften Silhouetten, gesichtslosen Stimmen, unbetastbaren Wesen. Der Apparat der Strafjustiz hat es nun mit dieser körperlosen Realität zu tun. (ÜS 22f., 26)

Foucaults Rede von der Ablösung der Tragödie durch die Komödie ist zunächst ein sehr spezifischer Bezug auf die seit Hegel anhaltende Diskussion um das Ende der Tragödie als literarischer Gattung bzw. ihre Ablösung durch die Komödie. Diese Bezüge sind oben bereits diskutiert worden. Hegels Gattungsüberlegungen zeichnen sich nun aber, wie gesagt, dadurch aus, daß sie sich nicht auf literarische Texte beschränken, sondern Epos, Tragödie und Komödie als historische Weltgestalten betrachten - eine Verknüpfung, die auch Foucault nahelegt, indem er die Gattungsbezeichnungen nicht in erster Linie für konkret auftretende Texte verwendet (Ilias, König Ödipus und die >lettres de cachet in Die Wahrheit und die juristischen Formen; Rosenroman, Le bon petit Henri und Analyse der Phobie eines füfjährigen Knaben in Überwachen und Strafen), sondern vor allem, ganz wie Hegel, um die Abfolge historischer Ereignisse oder Entwicklungen zu beschreiben (Marter, reformierte Strafe, Gefängnis). Damit droht die Entwicklung des Strafsystems ebenso wie die der verschiedenen Machtsysteme und der Epistemen gewissermaßen in den klassisch-idealistischen Kontext eines Fortschritts der Geschichte zu rücken.

Bekanntlich greift auch Marx Hegels Figur der Ablösung der Tragödie durch die Komödie auf. Es wäre also zu überlegen, ob Foucaults Gattungsbezüge vom Ruch einer idealistischen Geschichtsauffassung befreit werden könnten, indem man sie auf Marx zurückführt - namentlich auf den berühmten Anfang von Der achtzehnte Brumaire des Louis Bonaparte, der in geradezu aphoristischer Form Gattung und Geschichte direkt miteinander verknüpft. Marx schreibt: "Hegel bemerkte irgendwo, daß alle großen weltgeschichtlichen Tatsachen und Personen sich sozusagen zweimal ereignen. Er hat vergessen hinzuzufügen: das eine Mal als Tragödie, das andere Mal als Farce. $\aleph^{3}$ Die Forschung verweist diesbezüglich in der Regel auf die folgende Stelle aus Hegels Vorlesungen über die Philosophie der Geschichte, an der

3 MEW 8, S. 115. 
er den Übergang von der römischen Republik zur Kaiserherrschaft behandelt: 4

Unmittelbar darauf [i.e. auf die Ermordung Cäsars; Gw.E.] aber zeigte sich, daß nur einer den römischen Staat leiten könne, und nun mußten die Römer daran glauben; wie denn überhaupt eine Staatsumwälzung gleichsam im Dafürhalten der Menschen sanktioniert wird, wenn sie sich wiederholt. So ist Napoleon zweimal unterlegen, und zweimal vertrieb man die Bourbonen. Durch die Wiederholung wird das, was im Anfang nur als zufällig und möglich erschien, zu einem Wirklichen und Bestätigten. ${ }^{5}$

Zwar behauptet Hegel hier nicht die grundsätzliche Wiederholung geschichtlicher Ereignisse, aber er räumt ihr, so sie sich ereignet, zumindest für die Wahrnehmung dieser Ereignisse eine gewisse Bedeutung ein, und er nennt auch an anderer Stelle Beispiele für die »Wiederholung früherer Epochen in der Geschichte, ${ }^{6}$ worauf in der Forschung ebenfalls hingewiesen wird. ${ }^{7}$ Es bleibt also festzuhalten, daß Hegel die Errungenschaften der Französischen Revolution in der konstitutionellen Monarchie (Verfassung von 1791) als zunächst verwirklicht und dann gescheitert beschreibt, um diese in den Jahren 1814/15-1830 (Ludwig XVIII. und Karl X.) als eine mißlungene Wiederholung aufgeführt zu sehen - worauf dann in der Julirevolution die 'zweite Vertreibung der Bourbonen erfolgt, die damit ebenfalls zur "Farce" gerät. Auf vergleichbare Weise bezeichnet auch Marx in seiner Einleitung zur Kritik der Hegelschen Rechtsphilosophie die deutsche Monarchie seiner Gegenwart als Komödie: "Das moderne ancien régime ist nur mehr der Komödiant einer Weltordnung, deren wirkliche Helden gestorben sind. $\ll^{8}$ Hier taucht auch erstmals der Verweis auf die sich wiederholende Geschichte auf: "Die Geschichte ist gründlich und macht viele Phasen durch, wenn sie eine alte Gestalt zu Grabe trägt. Die letzte Phase einer

4 Vgl. dazu etwa Bruce Mazlish: The Tragic Farce of Marx, Hegel, and Engels. A Note, in: History and Theory 3 (1972), S. 335-337; sowie die Erläuterungen in MEGA, Abt. I, Bd. 2, Apparat, S. 673f. und Abt. I, Bd. 11, Apparat, S. 738. Die Kommentatoren der MEW-Ausgabe verweisen allgemeiner auf den dritten Teil von Hegels Vorlesungen über die Philosophie der Geschichte (vgl. MEW 8, S. 618). Vgl. mit Bezug auf die Komödie jüngst Stephan Kraft: Zum Ende der Komödie, S. 261-267.

5 G.W.F. Hegel: Vorlesungen über die Philosophie der Geschichte, S. 380.

6 Ebd., S. 417 f.

7 Vgl. Ulrich Profitlich (Hg.): Komödientheorie, S. 146, Anm. 9.

8 Karl Marx: Zur Kritik der Hegelschen Rechtsphilosophie. Einleitung, in: MEGA, Abt. I, Bd. 2, S. 170-183, hier S. 173. 
weltgeschichtlichen Gestalt ist ihre Komödie. ${ }^{9}$ Die deutschen Formen des Absolutismus führen die Tragödie des französischen Ancien Régime als Komödie auf. Ebenso sieht Marx dann im Achtzehnten Brumaire die Revolution von 1789 im Jahre 1848 als Parodie wiederkehren. Hegel und Marx beziehen sich auf fast den gleichen historischen Zeitraum, auf die jeweils jüngste Geschichte, und auf dieselbe Reihe von Ereignissen, nämlich die wechselhafte Herrschaftsabfolge in Frankreich seit der Revolution. ${ }^{10}$ Beiden gilt die jeweilige Gegenwart als »Farce« eines schon dagewesenen tragischen Originals. ${ }^{11}$ Die Idee einer Art dialektischer Wiederholung der Geschichte in modifizierter, nämlich entwickelterer Form ist in Hegels idealistischem System gleichermaßen angelegt wie in Marx' historischem Materialismus. $\mathrm{Ob}$ es sich bei Marx' Gattungsbezügen an dieser Stelle um tatsächlich substantiell geschichtsphilosophische, ironische oder bloß illustrative Bezüge handelt, ist (ähnlich wie bei Foucault) schwierig zu entscheiden und kann hier nicht näher erörtert werden. ${ }^{12}$ Wie auch immer man die Frage nach der Substantialität oder dem ontologischen Status der Gattungen bei Marx beantwortet - an der grundsätzlichen Problematik der Gattungsbezüge bei Foucault ändert es letztlich nichts. Denn auch, wenn Marx der Tragödie und der Komödie der Geschichte keine ontologische Realität zuspricht, sondern »die Beispiele aus der Literatur vor allem ihrer Anschaulichkeit wegen ein[ ]fügt «, ${ }^{13}$ bleibt sein materialistischer Blick auf die Geschichte, wie Hegels idealistischer, ein teleologischer Blick. Auch die bloße Veranschaulichung durch die Gattungsbezüge funktioniert bei Marx also nur deshalb, weil er Geschichte wesentlich als einen kontinuierlichen (wiewohl Revolutionen umfassenden) Prozeß begreift - ansonsten ließe diese sich nicht an der Gattungsabfolge veranschaulichen und wären die Gat-

9 Ebd., S. 173f. Die Begründung folgt sogleich: »Warum dieser Gang der Geschichte? Damit die Menschheit heiter von ihrer Vergangenheit scheide."

10 Vgl. dazu auch Stephan Kraft: Zum Ende der Komödie, S. 264.

11 Zur Komödie als Gestalt der Gegenwart(sanalyse) bei Hegel allgemein vgl. Gerhard Gamm: Komödie oder Tragödie. Die moderne Welt im Lichte Hegels und Nietzsches, in: Lettre international 27 (1994), S. 67-71.

12 Vgl. dazu Wolfgang Fietkau: Schwanengesang auf 1848. Ein Rendezvous am Louvre: Baudelaire, Marx, Proudhon und Victor Hugo, Reinbek bei Hamburg 1978, Teil 2, S. 127-217, insbes. Unterkap. »Adaptation des Hegelschen Tragödien-/Komödienmodells durch Marx" und »Repetition und Differenz in der Beziehung von Tragödie und Komödie bei Hegel und Marx«, S. 127-142; Stephan Kraft: Zum Ende der Komödie, S. 261-267.

13 Peter Christian Giese: Das »Gesellschaftlich-Komische«. Zu Komik und Komödie am Beispiel der Stücke und Bearbeitungen Brechts, Stuttgart 1974, S. 16. 
tungsanalogien verfehlt. Ebensowenig wie man eine organische Wachstumsmetapher für ein einzelnes Phänomen des Bruchs verwenden würde, würde man die Gattungsmetaphorik im Zusammenhang mit dem Diskontinuitätskonzept einsetzen. Genau das aber tut Foucault. So bleibt das Problem bestehen, daß der von ihm konstatierte epistemische Bruch zwischen Repräsentation und Humanwissenschaften auch dann zu einem Übergang verwischt oder geglättet wird, wenn man die Gattungsbezüge mehr auf Marx denn auf Hegel zurückführt, und auch dann, wenn man sie bei Marx nicht als substantielle, sondern als illustrative Bezüge betrachtet. Auch dürften bei Foucault Entwicklung und Wiederholung keinerlei Rolle spielen, da er sich explizit gegen eine teleologische Geschichtsauffassung wendet und dabei geneigt ist, Geschichtskontinuität und Geschichtsteleologie zu identifizieren, indem er von »einer kontinuierlichen Geschichte" spricht, "die gleichzeitig für die Arbeit einer Teleologie und die unbestimmten Prozesse der Kausalität geöffnet ist«. (AW 289f.) Er konzipiert Geschichte nicht als lineare Entwicklung, sondern als eine Serie von Brüchen und Diskontinuitäten. Die neue Komödie des Strafens ist demnach keine variierte (oder revolutionär umgekehrte) Form der zuvorigen Tragödie des Strafens und entwickelt sich nicht aus dieser heraus, sondern ist - folgt man Foucaults Diskontinuitätskonzept - eine gänzlich neue Strafform auf gänzlich neuen Grundlagen. Ebensowenig geht der Roman des Gefängnisses aus der Komödie der reformierten Strafe hervor. Um so dringlicher stellt sich daher die Frage nach dem Grund für Foucaults Verwendung der Analogie der historischen Abfolge von Tragödie und Komödie, die üblicherweise als Entwicklungsbewegung begriffen wird.

Dies also die erste Problematik: Seit Hegel implizieren Gattungsbezüge historische Kontinuitäten und Notwendigkeiten. Hiermit ist die zweite Problematik verbunden: Gattungsbezüge implizieren, ebenfalls seit Hegel, ein substantielles und also kontinuierliches Subjekt. Indem Hegel nämlich die Geschichte wesentlich als den Entwicklungsprozeß des Subjekts begreift, stellt er auch einen substantiellen Zusammenhang zwischen Gattungen und Subjekt her und identifiziert die historische Gattungsabfolge mit den dialektisch auseinander hervorgehenden Stufen des Selbstbewußtseins. Epos, Tragödie und Komödie sind damit nicht nur historische Weltgestalten, sondern auch - menschheitshistorische und individualpsychologische Bewußtseinsformen.

Auch Foucault verbindet die »kontinuierliche[] Geschichte", gegen die er zu Felde zieht, immer wieder explizit und direkt mit dem »konstitutiven 
Bewußtsein[ ] (AW 289f.) und also dem »Status des Subjekts«. (AW 291) Die durch die Beschreibung der verschiedenen Epistemen eigentlich angestrebte Historisierung und Entsubstantialisierung des Erkenntnissubjekts wird durch die Gattungsbezüge hintertrieben, die ebenjene »kontinuierliche Geschichte« herstellen, und das Erkenntnissubjekt wird geradezu essentialisiert. Foucault ordnet die jeweiligen »historischen Apriori«, die keine überzeitliche Gültigkeit beanspruchen dürfen, literarischen Gattungen zu, die, als Kategorien, ihrerseits in sich stabil sind. Dadurch erfolgt eine Historisierung der Gattungen wie, laut Szondi, erstmals bei Hegel; es erfolgt aber auch, ebenso wie bei Hegel, deren Substantialisierung - und die des Subjekts. Wie also bei Hegel, und das bildete ja den Ausgangspunkt der vorliegenden Arbeit, die Gattungstheorie nicht nur mit der Geschichts-, sondern auch mit der Subjektphilosophie verbunden ist, schließt Foucault die zentralen Wendepunkte in der Geschichte des Wahnsinns, der Episteme, der Strafen, kurz: der Macht tatsächlich mit Gattungswechseln kurz, und diese Wendepunkte sind zugleich Wendepunkte in der Geschichte des Subjekts - und zwar des Erkenntnissubjekts (Epistemen) ebenso wie des Subjekts der Macht (Straftechniken). ${ }^{14}$

Indem Foucault also nicht nur historische Entwicklungen und Ereignisse, sondern zugleich, untrennbar von diesen, auch seine subjekttheoretischen (bzw. antisubjekttheoretischen) Untersuchungen mit gattungstheoretischen Typisierungen grundiert, legt er deren Legitimationen und Notwendigkeiten auch für die Subjektkonzeption nahe - ein enormer Widerspruch gegen seinen entsubstantialisierten und radikal historisierten Subjektbegriff. Mit den Gattungsbezügen konterkariert Foucault nicht nur sein Konzept historischer Diskontinuitäten und die dazugehörige Ablehnung historischer Teleologien, sondern auch seine Dekonstruktion des Subjekts, riskiert also, sich nicht nur jene »kontinuierliche Geschichte«, sondern auch das moderne selbstbewußte Subjekt wieder einzuhandeln.

In Nietzsche, die Genealogie, die Historie nimmt Foucault neben der geschichtswissenschaftlich-methodischen Bestimmung der Genealogie noch eine inhaltliche Bestimmung vor - die subjektphilosophisch oder, wenn man so will, antisubjektphilosophisch ist, die sich jedenfalls auf das Subjekt bezieht: Er nennt als Ziel der Genealogie nichts geringeres als die "Opferung des erkennenden Subjekts« (NGH 188) oder die "Zerstörung des Erkenntnis-

$14 \mathrm{Zu}$ Foucaults systematischer Überblendung von Erkenntnissubjekt und Subjekt der Macht vgl. oben, Kap. I, Unterkap. »Das Subjekt bei Foucault«. 
subjekts« (NGH 191), und gleichzeitig rückt mit den 'genealogischen Untersuchungen das Machtsubjekt in seinen Blick. Damit bestimmt er das Subjekt explizit als den Gegenstand der Genealogie - wiewohl als ihren negativen Gegenstand. Wenn demnach Genealogie und Subjekt inhaltlich verknüpft sind und, wie oben dargelegt, Genealogie und Gattung verknüpft sind, sind auch Gattung und Subjekt inhaltlich miteinander verknüpft. Wenn man also die Gattung verabschiedet, verabschiedet man zugleich das Subjekt. Umgekehrt gilt: Wenn man das Subjekt verabschieden möchte, muß man auch die Gattung verabschieden. ${ }^{15}$ Genau das tut Foucault aber nicht. Foucault konzipiert seine Genealogie als Verknüpfung von historischer Methode und subjektphilosophischem Programm, und in der Tat führt er in Überwachen und Strafen in den Gattungsanalogien die drei Stränge Gattung, Geschichte und Subjekt zusammen.

\section{Funktionen des Gattungsdiskurses}

Wie erklärt sich dieser Widerspruch? Warum zieht Foucault die Parallelen zur Gattungstheorie? Man muß annehmen, daß die Gattungsbezüge Foucault nicht, wie laut White die Tropen, einfach unterlaufen; die Prominenz von Gattungsanalogien überhaupt (Marx, Hegel) und Foucaults explizit formulierter Zusammenhang zwischen literarischen Gattungen und Machtdiskursen etwa in In Verteidigung der Gesellschaft ${ }^{16}$ sprechen dagegen.

Die naheliegende Möglichkeit, die Gattungsbezüge - und damit auch ihre geschichts- und subjekttheoretischen Implikationen - ironisch (und also als Bekräftigung der Absage an die Kontinuität der Geschichte und des Subjekts) zu lesen, scheidet als Begründung sogleich aus. Zwar wird Foucaults Texten zuweilen eine ironische Grundhaltung attestiert. Burkhard Liebsch etwa spricht von "seine[n] früheren, fast durchweg ironisch gemeinten Buch-

15 Die Verbindung von Gattung und Subjekt gilt also auch negativ; die Infragestellung der Möglichkeit von Gattungen bedeutet auch die Infragestellung der Möglichkeit des Subjekts. So schreibt auch Duff über Croces Absage an Gattungsklassifikationen, leider ohne nähere Ausführung: »Croce's arguments [...] marked an escalation of the controversy over genre, and provided much of the impetus for the subsequent debate on the subject." David Duff: Introduction, S. 5.

16 Vgl. noch einmal VG 208 ("Mir scheint, daß es eine grundlegende und entscheidende Zusammengehörigkeit von Tragödie und Recht, von Tragödie und öffentlichem Recht gibt, genau wie es wahrscheinlich eine entscheidende Zusammengehörigkeit von Roman und Normproblemen gibt.«) und oben, Kap. VI. 
titel[n]«.17 Auch Fernando Suárez Müller bezeichnet Foucaults methodologisches Vorgehen als »ironische Haltung « und »ironisches Selbstverständnis" und meint damit die Tatsache, daß Foucault einerseits die Abkehr von allen »vorgefaßten Begriffen« und Kategorien fordert, andererseits selbst nicht ohne solche oder äquivalente Begriffe und Kategorien auskommt, und, und das ist Suárez Müller zufolge das Ironische, sich dessen bewußt ist: "Foucault nennt seinen methodologisch-ironischen Standpunkt deshalb einen ‘fröhlichen Positivismus «. ${ }^{18}$ Und auch Petra Gehring spricht in diesem Sinne vom »offensiv-ironischen Positivismus Foucaults ${ }^{19}{ }^{19}$ Diese Einschätzungen laufen im besten Fall darauf hinaus, die Ironie als integralen und konstitutiven Bestandteil von Foucaults archäologischer Methode zu begreifen. Dagegen ist einzuwenden, daß Foucault sich zwar zumindest in der Archäologie des Wissens ironischer Techniken und Wendungen bedient, ${ }^{20}$ diese jedoch gänzlich an der rhetorischen Oberfläche bleiben. Es handelt sich um ein der Form nach selbstironisches Kokettieren mit der Autorfunktion und um ironische intertextuelle Bezüge, die den methodologischen Standpunkt des Textes selbst indes letztlich völlig unangetastet lassen. Scheinbar legitimiert durch die ironische Rhetorik, affirmiert das Fazit am Ende stets das jeweilige Vorgehen. ${ }^{21}$

17 Burkhard Liebsch: Das menschliche Selbst in Geschichte und Gegenwart, S. 116.

18 Fernando Suárez Müller: Skepsis und Geschichte, S. 127.

19 Petra Gehring: Foucault - Die Philosophie im Archiv, S. 80.

20 Vgl. das Ende der Einleitung, AW 30, und den Schluß, AW 283-301.

21 Vgl. AW 30, wo Foucault (oder der angenommene Autor) auf den Vorwurf des Selbstwiderspruchs innerhalb seines Werks seitens eines fiktiven Lesers antwortet: "Man frage mich nicht, wer ich bin, und man sage mir nicht, ich solle der gleiche bleiben: das ist eine Moral des Personenstandes; sie beherrscht unsere Papiere. Sie soll uns frei lassen, wenn es sich darum handelt, zu schreiben." Im gleichen Zug, in dem Foucault (oder der angenommene Autor) das Wechseln des Standpunktes für sich reklamiert - was man in einem allgemeinen Sinn noch unter Ironisierung eines Standpunktes überhaupt fassen könnte -, affirmiert er seinen jeweiligen und also auch seinen aktuellen Standpunkt: den der Archäologie des Wissens. Es wirkt eher so, als versehe Foucault die Einleitung mit einem ironischen Abschnitt und den ganzen Text mit einem ironischen Schluß, um dem Vorwurf der Positivität zu entgehen, doch geraten diese Anfügungen schief. Foucault beharrt auf seiner Position, und die vermeintliche Ironie schlägt auf diese Weise in Affirmation und Positivität um. Daß Foucault sich dann selbstironisch als rglücklichen Positivisten nichts mehr daran. (Vgl. AW 182; Michel Foucault: Die Ordnung des Diskurses, Frankfurt a.M. ${ }^{9} 2003$ [Paris 1972], S. 44) Tatsächlich läßt sich, entgegen aller Verkündung des Todes des Autors und entgegen der Aushebelung der Autorfunktion, kaum ein gegenwärtigerer und dominanterer Autor denken als der der Archäologie des Wissens. 
In Überwachen und Strafen sprechen der ganze Duktus des Textes und seine Emphase gegen eine ironische Lesart. ${ }^{22}$ Philipp Sarasin spricht von Foucaults "grimmige[m] Ernst als Genealoge« und attestiert ihm, zu Recht, 'Ironiefestigkeit.$^{23}$ Auch Martin Saar stellt den "rhetorische[n] und irreduzibel hyperbolische[n] Charakter genealogischer Erzählungen« heraus, weist ihm aber eine spezifische methodische Funktion zu. Er begreift diesen Stil der Genealogie als »Kritikform sui generis", die »den Regeln, Konventionen und Vorgaben eines spezifischen Genres" gehorcht und »ihre kritische Kraft aus der dramatisierenden Geste, aus der »alarmierenden und überwältigenden Ausgestaltung von Zwangsszenarien [bezieht]«. Es gebe »keine genealogische Kritik ohne diese oder außerhalb dieser Darstellungsform. ${ }^{24}$ Die Gattungsbezüge in Überwachen und Strafen gehören zweifellos in diese genealogische Stilistik, unterlaufen Foucault also nicht, sind nicht bloß illustrativ und auch nicht ironisch. Vielleicht sind es genau die genannten geschichtsund subjektphilosophischen Implikationen, die Foucault sucht, bei allen Widersprüchen, die sie aufwerfen mögen. Es stellt sich demnach die Frage nach dem Status des Foucaultschen Gattungsdiskurses. Was leistet er für Foucaults Untersuchungen? Worin besteht seine Funktion?

\section{Gattungsdiskurs und Kontinuität}

Die erste Antwort lautet: Der Gattungsdiskurs stiftet Kontinuität. Diese Kontinuität ist, erstens, eine geschichtliche. Das zeigt sich deutlich an den oben kurz dargestellten intertextuellen Bezügen zwischen Die Ordnung der Dinge und Überwachen und Strafen. Die beiden fundamentalen Brüche der

22 Das kann man auch mit Megill erklären, dem zufolge mit der Genealogie und insbesondere mit Überwachen und Strafen ein aktives politisches Interesse in Foucaults Texte tritt. Vgl. Allan Megill: Prophets of Extremity, S. $243 \mathrm{ff}$.

23 Philipp Sarasin: Darwin und Foucault, S. 418; ders.: Foucault, Burckhardt, Nietzsche - und die Hygieniker, in: Jürgen Martschukat (Hg.): Geschichte schreiben mit Foucault, Frankfurt a.M./New York 2002, S. 195-218, hier S. 217.

24 Martin Saar: Genealogie und Subjektivität, S. 172ff. Zum genealogischen Stil vgl. auch Hayden White: Foucault Decoded, der ihn als "apokalyptisch" charakterisiert. Joseph Vogls Charakterisierung dagegen einer »eigene[n] genealogische[n] Stilistik « als "ironische $[\mathrm{r}]$ oder parodistische[r] Stil, der sich gegen die Dignität des historischen Gedächtnisses, gegen die Kontinuität der Überlieferung und gegen die Integrität eines Erkenntnissubjekts gleichermaßen wendet«, ist nicht zutreffend. (Joseph Vogl: Genealogie, in: Clemens Kammler/Rolf Parr/Ulrich Johannes Schneider [Hg.]: Foucault-Handbuch, S. 255-258, hier S. 255) 
abendländischen Episteme und ihre Entsprechungen in der Geschichte juridischer Strafgewalt werden mittels der Gattungsbezüge doch wieder durch eben die "Quasi-Kontinuität« (OD 25) verdeckt, die aufzudecken und zu umgehen eigentlich das Programm sowohl von Foucaults Archäologie als auch seiner Genealogie ist. In der Archäologie des Wissens von 1969 formuliert Foucault "die Infragestellung der Teleologien und Totalisierungen" (AW 28) als sein Ziel; durch die Gattungsbezüge in Überwachen und Strafen aber erfolgt genau das Gegenteil.

Die Kontinuität, die der Gattungsdiskurs stiftet, betrifft damit, zweitens, auch den Subjektdiskurs, denn die historische Kontinuität ermöglicht auch die Kontinuität des Subjekts. Diese konstitutive Verbindung von Geschichte und Subjekt stellt Foucault in der Archäologie des Wissens heraus. Er schreibt dort konjunktivisch:

Wenn die Geschichte des Denkens der Ort der ununterbrochenen Kontinuitäten bleiben könnte, [...] wäre sie für die Souveränität des Bewußtseins ein privilegierter Schutz. Die kontinuierliche Geschichte ist das unerläßliche Korrelat für die Stifterfunktion des Subjekts. (AW 23)

Genau diesen "Schutz« einer »kontinuierliche[n] Geschichte« gewährt dem Subjekt nun aber der Gattungsdiskurs. Zwar ändert dieser die Untersuchung in Überwachen und Strafen im doppelten Wortsinne unterlaufende literarische Gattungsdiskurs nichts daran, daß darin das Subjekt dekonstruiert wird (vgl. Sarasin), und natürlich vermag er nicht das moderne Subjekt im eigentlichen Sinne zu restituieren. So aber, wie er unterhalb der beschriebenen Brüche eine Art historischer Kontinuität herstellt, tut er das auch auf subjektphilosophischer Ebene - und impliziert ein ursprüngliches und kontinuierliches Subjekt. "Die kontinuierliche Geschichte ist das unerläßliche Korrelat für die Stifterfunktion des Subjekts.«Offenbar gilt aber nicht das implizierte Gegenteil dieser Aussage, nämlich daß eine diskontinuierliche Geschichte die Stifterfunktion des Subjekts - oder jedenfalls das Subjekt erläßlich macht. Wie die kontinuierliche Geschichte funktioniert auch die diskontinuierliche Geschichte anscheinend nicht ohne ein Subjekt. Die durch den Gattungsdiskurs gestiftete Kontinuität bietet auf diese Weise in subjektphilosophischer Hinsicht einen Ausweg aus der >Paradoxie ${ }^{25}$ eines

25 Vgl. Christine Hauskeller: Das paradoxe Subjekt. Unterwerfung und Widerstand bei Butler und Foucault, Tübingen 2000; Judith Butler: Psyche der Macht, S. 7. Foucault ist sich dieser Paradoxie natürlich bewußt; vgl. zur Frage des Außen des Diskurses und des »notwendigen Rückgriffs auf ein konstitutives Subjekt«. (AW 286. 289f., 292f.) 
nichtvorgängigen und substanzlosen Subjekts; die Lücke, die das 'Ender oder der >Tod des Subjekts hinterläßt, wird unbemerkt, doch wirksam, gefüllt. Zwar betont Foucault in Die Ordnung der Dinge, daß der Mensch eben gerade keine Lücke hinterläßt:

In unserer heutigen Zeit kann man nur noch in der Leere des verschwundenen Menschen denken. Diese Leere stellt kein Manko her, sie schreibt keine auszufüllende Lücke vor. Sie ist nichts mehr und nichts weniger als die Entfaltung eines Raums, in dem es schließlich aufs neue möglich ist, zu denken. (OD 412) ${ }^{26}$

Anscheinend gelingt dieses Denken win der Leere des verschwundenen Menschen« jedoch noch nicht recht. Die »Leere« ist offenbar doch eine Lükke, die gefüllt werden muß, und so stellen die Gattungsbezüge genau dort eine Kontinuität des Subjekts her, wo Foucaults Untersuchungen selbst seine Fortexistenz in Abrede stellen. Die Gattungsbezüge ermöglichen und sei es nur als Hilfskonstruktion - den Bezug auf ein Subjekt, ohne tatsächlich ein Substrat zugrunde legen zu müssen. Da, wo das moderne Subjekt verabschiedet wird, wird ein Stellvertretersubjekt eingesetzt: ein Gattungssubjekt.

\section{Das Gattungssubjekt}

Der Begriff des Gattungssubjekts bedarf der Erläuterung. Es ist Habermas, der ihn unter Rückbezug auf Hegel und Marx einführt: "Die Idee eines Bildungsprozesses, in dem sich das Gattungssubjekt als solches erst konstituiert, ist von Hegel entfaltet und von Marx unter materialistischen Voraussetzungen aufgenommen worden.«27 Der Begriff selbst kommt so weder

26 Übersetzung ergänzt, Gw.E. Das Original lautet: »où il est enfin à nouveau possible de penser «. (Michel Foucault: Les mots et les choses, S. 353)

27 Jürgen Habermas: Erkenntnis und Interesse, Frankfurt a.M. 1973 [1968], S. 243. Hiergegen ist einzuwenden, daß ein zentraler Kritikpunkt Marx' an Hegels Konzeption ist, daß das Subjekt sich laut Hegel erst konstituiere, wohingegen Marx das Subjekt voraussetzt. Ihm zufolge hat Hegel »nur den abstrakten, logischen, spekulativen Ausdruck für die Bewegung der Geschichte gefunden, die noch nicht wirkliche Geschichte des Menschen als eines vorausgesetzten Subjekts, sondern erst Erzeugungsakt, Entstehungsgeschichte des Menschen ist." (Karl Marx: Ökonomisch-philosophische Manuskripte aus dem Jahre 1844, in: MEW, Ergänzungsbd. 1, Berlin 1968, S. 465-588, hier S. 570; vgl. auch ebd. S. 577) Und, ebenfalls in kritischer Bewertung: "Dieser Prozeß muß einen Träger haben, ein Subjekt; aber das Subjekt wird [bei Hegel] erst als Resultat.« (Ebd., S. 584) Marx selbst spricht dementspre- 
bei Hegel noch bei Marx vor, benennt aber sehr treffend deren Konzeption eines sich im Verlauf der Geschichte verwirklichenden Gattungswesens. Marx beschreibt diesen Prozeß bei Hegel in seinen Ökonomisch-philosophischen Manuskripten folgendermaßen: "Hegel faßt [...] die Arbeit als den Selbsterzeugungsakt des Menschen, das Verhalten zu sich als fremdem Wesen und das Betätigen seiner als eines fremden Wesens als das werdende Gattungsbewußtsein und Gattungsleben.«28 Marx selbst schreibt:

Das praktische Erzeugen einer gegenständlichen Welt, die Bearbeitung der unorganischen Natur ist die Bewahrung des Menschen als eines bewußten Gattungswesens, d.h. eines Wesens, das sich zu der Gattung als seinem eignen Wesen oder zu sich als Gattungswesen verhält. [...] Eben in der Bearbeitung der gegenständlichen Welt bewährt sich der Mensch daher erst wirklich als ein Gattungswesen. [...] Der Gegenstand der Arbeit ist daher die Vergegenständlichung des Gattungslebens des Menschen [...]. Indem daher die entfremdete Arbeit dem Menschen den Gegenstand seiner Produktion entreißt, entreißt sie ihm sein Gattungsleben..$^{29}$

Das "Gattungsleben" des Menschen ist "die Lebenstätigkeit, das produktive Leben«; und die »entfremdete Arbeit [...] entfremdet dem Menschen die Gattung ${ }^{30}{ }^{30}$ Ein entscheidender Einwand Marx' gegen Hegels Konzeption lautet, daß bei Hegel Entfremdung und Aufhebung der Entfremdung bloß »im Bewußtsein, im reinen Denken, i.e. in der Abstraktion von sich geh[en]«, und ihre Gegenstände nur abstrakte »Gedanken und Gedankenbewegungen sind.${ }^{31}$ »Die Arbeit, welche Hegel allein kennt und anerkennt, ist die abstrakt geistige «, ${ }^{32}$ schreibt Marx, wohingegen er selbst das Werden

chend auch nicht von Bildung, sondern von "Bewahrung« und >Bewährung` des Menschen im Lauf der Geschichte (vgl. ebd., S. 516f., 548). Das mag in Habermas' Wendung "unter materialistischen Voraussetzungen« bereits berücksichtigt sein; strenggenommen ist die Behauptung einer 'Konstitution eines Gattungssubjekts bei Marx aber nicht gänzlich korrekt. Andererseits lassen andere Textstellen die Idee einer geschichtlichen Subjektkonstitution bei Marx durchaus zu; etwa diese: „Und wie alles Natürliche entstehn muß, so hat auch der Mensch seinen Entstehungsakt, die Geschichte, die aber für ihn eine gewußte und darum als Entstehungsakt mit Bewußtsein sich aufhebender Entstehungsakt ist. Die Geschichte ist die wahre Naturgeschichte des Menschen.«(Ebd., S. 579)

29 Ebd., S. 516f.

30 Ebd., S. 516. Vgl. ebd., S. 557: "[D]ie Teilung der Arbeit [ist] nichts andres als das entfremdete, entäußerte Setzen der menschlichen Tätigkeit als einer realen Gattungstätigkeit oder als Tätigkeit des Menschen als Gattungswesen."

31 Ebd., S. 573.

32 Ebd., S. 574. 
der Gattung in der Arbeit materialistisch denkt. Nicht "das allgemeine Dasein des Menschen, die Religion, oder die Geschichte in ihrem abstraktallgemeinen Wesen, als Politik, Kunst, Literatur etc.", sind als "menschliche Gattungsakte« zu betrachten, sondern »die Geschichte der Industrie und das gewordne gegenständliche Dasein der Industrie [ist] das aufgeschlagne Buch der menschlichen Wesenskräfte«. ${ }^{33}$ Im Begriff des "Gattungsakte[s] « wird deutlich, daß das "Gattungswesen" des Menschen sich über die Handlung bestimmt, mithin ein handelndes Gattungssubjekt ist. Indem Marx die Gesamtheit der geschichtlichen "Gattungsakte« als das das Wesen des Menschen als Gattungsmenschen Bestimmende faßt, betrachtet er die Geschichte des Menschen als die Geschichte eines einzigen handelnden Subjekts - eben des Gattungssubjekts, wie Habermas es nennt. Die Betätigung nämlich des Menschen "als eines wirklichen Gattungswesens, d.h. als menschlichen Wesens, ist nur möglich dadurch" - und hier verweist Marx erneut auf Hegel -, »daß er wirklich alle seine Gattungskräfte - was wieder nur durch das Gesamtwirken der Menschen möglich ist, nur als Resultat der Geschichte - herausschafft, sich zu ihnen als Gegenständen verhält«. ${ }^{34}$ Das "Gattungswesen« des Menschen ist damit die Geschichte des Menschen als das "Gesamtwirken« der "Gattungskräfte«, ist die Geschichte des Menschen als Geschichte eines kollektiven Gattungssubjekts. An dieser Stelle lautet Marx' Kritik an Hegel, daß der "Selbsterzeugungsakt" bei ihm "als ein nur formeller, weil als ein abstrakter, weil das menschliche Wesen selbst nur als abstraktes denkendes Wesen, als Selbstbewußtsein gilt«. ${ }^{35}$ Auch Marx' eigene Konzeption des "Gattungswesens» ist wesentlich selbstreflexiv, doch faßt Marx dieses Selbstbewußtsein als konkreten, materiell-natürlichen Bezug. Er bestimmt den Menschen als "Gattungswesen", dessen "Gattungsleben" sich im Gegensatz zu seiner entfremdeten Existenz definiert: »In der Art der Lebenstätigkeit liegt der ganze Charakter einer species, ihr Gattungscharakter, und die freie bewußte Tätigkeit ist der Gattungscharakter des Menschen."

Aber der Mensch ist nicht nur Naturwesen, sondern er ist menschliches Naturwesen; d.h. für sich selbst seiendes Wesen, darum Gattungswesen, als welches er sich sowohl in seinem Sein als in seinem Wissen bestätigen und betätigen muß. [...] Und wie alles Natürliche entstehn muß, so hat auch der Mensch seinen Entstehungs-

33 Ebd., S. 542.

34 Ebd., S. 574.

35 Ebd., S. 584. 
akt, die Geschichte, die aber für ihn eine gewußte und darum als Entstehungsakt mit Bewußtsein sich aufhebender Entstehungsakt ist. Die Geschichte ist die wahre Naturgeschichte des Menschen. ${ }^{36}$

Habermas' Bezeichnung des Gattungssubjekts ist sowohl für Marx als auch für Hegel deshalb treffend, weil, erstens, beide das Gattungswesen als wesentlich handelndes denken und weil sich, zweitens, bei beiden der Mensch zu seinem Gattungswesen "verhält", das Verhältnis von Mensch zu Gattung also ein reflexiver Selbstbezug ist - mit dem Unterschied, daß Marx diesen Selbstbezug ausschließlich materiell, in der Arbeit, konzipiert. Für Hegel wie Marx schließlich gilt gleichermaßen, daß dieses Gattungssubjekt ein geschichtliches, ein in der Geschichte sich konstituierendes ist, wobei Marx auch hier wieder an Hegel kritisiert, daß dessen "Gattungswesen« sich bloß geistig, nicht materiell verwirklicht: »Die Menschlichkeit der Natur und der von der Geschichte erzeugten Natur, der Produkte des Menschen, erscheint darin, daß sie Produkte des abstrakten Geistes sind und insofern also geistige Momente, Gedankenwesen.«37 Marx bemüht sich, diese Abstraktheit durch die materielle Arbeit, die spekulativen Momente durch einen materialistischen Naturbegriff und die Geschichte durch Naturgeschichte zu ersetzen, führt also im Gattungsbegriff Selbstbewußtsein und Natur, Geschichte und Naturgeschichte zusammen und bindet beides an »die freie bewußte Tätigkeit«, an die Freiheit des Menschen. Darin klingt nichts geringeres an als Kants aufklärerisches Konzept eines »im beständigen Fortschreiten zum Besseren" befindlichen "menschliche[n] Geschlecht[s]«, und zwar des "menschliche[n] Geschlecht $[\mathrm{s}]$ im Ganzen seiner Vereinigung (non singulorum, sed universorum) ${ }^{38}$ (Nicht umsonst bestimmt Marx den Kommunismus als Humanismus. ${ }^{39}$ ) Auch in Horkheimers früheren Ver-

36 Ebd., S. 579.

37 Ebd., S. 573.

38 Immanuel Kant: Der Streit der Fakultäten, in: Kants Werke. Akademie Textausgabe, Bd. 7, Berlin/New York 1972, S. 1-116, hier S. 87. Diese »so allgemeine[ ] und uneigennützige[ ] Teilnehmung « bezeichnet Kant als »das Phänomen nicht einer Revolution, sondern der Evolution einer naturrechtlichen Verfassung«. (Ebd.) Vgl. auch: "Am Menschen (als dem einzigen vernünftigen Geschöpf auf Erden) sollten sich diejenigen Naturanlagen, die auf den Gebrauch seiner Vernunft abgezielt sind, nur in der Gattung, nicht aber im Individuum vollständig entwickeln. « Ders.: Idee zu einer allgemeinen Geschichte in weltbürgerlicher Absicht, in: Kants Werke. Akademie Textausgabe, Bd. 8, Berlin/New York 1968, S. 15-32, hier S. 16.

$39 »$ Der Kommunismus als positive Aufhebung des Privateigentums als menschlicher Selbstentfremdung und darum als wirkliche Aneignung des menschlichen Wesens 
öffentlichungen zur Kritischen Theorie findet sich übrigens die "Idee der Selbstbestimmung des menschlichen Geschlechts «, ${ }^{40}$ »ein umgreifendes Subjekt, das heißt die selbstbewußte Menschheit« ${ }^{41}$ allerdings als noch zu verwirklichende: »Im Übergang von der gegenwärtigen zu einer künftigen Gesellschaftsform soll die Menschheit sich [...] erstmals zum bewußten Subjekt konstituieren und aktiv ihre eigenen Lebensformen bestimmen. «2 Auf je unterschiedliche Weise formulieren Kant, Hegel, Marx und Horkheimer also gleichermaßen die Idee eines Gattungssubjekts. Kant konzipiert die aufgeklärte, vernünftige Menschheit, die auf beständigem Weg zum Besseren ist, als kollektives Gattungssubjekt, Hegel ein individuelles wie kollektives Gattungssubjekt, das den dialektischen Selbstbewußtseinsstrukturen der idealistischen Vernunftwerdung folgt, Marx ein Gattungssubjekt, das dem - nun materialistisch begründeten - aufgeklärten Prinzip einer sich durchsetzenden vernünftigen Menschennatur verpflichtet bleibt, ${ }^{43}$ und

durch und für den Menschen; darum als vollständige, bewußt und innerhalb des ganzen Reichtums der bisherigen Entwicklung gewordne Rückkehr des Menschen für sich als eines gesellschaftlichen, d. h. menschlichen Menschen. Dieser Kommunismus ist als vollendeter Naturalismus Humanismus, als vollendeter Humanismus Naturalismus, er ist die wahrhafte Auflösung des Widerstreites zwischen dem Menschen mit der Natur und mit dem Menschen, die wahre Auflösung des Streits zwischen Existenz und Wesen, zwischen Vergegenständlichung und Selbstbestätigung, zwischen Freiheit und Notwendigkeit, zwischen Individuum und Gattung.» Karl Marx: Ökonomisch-philosophische Manuskripte, S. 536.

40 Max Horkheimer: Traditionelle und kritische Theorie [1937], in: ders.: Traditionelle und kritische Theorie. Vier Aufsätze, Frankfurt a.M. 1968, S. 12-64, hier S. 45.

41 Ebd., S. 55.

42 Ebd., S. 48f. Den Unterschied zu Hegels idealistischer und Marx' materialistischer Konzeption eines historischen Menschheitssubjekts macht Horkheimer sogleich deutlich: »Die gedankliche Entwicklung steht, wie oben dargelegt, zur geschichtlichen, wenn auch nicht in Parallele, so doch in feststellbarer Relation. Die wesentliche Bezogenheit der Theorie auf die Zeit liegt jedoch nicht in der Entsprechung einzelner Teile der Konstruktion zu geschichtlichen Abschnitten, eine Lehre, in der Hegels Phänomenologie des Geistes und seine Logik ebenso wie das Kapital von Marx als Zeugnisse der gleichen Methode übereinstimmen, sondern in der ständigen Veränderung des theoretischen Existenzialurteils über die Gesellschaft, die durch seinen bewußten Zusammenhang mit der geschichtlichen Praxis bedingt ist.« (Ebd., S. 49)

43 Allerdings verändert sich Marx' Verständnis von »Gattung«. In den Philosophisch-ökonomischen Manuskripten vom Anfang des Jahres 1844 verwendet Marx den Gattungsbegriff in der hier beschriebenen positiven Bedeutung; in der Deutschen Ideologie von 1845 dann tritt er negativ konnotiert auf und wird verneint (vgl. Karl Marx/Friedrich Engels: Die deutsche Ideologie, in: dies.: Werke, Bd. 3, hg. vom Institut für Marxismus-Leninismus beim ZK der SED, Berlin 1969, S. 5-530, hier S. 410ff.). Vgl. zu Marx' Verhältnis zu Feuerbach in bezug auf den Gattungsbegriff Louis Althusser: 
Horkheimer schließlich eine Menschheit, die sich über ihr kritisches Vernunftinteresse bestimmt, das es zu verwirklichen gilt. ${ }^{44}$ Bei allen Unterschieden ist diesen Konzeptionen der humanistische Glaube an eine sich dank und gemäß der Vernunft entwickelnde Menschheit gemein. Dieser Glaube an die vernünftige Menschheit wird dann durch die Totalitarismen des 20. Jahrhunderts und den Holocaust nachhaltig erschüttert; angesichts dessen geben Horkheimer und Adorno spätestens in der Dialektik der Aufklärung die Idee einer vernünftigen Menschheit als Gattungssubjekt auf. Der Begriff der Gattung taucht dort nur noch negativ konnotiert auf. ${ }^{45}$ Auch bei Habermas schließlich findet sich kein Konzept eines Gattungssubjekts mehr, kein »Makrosubjekt « ${ }_{46}^{6}$ verstanden als "Subjekte in Großformat $«,{ }^{47}$ allerdings nicht, weil er die Idee eines Gattungssubjekts an sich ablehnte, sondern weil intersubjektive Prozesse und "gesellschaftliche Systeme« »Ergebnis der soziokulturellen Evolution der Menschengattung sind « 48 »Der Historische Materialismus braucht kein Gattungssubjekt zu unterstellen,

Sur Feuerbach. II: Le genre (théorie de l'espèce) [1967], in: ders.: Écrits philosophiques et politiques, Bd. 2, hg. von François Matheron, Paris 1995, S. 229-244. Zum Gattungsbegriff bei Marx vgl. Victor Wallis: Gattungsfragen, in: Historisch-kritisches Wörterbuch des Marxismus, hg. von Wolfgang Fritz Haug, Bd. 4, Hamburg 1999, Sp. 1239-1248; Isabel Monal: Gattungswesen, in: Historisch-kritisches Wörterbuch des Marxismus, Bd. 4, Sp. 1248-1258.

44 Vgl. Sabine Doyé: Kritische Theorie, in: Theologische Realenzyklopädie, Bd. 20, hg. von Gerhard Krause und Gerhard Müller, Berlin 1990, S. 81-96, hier S. 81: »Auf der Grundlage der Kategorien materialistischer Geschichtstheorie konzeptualisiert die frühe Kritische Theorie `Gesellschaft ‘ als Totalität des geschichtlichen Lebenszusammenhangs der Gattung. Die Bezugnahme auf die Idee eines geschichtlich sich bildenden Gattungssubjekts kennzeichnet die geschichtsphilosophischen Prämissen der Theorie: Das erkenntnisleitende Interesse an Emanzipation gilt als das den Konstitutionsprozeß des Gattungssubjekts selber forttreibende Vernunftinteresse, mithin als ein der Geschichte immanentes vernünftiges Bildungspotential [...].«

45 Max Horkheimer/Theodor W. Adorno: Dialektik der Aufklärung. Philosophische Fragmente, Frankfurt a.M. ${ }^{2} 2000$ [1944]. Hier ist die »Gattung" nur noch »die Beliebigkeit des Exemplars« (ebd., S. 16); es ist die Rede von »bloßen Gattungswesen, einander gleich durch Isolierung in der zwangshaft gelenkten Kollektivität." (Ebd., S. 43) »Die Kulturindustrie hat den Menschen als Gattungswesen hämisch verwirklicht. Jeder ist nur noch, wodurch er jeden anderen ersetzen kann: fungibel, ein Exemplar.«(Ebd., S. 154)

46 Jürgen Habermas: Zur Rekonstruktion des Historischen Materialismus, Frankfurt a.M. 1976, S. 154.

47 Ders.: Theorie und Praxis. Sozialphilosophische Studien, 4., erw. und neu eingel. Aufl., Frankfurt a.M. 1971 [1963], S. 20.

48 Ebd., S. 21. 
an dem sich die Evolution vollzieht. Träger der Evolution sind vielmehr Gesellschaften und die ihr integrierten Handlungssubjekte.«49

Die vorangegangenen kurzen Ausführungen zum Gattungssubjekt gingen ja von der Feststellung eines Gattungsdiskurses - und zwar eines literarischen Gattungsdiskurses - bei Foucault und von der Idee aus, dessen Funktion als die Etablierung eines Stellvertretersubjekts für das verabschiedete selbstbewußte und autonome Subjekt zu bestimmen. Im hiesigen Zusammenhang eines literarischen Gattungsdiskurses müßte es sich beim vorgeschlagenen Gattungssubjekt demnach auch so etwas wie ein literarisches Gattungssubjekt oder um ein Subjekt literarischer Gattungen handeln - wobei sich sogleich die Frage stellt, was dieser Begriff bedeuten würde.

Der Zusammenhang zwischen einem Gattungssubjekt der Menschheit im Sinne Kants, Hegels, Marx' und Horkheimers einerseits und den literarischen Gattungen andererseits läßt sich über Hegel herstellen. Es wurde bereits erwähnt, daß Hegel im Kunstreligionskapitel der Phänomenologie die Selbstbewußtseinswerdung entlang der Abfolge der literarischen Gattungen Epos, Tragödie und Komödie nachzeichnet, die er zugleich jeweils historisch verortet. Durch diese Identifikation von Subjektwerdung, Gattungsabfolge und Geschichtsprozeß begreift er das menschheitsgeschichtliche Gattungssubjekt auch als Subjekt literarischer Gattungen, das die Entwicklungsstufen des epischen, tragischen und komischen Bewußtseins durchläuft. Die Frage nach dem Inhalt des Begriffs stellt sich allerdings weiterhin. Was ist ein literarisches Gattungssubjekt? Ist es die literarische Figur, die Erzählinstanz, der Autor, der Rezipient, die Gesamtheit all dieser Instanzen? Für Hegels Kunstreligionskapitel kann man das Gattungssubjekt am ehesten wohl in der Tat als die Gesamtheit, oder besser: als das Zusammenspiel der genannten Instanzen beschreiben, das Zusammenspiel von vorgestelltem epischen bzw. dargestelltem dramatischen Held, Sänger des Epos bzw. Schauspieler der Tragödie oder Komödie und Zuhörer bzw. Zuschauer. Der Unterschied zwischen tragischem und komischem Bewußtsein etwa liegt im unterschiedlichen Verhältnis, in dem dargestellter dramatischer Held, darstellender Schauspieler und Zuschauer zueinander stehen (vgl. Kap. IV) und bedeutet unterschiedliche Grade des Bewußtseins - und zwar des Bewußtseins des Helden ebenso wie des Schauspielers und des Zuschauers. Durch Hegels spekulatives Ineinander von Einzelnem und Allgemeinem, Individuum und Gattung, einzelnem Subjekt und Menschheitssubjekt

49 Ders.: Zur Rekonstruktion des Historischen Materialismus, S. 154. 
oder Subjekt der Geschichte - biologisch gesprochen: Ontogenese und Phylogenese - sind diese Bewußtseinsgrade außerdem menschheits- oder gattungsgeschichtliche Stadien des Bewußtseins; episches, tragisches und komisches Bewußtsein sind Formen des menschlichen Gattungsbewußtseins.

Nun soll hier natürlich nicht behauptet werden, daß Foucaults tragischer Verbrecher Hegels tragischem Bewußtsein oder daß Foucaults komischer Delinquent Hegels komischem Bewußtsein entspricht; es soll also nicht behauptet werden, daß Foucault Hegels spekulatives System übernimmt und weiterführt. Anders als Hegel, dessen Theorie zugleich sowohl das Werden des Subjekts in der Menschheitsgeschichte als auch das Werden des jeweils einzelnen menschlichen Subjekts betrifft, also ein Ineinander von psychischen Formen und Geschichte umfaßt, beschreibt Foucault zwar ein Ineinander von historischen Ereignissen und dem Subjekt, ganz entschieden aber nicht von Geschichte und realen psychischen Formen. ${ }^{50}$ Die Idee eines Gattungssubjekts stellt vielmehr eine zunächst bloß formale Kontinuität her, die die Möglichkeit der Bezugnahme auf eine Subjektinstanz garantiert, was Foucault gewissermaßen aus den Paradoxien einer subjektlosen Geschichte befreit. Allerdings, und dieses Problem (oder dieser Vorteil) bleibt bestehen, impliziert diese formale Kontinuität auch eine inhaltliche Kontinuität, nämlich das Fortbestehen des vermeintlich verschwundenen modernen Subjekts, das Fortbestehen einer im emphatischen Verständnis der Aufklärung freien und autonomen Menschheit. ${ }^{51}$ Das Gattungssubjekt ist damit, wie-

$50 \mathrm{Vgl} . \mathrm{WjF} 31,128 f$.

51 Eine ähnliche Funktion der Gattung weist Eva Geulen bei Adorno nach. Sie zeigt, daß die Idee der Menschheit bei Adorno in der literarischen Gattung, namentlich der Lyrik, fortbesteht, daß also die Lyrik für Adorno eine Menschheit repräsentiert, die als solche längst verabschiedet wurde. "[G]enre in Adorno turns out to have quasianthropological underpinnings". »It seems as if genres shelter a faith in enlightenment that has been thoroughly compromised by the dialectic of myth and enlightenment everywhere else." »Adorno insists that genre and generic demands assume the role of the universal once attributed to the human species." (Eva Geulen: Adorno and the Poetics of Genre, in: David Cunningham/Nigal Mapp [Hg.]: Adorno and Literature, London/New York 2006, S. 53-66, hier S. 56f.) Nachdem Horkheimer also angesichts der Katastrophen des 20. Jahrhunderts seine Gattungssubjektidee aufgegeben und in der Dialektik der Aufklärung gemeinsam mit Adorno die Vernunft in der Geschichte verabschiedet hatte (was insbesondere Adorno vorangetrieben hatte), sieht offenbar auch Adorno die Notwendigkeit eines Fortbestehens der Humanität und setzt einen Stellvertreter für das verabschiedete Menschheitssubjekt ein: das Gattungssubjekt der Lyrik. Lars Friedrich formuliert grundsätzlicher, »dass sich 
wohl auf je unterschiedliche Weise (Kant, Hegel, Marx, Horkheimer), nicht nur eine teleologische, sondern eine wesentlich humanistische Idee, die Foucault durch seinen Gattungsdiskurs, obgleich nur substitutiv, weiterführt.

In Foucaults "historisch-genealogische Dekonstruktion des Subjekts" in Überwachen und Strafen (Sarasin) schleicht sich also mit dem Gattungsdiskurs wieder ein Subjekt ein. ${ }^{52}$ Das literarische Gattungssubjekt tritt auf formaler Argumentationsebene in Stellvertreterschaft für das suspendierte cartesische oder transzendentale Erkenntnissubjekt und auf inhaltlicher Ebene für das verabschiedete autonome humanistische Subjekt. Die postulierte Entsubstantialisierung des Subjekts wird durch ein quasisubstantielles Gattungssubjekt konterkariert. Offenbar kommt auch der vermeintlich so abgeklärte postmoderne Theoriediskurs nicht ohne Subjekt und nicht ohne den

der Begriff der Gattung nicht auf seine Definition als formale Nomenklatur reduzieren lässt. Stets scheint er eine anthropologische Dimension zu beinhalten [...].« (Lars Friedrich: Der Achill-Komplex, S. 13) Auch Althusser ist sich dieser - in seinen Augen: ideologischen - Bedeutung des Gattungsbegriffs bewußt, wie aus seiner Bemerkung über eine nominalistische Gattungskonzeption hervorgeht: "[E]lle ouvre la voie à une critique de l'essence humaine comme nom, comme formulation arbitraire et contingente, liée à l'histoire, à la conjoncture politico-idéologique. [...] Dans ce cas, dans le cas d'un nominalisme, l'homme ou l'essence de l'espèce humaine est dans la dépendance totale des individus existants, de leurs conditions d'existence, et on peut facilement dénoncer l'idée ou l'essence de l'homme comme une notion artificielle, bon adéquate, exprimant seulement la nostalgie ou l'espérance, etc., des individus d'une époque déterminée.« Louis Althusser: Sur Feuerbach, S. 233.

52 Saar macht übrigens auch eine Art Gattungssubjekt, und zwar der Genealogie, aus (sozusagen ein Gattungssubjekt zweiter Ordnung): Er bestimmt die Genealogie als "sui generis", als eigenes "spezifische[s] Genre«. (Martin Saar: Genealogie und Subjektivität, S. 173) Dabei betont er die »Gerichtetheit oder >Adressierung« des genealogischen Texts: "Genealogie ist an ein Publikum gerichtet [...]. Der als Objekt genealogischer Erzählungen verhandelte Gegenstand ist das Subjekt, das gleichzeitig als Betroffener wie als Angesprochener Teil des genealogischen Textes ist. Auch in diesem Merkmal sind die Texte also reflexiv, beziehen sich auf ein selbst im Text, das Gegenstand und Adressat zugleich ist. [...] Die Implikation des Adressaten ist eine weitere 'Selbstimplikation, weil diese Geschichte dem erzählt wird, von dem sie handelt. Ein sSelbst‘, das Subjekt ist[,] also nicht nur Bezugspunkt der Historisierung und kritische Instanz, Objekt der kritischen Befragung, sondern ebenso Adressat und Implikat der genealogischen Darstellungen selbst. Die Genealogien sind 'Geschichte der Gegenwart ‘ für Bewohner dieser Gegenwart, für ein `wir`, und das sind die nicht genauer spezifizierten Adressaten, von denen der genealogische Autor [...] annimmt, daß für sie speziell seine Geschichtsschreibung seinschlägig` ist, daß sie von ihr betroffen und provoziert werden, weil ihnen ihre eigene Gewordenheit zum Skandal wird.« (Ebd., S. 176f.) 
Glauben an oder zumindest ein Konzept von Humanität aus. ${ }^{53}$ Dies also eine Erklärung dafür, daß Foucault den Gattungsdiskurs führt: Es geht um Kontinuitätsstiftung auf historischer und subjektphilosophischer Ebene. Dessen geschichts- und subjektphilosophischen Implikationen statten Foucaults Position mit dem Boden aus, den sie untergräbt, und dessen es bedarf, um ihn untergraben zu können.

\section{Gattungsdiskurs und Kausalität}

Neben der Stiftung von Kontinuität liegt eine weitere mögliche Funktion der Gattungsbezüge in der Stiftung von Kausalität. Foucaults Bemühen in der Archäologie des Wissens, Regeln der Diskursformationen zu formulieren, die sich nicht auf überkommene Einheiten stützen, trifft sich mit den strukturalistischen, semiotischen oder textlinguistischen Unternehmungen, Techniken der Textklassifikation zu entwickeln, die nicht den traditionellen Gattungsklassifikationen entsprechen, und wäre demnach den vielfach konstatierten »anti-generischen« Tendenzen seiner Zeit zuzurechnen. ${ }^{54}$ Weiter oben wurde allerdings auch die Frage nach möglichen Affinitäten zwischen Foucaults archäologischen "Einheiten des Diskurses" und herkömmlichen Kategorien generischer Klassifikation aufgeworfen. Zweifellos jedenfalls tritt mit dem, was Foucault Genealogie nennt, ein manifester Gattungsdiskurs auf. Wenn es tatsächlich einen konstitutiven methodischen Zusammenhang von Genealogie und Gattungsdiskurs gibt, kann die Funktion des Gattungsdiskurses über die Funktion der Genealogie bestimmt werden. Zur Unterscheidung von Archäologie und Genealogie schreibt Sarasin, die archäologische Perspektive bleibe darauf beschränkt,

die Serien von diskursiven Elementen im Rahmen einer bestimmten Ordnung oder Konfiguration zu beschreiben, ihren Anfang, ihre Grenzen und ihr zeitliches Ende festzustellen, ohne dass der Diskursanalytiker den tieferen Grund dafür anzugeben vermöchte, warum ein Diskurs auftaucht und wieder verschwindet. Erst der Genea-

53 Die Untersuchung der Idee eines Gattungssubjekts von Kant über Hegel, Feuerbach, Marx und Engels, evtl. Nietzsche, dann Lukács, Horkheimer und Adorno, seine Ablehnung bei Althusser, bis hin zu Habermas und Foucault, und zwar insbesondere mit Blick auf mögliche Querverbindungen zur literarischen Gattung, erscheint überaus aussichtsreich und stellt ein echtes Forschungsdesiderat dar.

54 Vgl. oben, Kap. VII. 
loge der 1970er Jahre wird [...] solche Gründe in den Veränderungen von Machtstrukturen und Machtpraktiken erkennen. ${ }^{55}$

Demnach gilt in der Archäologie noch »die Zufallsreihe der Ereignisse«, 56 wohingegen die Genealogie als deren »tieferen Grund« die spezifischen Strukturen der Macht am Werk sieht. Wenn aber die »Veränderungen von Machtstrukturen und Machtpraktiken« die "Gründe« für das Aufkommen und Verschwinden von Diskursen sind, ist die Begründungsfrage nur verschoben, denn dann stellt sich die Frage nach den »Gründen« ebenjener begründenden »Veränderungen von Machtstrukturen und Machtpraktiken«.

Ute Frietsch unterscheidet Archäologie und Genealogie folgendermaßen:

Foucault setzt sich mit seiner Archäologie das Ziel, das Gemeinsame unterschiedlicher Felder des Wissens einer Zeit zu beschreiben [...]. Foucault hat diesen »archäologischen" Ansatz in den 1970er Jahren durch einen genealogischen Ansatz ergänzt. Die archäologische Methode, die sich zur Beschreibung der Gleichzeitigkeiten und des "Gleichen« eignet, bekommt offenbar zwei Fragen nicht in den Griff: Die nach der Kausalität von Veränderung und die nach der Macht. ${ }^{57}$

Sie impliziert, daß die Genealogie, anders als die Archäologie, diese beiden Fragen - die eigentlich nur eine einzige Frage sind, da Foucault die Macht ja als das den Veränderungen zugrunde liegende Prinzip bestimmt - »in den Griff« bekommt. Foucaults Versuche, die sich vollziehenden Veränderungen nicht nur zu beschreiben, sondern auch zu begründen, bezeugen das Gegenteil: Meist beschränkt er sich darauf, nach der Begründung zu fragen, ohne diese Frage dann aber zu beantworten. Die Begründungen erfolgen entweder ex negativo, ohne zu einer positiven Antwort zu kommen, oder im immer wieder gleichen tastenden Duktus und in Wiederholung der immer wieder gleichen unbestimmten Attribute wie "komplex" und "heterogen", "verschiedenartig" und "vielschichtig", vagen Umschreibungen und Verweise auf Begriffe wie "Strategie" (kaum ein Wort verwendet Foucault in diesem Zusammenhang häufiger), "Kräfte« oder »Relationen", die ihrerseits nicht begründet werden können. Exemplarisch sei hier aus einem Interview aus dem Jahre 1975 zum kurz zuvor erschienenen Überwachen und Strafen zitiert, in dem Foucaults Unvermögen, die Gründe für die Macht und ihre

55 Philipp Sarasin: Foucault zur Einführung, S. 106.

56 Michel Foucault: Die Ordnung des Diskurses, S. 37.

57 Ute Frietsch: Die Ordnung der Dinge, S. 44. 
Veränderungen anzugeben, überdeutlich wird. Er vermag nur vage Umschreibungen als Antwort anzubieten und weicht der Frage letztlich aus, indem er sie als unwesentlich zurückweist:

- Wer koordiniert das Handeln der Handlungsträger der Politik der Körper?

- Das ist ein äußerst komplexes Ganzes, bei dem man sich letztlich fragen muss, wie es in seiner Verteilung, in seinen Mechanismen, seinen wechselseitigen Kontrollen und seinen Justierungen so subtil zu sein vermag, wo es doch niemanden gibt, der das Ganze erdacht hat. Es ist ein sehr verwickeltes Mosaik. [...] Das Interessante ist, nicht den Entwurf zu erkennen, der all dem vorangegangen ist, sondern durch eine strategische Betrachtung zu erkennen, wie die Dinge an ihren Platz gekommen sind. ${ }^{58}$

Hier endet das Interview. Es ließen sich zahllose weitere Beispiele dafür nennen, wie Foucault die Frage "nach der Kausalität von Veränderung und [...] nach der Macht« (und damit auch die nach dem Subjekt) eben nicht »in den Griff bekommt«. Diese sprachlichen Unklarheiten und das Ausbleiben einer monokausalen Erklärung sind gewissermaßen methodisch konsequent, da jede Begründung ein Wiedereinsetzen jenes Kausalitätsprinzips bedeuten würde, das Foucaults Genealogie außer Kraft zu setzen bestrebt ist. Andererseits kündigt Foucault die Suche nach einer Antwort selbst immer wieder an. So faßt er etwa in Überwachen und Strafen in einer Art Zwischenbilanz die Ergebnisse seiner Untersuchung zusammen und läßt sie in die Frage nach den Gründen für die Veränderung der Straftechniken,

58 Michel Foucault: Macht und Körper, in: ders.: S II, S. 932-941, hier S. 940f. Vgl. auch kurz zuvor:

»- Durch Ihre Untersuchungen über den Wahnsinn und über das Gefängnis erhält man Einblick in die Ausbildung einer immer disziplinarischeren Gesellschaft. Diese geschichtliche Entwicklung scheint von einer gleichsam unumgänglichen Logik geleitet...

- [...] Der Zusammenhang ergibt sich nicht aus der Aufdeckung eines Vorhabens, sondern aus der Logik der Strategien, die einander gegenüberstehen. In der Untersuchung der Machtmechanismen, die den Körper besetzt haben, der Gesten und Verhaltensweisen gilt es, die Archäologie der Humanwissenschaften aufzubauen. Sie findet im Übrigen eine der Bedingungen ihrer Entstehung wieder: das vom 19. Jahrhundert verfolgte starke Bemühen um Disziplinierung und Normierung.« (Ebd., S. 939)

Die Frage galt einer "unumgänglichen Logik« hinter den Machtmechanismen, und Foucault antwortet, ihnen liege kein »Vorhaben" zugrunde, sondern eine "Logik der Strategien". Die Frage galt der "Ausbildung einer immer disziplinarischeren Gesellschaft«, und Foucault antwortet, es gebe ein im »19. Jahrhundert verfolgte[s] starke[s] Bemühen um Disziplinierung und Normierung". 
also die Frage nach »Veränderungen von Machtstrukturen und Machtpraktiken« (Sarasin) münden:

Vereinfachend könnte man sagen, daß im monarchischen Recht die Bestrafung ein Zeremoniell der Souveränität ist; sie brandmarkt den Körper des Verurteilten mit den Malen der Rache; und sie entfaltet vor den Augen der Zuschauer eine Schrekkenswirkung, ${ }^{59}$ die um so stärker ist, als die physische Gegenwart des Souveräns und seiner Macht unvorhersehbar, unregelmäßig ist und über ihren eigenen Gesetzen steht. Für die Reform-Juristen ist die Bestrafung eine Maßnahme, durch welche die Individuen wieder zu Rechtssubjekten gemacht werden sollen; sie arbeitet nicht mit Brandmalen, sondern mit Zeichen, mit codierten Vorstellungskomplexen, die durch die Strafszenen in den schnellsten Umlauf gesetzt und zu allgemeinster Anerkennung gebracht werden müssen. Und im Projekt der Kerkerinstitution ist die Bestrafung eine Technik des Einzwängens der Individuen; sie arbeitet mit Dressurmethoden, die am Körper nicht Zeichen, sondern Spuren hinterlassen: die Gewohnheiten des Verhaltens; und sie setzt die Etablierung einer eigens institutionalisierten Strafgewalt voraus. Gewalt des Souveräns, Gesellschaftskörper, Verwaltungsapparat; Mal, Zeichen, Spur; Zeremonie, Vorstellung, Übung; besiegter Feind, wiedereingebürgertes Rechtssubjekt, unmittelbarem Zwang unterworfenes Individuum; gemarterter Körper, manipulierte Vorstellungen der Seele, dressierter Körper: diese drei Serien von Elementen charakterisieren die drei konkurrierenden Strafsysteme der zweiten Hälfte des 18. Jahrhunderts. Man kann sie nicht auf Rechtstheorien reduzieren (obwohl sie sich damit decken), man kann sie nicht mit Apparaten oder Institutionen identifizieren (obwohl sie sich darauf stützen) und man kann sie nicht von moralischen Wertungen herleiten (obwohl sie darin ihre Rechtfertigung finden). Es handelt sich um Modalitäten der Ausübung von Strafgewalt, um drei Technologien der Macht.

Das Problem stellt sich also folgendermaßen: Wie kommt es, daß sich das dritte Modell schließlich durchgesetzt hat? Wieso hat das zwanghafte, körperliche, isolierende und verheimlichende Modell der Strafgewalt das repräsentative, szenische, zeichenhafte, öffentliche und kollektive Modell verdrängt? Warum hat sich die physische Vollstreckung der Bestrafung (die von der Marter zu unterscheiden ist) mitsamt ihrer institutionellen Basis, dem Gefängnis, gegenüber dem gesellschaftlichen Spiel der Strafzeichen und dem geschwätzigen Fest, das sie in Umlauf bringt, durchgesetzt? (ÜS 169f.)

Man kann die drei Strafsysteme also »nicht auf Rechtstheorien reduzieren«, "nicht mit Apparaten oder Institutionen identifizieren" und »nicht von moralischen Wertungen herleiten«. Was man aber kann, ist, das wurde im

59 Seitter übersetzt »Terroreffekt«; im Französischen »effet de terreur« klingt aber der tragödientheoretische Schrecken und die Katharsis an, daher meine Übersetzung "Schreckenswirkung". 
zweiten Teil der vorliegenden Arbeit gezeigt, sie Gattungen zuzuordnen. »Es handelt sich um Modalitäten der Ausübung von Strafgewalt, um drei Technologien der Macht« - und um drei Gattungen. Der Reihung

Gewalt des Souveräns, Gesellschaftskörper, Verwaltungsapparat; Mal, Zeichen, Spur; Zeremonie, Vorstellung, Übung; besiegter Feind, wiedereingebürgertes Rechtssubjekt, unmittelbarem Zwang unterworfenes Individuum; gemarterter Körper, manipulierte Vorstellungen der Seele, dressierter Körper

läßt sich daher anfügen: Tragödie, Komödie, Roman. Die »drei Technologien der Macht « werden erst durch den Gattungsdiskurs zu »drei Serien von Elementen" geordnet und zusammengehalten. Die in Überwachen und Strafen eingangs gestellte Frage nach "eine[r] gemeinsame[n] Matrix" der "Geschichte des Strafrechts" und der "Geschichte der Humanwissenschaften", die Foucault dort nicht oder nur mit dem allgemeinen Verweis auf eine »Technologie der Macht« beantwortet (ÜS 34), beantwortet er auch im Laufe seines Textes nicht. Aus den obigen Untersuchungen kann sie aber abgeleitet werden: Die gesuchte "gemeinsame Matrix" ist das literarische Gattungssystem. Der gesuchte »eine[] einzige[] repistemologisch-juristi-

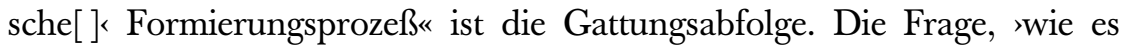
kommt<, daß sich das eine "Modell« schließlich gegenüber den anderen beiden durchgesetzt hat, und die Foucault im weiteren Verlauf des Textes nicht beantwortet, entspricht damit der Frage, wie es kommt, daß sich der Roman gegenüber der Tragödie und der Komödie durchgesetzt hat, womit sie implizit eine Antwort erfährt - eine Antwort, die nach dem Ende der großen Systeme (oder, mit Lyotard, dem »Ende der großen Erzählungen«) eigentlich nicht mehr gelten kann: Weil die Gattungsabfolge nun einmal so ist. Der Gattungsdiskurs übernimmt damit die Funktion eines Begründungszusammenhangs. Er ist Ausdruck und Folge dessen, daß Foucault die Veränderungen, die er beschreibt, eben nicht begründen kann und daß der Verweis auf die Machtstrukturen nicht ausreicht, weil diese ihrerseits begründungsbedürftig sind. Die Genealogie bekommt die Frage »nach der Kausalität von Veränderung und [...] nach der Macht« (Frietsch) nur über den Gattungsdiskurs »in den Griff«.

Während also in der Archäologie noch "die Zufallsreihe der Ereignisse» gilt, ${ }^{60}$ gelten in der Genealogie die spezifischen Strukturen der Macht - die,

60 Michel Foucault: Die Ordnung des Diskurses, S. 37. 
wie die vorliegende Arbeit zeigt, die spezifischen Strukturen literarischer Gattungen sind. Während sich die Archäologie der bloßen Beschreibung "diskursiver Einheiten" widmet und damit an die klassische deskriptiv-induktive Gattungsklassifikation (bzw. an strukturalistische, linguistische oder semiotische Textsortenklassifikationen) erinnert, ließe sich die Genealogie, die nach den Gründen dieser sdiskursiven Einheiten sucht, demnach mit der spekulativen Gattungstheorie vergleichen. Der methodische Übergang von Archäologie zu Genealogie entspräche dann dem von Szondi für die Gattungspoetik beschriebenen Schritt »vom Gegebenen zur Idee, von der Historie zur Philosophie, vom Deskriptiv-Induktiven zum Spekulativ-Deduktiven. ${ }^{61}$ Die Genealogie mit idealistischer Spekulation gleichzusetzen, widerspricht nun natürlich ihren erklärten Zielen. Dieser Widerspruch weist aber auf ein Problem in Foucaults genealogischer Machtanalytik hin bzw. ist ihr inhärent: Wie lassen sich verschiedene Machtdispositive unterscheiden und ihr historisches Auftreten und Verschwinden erklären, wenn man zugleich das Kausalitätsprinzip außer Kraft setzt? Wie ist die Ablehnung von Teleologie mit der Idee einer Strategie vereinbar? Wie ist eine Strategie denkbar, die nicht zielgerichtet ist? Bzw., wenn sie doch zielgerichtet ist, von wo geht diese ihre Zielrichtung aus? Foucaults Bemühen darum, die Machtstrukturen als etwas Kontingentes darzustellen, wird durch den metaphysischen Unterton ihres "strategischen" Charakters konterkariert. ${ }^{62}$ Foucault ist sich dieser grundlegenden Aporie seines Machtbegriffs durchaus bewußt; als um so zweckmäßiger erscheint daher die Einsetzung des Gattungsdiskurses, der nicht nur Kontinuität, sondern auch Kausalität stiftet.

61 Peter Szondi: Von der normativen zur spekulativen Gattungspoetik, S. 10.

$62 \mathrm{Zu}$ Ontologisierung und Universalisierung von Foucaults Machtbegriff vgl. Michael Gans: Das Subjekt der Geschichte, S. 263f.; zu seinem metaphysischen oder gar theistischen Charakter vgl. Allan Megill: Prophets of Extremity, S. 249. Sarasin schreibt, Foucault zitierend, "Macht [erscheint] bei Foucault ganz nominalistisch als der Name, den man einer komplexen strategischen Situation in der Gesellschaft gibt‘." (Philipp Sarasin: Foucault zur Einführung, S. 151) Passenderweise bringt Sarasin im Zusammenhang mit dem Machtbegriff bei Foucault mit "nominalistisch" eine der beiden Positionen jenes Universalienstreits ins Spiel, der auch jeder Gattungsdiskussion zugrunde liegt. Allerdings ist Foucaults Position sehr viel weniger nominalistisch, als er behauptet. Zudem knüpft Sarasin an dieser Stelle ausgerechnet Verbindungen zum Marx der Ökonomisch-philosophischen Manuskripte, wo es um das Gattungswesen geht. 


\section{Das Gespenst der Gattung}

Es wurde bereits kurz angesprochen, daß Marx die Komödie mit dem Gespenstischen in Zusammenhang bringt. In seiner Einleitung zur Kritik der Hegelschen Rechtsphilosophie schreibt er: "Es ist lehrreich für sie [die modernen Völker; Gw.E.], das ancien régime, das bei ihnen seine Tragödie erlebte, als deutschen Revenant seine Komödie spielen zu sehen. «"3 Das gegenwärtige "deutsche Regime" ist laut Marx ein Wiedergänger, ein komisches Gespenst des französischen Ancien Régime. Und im Achtzehnten Brumaire kontrastiert er den Geist der Revolution als die angemessene oder legitime Bezugnahme der Französischen Revolution auf die Römer, verstanden als Tragödie, mit dem Gespenst der Revolution als der unangemessenen oder illegitimen Bezugnahme der Februarrevolution von 1848 auf die Römer, verstanden als Komödie. ${ }^{64}$ Derrida argumentiert in Marx' Gespenster, daß Marx diese Trennung von Geist und Gespenst nicht gelingt, sondern daß der Geist immer auch vom Gespenst heimgesucht wird, und nennt das die "wesenhafte Kontamination des Geistes durch das Gespenst« ${ }^{65}$ Per Rückschluß auf Marx' Gattungszuordnung von Geist zu Tragödie und Gespenst zu Komödie bedeutet das auch die wesenhafte Kontamination der Tragödie durch die Komödie. ${ }^{66}$

Bei Foucault wäre weniger von einer Kontamination der Tragödie durch die Komödie zu sprechen als von einer wesenhaften Kontamination der Genealogie durch die Gattung. Bei ihm tritt der Gattungsdiskurs als Gespenst auf und spukt durch den von den alten Gespenstern vermeintlich befreiten postmodernen Theoriediskurs. ${ }^{67}$ Tatsächlich ist es Foucault selbst, der in

63 Karl Marx: Zur Kritik der Hegelschen Rechtsphilosophie, S. 381.

64 Ontologischer Unterschied: Während Marx in der Einleitung zur Kritik der Hegelschen Rechtsphilosophie (1843) noch die jeweilige Revolution selbst eine Tragödie oder eine Komödie nennt, bezeichnet er im Achtzehnten Brumaire (1852) die Form der Bezugnahme auf eine vorangegangene Revolution als eine Tragödie oder eine Komödie.

65 Jacques Derrida: Marx' Gespenster. Der Staat und die Schuld, die Trauerarbeit und die neue Internationale, Frankfurt a.M. 2004 [Paris 1993], S. 159.

66 Indirekt und in gänzlich anderem Zusammenhang greift Derrida damit, könnte man sagen, seine These von der wesenhaften Vermischung der Gattungen auf (vgl. ders.: La loi du genre, in: Glyph 7 [1980], S. 176-201).

67 Auch bei Marx und Engels gibt es einen direkten Hinweis auf den Zusammenhang der Gattungsthematik (hier nicht im literarischen Sinne) und der Geist/GespenstTerminologie, und zwar in der Auseinandersetzung mit Max Stirner in der Deutschen Ideologie, dem ausführlicher nachzugehen vielversprechend erscheint (vgl. Karl Marx/ Friedrich Engels: Die deutsche Ideologie, S. 411f.). 
Die Ordnung des Diskurses, wo er auch den Begriff der Genealogie methodisch einführt, zwar nicht den Gattungsdiskurs, aber mit Hegel sozusagen dessen vornehmsten Vertreter als Gespenst apostrophiert. Er spricht vom "großen und etwas gespenstischen Schatten Hegels, der seit dem 19. Jahrhundert herumgeisterte und mit dem man sich im Dunkeln herumschlug «, 68 und warnt davor, das gegenwärtige Denken leichthin als eines anzusehen, das Hegel hinter sich gelassen hätte:

Aber um Hegel wirklich zu entrinnen, muß man ermessen, was es kostet, sich von ihm loszusagen; muß man wissen, wie weit uns Hegel insgeheim vielleicht nachgeschlichen ist; und was in unserem Denken gegen Hegel vielleicht noch von Hegel stammt; man muß ermessen, inwieweit auch noch unser Anrennen gegen ihn seine List ist, hinter der er uns auflauert. ${ }^{69}$

Doch setzt er sich zugleich über seine eigene Warnung hinweg, indem er den hegelianischen Spuk mittels der Präterita "geisterte« und »herumschlug« als Vergangenes zu bannen sucht. In Wirklichkeit rgeistert Hegels Schatten in Form des Gattungsdiskurses auch noch durch Foucaults eigene Texte ${ }^{70}-$

68 Michel Foucault: Die Ordnung des Diskurses, S. $45 f$.

69 Ebd., S. 45.

70 Ähnlich verhält es sich übrigens bei Pornschlegel, der im Zusammenhang mit Blanchots Ablehnung literarischer Gattungseinteilungen von "gespenstisch gewordenen Gattungsbestimmungen" spricht und dabei mit dem Begriff des Gespenstischen die Gattung noch in seine Behauptung einer Absage an die Gattung in der Postmoderne wieder mit hineinnimmt. (Clemens Pornschlegel: Vögel mit Schlangen, S. 249) Pornschlegel zitiert Blanchot: "Es macht also ganz den Eindruck, als ob nach dem Verschwinden der Gattungen die Literatur allein Bestand hätte [...] - als gäbe es also wirklich ein >Wesen der Literatur. Aber es ist gerade das Wesen der Literatur, daß sie sich jeder Wesensbestimmung entzieht, jeder Behauptung, die sie festlegt oder gar zu etwas Wirklichem macht, Hohn spricht.« (Ebd., S. 248f.) Und er kommentiert: "Der literarische Text, wie Blanchot ihn konzipiert, zeichnet sich mithin dadurch aus, daß er allen gespenstisch gewordenen Gattungsbestimmungen von vornherein jede Macht über sich abspricht, daß er die generische Identität seiner Form und seines Orts in der Ordnung der Diskurse unterläuft und sich darum bemüht, seine swesentliche Unwesentlichkeit<, seine originäre Fragmentarität und Nicht-Geschlossenheit ins Spiel zu bringen: die Ortlosigkeit und Flüchtigkeit, das Nicht-Festgelegtsein, die unvorhersehbare, unabschließbare Bewegung des Schreibens selbst, die eins ist mit einer Fluchtbewegung vor (un-)möglichen klassifikatorisch-identifizierenden Zugriffen.« (Ebd., S. 249) Pornschlegel nennt die "generische Identität« des Textes gespenstisch; seine Beschreibung dessen aber, was Blanchot an deren Stelle setzen möchte, die »wesentliche Unwesentlichkeit» des Textes, seine »Ortlosigkeit und Flüchtigkeit», klingt viel gespenstischer. 
die Gattung erweist sich als Wiedergänger, als Gespenst. ${ }^{71}$ Bei aller postmodernen Ablehnung jeglicher Substanzen und überkommenen Kategorien, bei aller Emphase der Diagnose eines "Endes der großen Erzählungen« spukt der Gattungsdiskurs durch die Postmoderne. So kommt noch Lyotards »Bericht" vom "Ende der großen Erzählungen" nicht ohne die große Erzählung des Gattungsdiskurses, nicht ohne die große Erzählung vom Ende der Erzählung aus. So wie die Absage an Gattungseinteilungen (zumindest in Crocescher Form) dem Selbstwiderspruch unterliegt, Literatur als Überschreitung der Gattungseinteilungen zu bestimmen und dadurch dieser Einteilungen zu bedürfen, stützt sich die Postmoderne auf die Absage an den Gattungsdiskurs und bleibt ebendiesem Diskurs daher letztlich verhaftet.

71 Allerdings als herbeigerufenes Gespenst. Denn während Marx das Gespenst nicht bannen kann, will Foucault es nicht bannen. Die Gattungsbezüge unterlaufen ihm nicht, sondern er braucht sie. Es ist also weniger so, daß das Gespenst der Gattung in Foucaults Texten spukt, als daß er es heraufbeschwört, damit es einen Platz einnimmt, bis es nicht mehr nötig ist und durch das biologische Gattungssubjekt ausgelöst wird (vgl. das folgende Kap.). 


\section{Gattung und Biopolitik}

\section{Genealogie und Evolutionstheorie}

Die literarischen Gattungsbezüge liefern also implizit eine Begründung für die strategische Gerichtetheit der Macht, deren paradoxe Struktur anders nicht erklärt werden kann. Der genealogische Gattungsdiskurs in Überwachen und Strafen übernimmt damit eine spekulative Funktion. Daß das problematisch ist, wurde bereits gezeigt. Peter Atterton bietet eine andere Erklärung für die Strategien an. Er schlägt, sehr überzeugend, "Darwinism as a model for Foucault's genealogical project " vor. ${ }^{1}$ Auf diese Weise läßt sich die Problematik eines diskontinuierlichen Werdens lösen, denn "modern evolutionist theory à la Darwin [...] presupposes such discontinuity «. ${ }^{2}$ Das betrifft vor allem Foucaults Archäologie und Diskursanalyse, deren methodische Verwandtschaft mit Darwins Serienbildung Sarasin herausarbeitet. ${ }^{3}$ Doch auch das genealogische Grundproblem nichtsubjektiver Intentionalität (vgl. WW 116), auf das u.a. Dreyfus und Rabinow hinwei-

1 Peter Atterton: Power's blind struggle for existence: Foucault, genealogy and Darwinism, in: History of the Human Sciences 7.4 (1994), S. 1-20, hier S. 1; Philipp Sarasin: Darwin und Foucault. Daß Nietzsche hier eine vermittelnde Rolle spielt, erwähnt Sarasin nebenbei; zu Nietzsches Darwin-Rezeption vgl. Werner Stegmaier: Darwin, Darwinismus, Nietzsche. Zum Problem der Evolution, in: Nietzsche-Studien 16 (1987), S. 264-287; Volker Gerhardt/Renate Reschke (Hg.): Nietzsche, Darwin und die Kritik der Politischen Theologie, Berlin 2010; Maurice Erb: Evolution, Genealogie und `Gegen-Anthropologier. Michel Foucaults frühe Auseinandersetzung mit Darwin und Nietzsche, in: Volker Gerhardt/Renate Reschke (Hg.): Nietzsche, Darwin und die Kritik der Politischen Theologie, S. 137-148. Kritisch zu Darwins Einfluß auf Nietzsche: John Richardson: Nietzsche's New Darwinism, Oxford 2004; Dirk R. Johnson: Nietzsche's Anti-Darwinism, Cambridge 2010.

2 Peter Atterton: Power's blind struggle for existence, S. 4. Ähnliches zeigt Lars Friedrich übrigens für die Rolle, die Buffons Discours sur la nature des animaux (Bd. 4 seiner Histoire naturelle, 1753) für Diderots dramentheoretische Überlegungen in De la poésie dramatique (1758) spielt - allerdings mit etwas beschränkterem Gegenstandsbezug, nämlich dramatischen Charakteren: Diderots Gewährsmann in seiner Argumentation zugunsten "gradueller Unterschiede« und »bruchloser Übergänge« in der dramatischen Charakterzeichnung ist demnach Buffon (vgl. Lars Friedrich: Der Achill-Komplex, S. 140ff.), so wie Foucaults Gewährsmann in Sachen Brüchen und Diskontinuität Darwin ist.

3 Philipp Sarasin: Darwin und Foucault, darin: Kap. "Serien und Ereignisse«, S. 133-186, insbes. S. 151-163. 
sen, ${ }^{4}$ wird ausgeräumt, wenn man mit Atterton annimmt, daß Machtstrukturen sich analog zur Evolution der Arten entwickeln, durch natürliche Auslese, ${ }^{5}$ in Anpassung an ihren 'Lebensraum<, d.h. die jeweiligen historischen Gegebenheiten:

$»[$ F $]$ orms of modern cultural practice, amid the historical alluvia of various institutions, pursue individual strategies whose overall integration as bio-power serves as a kind of stochastic (rather than deterministic) principle with which to give retroactive intelligibility and teleonomic-like structure." [...] [T]hese integral or component strategies of bio-power may be likened to the set of programmable behavioral policies adopted by different organsims in response to a particular environment. Like the latter, they are not therefore to be understood as intentionally constructed or entertained. If they are followed, or, better yet, sselected, it is only through the relative stability that accrues to themon account of their sfitness< to withstand the pressures imposed upon them via the institutions and other dominant blocs composite of a particular sociohistorical setting. ${ }^{6}$

Die Genealogie methodisch auf die Evolutionstheorie zurückzuführen, scheint den Vorteil zu haben, daß man den spekulativen Implikationen des literarischen Gattungsdiskurses entgeht, doch ergibt sich damit für Foucaults Position eine ganze Reihe neuer Probleme:

Erstens ein methodisches, weil Foucault sich mit der Evolutionstheorie eines der prominentesten Paradigmen der humanwissenschaftlichen Episteme bedienen würde und also nicht mehr programmatisch »den Boden [miede], auf den er sich stütz[t] «. (AW 292)

Zweitens: Wenn allein die Evolutionstheorie ein brauchbares Modell für die diskontinuierlichen Begründungsstrukturen in Foucaults genealogischer Methode abgibt, erscheint die Abfolge der Epistemen und der Straftechniken als eine quasibiologische Evolution und werden für die historischgesellschaftlichen Prozesse und die Machtstrukturen wiederum Kausalitäten und Notwendigkeiten nahegelegt. Nun setzt Evolutionstheorie nicht notwendigerweise eine Teleologie voraus. Namentlich die Evolution nach Darwin zeichnet sich sowohl gegenüber früheren biologischen (Buffon, Lamarck) als auch gegenüber zeitgenössischen oder späteren kulturtheore-

4 Vgl. Hubert L. Dreyfus/Paul Rabinow: Michel Foucault. Beyond Structuralism and Hermeneutics, New York 1982, S. 187: "How to talk about intentionality without a subject, a strategy without a strategist?《

5 Vgl. Peter Atterton: Power's blind struggle for existence, S. 4, 8.

6 Ebd., S. 7f. 
tischen Evolutionsmodellen (Morgan, Spencer) dadurch aus, daß sie eben nicht zielgerichtet und fortschrittsorientiert verläuft - genau das ist ja der Punkt von Attertons Argumentation zugunsten einer Verwandtschaft zwischen Darwin und Foucault. Die Verbindung von Darwinscher Evolutionstheorie und Foucaultscher Genealogie an sich wäre damit also eigentlich noch nicht problematisch. Es ist aber so, daß 'Evolutionstheorie und insbesondere 'Darwinismus`sehr häufig nicht in dieser distinkten Bedeutung, sondern in einem vulgärdarwinistischen Verständnis einer kontinuierlichen und fortschrittsgerichteten Entwicklung, im Sinne eines Evolutionismus, verwendet werden und dabei an zentralen Annahmen der Darwinschen Theorie - Diskontinuität, Zufall etc. - vorbeigehen. ${ }^{7}$ Und, wichtiger: Auch Foucault selbst folgt diesem gewöhnlichen Sprachgebrauch, wenn er das Konzept der Evolution für seine Genealogie grundsätzlich ablehnt und programmatisch schreibt: "Nichts ähnelt hier der Entwicklung der Arten." (NGH 172) Atterton wie Sarasin betonen, daß Foucault sich hier nicht auf Darwins, sondern auf Lamarcks Theorie der Evolution als steter Höherentwicklung bezieht; ${ }^{8}$ klar bleibt aber, daß Foucault mit 'Evolution< allgemein eine Teleologie assoziiert. Auch Habermas warnt im Rahmen seines Plädoyers für die Einbeziehung einer "Theorie der sozialen Evolution« in die Geschichtsschreibung grundsätzlich:

\begin{abstract}
Wenn evolutionistische Theoreme [...] in die Geschichtsschreibung eingeschleust, wenn gar die Evolutionstheorie selbst als eine überlebensgroße Historie aufgezogen wird, entstehen theoretisch-narrative Mischformen, die einen problematischen Status haben. Das führt nämlich zu einer Aufladung der Evolutionstheorie mit Voraussetzungen und Begriffen, die nur in der narrativen Darstellung sinnvoll sind. Sobald Grundannahmen der Evolutionstheorie auf die Ebene einer Erzählung der Menschheitsgeschichte projiziert werden, gewinnen die formalen Voraussetzungen der Einheit, der Kontinuität und der Begrenzung der erzählten Geschichte einen substantiellen und damit irreführenden Sinn. Es erscheint dann so, als sei die Totalität der Geschichte Gegenstand der ins Narrative überspielten Evolutionstheorie, und als vollziehe sich die Evolution an einem Gattungssubjekt, dem Träger einer kontinuierlich verlaufenden Gattungsgeschichte. ${ }^{9}$
\end{abstract}

7 Vgl. z.B. Peter J. Bowler: Evolution, in: Philipp Sarasin/Marianne Sommer (Hg.): Evolution, S. 18-20; ders.: "On the Origins of Species" und die Evolutionsbiologie bis 1900, in: Philipp Sarasin/Marianne Sommer (Hg.): Evolution, S. 89-102; Philipp Sarasin: Darwin und Foucault, Kap. I.3: "Die Entstehung der Arten«, S. 78-96.

8 Vgl. Peter Atterton: Power's blind struggle for existence, S. 3; Philipp Sarasin: Darwin und Foucault, S. 201.

9 Jürgen Habermas: Zur Rekonstruktion des Historischen Materialismus, S. $246 \mathrm{f}$. 
Und genau das geschieht, wenn man die Genealogie mit der Evolutionstheorie verknüpft; man droht letztlich doch wieder den Eindruck von Einheit, Kontinuität, Substantialität zu erwecken.

Drittens: Vor dem Hintergrund der Evolutionstheorie verbinden sich auch die literarischen Gattungsbezüge in Foucaults Untersuchungen direkt mit dem biologischen Gattungsbegriff. In gattungstheoretischer Hinsicht rückt damit der im zweiten Teil der vorliegenden Arbeit für Überwachen und Strafen herausgearbeitete Zusammenhang von gattungstheoretischem Diskurs und genealogischer Untersuchung in die Nähe evolutionistischer oder sdarwinistischer Theorien literarischer Gattungen. Tatsächlich ist Darwins Evolutionstheorie nicht nur mit denselben kausalen Schwierigkeiten konfrontiert wie Foucaults Genealogie der Machttechniken, sondern auch wie die literarische Gattungstheorie; man vergleiche etwa die Problematik von Abstraktion der Spezies vs. Betrachtung des Individuums ${ }^{10}$ mit der Problematik von Allgemeinheit der Gattung vs. Individualität des einzelnen Kunstwerks. Bei evolutionistischen Gattungstheorien wäre zum einen an die russischen Formalisten zu denken, die sich vergleichsweise eng an Darwins Theorie halten. ${ }^{11}$ Einen anderen Bezugspunkt stellen die evolutionistischen Gattungsüberlegungen John Addington Symonds' und Ferdinand Brunetières dar, ${ }^{12}$ woraus sich wiederum zwei Probleme ergeben würden. Zum

10 Vgl. Philipp Sarasin: Darwin und Foucault, S. 133f.

11 Vgl. zum Beispiel Jurij Tynjanow, der Reihenbildung ins Zentrum der Betrachtung rückt: "Die Evolution der Literatur läßt sich nur dann erforschen, wenn man die Literatur als Reihe, als System nimmt, das auf andere Reihen und Systeme bezogen und durch sie bedingt ist. [...] Aufzudecken ist das evolutionäre Wechselverhältnis der Funktionen und Formen." (Jurij Tynjanow: Über literarische Evolution, in: ders.: Die literarischen Kunstmittel und die Evolution in der Literatur, Frankfurt a.M. 1967, S. 37-60, hier S. 59) Siehe auch die Textsammlung von Jurij Striedter (Hg.): Russischer Formalismus. Texte zur allgemeinen Literaturtheorie und zur Theorie der Prosa, München 1988. Zur Verbindung von Darwinismus und russischem Formalismus vgl. genauer David Fishelov: Metaphors of genre. The role of analogies in genre theory, University Park/Pennsylvania 1993, Kap. 2: "Literary Genres as Biological Species«, insbes. S. 33-39, 44-51. Einen konkreter ausgearbeiteten Versuch einer evolutionären Darstellung einer literarischen Gattung (am Beispiel des englischen Detektivromans) und literarischer Phänomene (am Beispiel der erlebten Rede in der modernen Erzählliteratur) legt Franco Moretti vor: Kurven, Karten, Stammbäume. Abstrakte Modelle für die Literaturgeschichte, Frankfurt a.M. 2009 [Turin 2005], S. 82-110.

12 John Addington Symonds: On the Application of Evolutionary Principles to Art and Literature, in: ders.: Essays Speculative and Suggestive, London ${ }^{3} 1907$ [1893], S. 27-52; Ferdinand Brunetière: Évolution des genres dans l'histoire de la littérature, 
einen nämlich merkt Hempfer an, daß Brunetière durch seinen Versuch, "die Darwinsche Konzeption unmittelbar auf historische Prozesse [zu] übertragen «13 und »historische Feststellungen auf allgemeine Gesetzmäßigkeiten zu gründen", seine Gattungstheorie letztlich »erneut in spekulative Geschichtsphilosophie überführt «, ${ }^{14}$ weswegen die Rückführung der Genealogie auf die Evolutionstheorie nichts an den spekulativen Verwicklungen von Foucaults Gattungsdiskurs ändern würde. Zum anderen legen Symonds wie Brunetière ihren Überlegungen ein stark vereinfachtes Evolutionskonzept zugrunde ${ }^{15}$ und gehören insgesamt in den biologistisch-deterministischen, >darwinistischen Kontext des späteren 19. Jahrhunderts. Ganz im Sinne dieses Diskurses setzt auch Foucault selbst die »Themen" der »Evolutionstheorie, in einem weiten Sinne verstanden", mit Rassismus gleich. (VG 303f.) Während nämlich Darwins Konzept der Evolution als, zumindest potentiell, "kulturell korrosiv« und "politisch subversiv« beschrieben werden kann, ${ }^{16}$ spricht Sarasin mit Bezug auf neodarwinistische Theoretiker des ersten Drittels des 20. Jahrhunderts von einem »Konzept der Evolution, welches auf der sehr ideologieanfälligen Melange Darwin-cum-Goethe-Schelling-Hegel basiert «, ${ }^{17}$ deutet also auf ebenjene Gefahr der Kombination von evolutionsbiologischen Theoremen mit spekulativen Konzepten hin - und dies ganz unabhängig von einem etwaigen literarischen Gattungsdiskurs. Besagte heikle "Melange» aber entsteht erst recht, wenn man Genealogie und Evolutionstheorie vor dem Hintergrund von

Paris ${ }^{4} 1906$ [1890]. Brunetières Überlegungen können nicht eigentlichen als Gattungstheorie bezeichnet werden. In seinem Buch bezieht er sich lediglich in der einführenden Vorlesung (ebd., S. 1-34) auf die biologische Evolutionstheorie und nennt Darwin und Haeckel mehr, als daß er sich auf sie bezöge; der Rest des Buches folgt dem Schema einer klassischen Literaturgeschichte.

13 Klaus W. Hempfer: Gattungstheorie, S. 203.

14 Ebd., S. 204. Symonds bezieht sich explizit auf Goethe und Hegel (vgl. John Addington Symonds: The Philosophy of Evolution, in: ders.: Essays Speculative and Suggestive, S. 1-26, hier S. 1f.) und schreibt: »Evolution implies belief in cosmic unity, in the development of the universe on one consistent plan. "Ders.: On the Application of Evolutionary Principles to Art and Literature, S. 27.

15 So stellt Brunetière Saint-Hilaire und Cuvier zwar Darwin und Haeckel entgegen, unterscheidet dabei aber bezeichnenderweise nicht zwischen den beiden letzteren, sondern nennt sie in einem Zug, woraus deutlich wird, daß er Darwins Theorie teleologisch versteht (vgl. Ferdinand Brunetière: Évolution des genres dans l'histoire de la littérature, S. 18).

16 Jakob Tanner: Evolutionstheorie in der Gesellschaft: Politik, in: Philipp Sarasin/Marianne Sommer (Hg.): Evolution, S. 358-366, hier S. 359.

17 Philipp Sarasin: Darwin und Foucault, S. 242f. 
Foucaults Gattungsdiskurs zusammenbringt. Genealogie, Evolutionstheorie und, entscheidend, literarische Gattungstheorie verschmelzen dann zu einem spekulativ-evolutionistischen gattungstheoretischen Paradigma - mit den entsprechenden politisch-ideologischen Implikationen.

\section{Gattungstheorie und Biopolitik - Gattungspolitik}

David Duff bezeichnet den Einfluß von Darwins Origin of Species auf die Gattungstheorie als »equally great, if less direct« wie Hegels Vorlesungen über die Ästhetik. ${ }^{18}$ Die evolutionstheoretische Biologisierung der literarischen Gattungstheorie gegen Ende des 19. Jahrhunderts ermöglicht Querverbindungen zwischen literarischem Gattungsdiskurs einerseits und Sozialdarwinismus und Rassenpolitik seit Mitte des 19. Jahrhunderts andererseits. Durch die Überblendung von gattungstheoretischem Modell und politischer Programmatik wird literarische Gattungstheorie als Rassenpolitik deutbar. Pornschlegel zufolge ist aus diesem Grund seit der »Gattungspolitik der Totalitarismen des 20. Jahrhunderts «19 jegliche literarische Gattungsklassifikation politisch diskreditiert. 'Biopolitisch', schreibt er, impliziert immer auch rgenerisch $<, 20$ und "Biopolitik, wie sie sich im 19. und 20. Jahrhundert durchsetzt, ist biologisch definierte Gattungspolitik «. ${ }^{21}$ Seine Argumentation zugunsten einer Verwandtschaft von praktischer Biopolitik und literarischer Gattungstheorie bleibt allerdings vage und die Textbelege erscheinen nicht zwingend. ${ }^{22}$ In den spostmodernen $<$ Texten, auf die er sich bezieht (Blanchot, Barthes, Kristeva, Derrida), weist nichts darauf hin, daß Bezüge zwischen literarischen Gattungen und biologischen Gattungen (oder 'Rassen`) der Grund für ihren »anti-generischen Affekt« wären und die "anti-generische Ästhetik der Postmoderne als Reaktion auf die

18 David Duff: Introduction, S. 4.

19 Clemens Pornschlegel: Vögel mit Schlangen, S. 250.

20 Vgl. ebd.

21 Ebd., S. 251.

22 Als Beispiel sei seine Argumentation zu einem Trotzkizitat genannt, in dem zwar in der Tat »das Verhältnis von Kunst und menschlicher Gattungserneuerung « deutlich wird, das aber keinerlei Hinweis darauf enthält, daß dieses Verhältnis »a fortiori« »das intrikate Verhältnis zwischen poetischen Genres und biologisch-naturaler Gattungspolitik« bedeutet (vgl. Clemens Pornschlegel: Vögel mit Schlangen, S. 257). 
Gattungspolitik der Totalitarismen des 20. Jahrhunderts« ${ }^{23} \mathrm{zu}$ verstehen wäre. ${ }^{24}$

Angesichts des herausgearbeiteten Gattungsdiskurses bei Foucault indessen verspricht die Verbindung von literarischer und biologischer Gattung interessant zu sein, und zwar insbesondere hinsichtlich seines Konzepts der Biopolitik - eine Gelegenheit, die Pornschlegel ungenutzt läßt, indem er zwar die Biopolitik im allgemeinen, nicht aber deren Theoretisierung bei Foucault ins Auge faßt. Genealogie und Evolutionstheorie weisen nämlich nicht nur methodische, sondern auch inhaltliche Gemeinsamkeiten auf, denn zumindest seit In Verteidigung der Gesellschaft und Der Wille zum Wissen nehmen Foucaults genealogische Untersuchungen die Bevölkerung in den Blick. Gemeinsamer Gegenstand von Genealogie und Evolutionstheorie ist damit die - biologische - Gattung. Foucault unterscheidet zwei verschiedene Machtformen, die souveräne Macht und die Biomacht, wobei sich letztere aus zwei »Entwicklungsstränge[n]« (WW 135) oder »Entwicklungsachsen« (WW 140) zusammensetzt - den etwas früheren, sich seit dem 17.Jahrhundert ausbildenden "Machtprozeduren der Disziplinen: Anatomo-Politik $^{25}$ des menschlichen Körpers", die er bereits in Die Wahrheit und die juristischen Formen und Überwachen und Strafen beschrieben hatte, und den etwas

23 Ebd., S. 250.

24 Pornschlegel beruft sich in seiner These u.a. auf eine Interviewäußerung Foucaults, wonach das "Prinzip der Intransitivität der Literatur", wie es Barthes und Blanchot vertreten, dazu geführt habe, Schreiben per se als subversiven Akt zu begreifen. Daß Foucault darin "politische[ ] Implikationen des intransitiven Schreibens und der entsprechenden subversiven 'Poetik`, wie sie sich im Gefolge der Arbeiten Blanchots dann ausgebildet hat", sieht, ist richtig, allerdings schreibt er sie ausdrücklich nicht Barthes und Blanchot selbst zu. Vielmehr seien deren Texte für jene "politischen Implikationen« »benutzt" worden, um, entgegen ihrer Absicht, aus ihnen abzuleiten, "daß das Schreiben als solches bereits ein subversiver Akt sei.« (Roger-Pol Droit: Interview mit Michel Foucault, zit. nach Clemens Pornschlegel: Vögel mit Schlangen, S. 249.) Pornschlegel gibt den letzten Satz des zitierten Interviewabschnitts nicht wieder. Er lautet: "Vous savez que ce sont des choses qui ont malheureusement été dites..." Abgesehen davon, daß Foucault Barthes' und Blanchots literarische "Intransitivität« keineswegs politisch liest - geradezu im Gegenteil -, richten sich die aus deren Texten "unglücklicherweise « abgeleiteten "politischen Implikationen« nicht gezielt gegen eine Gattungspolitik, sondern sind Ausdruck einer sehr allgemeinen Idee von politischer "Subversion«.

25 Übersetzung verändert, Gw.E. Raulff und Seitter übersetzen das französische Original "anatomo-politique" (Michel Foucault: Histoire de la sexualité I: La volonté de savoir, Paris 1976, S. 183) mit "politische Anatomie«, womit die direkte Gegenüberstellung mit der »Bio-Politik« verlorengeht. 
späteren, um die Mitte des 18. Jahrhunderts entstehenden »eingreifende[n] Maßnahmen und regulierende[n] Kontrollen: Bio-Politik der Bevölkerung." (WW 134f.) Die Disziplinen nehmen zwar den Weg über das einzelne Individuum, richten sich aber letztlich, um die Biopolitik zur Biomacht ergänzt, auf die Bevölkerung als Gesamtheit. Fortan ist die Macht »dazu bestimmt, Kräfte hervorzubringen, wachsen zu lassen und zu ordnen, anstatt sie zu hemmen, zu beugen oder zu vernichten" (WW 132); das Prinzip des Lebens und der Produktion, das Prinzip von "Wachstum und Mehrung" werden zum Ziel moderner Politik. Es formiert sich eine "Gesellschaft, in der die politische Macht eben die Verwaltung des Lebens übernommen" hat. (WW 134) Unter der Herrschaft dieses historisch neuen Machtmechanismus gilt als politisches Prinzip zwischen Staaten »nicht mehr die juridische Existenz der Souveränität, sondern die biologische Existenz einer Bevölkerung«, und spielt sich »die Macht auf der Ebene des Lebens, der Gattung, der Rasse und der Massenphänomene der Bevölkerung ab«. (WW 133) Damit geht es nicht mehr um den Körper des Verurteilten und den Körper des Königs (wie in der Tragödie) noch um den Gesellschaftskörper (wie in der Komödie) und auch nicht mehr nur um den des einzelnen Disziplinarindividuums (wie im Roman), sondern es geht um den Körper der Bevölkerung, um den "Gattungskörper«. (WW 135) Die Biopolitik ist demnach eine Politik, die sich auf die biologische Gattung richtet, ist Gattungspolitik.

Oben ist gesagt worden, daß Foucault die Genealogie als ein methodischhistoriographisches Konzept entwirft, das zugleich inhaltlich bestimmt ist: Sie hat das Subjekt zu ihrem Gegenstand. Es wurde auch gezeigt, daß der Genealogie ein Gattungsdiskurs zugrunde liegt, der sowohl auf methodischer Ebene Ähnlichkeiten mit der idealistisch-spekulativen Gattungstheorie aufweist als auch sich inhaltlich darin mit ihr trifft, daß er sich auf das Subjekt bezieht - in diesem Falle auf das tragische, komische oder romanhafte `Gattungssubjekt . Hier nun wurde als methodisches Alternativkonzept zu diesem spekulativen Gattungsdiskurs die Evolutionstheorie vorgeschlagen, wonach die Genealogie sowohl auf methodischer Ebene mit der Evolutionstheorie übereinkommt als auch auf inhaltlicher, indem sie, wie diese, die biologische Gattung zu ihrem Gegenstand hat - das biologische 'Gattungssubjekt $<$, den "Gattungs-Mensch[en] « (VG 286) der Bevölkerung. Die beiden methodischen Begründungsvarianten der Genealogie treffen sich also in ihrem Gegenstandsbezug, der Gattung, wobei diese einmal als literarische und einmal als biologische Gattung begriffen wird. Die eigent- 
liche Verbindung aber zwischen literarischer und biologischer Gattung und also auch zwischen spekulativem Gattungsdiskurs und Evolutionstheorie leistet eine sdarwinistischer Gattungstheorie. Pornschlegels gesamte Argumentation basiert auf der Gleichsetzung von literarischer und biologischer Gattung, ohne daß er diese Basis begründet. Erst über eine evolutionistische Gattungstheorie läßt sich seine Aussage »biopolitisch heißt implizit auch: 'generisch « ${ }^{26}$ überhaupt auf literarische Gattungen beziehen. Und die evolutionistische Gattungstheorie ist nun in der Tat politisch verdächtig, indem sie durch ihre Überblendung von literarischer und biologischer Gattung ermöglicht, ästhetische mit rassistischen Argumenten gleichzusetzen und auf diese Weise letztere zu legitimieren. In diesem Zusammenhang kann auch die evolutionistische Gattungstheorie als Gattungspolitik verstanden werden, die Gattungstheorie und Biopolitik miteinander verbindet. So schließen die beiden vorgeschlagenen methodischen Paradigmen der Genealogie - Evolutionstheorie und Gattungstheorie - einander nicht aus, sondern sind gleichermaßen mögliche Varianten, die im Begriff der Gattungspolitik zusammenlaufen. Dieser Begriff ist in der Forschung bisher erstaunlicherweise kaum in Erscheinung getreten. Bei Pornschlegel fällt zwar das Wort "Gattungspolitik «, aber im eigentlichen Sinne der "Gattungspolitik der Totalitarismen des 20. Jahrhunderts «, ${ }^{27}$ also der ’Rassenpolitik . In einem gattungstheoretischen Sinn verwendet Friedrich Balke diesen Begriff und greift dabei direkt auf W.J.T. Mitchell zurück, der Lessings Laokoon und dessen Unterscheidung zwischen Zeitkunst und Raumkunst als eine gattungstheoretische Projektion gesellschaftlicher Ausschlußmechanismen und Geschlechterdifferenzen beschreibt und sie als "politics of genre« bezeichnet, ${ }^{28}$ und jüngst haben Claude Haas und Andrea Polaschegg den

26 Clemens Pornschlegel: Vögel mit Schlangen, S. 250.

27 Ebd.

28 Friedrich Balke: Gattungspolitik. Über das Verhältnis von medienästhetischer Normativität und anthropologischer Differenz in Lessings Laokoon, in: Zeitschrift für deutsche Philologie 126 (2007), S. 481-507. Vgl. W.J.T. Mitchell: Space and Time: Lessing's "Laocoon" and the Politics of Genre, in: ders.: Iconology: Image, Text, Ideology, Chicago 1986, S. 95-115, hier S. 112: »One thing he [i.e. Lessing; Gw.E.] teaches us [...] is that the relation of genres like poetry and painting is not a purely theoretical matter, but something like a social relationship - thus political and psychological, or (to conflate the terms) ideological. Genres are not technical definitions but acts of exclusion and appropriation which tend to reify some significant other. The 'kind and its snature is inevitably grounded in a contrast with sunkind and its propensity for sunnaturak behavior.« 
Begriff wieder neu ins Spiel gebracht. ${ }^{29}$ Mit 'Gattungspolitik in diesem Sinne ist im Grunde der gattungssoziologische oder institutionentheoretische Ansatz der Gattungstheorie angesprochen, der die Wechselwirkung zwischen konkreten literarischen Werken oder konkreten Gattungstheorien und politisch-gesellschaftlichen Phänomenen untersucht. ${ }^{30}$ Dagegen geht es in den vorliegenden Überlegungen um den Zusammenhang von konkreten Politiken und dem Gattungsdiskurs, wodurch sich eine Begriffsverwendung auf zwei Ebenen ergibt, nämlich einmal auf Foucaults Gegenstandsebene und einmal auf seiner Untersuchungsebene. Die Machttechniken in Überwachen und Strafen kann man als Politiken (im weiteren Bedeutungsumfang des englischen spolitics`) bezeichnen. Indem Foucault sie mit literarischen Gattungen parallelisiert und mit der Abfolge von Gattungen begründet, handelt es sich bei den beschriebenen Machtstrategien um Gattungspolitiken. Der Begriff der Gattungspolitik ist in diesem Falle doppeldeutig; er bezieht sich einerseits auf dasjenige, was Foucault beschreibt, nämlich auf die die Abfolge der Epistemen und der Straftechniken begründenden Machttechniken. Indem der literarische Gattungsdiskurs in Überwachen

29 Claude Haas/Andrea Polaschegg: Der Einsatz des Dramas. Dramenanfänge, Wissenschaftspoetik und Gattungspolitik, Freiburg i.Br. 2012.

30 Köhler etwa beschreibt die Gattungen als Ergebnis von »Interessenkongruenzen ökonomischer und politischer Natur«, stellt eine direkte Wechselwirkung zwischen »literarische[m] System[ ] « und "gesellschaftlicher Entwicklung« fest und spricht von den »Epochen und einschneidende Umbesetzungen im Gattungssystem bewirkenden Wendepunkten in der Geschichte des Gesellschaftssystems«. (Erich Köhler: Gattungssystem und Gesellschaftssystem, in: Romanistische Zeitschrift für Literaturgeschichte 1 [1977], S. 7-22, hier S. 10, 20) Und Todorov identifiziert Gattungen direkt als (gesellschaftliche) Institutionen: "Comme n'importe quelle institution, les genres mettent en évidence les traits constitutifs de la société à laquelle ils appartiennent." (Tsvetan Todorov: L'origine des genres, S. 51) Vgl. außerdem Hans Robert Jauß: Littérature médiévale et théorie des genres, in: Poétique 1 (1970), S. 79-101 (auch in: Gérard Genette/Tzvetan Todorov [Hg.]: Théorie des genres, S. 37-76); Erich Köhler: Einige Thesen zur Literatursoziologie, in: Germanisch-Romanische Monatsschrift 24 (1974), S. 257-264; Wilhelm Voßkamp: Gattungen als literarisch-soziale Institutionen, in: Walter Hinck (Hg.): Textsortenlehre - Gattungsgeschichte, S. 27-44; ders.: Methoden und Probleme der Romansoziologie. Über Möglichkeiten einer Romansoziologie als Gattungssoziologie, in: Internationales Archiv für Sozialgeschichte der Literatur 3 (1978), S. 1-37; Tony Bennett: Outside Literature, New York 1990, darin Kap. 3: "The Sociology of Genres: A Critique«, S. 78-114. Dieser Ansatz scheint jüngst wieder Konjunktur zu erlangen; vgl. Ethel Matala de Mazza: Gesetze der Gattung. Institutionen kultureller Genealogien. Projektskizze, http://www.exc16.de/cms/1768.html [letzter Zugriff: 24.04.2012]; Claude Haas/Andrea Polaschegg: Der Einsatz des Dramas. 
und Strafen aber ein untergründig-methodischer ist, ist `Gattungspolitik ‘ bei Foucault andererseits ein methodisches Konzept und bezieht sich also auf dasjenige, was er selbst betreibt. ${ }^{31}$ Foucaults eigener Diskurs erwiese sich dann als ein gattungspolitischer, womit sich wiederum das Problem der politisch-ästhetischen Implikationen auftut. Gleiches gilt für den Begriff der Biopolitik, wenn er gemeinsam mit literarischen Gattungsbegriffen verwendet wird. Foucaults bereits mehrfach zitierte Bemerkung von der " $\mathrm{Zu}$ sammengehörigkeit« von Tragödie und Recht sowie von Roman und Norm entstammt der Vorlesung In Verteidigung der Gesellschaft, die er Anfang 1976 hielt. In derselben Vorlesung führt Foucault erstmals den Begriff der Biopolitik ein und nimmt die Bevölkerung und den "Gattungs-Mensch[en]« in den Blick, womit zusätzlich zum literarischen ein biologischer Gattungsbegriff auftaucht und die genannte ideologisch zweifelhafte Verbindung zur Gattungspolitik mit jenem einzugehen droht.

Indes zeigt sich beim Versuch einer konkreten Rückbindung an den in Überwachen und Strafen geführten Gattungsdiskurs als der Abfolge von Tragödie, Komödie und Roman, daß sich das biopolitische Paradigma nicht mehr in das literarische Gattungssystem aus Überwachen und Strafen einfügen lässt. Zwar verknüpft Foucault Roman und Norm miteinander (vgl. VG 208) und bestimmt die Biomacht als die Macht einer "Normalisierungsgesellschaft«, in der sich »die Norm der Disziplin und die Norm der Regulierung miteinander verbinden" (VG 299), wonach die Biomacht dem Roman zuzuordnen wäre. Die Gattung des modernen Romans korrespondiert aber vielmehr mit der Disziplin, ${ }^{32}$ also nur der einen, historisch etwas früheren Komponente der Biomacht und nur einer Spielart der Norm, die sich auf das Disziplinarindividuum richtet. Die andere Spielart dagegen, die Biopolitik, bezieht sich auf die Bevölkerung als ganze, auf den »Gat-

31 Diese Doppeldeutigkeit gilt auch für den Begriff der Biopolitik, wie bei Sarasin deutlich wird, wenn er ihn einmal "als gesellschaftsanalytisches Konzept« bestimmt, gleich darauf aber schreibt, "Biopolitik ist die Machtform des Sexualitätsdispositivs". (Philipp Sarasin: Foucault zur Einführung, S. 166f.) Muhle zufolge ist die Biopolitik bei Foucault dadurch bestimmt, "dass sie das Modell des Lebens, d.h. seine vitale Normativität in ihrer ausgestellten Irrtümlichkeit und Dynamik, als Funktionsmodell adaptiert«. (Maria Muhle: Eine Genealogie der Biopolitik, S. 238f.) Wenn sich also, wie Muhle behauptet, Foucaults Biomacht nicht nur auf das Leben bezieht, sondern auch wie Lebensprozesse funktioniert (vgl. ebd., S. 263f.), die Biomacht aber, mit Sarasin, zugleich auch ein analytisches Konzept ist, dann funktioniert Foucaults eigene Methodik analog zu Lebensprozessen, dann gehorcht die Genealogie selbst biopolitischen Strukturen.

32 Vgl. oben, Kap. VI. 
tungs-Menschen", und ist daher mit den gattungsspezifischen individuelldisziplinierenden und panoptisch-subjektivierenden Strukturen des Romans nicht vereinbar (vgl. WW 134f.). Wie die Disziplinen in ein Ende der Literatur führen, ${ }^{33}$ gelangt mit dem Aufkommen der Biopolitik auch das literarische Gattungssystem aus Überwachen und Strafen ans Ende seiner Gültigkeit. Nur ein Jahr nach dessen Veröffentlichung und im selben Jahr, in dem Foucault die Vorlesung In Verteidigung der Gesellschaft hält, erscheint Der Wille zum Wissen, wo sich, folgerichtig, keinerlei literarische Gattungsbezüge mehr finden. Der literarische Gattungsdiskurs gibt genau da seinen Geltungsanspruch auf, wo mit der Biopolitik die Bevölkerung auftritt. ${ }^{34}$ Folglich nimmt Foucault mit dem Konzept der Biopolitik keine (methodischinhaltliche) Überblendung von literarischer und biologischer Gattung vor, sondern ersetzt vielmehr erstere durch letztere. Indem er den literarischen Gattungsbegriff aufgibt und durch den biologischen oder bevölkerungspolitischen Gattungsbegriff der Biomacht ersetzt, löst er sich aus den spekulativen und gattungspolitischen Verstrickungen seiner genealogischen Methode, entgeht also sowohl dem spekulativen Gattungsdiskurs und seinen idealistischen Implikationen als auch dem Vorwurf der heiklen Verbindung von spekulativem und biologischem Gattungsdiskurs, dem Vorwurf der Gattungspolitik. Anscheinend, so könnte man meinen, wird angesichts der Bevölkerung als des neuen materiellen biologischen Gattungssubjekts, angesichts des "Gattungs-Mensch[en]«, die Stellvertreterfunktion des literarischen Gattungssubjekts obsolet und der Gattungsdiskurs als metatheoretischer Begründungsdiskurs nicht mehr gebraucht. Diese Überlegung geht

33 Vgl. oben, Kap. VI.

34 Man könnte die gattungstheoretischen Überlegungen allerdings auch noch etwas weiterführen und erwägen, die entsubjektivierte Biopolitik mit dem Nouveau Roman kurzzuschließen, womit die von Foucault beschriebene Gattungsabfolge auch literarhistorisch chronologisch passend ergänzt würde. Die Biopolitik hat gewissermaßen kein literarisches Gattungssubjekt mehr, wie auch Alain Robbe-Grillet in Pour un Nouveau Roman (1963) die Notwendigkeit von psychologischen Porträts und von Figuren überhaupt bestreitet. Er fordert mithin eine Entsubjektivierung des Romans, deren Pendant in Foucaults entsubjektivierter Biopolitik bestünde. Die Bestimmung der Avantgarde als Übergang der Literatur (oder, allgemeiner, der Kunst) ins Leben fände sich in der Ersetzung der literarischen durch die biologische Gattung verwirklicht, allerdings, und das wäre der Unterschied, ins Leben verstanden als zoé, nicht als bios. Die literarische Gattung würde zum bloßen Leben der biologischen Gattung, das Gattungssubjekt zum Gattungsobjekt. Die Abfolge lautete dann: Tragödie und Recht; Roman und disziplinare Norm; Nouveau Roman/Avantgarde und biopolitische Norm. Daraus würde dann allerdings die Behauptung eines Antihumanismus der Avantgarde folgen. 
jedoch nicht auf, denn Foucaults "Gattungs-Mensch" der Biopolitik ist gerade nicht mehr das - zwar je unterschiedliche, aber stets wesentlich humanistische - Gattungssubjekt Kants, Hegels, Marx' und Horkheimers. Er ist genau das Gegenteil, ist eben nicht Marx' "Gattungsleben« des Menschen, sondern nur dessen "materielles Leben«. Wie, Marx zufolge, Hegels Staatskonzeption das rein abstrakte Gattungswesen des Menschen ins Zentrum rückt und darüber dessen materielles Leben vernachlässigt (es ihm entfremdet), ${ }^{35}$ diagnostiziert Foucault die Biopolitik umgekehrt als die Konzentration des Staates auf das bloß materielle, biologische Leben des Menschen. Der Begriff des "Gattungs-Mensch[en]« als Gegenstand der Biopolitik ist damit die Umkehrung der beschriebenen Gattungssubjektkonzeptionen; der "Gattungs-Mensch" ist nicht Gattungssubjekt, sondern Gattungsobjekt. Als solches kann er das autonome Gattungssubjekt gar nicht ersetzen. Die Bevölkerung handelt nicht selbst, sondern ist Gegenstand der Biopolitik, womit sich die Frage nach der Subjektinstanz ebenso aufs neue stellt wie die nach der subjektlosen Intentionalität der Machtmechanismen, die nun ihrer spekulativen Begründungsstruktur beraubt ist. (Und daß ein evolutionstheoretisches Modell hier noch problematischer wäre als im Falle der genealogischen Methode, dürfte klar sein: Das wäre reiner politischer Darwinismus.) Zudem werden zusammen mit dem literarischen Gattungsdiskurs auch die anderen Funktionen, die dieser übernommen hatte, ${ }^{36}$ aufgegeben. Neben der (substitutiven) Lösung der Subjektproblematik geht auf methodisch-struktureller Ebene auch die durch die Gattungsabfolge implizierte (historiographische) Kontinuität verloren, und auf inhaltlicher Ebene bedeutet das Ende des Gattungsdiskurses die Preisgabe des bisher zumindest noch implizierten humanistischen Subjekts.

\section{Der Staat als Subjekt}

Die durch Aufgabe des Gattungsdiskurses aufs neue entstandene Problematik einer fehlenden Subjektinstanz löst Foucault zumindest teilweise noch in der Vorlesung Zur Verteidigung der Gesellschaft und dann auch in Der Wille zum Wissen, und zwar über den Staat. Die Paradoxie einer nichtsubjektiven

35 Vgl. Karl Marx: Zur Judenfrage [entstanden 1843, erschienen 1844], in: MEW, Bd. 1, Berlin 1976, S. 347-377, hier S. 354.

36 Vgl. oben, Kap. VIII. 
Intentionalität der Machtmechanismen, die die Stellvertreterschaft des Gattungssubjekts notwendig gemacht hatte, wird mit Foucaults Konzeption der Biopolitik insofern aufgehoben, als in ihr ein handelndes Subjekt zurückkehrt: in Gestalt des Staates, der Krieg führt. ${ }^{37}$ Hatte Foucault noch Mitte 1975 in einem Interview betont, "dass die Macht nicht", und zwar nicht mehr, »im Staatsapparat lokalisiert" sei und man sich vor allem den Machtmechanismen zuwenden müsse, "die außerhalb der Staatsapparate, unterhalb davon und neben ihnen, auf einem sehr viel niedrigeren, alltäglichen Niveau funktionieren ", 38 nimmt er Anfang 1976 gezielt den Staat in den Blick. Er "möchte untersuchen, in welchem Maße das binäre Schema von Krieg, Kampf und Zusammenstoß der Kräfte tatsächlich als Grundlage der Zivilgesellschaft, zugleich als Prinzip und Motor der Ausübung politischer Macht aufgewiesen werden kann." (VG 35) Er versucht, den »Krieg für die Analyse der Machtverhältnisse und als Matrix der Herrschaftstechniken« (VG 62) zu verwenden und ihn "als das Erkenntnisprinzip der Ordnung, des Staates, seiner Institutionen und seiner Geschichte" (VG 63) zu betrachten. Zwar faßt er den Begriff des Krieges sehr weit, als Kampf, oder vielmehr als die Kämpfe, die auf allen Ebenen und bis hinein in die kleinsten Winkel der Gesellschaft stattfinden, doch spricht er vom Krieg stets dezidiert als einem politischen Phänomen. Und, wichtiger: Er betont, daß sich mit Beginn der Neuzeit die

Kriegshandlungen und -einrichtungen [...] immer mehr in den Händen einer Zentralmacht konzentriert [haben], bis es schließlich so weit kam, daß de facto und de jure nur die Staatsmächte Krieg anzetteln und Kriegsinstrumente einsetzen konnten: eine Art Verstaatlichung des Krieges mithin. (VG 64)

Auch in Der Wille zum Wissen bestimmt er die Biopolitik als »das Prinzip der Strategie zwischen den Staaten« (WW 133); der moderne Staat tritt hier also als Akteur auf, ebenso wie in den Vorlesungen über die Geschichte der Gou-

37 Gattungssubjekt und Staat hängen sowohl bei Kant (dem zufolge der Staat zur Bildung [im doppelten Wortsinne] des Gattungssubjekts notwendig ist) und Schiller (im Zusammenhang mit dem "ästhetischen Staat«) als auch bei Hegel, Feuerbach und Marx (der Staat als das verwirklichte Gattungsleben des Menschen) zusammen, stehen also in direktem, positivem Zusammenhang. Bei Foucault ist es seit In Verteidigung der Gesellschaft und dem in den Vorlesungen von 1977-79 entwickelten Konzept der Gouvernementalität genau andersherum: Hier rückt der Staat an die Stelle des Gattungssubjekts, indem er selbst handelndes Subjekt wird.

38 Michel Foucault: Macht und Körper, in: Schriften II, S. 932-941, hier S. 938. 
vernementalität (1977-1979), wo Foucault »den modernen Staat in eine Gesamttechnologie der Macht wiedereinzusetzen« unternimmt (GG I, 180) und ihn als "Regierungsinstanz" beschreibt, die sich, wie Saar richtig sieht, "von der gewissermaßen ssubjektlosen Rationalität des Regierens unterscheidet.$^{39}$ Diese Lösung des Problems eines fehlenden Subjekts in Form des Staats als Subjektinstanz betrifft allerdings nur das Subjekt in der Bestimmung des Handelnden; ${ }^{40}$ die Problematik des Erkenntnissubjekts ebenso wie die des humanistischen freien Subjekts dagegen bleibt weiterhin bestehen. Doch eröffnet sich auch hierfür eine Lösung, und sei es wiederum nur über eine Verschiebung des Untersuchungsgegenstands. Der Staat wird hier vor allem über die "Gouvernementalität« bestimmt, die gewissermaßen das Verbindungsglied zwischen der Politik des Staates und ihrem Gegenstand, der Bevölkerung und den sie bildenden Individuen, darstellt, die also zwischen Macht und Subjektivität vermittelt. Der moderne westliche Staat aktualisiert eine Form der christlichen Pastoralmacht, die die ihr unterworfenen Individuen »in Subjekte verwandelt«.

Das Wort >Subjekt « hat zwei Bedeutungen: Es bezeichnet das Subjekt, das der Herrschaft eines anderen unterworfen ist und in seiner Abhängigkeit steht; und es bezeichnet das Subjekt, das durch Bewusstsein und Selbsterkenntnis an seine eigene Identität gebunden ist. In beiden Fällen suggeriert das Wort eine Form von Macht, die unterjocht und unterwirft. ${ }^{41}$

Mit dem selbstreflexiven Subjekt der Pastoralmacht bzw. der Gouvernementalität erübrigt sich die Problematik eines nichtvorgängigen und nichtuniversellen Subjekts, weil es sich um ein konkret verortbares, individuelles Subjekt handelt. Die Analyse des modernen Liberalismus führt auch zur Konzeption einer - wiewohl nur in Beziehung auf den Staat gedachten -

39 Martin Saar: Macht, Staat, Subjektivität, S. 33. Vgl. auch Colin Gordon: Governmental Rationality: An Introduction, in: ders./Graham Burchell/Peter Miller (Hg.): The Foucault Effect. Studies in Governmentality, Chicago 1991, S. 1-48; Barry Hindess: Politics and Governmentality, in: Economy and Society 26 (1997), S. 257-272. Angesichts des Staates als handelnder Instanz eröffnet sich hier wiederum die Möglichkeit der Tragödie, und man könnte nun, sozusagen zirkulär, zur Behauptung einer Tragödie des Subjekts zurückkehren, wie es Basterra in ihrer oben im Unterkap. zu "Subjekt und Tragödie bei Foucault« kurz beschriebenen Argumentation einer tragischen Subjektivität bei Foucault tut (vgl. Basterra: Seductions of Fate).

40 Womit dann übrigens auch die Frage nach einem »Subjekt der Geschichte» (VG 163) beantwortet wäre.

41 Michel Foucault: Subjekt und Macht, S. 275. 
individuellen Freiheit. ${ }^{42}$ Diese bildet auch den Ausgangspunkt von Foucaults Hinwendung zum individuellen ethischen Subjekt der Selbstsorge, ${ }^{43}$ dem Subjekt der antiken Selbstpraktiken und der Sorge um sich seit Anfang der achtziger Jahre. ${ }^{44}$ Die Stellvertreterfunktion des Gattungssubjekts, des Subjekts der Tragödie, der Komödie und des Romans, wird hier für Foucault entbehrlich. Es darf abtreten.

42 Vgl. Michel Foucault: Sicherheit, Territorium, Bevölkerung, S. 77ff. und Philipp Sarasin: Michel Foucault zur Einführung, S. 178-182.

43 Vgl. ebd., S. 183ff.; Martin Saar: Macht, Staat, Subjektivität, S. 36ff.

44 Michel Foucault: Hermeneutik des Subjekts; ders.: Der Gebrauch der Lüste; ders.: Die Sorge um sich. 


\section{Ausblick}

Das Gattungssubjekt darf also abtreten - aber nicht etwa, weil die Subjektproblematik gelöst wäre, sondern weil Foucault seinen theoretischen Blick verschiebt und auf das einzelne ethische Subjekt (aktualisierter) antiker Selbsttechniken richtet, womit die Frage nach dem freien Subjekt der Moderne in den Hintergrund tritt. Jenseits dieses Schrittes hin zur Individualethik dagegen bleibt gültig, was in der vorliegenden Arbeit herausgearbeitet worden ist: Foucaults Verkündung des Todes oder des Endes des Subjekts, schon der Form nach ein Parallelismus zum sogenannten Tod der Tragödie, geht mit einer Rückbesinnung auf die literarischen Gattungen einher. Mit der im Gattungsdiskurs implizierten Gestalt des Gattungssubjekts hält Foucault indirekt an der Konzeption eines modernen freien Subjekts fest.

Daß es gerade der Gattungsdiskurs ist, der dem modernen Subjekt in der sogenannten Postmoderne ein heimliches Fortbestehen sichert, eröffnet neue Perspektiven. Während nämlich Foucaults literarischer Gattungsbegriff und sein stellvertretendes Gattungssubjekt in einen biologischen oder bevölkerungspolitischen Gattungsbegriff, in den biopolitischen Staat und schließlich in die Hinwendung zu antiken Individualethiken und zum einzelnen Subjekt münden, ${ }^{1}$ könnte die Verbindung von Gattungspolitik und Gattungstheorie, statt letztere unter Verweis auf erstere zu diskreditieren, ${ }^{2}$ vielmehr als Einsatzpunkt gegen die biopolitische Diskurshoheit begriffen werden und spricht für neue gattungstheoretische Überlegungen, in denen der so anachronistisch anmutenden Konzeption eines Gattungssubjekts zentrale Bedeutung zukommen müßte. ${ }^{3}$

$1 \mathrm{Ob}$ dies als ein Rückzug ins Private und als Kapitulation vor der Biomacht oder, im Gegenteil, als Ausgangspunkt möglichen Widerstands verstanden werden muß, steht zur Diskussion.

2 Vgl. oben, Kap. VII, Unterkap. »Gegen die Gattung«.

3 Vgl. das oben in Kap. VII, Unterkap. "Das Gattungssubjekt" bereits erwähnte Forschungsdesiderat bezüglich des Zusammenhangs zwischen literarischen Gattungen und den Gattungssubjektkonzeptionen bei Kant, Hegel, Feuerbach, Marx und Engels, Nietzsche, Lukács, Horkheimer und Adorno, Althusser, Habermas und Foucault. 
Siglen

Ä I $\quad$ G.W.F. Hegel: Vorlesungen über die Ästhetik I

Ä II $\quad$ G.W.F. Hegel: Vorlesungen über die Ästhetik II

Ä III G.W.F. Hegel: Vorlesungen über die Ästhetik III

AW Michel Foucault: Archäologie des Wissens

GT Friedrich Nietzsche: Die Geburt der Tragödie. Oder: Griechenthum und Pessimismus

HF [1961] Michel Foucault: Folie et déraison. Histoire de la folie à l'age classique

HF [1972] Michel Foucault: Histoire de la folie à l'age classique. Folie et déraison

MEW Karl Marx/Friedrich Engels: Werke

$\mathrm{N}$

G.W.F. Hegel: Über die wissenschaftlichen Behandlungsarten des Naturrechts, seine Stelle in der praktischen Philosophie und sein Verhältnis zu den Rechtswissenschaften

NGH Michel Foucault: Nietzsche, die Genealogie, die Historie

OD Michel Foucault: Die Ordnung der Dinge. Eine Archäologie der Humanwissenschaften

PG G.W.F. Hegel: Phänomenologie des Geistes

$\mathrm{S}$

Michel Foucault: Schriften in vier Bänden. Dits et écrits

SP Michel Foucault: Surveiller et punir. Naissance de la prison

ÜS Michel Foucault: Überwachen und Strafen. Die Geburt des Gefängnisses

VG Michel Foucault: In Verteidigung der Gesellschaft. Vorlesungen am Collège de France 1975/76

WG Michel Foucault: Wahnsinn und Gesellschaft. Eine Geschichte des Wahns im Zeitalter der Vernunft

WjF Michel Foucault: Die Wahrheit und die juristischen Formen

WW Michel Foucault: Der Wille zum Wissen. Sexualität und Wahrheit 1 


\section{Literatur}

Adorno, Theodor W.: Standort des Erzählers im zeitgenössischen Roman [1954], in: ders.: Noten zur Literatur, Frankfurt a.M. 1981, S. 41-48.

Alt, Peter-André: Barock. Einleitung, in: Ulrich Profitlich (Hg.): Komödientheorie. Texte und Kommentare. Vom Barock bis zur Gegenwart, Reinbek bei Hamburg 1998, S. 19-21.

Althusser, Louis: Sur Feuerbach. II: Le genre (théorie de l'espèce) [1967], in: ders.: Écrits philosophiques et politiques, Bd. 2, hg. von François Matheron, Paris 1995, S. 229-244.

Ansell-Pearson, Keith: The Significance of Foucault's Reading of Nietzsche, in: Nietzsche-Studien 20 (1991), S. 267-283.

Aristoteles: Poetik, übers. und hg. von Manfred Fuhrmann, Stuttgart 1982.

- Poetik, übers. und erläut. von Arbogast Schmitt, Berlin 2008.

Arntzen, Helmut: Bemerkungen zur immanenten Poetologie der »Ernsten Komödie« im 19. und frühen 20. Jahrhundert, in: Ralf Simon (Hg.): Theorie der Komödie - Poetik der Komödie, Bielefeld 2001, S. 157-172.

Atterton, Peter: Power's blind struggle for existence: Foucault, genealogy and Darwinism, in: History of the Human Sciences 7.4 (1994), S. 1-20.

Balke, Friedrich: Figuren der Souveränität, München 2009.

- Gattungspolitik. Über das Verhältnis von medienästhetischer Normativität und anthropologischer Differenz in Lessings Laokoon, in: Zeitschrift für deutsche Philologie 126 (2007), S. 481-507.

- »Phädra« oder die Moralphysiologie des königlichen Fleisches, in: Bettine Menke/Christoph Menke (Hg.): Tragödie - Trauerspiel - Spektakel, Berlin 2007, S. 128-146.

Baroni, Raphaël/Macé, Marielle: Avant-propos, in: dies. (Hg.): Le savoir des genres, Rennes 2007, S. 7-17.

Barthes, Roland: De l'œuvre au texte, in: Revue d'esthétique 24 (1971), S. 225-232.

- Introduction à l'analyse structurale des récits, in: Communications 8 (1966), S. $1-27$.

- La mort de l'auteur [1968], in: ders.: Le bruissement de la langue, Paris 1984, S. 61-67.

Bartl, Andrea: Die deutsche Komödie. Metamorphosen des Harlekin, Stuttgart 2009.

Basterra, Gabriella: Seductions of Fate: Tragic Subjectivity, Ethics, Politics, New York 2004. 
Baumgartner, Hans Michael: Welches Subjekt ist verschwunden? Einige Distinktionen zum Begriff der Subjektivität, in: Hermann Schrödter (Hg.): Das Verschwinden des Subjekts, Würzburg 1994, S. 19-28.

Beistegui, Miguel de: Hegel: or the tragedy of thinking, in: ders./Simon Sparks (Hg.): Philosophy and Tragedy, London/New York 2000, S. 11-37.

-/Sparks, Simon: Introduction, in: dies. (Hg.): Philosophy and Tragedy, London/New York 2000, S. 1-8.

Bennett, Tony: The Sociology of Genres: A Critique, in: ders.: Outside Literature, New York 1990, S. 78-114.

Bersani, Leo: The Subject of Power, in: Diacritics 7.3 (1977), S. 2-21.

Blanchot, Maurice: Michel Foucault vorgestellt von Maurice Blanchot, Tübingen 1987.

- Wohin geht die Literatur? [1962], in: ders.: Der Gesang der Sirenen. Essays zur modernen Literatur, Frankfurt a.M./Berlin/Wien 1982, S. 263-339.

Bloch, Ernst: Subjekt - Objekt. Erläuterungen zu Hegel, erw. Ausgabe, Frankfurt a.M. 1972.

Bogdal, Klaus-Michael: Das Geheimnis des Nichtdiskursiven, in: ders./Achim Geisenhanslüke (Hg.): Die Abwesenheit des Werkes. Nach Foucault, Heidelberg 2006, S. 13-24.

Borgstedt, Thomas: Gattungstheorie im 21. Jahrhundert, in: Rüdiger Zymner (Hg.): Handbuch Gattungstheorie, Stuttgart/Weimar 2010, S. 217-219.

Bowler, Peter J.: Evolution, in: Philipp Sarasin/Marianne Sommer (Hg.): Evolution. Ein interdisziplinäres Handbuch, Stuttgart/Weimar 2010, S. 18-20.

- »On the Origins of Species" und die Evolutionsbiologie bis 1900, in: Philipp Sarasin/ Marianne Sommer (Hg.): Evolution. Ein interdisziplinäres Handbuch, Stuttgart/Weimar 2010, S. 89-102.

Brunetière, Ferdinand: Évolution des genres dans l'histoire de la littérature, Paris ${ }^{4} 1906$ [1890].

Bublitz, Hannelore: Subjekt, in: Clemens Kammler/Rolf Parr/Ulrich Johannes Schneider (Hg.): Foucault-Handbuch. Leben - Werk - Wirkung, Stuttgart/ Weimar 2008, S. 293-296.

Bührmann, Andrea D.: Der Diskurs als Diskursgegenstand im Horizont der kritischen Ontologie der Gegenwart, in: dies. u.a. (Hg.): Das Wuchern der Diskurse. Perspektiven der Diskursanalyse Michel Foucaults, Frankfurt a.M./New York 1999, S. 49-62.

Butler, Judith: Antigones Verlangen: Verwandtschaft zwischen Leben und Tod, Frankfurt a.M. 2001.

- Noch einmal: Körper und Macht, in: Axel Honneth/Martin Saar (Hg.): Michel Foucault. Zwischenbilanz einer Rezeption, Frankfurt a.M. 2003, S. 52-67.

- Psyche der Macht. Das Subjekt der Unterwerfung, Frankfurt a.M. 2001. 
- Subjects of Desire. Hegelian Reflections in Twentieth-Century France, um ein Vorwort ergänzte Neuaufl. der Erstausg. 1987, New York 1999.

Campe, Rüdiger: Robert Walsers Institutionen. "Jakob van Gunten«, in: Rudolf Behrens/Jörg Steigerwald (Hg.): Die Macht und das Imaginäre, Würzburg 2005, S. 235-250.

Canvat, Karl: Enseigner la littérature par les genres. Pour une approche théorique et didactique de la notion de genre littéraire, Brüssel 1999.

Cassirer, Ernst: Philosophie der symbolischen Formen I-III (= Gesammelte Werke, Bd. 11-13), Hamburg 2002.

Castel, Robert: The two readings of "Histoire de la folie" in France, in: Arthur Still/Irving Velody (Hg.): Rewriting the history of madness. Studies in Foucault's Histoire de la folie, London/New York 1992, S. 65-68.

Catholy Eckehard: Das deutsche Lustspiel vom Mittelalter bis zum Ende der Barockzeit, Darmstadt 1968.

Chapman, Raymond: Changing perspectives in genre theory, in: Revue belge de philologie et d'histoire 75.3 (1997), S. 617-628.

Cicchini, Marco/Porret, Michel: Michel Foucault: Penser le droit de punir, in: dies. (Hg.): Les sphères du pénal avec Michel Foucault. Histoire et sociologie du droit de punir, Lausanne 2007, S. 7-16.

Clifford, Michael: Hegel and Foucault. Towards a history without man, in: Clio 29.1 (1999/2000), S. 1-22.

Cobben, Paul: Die "Phänomenologie des Geistes" und die "Grundlinien der Philosophie des Rechts", in: Andreas Arndt/Karol Bal/Henning Ottmann (Hg.): Phänomenologie des Geistes. Zweiter Teil, Berlin 2003, S.165-168.

Combe, Dominique: Les genres littéraires, Paris 1992.

Cook, Deborah: Nietzsche and Foucault on Ursprung and Genealogy, in: Clio 19.4 (1990), S. 299-309.

- Nietzsche, Foucault, Tragedy, in: dies.: The subject finds a voice: Foucaults turn towards subjectivity, New York u.a. 1993, S. 37-49.

Couvrat, Pierre: Les cocasseries du droit des peines, in: Drôle(s) de droit(s). Mélanges en l'honneur d'Elie Alfandari, Paris 2000, S. 47-57.

Cutrofello, Andrew: Foucault on tragedy, in: Philosophy \& Criticism 31.5/6 (2005), S. 573-584.

Derrida, Jacques: La loi du genre, in: Glyph 7 (1980), S. 176-201.

- Marx' Gespenster. Der Staat und die Schuld, die Trauerarbeit und die neue Internationale, Frankfurt a.M. 2004 [Paris 1993].

Descombes, Vincent: Das Selbe und das Andere. Fünfundvierzig Jahre Philosophie in Frankreich (1933-1978), Frankfurt a.M. 1981.

Desmond, William: Beyond Hegel and Dialectic: Speculation, Cult, and Comedy, New York 1992.

Detel, Wolfgang: Foucault und die klassische Antike. Macht, Moral, Wissen. Mit einem neuen Vorwort, Frankfurt a.M. 2006. 
- Foucault und die Suche nach großen Strukturen, in: Klaus-Michael Bogdal/ Achim Geisenhanslüke (Hg.): Die Abwesenheit des Werkes. Nach Foucault, Heidelberg 2006, S. 37-52.

Dews, Peter: The Return of the Subject in Late Foucault, in: Radical Philosophy 51 (1994), S. 37-41.

Diderot, Denis: Das Paradox über den Schauspieler, in: Ästhetische Schriften, übers. von Friedrich Bassenge und Theodor Lücke, Bd. 2, Frankfurt a.M. 1968, S. 481-539.

- Dorval und ich, in: Ästhetische Schriften, übers. von Friedrich Bassenge und Theodor Lücke, Bd. 1, Frankfurt a.M. 1968, S. 159-238.

- Von der dramatischen Dichtkunst, in: Ästhetische Schriften, übers. von Friedrich Bassenge und Theodor Lücke, Bd. 1, Frankfurt a.M. 1968, S. 239-333.

Doyé, Sabine: Kritische Theorie, in: Theologische Realenzyklopädie, Bd. 20, hg. von Gerhard Krause und Gerhard Müller, Berlin 1990, S. 81-96.

Dreyfus, Hubert L./Rabinow, Paul: Michel Foucault. Beyond Structuralism and Hermeneutics, New York 1982.

Duff, David: Modern genre theory, Harlow 2000.

Eibl, Karl/Mellmann, Katja/Zymner, Rüdiger (Hg.): Im Rücken der Kulturen, Paderborn 2007.

Erb, Maurice: Evolution, Genealogie und `Gegen-Anthropologier. Michel Foucaults frühe Auseinandersetzung mit Darwin und Nietzsche, in: Volker Gerhardt/Renate Reschke (Hg.): Nietzsche, Darwin und die Kritik der Politischen Theologie, Berlin 2010, S. 137-148.

Erickson, Mark: "Madness and Civilization«: a selective bibliography with critical notations, in: Arthur Still/Irving Velody (Hg.): Rewriting the history of madness. Studies in Foucault's Histoire de la folie, London/New York 1992, S. 185-217.

Ette, Ottmar (Hg.): Literaturwissenschaft als Lebenswissenschaft, Tübingen 2010.

Fan, Changyang: Sittlichkeit und Tragik. Zu Hegels Antigone-Deutung, Bonn 1998.

Fietkau, Wolfgang: Schwanengesang auf 1848. Ein Rendezvous am Louvre: Baudelaire, Marx, Proudhon und Victor Hugo, Reinbek bei Hamburg 1978.

Fink-Eitel, Hinrich: Foucault zur Einführung, Hamburg 1989.

Fischer-Lichte, Erika: Einleitung, in: dies. (Hg.): Theatralität und die Krisen der Repräsentation, Stuttgart/Weimar 2001, S. 1-19.

- Semiotik des Theaters, 3 Bde., Tübingen 1983.

Fishelov, David: Literary genres - alive and kicking. The productivity of a literary concept, in: Revue belge de philologie et d'histoire 75.3 (1997), S. 653-663. 
- Metaphors of genre. The role of analogies in genre theory, University Park (Pennsylvania) 1993.

Fohrmann, Jürgen: Die Möglichkeit (mit Foucault gelesen) von Kritik, in: Klaus-Michael Bogdal/Achim Geisenhanslüke (Hg.): Die Abwesenheit des Werkes. Nach Foucault, Heidelberg 2006, S. 169-180.

- /Müller, Harro (Hg.): Diskurstheorien und Literaturwissenschaft, Frankfurt a.M. 1988.

Foucault, Michel: Archäologie des Wissens, Frankfurt a.M. 122005 [Paris 1969].

- Der Gebrauch der Lüste. Sexualität und Wahrheit 2, Frankfurt a.M. ${ }^{8} 2004$ [Paris 1984].

- Der Wille zum Wissen. Sexualität und Wahrheit 1, Frankfurt a.M. ${ }^{152005}$ [Paris 1976].

- Die Geburt der Biopolitik. Geschichte der Gouvernementalität II, Vorlesung am Collège de France 1978/79, Frankfurt a.M. 2006.

- Die Ordnung der Dinge. Eine Archäologie der Humanwissenschaften, Frankfurt a.M. ${ }^{182003}$ [Paris 1966].

- Die Ordnung des Diskurses, Frankfurt a.M. ${ }^{9} 2003$ [Paris 1972].

- Die Sorge um sich. Sexualität und Wahrheit 3, Frankfurt a.M. ${ }^{82004}$ [Paris 1984].

- Die Wahrheit und die juristischen Formen [1973], Frankfurt a.M. 2003.

- Folie et déraison. Histoire de la folie à l'age classique, Paris 1961 [überarb. Neuausgabe: Histoire de la folie à l'age classique. Folie et déraison, Paris 1972].

- Hermeneutik des Subjekts. Vorlesung am Collège de France 1981/82, Frankfurt a.M. 2004.

- In Verteidigung der Gesellschaft. Vorlesungen am Collège de France 1975/ 76, Frankfurt a.M. 22004.

- L'Archéologie du savoir, Paris 1969.

- Les mots et les choses. Une archéologie des sciences humaines, Paris 1966.

- Maladie mentale et personnalité, Paris 1954.

- Maladie mentale et psychologie, Paris 1962.

- Nietzsche, die Genealogie, die Historie [1971], in: ders.: Schriften in vier Bänden. Dits et écrits, hg. von Daniel Defert und François Ewald, Bd. 2, Frankfurt a.M. 2002, S. 166-191.

- Psychologie und Geisteskrankheit, Frankfurt a.M. 122002 [Paris 1954/1962].

- Schriften in vier Bänden. Dits et écrits, hg. von Daniel Defert und François Ewald, Frankfurt a.M. 2001-2005.

- Sicherheit, Territorium, Bevölkerung. Geschichte der Gouvernementalität I, Vorlesung am Collège de France 1977/78, Frankfurt a.M. 2006.

- Subjekt und Macht [1982], in: ders.: Schriften in vier Bänden. Dits et écrits, hg. von Daniel Defert und François Ewald, Bd. 4, Frankfurt a.M. 2005, S. 269-294. 
- Surveiller et punir. Naissance de la prison, Paris 1975.

- Überwachen und Strafen. Die Geburt des Gefängnisses, Frankfurt a.M. 152004.

- Wahnsinn und Gesellschaft. Eine Geschichte des Wahns im Zeitalter der Vernunft, Frankfurt a.M. 162005 [Paris 1961].

- Was ist ein Autor? [1968], in: ders.: Schriften in vier Bänden. Dits et écrits, hg. von Daniel Defert und François Ewald, Bd. 1, Frankfurt a.M. 2001, S. 1003-1042.

- /Arlette Farge (Hg.): Familiäre Konflikte. Die sLettres de cachet‘, Frankfurt a.M. 1989 [Paris 1982].

Frank, Manfred: Das Subjekt kommt zurück, in: Die Zeit, 08.07.2004 (Rezension zu Michel Foucaults »Hermeneutik des Subjekts. Vorlesung am Collège de France 1981/82«, Frankfurt a.M. 2004), http://www.zeit.de/2004/29/STFoucault [letzter Zugriff: 24.04.2012].

- Die Unhintergehbarkeit von Individualität, Frankfurt a.M. 1986.

- Selbstbewußtsein und Subjektivität, Stuttgart 1991.

- Was ist Neostrukturalismus?, Frankfurt a.M. 1984.

- Zum Diskursbegriff bei Foucault, in: Jürgen Fohrmann/Harro Müller (Hg.): Diskurstheorien und Literaturwissenschaft, Frankfurt a.M. 1988, S. 25-44.

Frédéric, Madeleine: Avant-propos, in: Revue belge de philologie et d'histoire 75.3 (1997), S. 613-616.

Freud, Sigmund: Analyse der Phobie eines fünfjährigen Knaben, in: Gesammelte Werke, Bd. 7, hg. von Anna Freud u.a., Frankfurt a.M. 1999, S. 241-377.

Friedrich, Lars: Der Achill-Komplex. Versuch einer dekonstruktiven Gattungspoetik, München 2009.

Frietsch, Ute: Die Ordnung der Dinge, in: Clemens Kammler/Rolf Parr/Ulrich Johannes Schneider (Hg.): Foucault-Handbuch. Leben - Werk - Wirkung, Stuttgart/Weimar 2008, S. 38-50.

Fuhrmann, Manfred: Person. Von der Antike bis zum Mittelalter, in: Historisches Wörterbuch der Philosophie, hg. von Joachim Ritter u.a., Bd. 7, Basel 1989, S. 269-283.

Gamm, Gerhard: Komödie oder Tragödie. Die moderne Welt im Lichte Hegels und Nietzsches, in: Lettre international 27 (1994), S. 67-71.

Gans, Michael: Das Subjekt der Geschichte. Studien zu Vico, Hegel und Foucault, Hildesheim 1993.

Gasché, Rodolphe: Self-dissolving seriousness: on the comic in the Hegelian concept of tragedy, in: Miguel de Beistegui/Simon Sparks (Hg.): Philosophy and Tragedy, London/ New York 2000, S. 38-56.

Gehring, Petra: Foucault - die Philosophie im Archiv, Frankfurt a.M. 2004.

- Foucaults "juridischer Machttyp«, die "Geschichte der Gouvernementalität» und die Frage nach der Rechtstheorie, in: Susanne Krasmann/Michael 
Volkmer (Hg.): Michel Foucaults Geschichte der Gouvernementalität in den Sozialwissenschaften, Bielefeld 2007, S. 157-180.

Geisenhanslüke, Achim: Antihumanismus? Michel Foucault und die Folgen, in: Richard Faber (Hg.): Streit um den Humanismus, Würzburg 2003, S. 235-246.

- Foucault und die Literatur. Eine diskurskritische Untersuchung, Opladen 1997.

- Gegendiskurse. Literatur und Diskursanalyse bei Michel Foucault, Heidelberg 2008.

- Tragödie und Infamie. Literatur und Recht bei Michel Foucault, in: KlausMichael Bogdal/ Achim Geisenhanslüke (Hg.): Die Abwesenheit des Werkes. Nach Foucault, Heidelberg 2006, S. 91-110.

Gerhardt, Volker, Renate Reschke (Hg.): Nietzsche, Darwin und die Kritik der Politischen Theologie (= Nietzscheforschung 17), Berlin 2010.

Geulen, Eva: Adorno and the Poetics of Genre, in: David Cunningham/Nigal Mapp (Hg.): Adorno and Literature, London/New York 2006, S. 53-66.

Geyer, Paul: Foucaults "Les mots et le choses«: Ende oder Anfang einer modernen Subjekttheorie?, in: Literaturwissenschaftliches Jahrbuch 38 (1997), S. 245-260.

Giese, Peter Christian: Das »Gesellschaftlich-Komische«. Zu Komik und Komödie am Beispiel der Stücke und Bearbeitungen Brechts, Stuttgart 1974.

Gordon, Colin: Governmental Rationality: An Introduction, in: ders./Graham Burchell/Peter Miller (Hg.): The Foucault Effect. Studies in Governmentality, Chicago 1991, S. 1-48.

- "Histoire de la folie«: an unknown book by Michel Foucault, in: Arthur Still/Irving Velody (Hg.): Rewriting the history of madness. Studies in Foucault's Histoire de la folie, London/New York 1992, S. 19-42.

Gottsched, Johann Christoph: Versuch einer Critischen Dichtkunst. Anderer Besonderer Theil (= Ausgewählte Werke, hg. von Joachim Birke und Brigitte Birke, Berlin/New York 1968-1987, Bd. 6.2), Berlin 1973.

Graczyk, Annette: Das literarische Tableau zwischen Kunst und Wissenschaft, München 2004.

Greiner, Bernard: Die Komödie. Eine theatralische Sendung: Grundlagen und Interpretationen, Tübingen 1992.

Gros, Frédéric: Foucault et la folie, Paris 1997.

Haas, Claude/Polaschegg, Andrea (Hg.): Der Einsatz des Dramas. Dramenanfänge, Wissenschaftspoetik und Gattungspolitik, Freiburg i.Br. 2012.

Habermas, Jürgen: Der philosophische Diskurs der Moderne. Zwölf Vorlesungen, Frankfurt a.M. 1988 [1983].

- Erkenntnis und Interesse, Frankfurt a.M. 1973 [1968].

- Theorie und Praxis. Sozialphilosophische Studien, 4., erw. und neu eingeleitete Aufl., Frankfurt a.M. 1971 [1963]. 
- Zur Rekonstruktion des Historischen Materialismus, Frankfurt a.M. 1976.

Hamacher, Werner: (Das Ende der Kunst mit der Maske), in: Karl Heinz Bohrer (Hg.): Sprachen der Ironie - Sprachen des Ernstes, Frankfurt a.M. 2000, S. 121-155.

Hamburger, Käte: Die Logik der Dichtung, 2., stark veränd. Aufl., Stuttgart 1968.

Haug, Wolfgang Fritz: Charaktermaske, in: ders. (Hg.): Historisch-Kritisches Wörterbuch des Marxismus, Bd. 2, Hamburg 1995, Sp. 435-451.

Hauskeller, Christine: Das paradoxe Subjekt. Unterwerfung und Widerstand bei Judith Butler und Michel Foucault, Tübingen 2000.

Hegel, G.W.F.: Enzyklopädie der philosophischen Wissenschaften III (=Werke, hg. von Eva Moldenhauer und Karl Markus Michel, Bd. 10), Frankfurt a.M. ${ }^{4} 1999$.

- Grundlinien der Philosophie des Rechts (=Werke, hg. von Eva Moldenhauer und Karl Markus Michel, Bd. 7), Frankfurt a.M. 1986.

- Phänomenologie des Geistes (=Werke, hg. von Eva Moldenhauer und Karl Markus Michel, Bd. 3), Frankfurt a.M. 82003.

- Über die wissenschaftlichen Behandlungsarten des Naturrechts, seine Stelle in der praktischen Philosophie und sein Verhältnis zu den Rechtswissenschaften, in: Werke, hg. von Eva Moldenhauer und Karl Markus Michel, Bd. 2, Frankfurt a.M. ${ }^{4} 2000$, S. 434-530.

- Vorlesungen über die Ästhetik I (= Werke, hg. von Eva Moldenhauer und Karl Markus Michel, Bd. 13), Frankfurt a.M. 82003.

- Vorlesungen über die Ästhetik II (= Werke, hg. von Eva Moldenhauer und Karl Markus Michel, Bd. 14), Frankfurt a.M. ${ }^{6} 2004$.

- Vorlesungen über die Ästhetik III (= Werke, hg. von Eva Moldenhauer und Karl Markus Michel, Bd. 15), Frankfurt a.M. ${ }^{4} 1996$.

- Vorlesungen über die Philosophie der Geschichte (= Werke, hg. von Eva Moldenhauer und Karl Markus Michel, Bd. 12), Frankfurt a.M. ${ }^{7} 2005$.

- Vorlesungen zur Geschichte der Philosophie I (= Werke, hg. von Eva Moldenhauer und Karl Markus Michel, Bd. 18), Frankfurt a.M. 1986.

Heise, Wolfgang: Gedanken zu Hegels Konzeption des Komischen und der Komödie, in: Hegel-Jahrbuch 1966, S. 8-31.

- Hegel und das Komische, in: Sinn und Form 16 (1964), S. 811-830.

Hempfer, Klaus W.: Gattungstheorie, München 1973.

Hillebrand, Karl: Die klassische Komödie und ihre Voraussetzungen, in: Norbert Altenhofer (Hg.): Komödie und Gesellschaft, Frankfurt a.M. 1973, S. 25-126.

Hinck, Walter (Hg.): Textsortenlehre - Gattungsgeschichte, Heidelberg 1977. Hindess, Barry: Politics and Governmentality, in: Economy and Society 26 (1997), S. 257-272. 
Holtermann, Martin: Der deutsche Aristophanes. Die Rezeption eines politischen Dichters im 19. Jahrhundert, Göttingen 2004.

Horkheimer, Max: Traditionelle und kritische Theorie [1937], in: ders.: Traditionelle und kritische Theorie. Vier Aufsätze, Frankfurt a.M. 1968, S. 12-64.

-/Adorno, Theodor W.: Dialektik der Aufklärung. Philosophische Fragmente, Frankfurt a.M. ${ }^{12} 2000$ [1944].

Hübener, Wolfgang: Der dreifache Tod des modernen Subjekts, in: Manfred Frank/Gérard Raulet/Willem van Reijen (Hg.): Die Frage nach dem Subjekt, Frankfurt a.M. 1988, S. 101-127.

Hyppolite, Jean: Genèse et structure de la Phénoménologie de l'Esprit de Hegel, Paris 1946.

- Introduction à la philosophie de l'histoire de Hegel, Paris 1968.

Ianelli, Francesca: Entwicklung und Entfaltung des Begriffs der Subjektivität in Hegels »Phänomenologie des Geistes", in: Andreas Arndt/Karol Bal/Henning Ottmann (Hg.): Phänomenologie des Geistes. Zweiter Teil, Berlin 2003, S. 64-69.

Jameson, Fredric: Magical Narratives: Romance as Genre, in: New Literary History 7.1, (1975), S. 135-163.

Jannidis, Fotis: Figur, literarische, in: Metzler Lexikon Literatur- und Kulturtheorie, hg. von Ansgar Nünning, Stuttgart/Weimar 1998, S. 149.

Jauß, Hans Robert: Littérature médiévale et théorie des genres, in: Poétique 1 (1970), S. 79-101 (auch in: Gérard Genett/Tzvetan Todorov [Hg.]: Théorie des genres, Paris 1986, S. 37-76).

Jodelet, Denise: Le mouvement de retour vers le sujet et l'approche des représentations sociales, in: Connexions 89 (2008), S. 25-46.

Johnson, Dirk R.: Nietzsche's Anti-Darwinism, Cambridge 2010.

Kahl, Stefan: Michel Foucaults politische Analytik. Studien zum Verhältnis von Wissen und Macht, Hamburg 2004.

Kammler, Clemens: Archäologie des Wissens, in: ders./Rolf Parr/Ulrich Johannes Schneider (Hg.): Foucault-Handbuch. Leben - Werk - Wirkung, Stuttgart/Weimar 2008, S. 51-62.

- Die Abwesenheit der Theorie. Zur Frage der Anwendbarkeit des Foucaultschen Diskursbegriffs auf die Literatur, in: Klaus-Michael Bogdal/Achim Geisenhanslüke (Hg.): Die Abwesenheit des Werkes. Nach Foucault, Heidelberg 2006, S. 231-241.

- Michel Foucault. Eine kritische Analyse seines Werks, Bonn 1986.

Kant, Immanuel: Der Streit der Fakultäten, in: Kants Werke. Akademie Textausgabe, Bd. 7, Berlin/New York 1972, S. 1-116.

- Idee zu einer allgemeinen Geschichte in weltbürgerlicher Absicht, in: Kants Werke. Akademie Textausgabe, Bd. 8, Berlin/New York 1968, S. 15-32. 
Kaute, Brigitte: Die Ordnung der Fiktion. Eine Diskursanalytik der Literatur und exemplarische Studien, Wiesbaden 2006.

Kayser, Wolfgang: Entstehung und Krise des modernen Romans, Stuttgart ${ }^{4} 1963$ [1954].

Kittler, Friedrich/Turk, Horst (Hg.): Urszenen: Literaturwissenschaft als Diskursanalyse und Diskurskritik, Frankfurt a.M. 1977.

Klawitter, Arne: Michel Foucault als Ausgangspunkt einer Ontologie der Literatur, in: Zeitschrift für Semiotik 27 (2005), S. 115-136.

Klimis, Sophie: Archéologie du sujet tragique, Paris 2003.

Kögler, Hans Herbert: Michel Foucault, Stuttgart/Weimar 1994.

Köhler, Erich: Einige Thesen zur Literatursoziologie, in: Germanisch-Romanische Monatsschrift 24 (1974), S. 257-264.

- Gattungssystem und Gesellschaftssystem, in: Romanistische Zeitschrift für Literaturgeschichte 1 (1977), S. 7-22.

Kraft, Stephan: Zum Ende der Komödie. Eine Theoriegeschichte des Happyends, Göttingen 2011.

LaCapra, Dominick: Foucault, history and madness, in: Arthur Still/Irving Velody (Hg.): Rewriting the history of madness. Studies in Foucault's Histoire de la folie, London/ New York 1992, S. 78-85.

- Rereading Foucault's History of Madness, in: ders.: History and Reading. Toqueville, Foucault, French Studies, Toronto 2000, S. 123-168.

Lamping, Dieter: Einführung. Literaturwissenschaftliche Gattungsforschung, in: ders. (Hg.): Handbuch der literarischen Gattungen, Stuttgart 2009, S. XV-XXVI.

Lehmann, Hans-Thies: Theater und Mythos. Die Konstruktion des Subjekts im Diskurs der antiken Tragödie, Stuttgart 1991.

- Tragödie und Trauerspiel, in: Fischer Lexikon Literatur, hg. von Ulfert Ricklefs, Frankfurt a.M. 1996, Bd. 3, S. 1857-1883.

Lemke, Thomas: Die Macht und das Leben. Foucaults Begriff der "Biopolitik" in den Sozialwissenschaften, in: Clemens Kammler/Rolf Parr (Hg.): Foucault in den Kulturwissenschaften. Eine Bestandsaufnahme, Heidelberg 2007, S. 135-156.

Lessing, Gotthold Ephraim: Abhandlungen von dem weinerlichen oder rührenden Lustspiele, in: Werke, hg. von Herbert G. Göpfert, Bd. 4, München 1973, S. 12-58.

- Hamburgische Dramaturgie, in: Werke, hg. von Herbert G. Göpfert, Bd. 4, München 1973, S. 231-707.

- Theater des Herrn Diderot. Vorrede des Übersetzers, in: Werke, hg. von Herbert G. Göpfert, Bd. 4, München 1973, S. 147-151.

Leventhal, Robert S. (Hg.): Reading after Foucault: Institutions, Disciplines, and Technologies of the Self in Germany, 1750-1830, Detroit 1994. 
Liebsch, Burkhard: Das menschliche Selbst in Geschichte und Gegenwart. Eine Bilanz der »Hermeneutik " Michel Foucaults, in: Zeitschrift für Kulturphilosophie 1 (2008), S. 113-135.

- Probleme einer genealogischen Kritik der Erinnerung: Anmerkungen zu Hegel, Nietzsche und Foucault, in: Hegel-Studien 31 (1996), S. 113-140.

Lyotard, Jean-François: Das postmoderne Wissen. Ein Bericht, 6., überarb. Aufl., Wien 2009 [Paris 1979].

- Postmoderne für Kinder. Briefe aus den Jahren 1982-1985, Wien 1996.

Mahon, Michael: Foucault's Nietzschean Genealogy. Truth, Power and the Subject, New York 1992.

Marmontel, Jean-François: Comédie, in: Encyclopédie ou Dictionnaire raisonné des sciences, des arts et des métiers, hg. von Denis Diderot u.a., Bd. 3, Paris 1753, S. 665-669.

Martinez, Matias/Scheffel, Michael: Einführung in die Erzähltheorie, München 2000 .

Marx, Karl: Der achtzehnte Brumaire des Louis Bonaparte, in: ders./Friedrich Engels: Werke, Bd. 8, hg. vom Institut für Marxismus-Leninismus beim ZK der SED, Berlin ${ }^{3} 1972$, S. 115-207.

- Ökonomisch-philosophische Manuskripte aus dem Jahre 1844, in: ders./ Friedrich Engels: Werke, Ergänzungsbd. 1, hg. vom Institut für MarxismusLeninismus beim ZK der SED, Berlin 1968, S. 465-588.

- Zur Judenfrage, in: ders./Friedrich Engels: Werke, Bd. 1, hg. vom Institut für Marxismus-Leninismus beim ZK der SED, Berlin 1976, S. 347-377.

- Zur Kritik der Hegelschen Rechtsphilosophie. Einleitung, in: ders./Friedrich Engels: Werke, Bd. 1, hg. vom Institut für Marxismus-Leninismus beim ZK der SED, Berlin 1976, S. 378-391.

-/Engels, Friedrich: Die deutsche Ideologie, in: dies.: Werke, Bd. 3, hg. vom Institut für Marxismus-Leninismus beim ZK der SED, Berlin 1969, S. 5-530.

Marx, Werner: Das Selbstbewußtsein in Hegels Phänomenologie des Geistes, Frankfurt a.M 1986.

Matala de Mazza, Ethel: Gesetze der Gattung. Institutionen kultureller Genealogien. Projektskizze, http://www.exc16.de/cms/1768.html [letzter Zugriff: 24.04.2012].

Mazlish, Bruce: The Tragic Farce of Marx, Hegel, and Engels. A Note, in: History and Theory 3 (1972), S. 335-337.

Megill, Allan: Foucault, ambiguity and the rhetoric of historiography, in: Arthur Still/Irving Velody (Hg.): Rewriting the history of madness. Studies in Foucault's Histoire de la folie, London, New York 1992, S. 86-104.

- Prophets of Extremity: Nietzsche, Heidegger, Foucault, Derrida, Berkeley 1995. 
Meier, Albert: Lyrisch - episch - dramatisch, in: Ästhetische Grundbegriffe, hg. von Karlheinz Barck u.a., Bd. 3, Stuttgart 2001, S. 709-723.

Menke, Bettine/Menke, Christoph (Hg.): Tragödie - Trauerspiel - Spektakel, Berlin 2007.

Menke, Christoph: Die Gegenwart der Tragödie. Eine ästhetische Aufklärung, in: Neue Rundschau, 111.1 (2000), S. 85-95.

- Die Gegenwart der Tragödie. Versuch über Urteil und Spiel, Frankfurt a.M. 2005.

- Ethischer Konflikt und ästhetisches Spiel. Zum geschichtsphilosophischen Ort der Tragödie bei Hegel und Nietzsche, in: Andreas Arndt/Karol Bal/ Henning Ottmann (Hg.): Hegels Ästhetik. Die Kunst der Politik - die Politik der Kunst, Berlin 2000, S. 16-28.

- Tragödie im Sittlichen. Gerechtigkeit und Freiheit nach Hegel, Frankfurt a.M. 1996.

Meyer-Drawe, Käthe: Zur Doppeldeutigkeit des Subjekts, in: Paul Geyer, Monika Schmitz-Emans (Hg.): Proteus im Spiegel. Kritische Theorie des Subjekts im 20. Jahrhundert, Würzburg 2003, S. 43-49.

Mitchell, W.J.T.: Space and Time: Lessing's Laocoon and the Politics of Genre, in: ders.: Iconology: Image, Text, Ideology, Chicago 1986, S. 95-115.

Monal, Isabel: Gattungswesen, in: Historisch-kritisches Wörterbuch des Marxismus, hg. von Wolfgang Fritz Haug, Bd. 4, Hamburg 1999, Sp. 1248-1258.

Moretti, Franco: Kurven, Karten, Stammbäume. Abstrakte Modelle für die Literaturgeschichte, Frankfurt a.M. 2009 [Turin 2005].

Muhle, Maria: Eine Genealogie der Biopolitik. Zum Begriff des Lebens bei Foucault und Canguilhem, Bielefeld 2008.

Mutschler, H.D.: »Verschwinden des Subjekts«, in: Hermann Schrödter (Hg.): Das Verschwinden des Subjekts, Würzburg 1994, S. 191-208.

Neumann, Birgit/Nünning, Ansgar: Einleitung: Probleme, Aufgaben und Perspektiven der Gattungstheorie und Gattungsgeschichte, in: Marion Gymnich/Birgit Neumann/Ansgar Nünning (Hg.): Gattungstheorie und Gattungsgeschichte, Trier 2007, S. 1-21.

Nietzsche, Friedrich: Die Geburt der Tragödie. Oder: Griechenthum und Pessimismus (= Werke. Kritische Studienausgabe, hg. von Giorgio Colli und Mazzino Montinari, Bd. 1), München/Berlin 1980.

- Ecce Homo (=Werke. Kritische Studienausgabe, hg. von Giorgio Colli und Mazzino Montinari, Bd. 6), München/Berlin 1980.

- Nachgelassene Fragmente 1869-1874 (= Werke. Kritische Studienausgabe, hg. von Giorgio Colli und Mazzino Montinari, Bd. 7), München/Berlin 1980.

Palmeri, Frank: History of Narrative Genres after Foucault, in: Configurations 7.2 (1999), S. 267-277. 
Palti, Elías: The 'Return of the Subject as a Historico-Intellectual Problem, in: History and Theory 43.1 (2004), S. 57-82.

Pillen, Angelika: Referenzautoren - G.W.F. Hegel und Karl Marx, in: Clemens Kammler, Rolf Parr/Ulrich Johannes Schneider (Hg.): Foucault-Handbuch. Leben - Werk - Wirkung, Stuttgart/Weimar 2008, S. 169-172.

Pizer, J.: The Use and Abuse of 'Ursprung`. On Foucault's Reading of Nietzsche, in: Nietzsche-Studien 19 (1990), S. 462-478.

Pornschlegel, Clemens: Die Literatur von der Literatur befreien. Notizen zu Foucaults "Das Leben der infamen Menschen«, in: Die Nummer. Kunst Literatur - Theorie, 3. 4/5 (1996), S. 92-100.

- Vögel mit Schlangen. Zur Problematik generischer Klassifikationen in der Postmoderne, in: Uwe Hebekus/Ethel Matala de Mazza/Albrecht Koschorke (Hg.): Das Politische. Figurenlehren des sozialen Körpers nach der Romantik, München 2003, S. 248-260.

Profitlich, Ulrich: Von der frühen Aufklärung bis zur Weimarer Klassik, in: ders. (Hg.): Komödientheorie. Texte und Kommentare. Vom Barock bis zur Gegenwart, Reinbek bei Hamburg 1998, S. 35-42.

Raible, Wolfgang: Was sind Gattungen? Eine Antwort aus semiotischer und textlinguistischer Sicht, in: Poetica 12 (1980), S. 320-349.

Reibnitz, Barbara von: Ein Kommentar zu Friedrich Nietzsche, »Die Geburt der Tragödie aus dem Geiste der Musik«, Kap. 1-12, Stuttgart 1992.

Richardson, John: Nietzsche's New Darwinism, Oxford 2004.

Riedel, Christoph: Subjekt und Individuum. Zur Geschichte des philosophischen Ich-Begriffs, Darmstadt 1989.

Roche, Mark W.: Hegel's Theory of Comedy in the Context of Hegelian and Modern Reflections on Comedy, in: Revue internationale de philosophie $221(2002 / 03)$, S. 411-430.

- Tragedy and Comedy. A Systematic Study and a Critique of Hegel, Albany 1998.

Rose, Gillian: The Comedy of Hegel and the Trauerspiel of Modern Philosophy, in: Bulletin of the Hegel Society of Great Britain 29 (1994), S. 14-22.

Rosenstein, Leon: Metaphysical Foundations of the Theories of Tragedy in Hegel and Nietzsche, in: Journal of Aesthetics and Art Criticism 28 (1970), S. 521-533.

Roudinesco, Élisabeth: Lectures de l'»Histoire de la folie« (1961-1986). Introduction, in: dies. (Hg.): Penser la folie. Essais sur Michel Foucault, Paris 1992, S. 9-36.

Rüb, Matthias: Das Subjekt und sein Anderes. Zur Konzeption von Subjektivität beim frühen Foucault, in: Eva Erdmann/Rainer Forst/Axel Honneth (Hg.): Ethos der Moderne. Foucaults Kritik der Aufklärung, Frankfurt/New York 1992, S. 187-201. 
- Foucaults 'Kehrer. Neuere Literatur zum Werk Michel Foucaults, in: Philosophischer Literaturanzeiger 41 (1988), S. 198-207.

- Suche nach den Wurzeln des Subjekts. Der erstaunliche Wandel im Spätwerk des Michel Foucault, in: Spuren in Kunst und Gesellschaft 18 (1987), S. 49-52.

Saar, Martin: Genealogie als Kritik. Geschichte und Theorie des Subjekts nach Nietzsche und Foucault, Frankfurt a.M./New York 2007.

- Genealogie und Subjektivität, in: ders./Axel Honneth (Hg.): Michel Foucault. Zwischenbilanz einer Rezeption, Frankfurt a.M. 2003, S. 157-177.

- Macht, Staat, Subjektivität. Foucaults Geschichte der Gouvernementalität im Werkkontext, in: Susanne Krasmann/Michael Volkmer (Hg.): Michel Foucaults Geschichte der Gouvernementalität in den Sozialwissenschaften, Bielefeld 2007, S. 23-45.

Sarasin, Philipp: Darwin und Foucault. Genealogie und Geschichte im Zeitalter der Biologie, Frankfurt a.M. 2009.

- Foucault, Burckhardt, Nietzsche - und die Hygieniker, in: Jürgen Martschukat (Hg.): Geschichte schreiben mit Foucault, Frankfurt a.M./New York 2002, S. 195-218.

- Michel Foucault zur Einführung, Hamburg 2005.

Schaeffer, Jean-Marie: Des genres discursifs aux genres littéraires: Quelles catégorisations pour quels faits textuels?, in: Raphaël Baroni/Marielle Macé (Hg.): Le savoir des genres, Rennes 2007, S. 357-364.

- Du texte au genre. Notes sur la problématique générique, in: Gérard Genette/ Tzvetan Todorov (Hg.): Théorie des genres, Paris 1986, S. 179-205 (zuerst veröffentlicht in: Poétique 53 [1983], S. 3-18).

Schiller, Friedrich: Über naive und sentimentalische Dichtung, in: ders.: Sämtliche Werke, hg. von Peter-André Alt u.a., Bd. 5, München 2004, S. 694-780.

Schlesier, Renate: Archäologie und Philologie. Fußnoten zu Foucaults Projekt, in: Klaus-Michael Bogdal/Achim Geisenhanslüke (Hg.): Die Abwesenheit des Werkes. Nach Foucault, Heidelberg 2006, S. 25-36.

Schmid, Wilhelm: Auf der Suche nach einer neuen Lebenskunst. Die Frage nach dem Grund und die Neubegründing der Ethik bei Foucault, Frankfurt a.M. 2000.

Schmuhl, Hans-Walter: Sozialdarwinismus, Rassismus, Eugenik/Rassenhygiene, in: Philipp Sarasin/Marianne Sommer (Hg.): Evolution. Ein interdisziplinäres Handbuch, Stuttgart/ Weimar 2010, S. 366-375.

Schneider, Helmut: Hegels Theorie der Komik und die Auflösung der schönen Kunst, in: Jahrbuch für Hegelforschung 1 (1995), S. 81-110.

Schrödter, Hermann (Hg.): Das Verschwinden des Subjekts, Würzburg 1994.

Schulte, Michael: Hypokrisie und Maske. Zum Verhältnis von Tragödien- und Komödientheorie in Hegels rechtsphilosophischer Schrift »Über die Be- 
handlungsarten des Naturrechts« und im Religionskapitel der »Phänomenologie des Geistes«, in: Klaus Detering (Hg.): Wahrnehmungen im poetischen All, Heidelberg 1993, S. 207-253.

- Tragödie im Sittlichen. Zur Dramentheorie Hegels, München 1992.

- Von der Romantik bis zum Realismus. Einleitung, in: Ulrich Profitlich (Hg.): Komödientheorie. Texte und Kommentare. Vom Barock bis zur Gegenwart, Reinbek bei Hamburg 1998, S. 87-96.

Schulz, Georg-Michael: Einführung in die deutsche Komödie, Darmstadt 2007. Seigel, Jerrold : La mort du sujet: Origines d'un thème, in: Le Débat 58.1 (1990), S. 160-170.

Selbmann, Rolf: Der deutsche Bildungsroman, 2., überarb. und erw. Aufl., Stuttgart 1994.

Seltzer, Mark: Reading Foucault. Cells, Corridors, Novels, in: Diacritics 14.1 (1984), S. 78-89.

- The Princess Casamassima: Realism and the Fantasy of Surveillance, in: Nineteenth-Century Fiction 35.4 (1981), S. 506-534.

Siep, Ludwig: Der Weg der Phänomenologie des Geistes. Ein kooperativer Kommentar, Frankfurt a.M. 2000.

Simon, Ralf: Theorie der Komödie, in: ders. (Hg.): Theorie der Komödie Poetik der Komödie, Bielefeld 2001, S. 47-66.

- Vorwort. Theorie der Komödie - Poetik der Komödie, in: ders. (Hg.): Theorie der Komödie - Poetik der Komödie, Bielefeld 2001, S. 7-12.

Soboul, Albert (Hg.): Dictionnaire historique de la Révolution française, Paris 2005.

Sophokles: Antigone, übers. von Wilhelm Kuchenmüller, durchges. Ausgabe, Stuttgart 2000.

Stanzel, Franz Karl: Typische Formen des Romans, Göttingen 1964.

Stegmaier, Werner: Darwin, Darwinismus, Nietzsche. Zum Problem der Evolution, in: Nietzsche-Studien 16 (1987), S. 264-287.

Steiner, George: Die Antigonen, München 1990.

Stern, David: The return of the subject? Power, reflexivity and agency, in: Philosophy \& Social Criticism 26.5 (2000), S. 109-122.

Stingelin, Martin: Foucault-Lektüren. Die Literatur im Denkraum der drei Dimensionen Wissen, Macht und Selbstverhältnis, in: Michel Foucault: Schriften zur Literatur, Frankfurt a.M. 2003, S. 371-400.

Stolz, Peter: Der literarische Gattungsbegriff. Aporien einer literaturwissenschaftlichen Diskussion. Versuch eines Forschungsberichtes zum Problem der »literarischen Gattungen«, in: Romanistische Zeitschrift für Literaturgeschichte 14 (1990), S. 209-227.

Striedter, Jurij (Hg.): Russischer Formalismus. Texte zur allgemeinen Literaturtheorie und zur Theorie der Prosa, München 1988. 
Strozier, Robert M.: Foucault, Subjectivity and Identity. Historical Constructions of the Subject and Self, Detroit 2002.

Suárez Müller, Fernando: Skepsis und Geschichte. Das Werk Michel Foucaults im Lichte des absoluten Idealismus, Würzburg 2004.

Symonds, John Addington: On the Application of Evolutionary Principles to Art and Literature, in: ders.: Essays Speculative and Suggestive, London 31907 [1893], S. 27-52.

- The Philosophy of Evolution, in: ders.: Essays Speculative and Suggestive, London ${ }^{3} 1907$ [1893], S. 1-26.

Szondi, Peter: Friedrich Schlegels Theorie der Dichtarten. Versuch einer Rekonstruktion auf Grund der Fragmente aus dem Nachlaß, in: ders.: Schriften II, Frankfurt a.M. 1978, S. 32-58.

- Hegels Lehre von der Dichtung, in: ders.: Poetik und Geschichtsphilosophie I, Frankfurt a.M. 1974, S. 267-511.

- Versuch über das Tragische, in: ders.: Schriften I, Frankfurt a.M. 1978, S. $151-260$.

- Von der normativen zur spekulativen Gattungspoetik, in: ders.: Poetik und Geschichtsphilosophie II, Frankfurt a.M. 1974, S. 7-183.

Tanner, Jakob: Evolutionstheorie in der Gesellschaft: Politik, in: Philipp Sarasin/Marianne Sommer (Hg.): Evolution. Ein interdisziplinäres Handbuch, Stuttgart/Weimar 2010, S. 358-366.

Todorov, Tzvetan: Introduction à la littérature fantastique, Paris 1970; Kap. 1: Les genres littéraires, S. 7-27.

- Les catégories du récit littéraire, in: Communications 8 (1966), S. 125-151.

- L'origine des genres, in: ders. (Hg.): Les genres du discours, Paris 1978, S. 44-60.

Tynjanow, Jurij: Die literarischen Kunstmittel und die Evolution in der Literatur, Frankfurt a.M. 1967.

Unterthurner, Gerhard: Foucaults Archäologie als Kritik der Erfahrung. Wahnsinn - Literatur - Phänomenologie, Wien 2007.

Vattimo, Gianni: Das Ende der Moderne, Stuttgart 1990.

Védrine, Hélène: Le sujet éclaté, Paris 2000.

Veyne, Paul: Michel Foucaults Denken, in: Martin Saar/Axel Honneth (Hg.): Michel Foucault. Zwischenbilanz einer Rezeption, Frankfurt a.M. 2003, S. 27-51.

Vogl, Joseph: Genealogie, in: Clemens Kammler/Rolf Parr/Ulrich Johannes Schneider (Hg.): Foucault-Handbuch. Leben - Werk - Wirkung, Stuttgart/ Weimar 2008, S. 255-258.

Voßkamp, Wilhelm: Gattungen als literarisch-soziale Institutionen, in: Walter Hinck (Hg.): Textsortenlehre - Gattungsgeschichte, Heidelberg 1977, S. 27-44. 
- Methoden und Probleme der Romansoziologie. Über Möglichkeiten einer Romansoziologie als Gattungssoziologie, in: Internationales Archiv für Sozialgeschichte der Literatur 3 (1978), S. 1-37.

Wallis, Victor: Gattungsfragen, in: Historisch-kritisches Wörterbuch des Marxismus, hg. von Wolfgang Fritz Haug, Bd. 4, Hamburg 1999, Sp. 1239-1248.

Warning, Rainer: Komik/Komödie, in: Fischer Lexikon Literatur, hg. von Ulfert Ricklefs, Frankfurt a.M. 1996, Bd. 2, S. 897-936.

- Theorie der Komödie. Eine Skizze, in: Ralf Simon (Hg.): Theorie der Komödie - Poetik der Komödie, Bielefeld 2001, S. 31-46.

Weitin, Thomas: Recht und Literatur, Münster 2010.

White, Hayden: Foucault decodiert: Notizen aus dem Untergrund, in: ders.: Auch Klio dichtet oder Die Fiktion des Faktischen. Studien zur Tropologie des historischen Diskurses, Stuttgart 1986, S. 268-302 (zuerst veröffentlicht in: History and Theory 12 [1973], S. 23-54).

- Foucault's Discourse. The Historiography of Anti-Humanism, in: ders.: The Content of the Form, Baltimore/London 1987, S. 104-141.

- Metahistory. Die historische Einbildungskraft im 19. Jahrhundert in Europa, Frankfurt a.M. 1991 [New York 1973].

- The Politics of Historical Interpretation: Discipline and De-Sublimation, in: ders.: The Content of the Form, Baltimore/London 1987, S. 58-82.

- The Question of Narrative in Contemporary Historical Theory, in: ders.: The Content of the Form, Baltimore/London 1987, S. 26-57.

Wolfers, Carsten: Die Foucaultschen Subjekte, Wien u.a. 2009.

Wunderlich, Stefan: Foucault und die Frage der Literatur: Beitrag zu einer Archäologie des poststrukturalistischen Denkens, [Norderstedt] 2000. 
